VICTORIA UNIVERSITY OF WELLINGTON

Te Whare Wānanga o te Ūpoko

o te Ika a Māui

\title{
"What is the influence of communication quality between the business and IT project team on ERP implementation project success?"
}

by

Alexander Schnepel

\author{
A thesis \\ submitted to the Victoria University of Wellington \\ in fulfilment of the \\ requirements for the Masters degree \\ in Information Systems.
}

Victoria University ofWellington

2007 


\begin{abstract}
Communication between the information systems (IS) specialist and the user has long been recognised in the IS literature as an important aspect of successful information system development projects. Since the 1970s IS researchers have studied the role of communication in the system development process and its influence on project/system success. Communication has been studied as a broad concept as well as in regard to specific aspects such as communication frequency, quantity, and the fit between the communication medium and the task. Yet, quality has been neglected. Therefore, this study presents the concept of "communication quality". The study investigated the influence of communication quality on project success in an Enterprise Resource Planning system implementation at a large North-American manufacturing company. ERP project implementation success was assessed by a multidimensional framework including multiple stakeholder perspectives. The study used supplementary secondary analysis of 54 interviews with project stakeholders from the IT project team and the business side of this organisation. The current study found support for the individual attributes of communication quality, namely completeness, credibility, accuracy, purpose adequacy, timeliness, openness, audience adequacy, bidirectionality, and a balance of formality vs. informality. The study found indications that a lack of communication quality might impact ERP implementation project success negatively whereas better communication quality might foster success. The ERP project at the organisation was successful in terms of traditional project success measures such as "on time" and "within budget". However, communication quality seemed to have a negative correlation to the quality of the relationship between the project team and the business as well as user satisfaction. System acceptance and use appeared to have been facilitated by better communication quality. The study enriches the IS literature by increasing the understanding of communication aspects during ERP implementation projects. It is also one of the first studies to introduce the new research method of secondary analysis of qualitative data from sociology into the IS field. Practitioners can apply the findings of this study to facilitate ERP implementation project success on a more holistic level addressing also user satisfaction and the quality of the relationship between the IT project team and the rest of the business.
\end{abstract}




\section{Table of Contents}

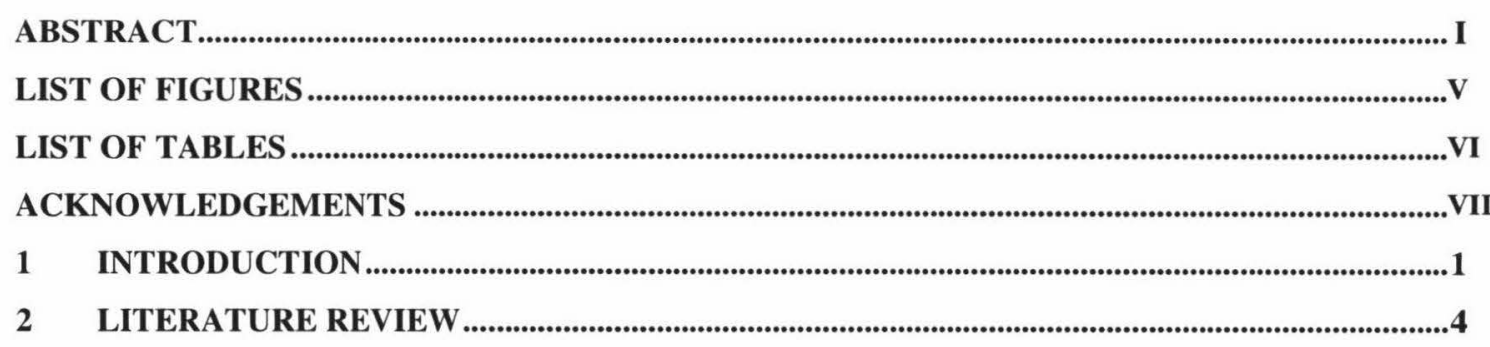

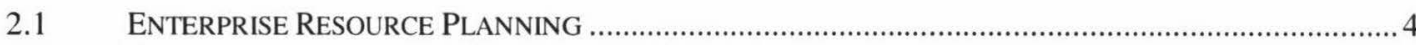

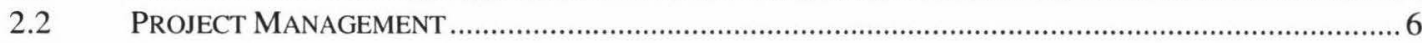

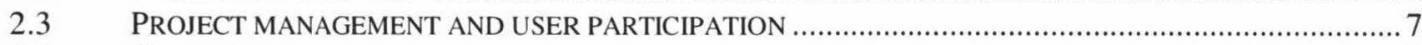

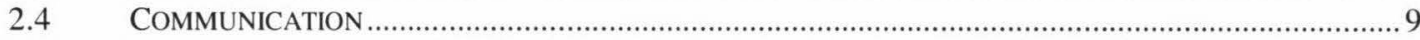

2.5 INTERACTION QUALITY AND COMMUNICATION QUALITY......................................................

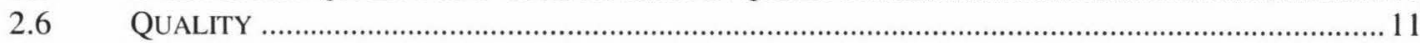

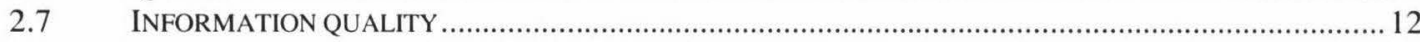

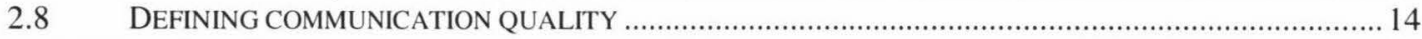

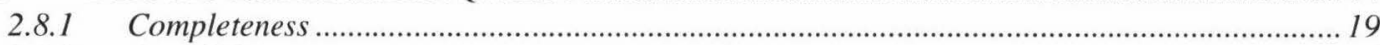

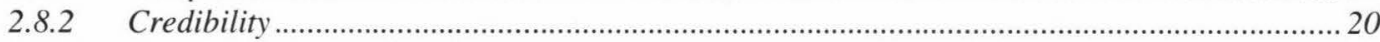

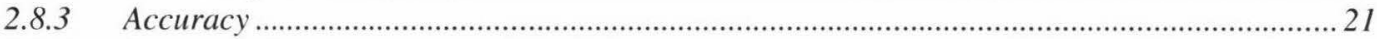

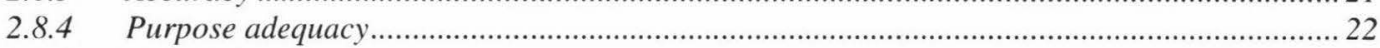

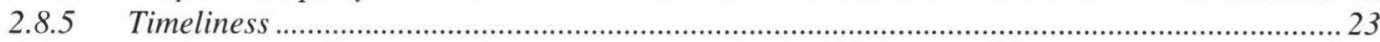

2.8 .6 Openness

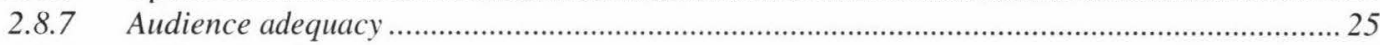

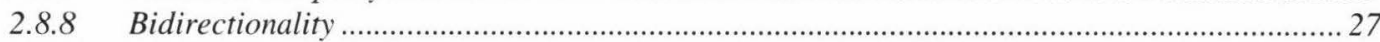

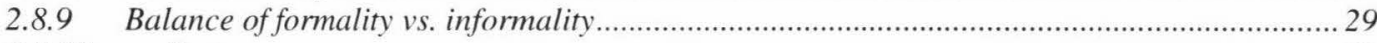

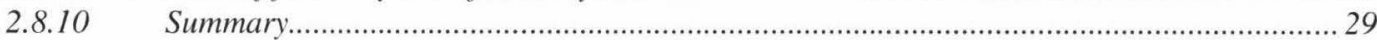

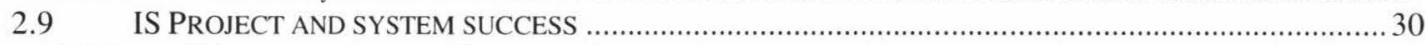

2.9.1 ERP project success Framework ………………...........................................................

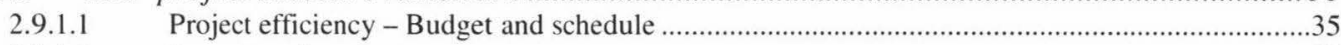

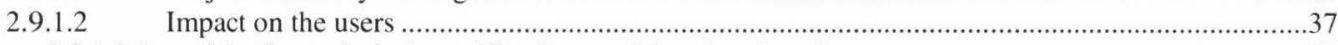

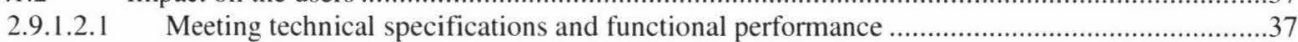

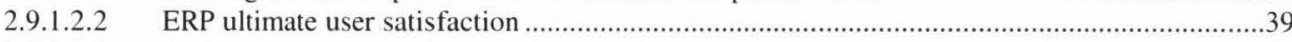

$2.9 .1 .2 .3 \quad$ System acceptance and $u$

2.9.1.3 Business success and business benefits .............................................................................43

2.10 IMPACT OF COMMUNICATION QUALITY ON THE ERP PROJECT SUCCESS VARIABLES ..........................4

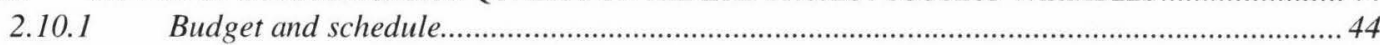

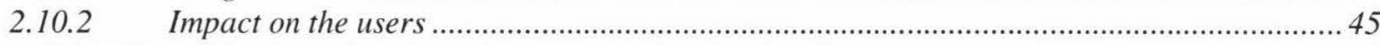

2.10.2.1 Meeting technical specifications and functional performance …………………………...............45

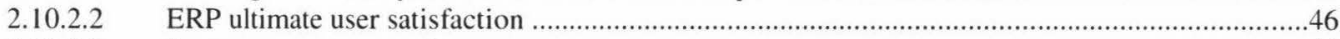

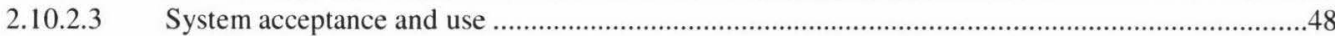

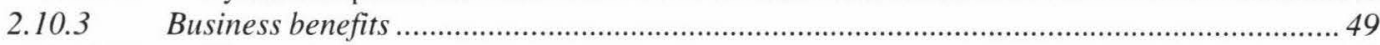

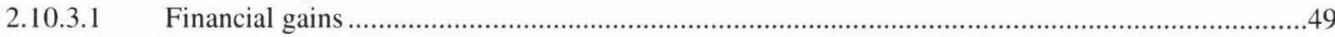

2.10.3.2 Better process performance

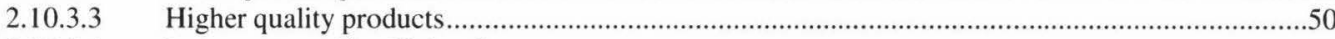

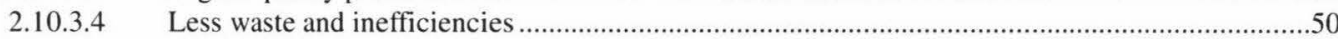

2.10.3.5 Link between daily work and business benefits clear to users ..............................................51

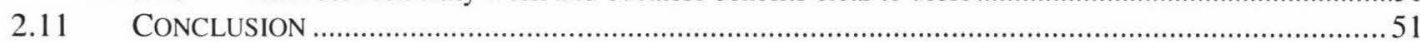

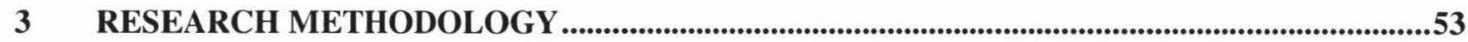

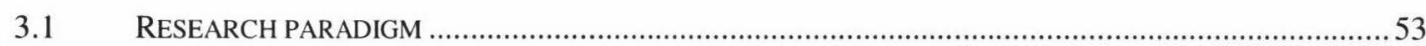

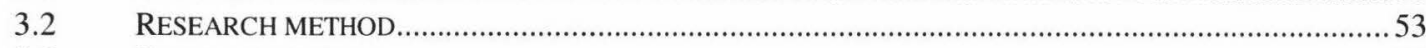

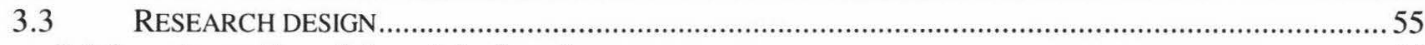

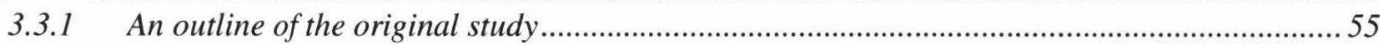

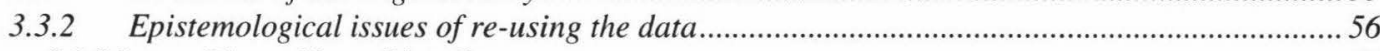

3.3.2.1 The problem of data fit...........................................................................................57

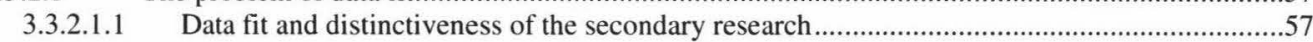




\begin{tabular}{|c|c|}
\hline 3.3.2.1.2 & Appropriateness of secondary analysis method \\
\hline 3.3.2.1.3 & Quality of data \\
\hline 3.3.2.1.4 & 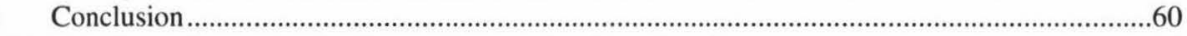 \\
\hline 3.3.2.2 & 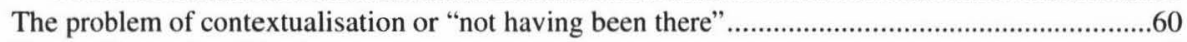 \\
\hline 3.3.2.3 & The problem of verification \\
\hline 3.3.2.4 & Ethical and legal considerations \\
\hline 3.3.2.4.1 & Ethical issues \\
\hline 3.3.2.4.2 & 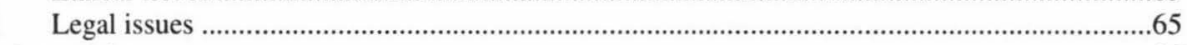 \\
\hline 3.3.3 Selec & . \\
\hline 3.3.4 & ysis ........................... \\
\hline 3.3.5 Qual & ity assurance ... \\
\hline 3.3.5.1 & Triangulation \\
\hline 3.3.5.2 & Member validation \\
\hline 3.3.5.3 & Reportage \\
\hline 3.3.5.4 & 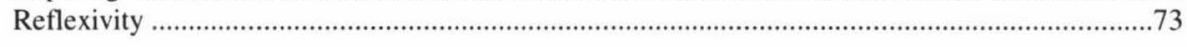 \\
\hline
\end{tabular}

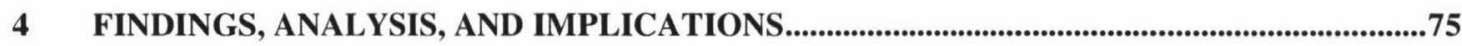

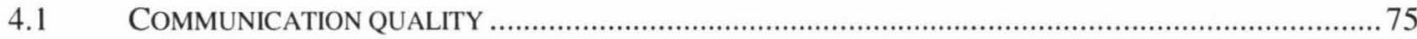

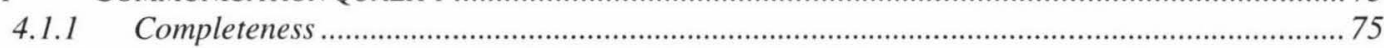

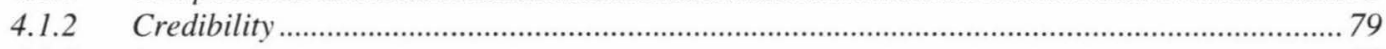

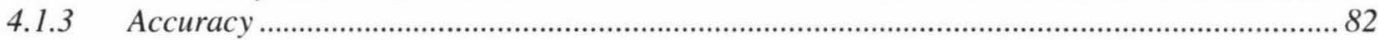

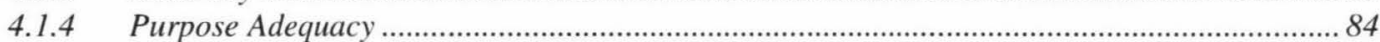

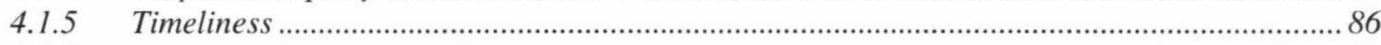

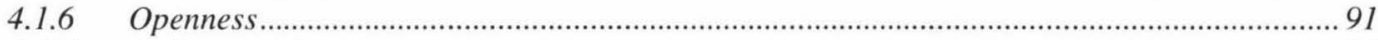

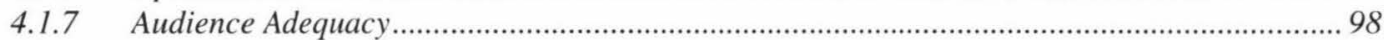

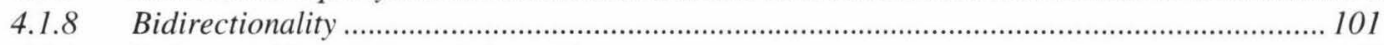

4.1.9 Balance of formality vs. informality .......................................................................... 108

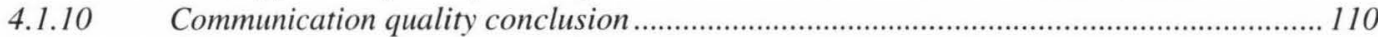

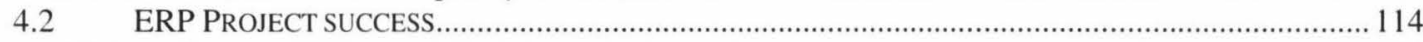

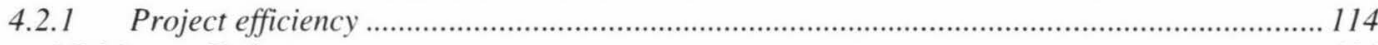

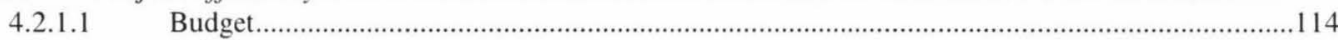

4.2.1.2 Schedule $\quad$.

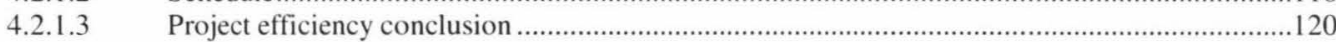

4.2.2 Impact on the users ......................................................................................................... 120

4.2.2.1 Meeting functional and technical requirements ................................................................. 120

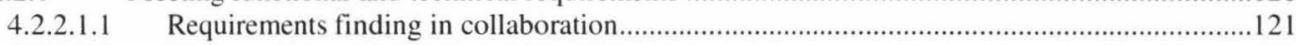

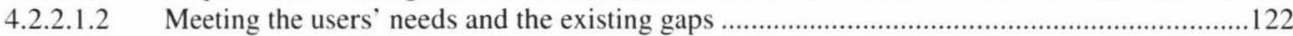

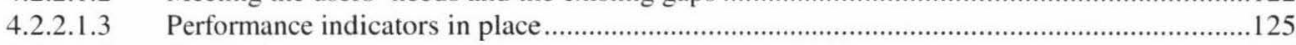

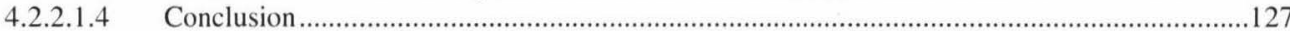

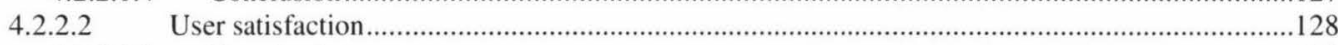

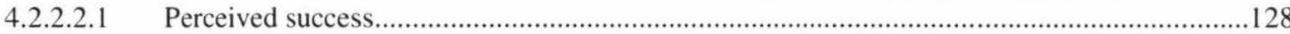

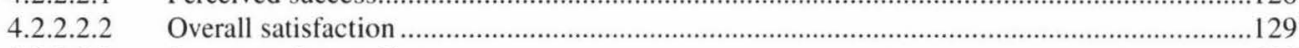

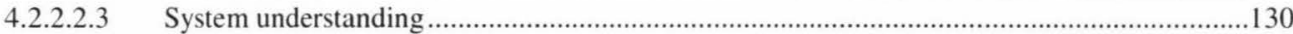

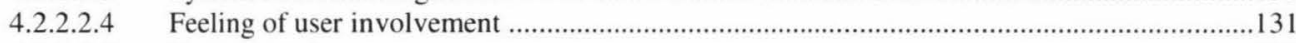

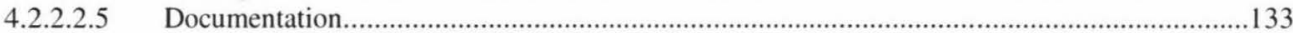

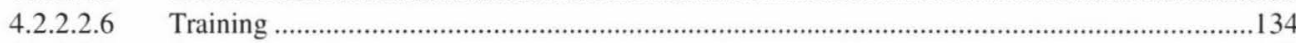

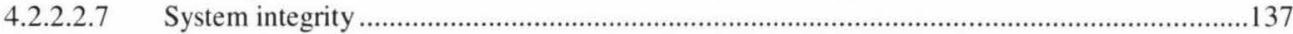

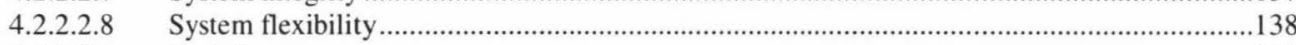

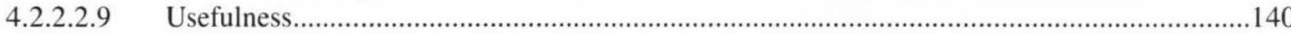

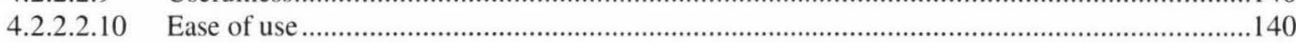

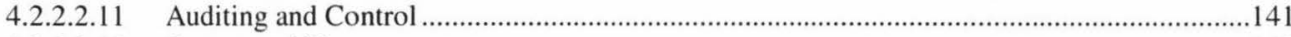

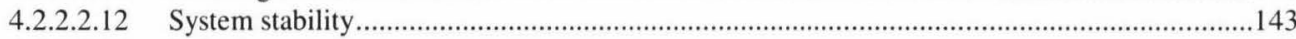

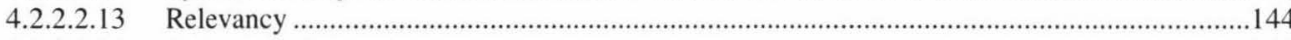

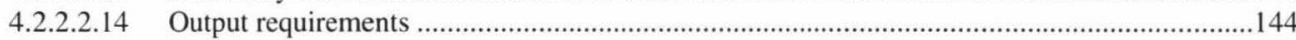

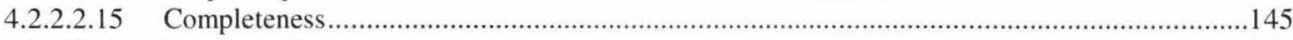

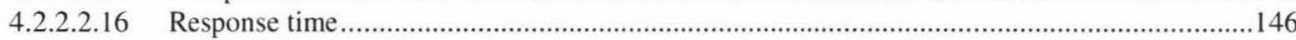

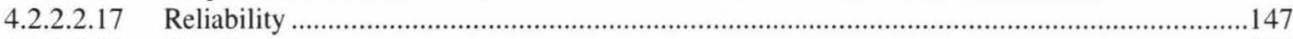

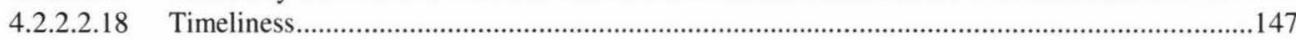

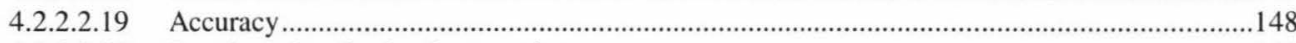

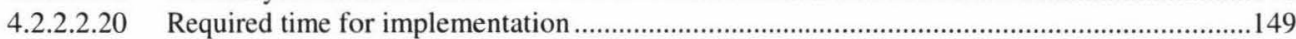

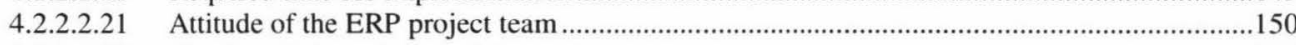

4.2.2.2.22 The domain knowledge of the project team ...................................................................153

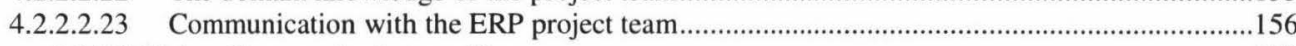

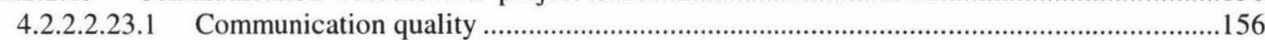

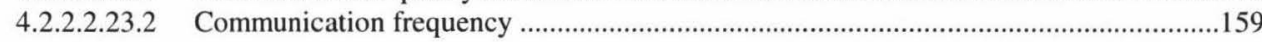




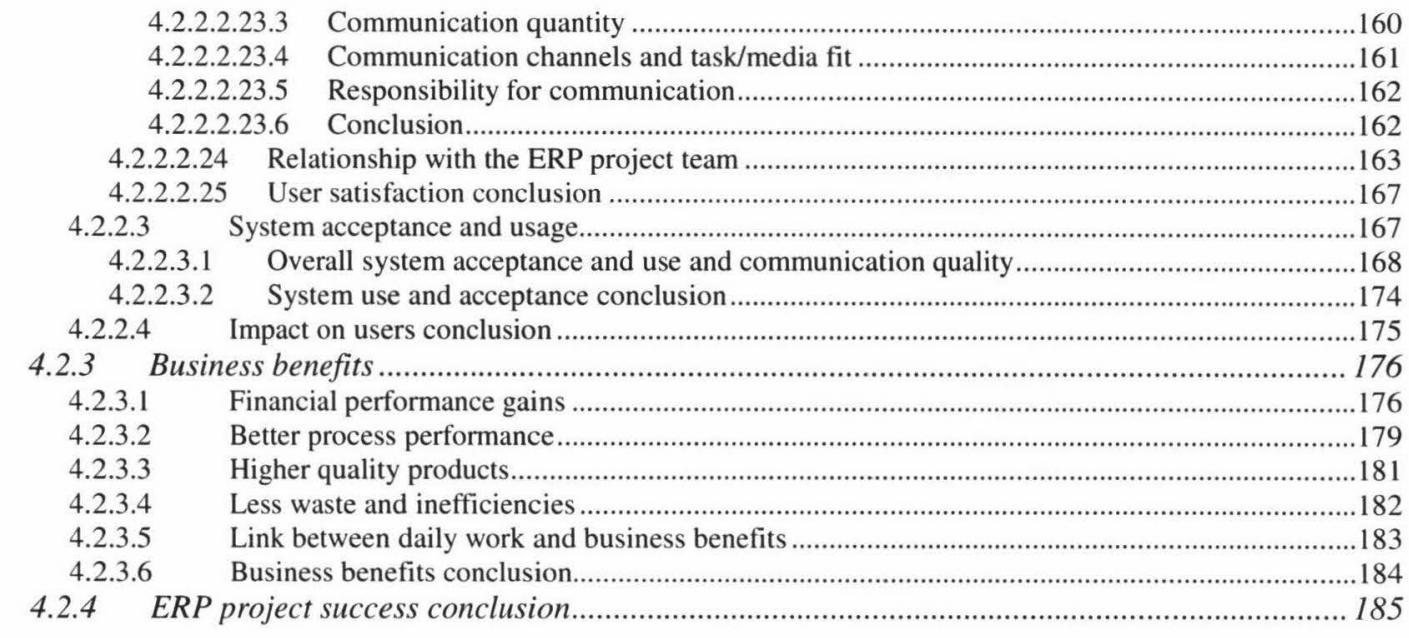

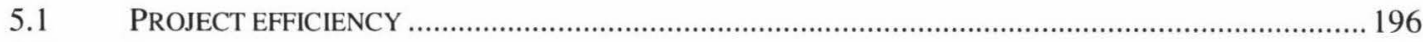

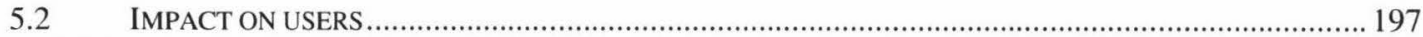

5.2.1 Meeting function requirements and technical performance .................................................... 197

5.2.2 ERP ultimate user satisfaction ........................................................................................... 197

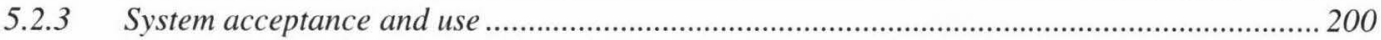

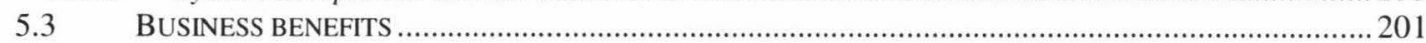

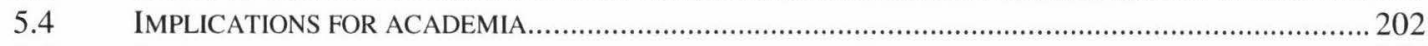

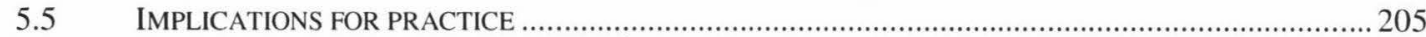

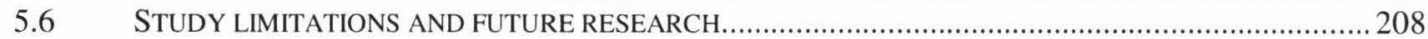

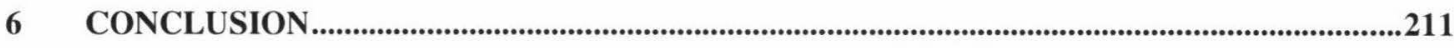

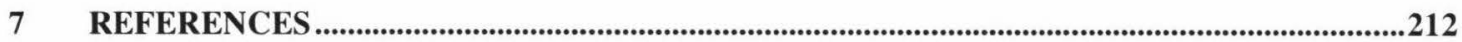

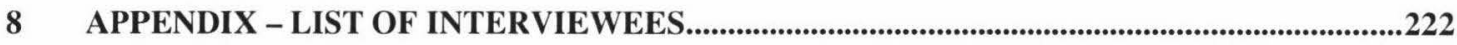

9 APPENDIX - GUIDELINES FOR ASSESSING THE RE-USABILITY OF QUALITATIVE DATA SETS

10 APPENDIX - CROSSTABLES AND KAPPA-COEFFICIENT CALCULATIONS ...................227

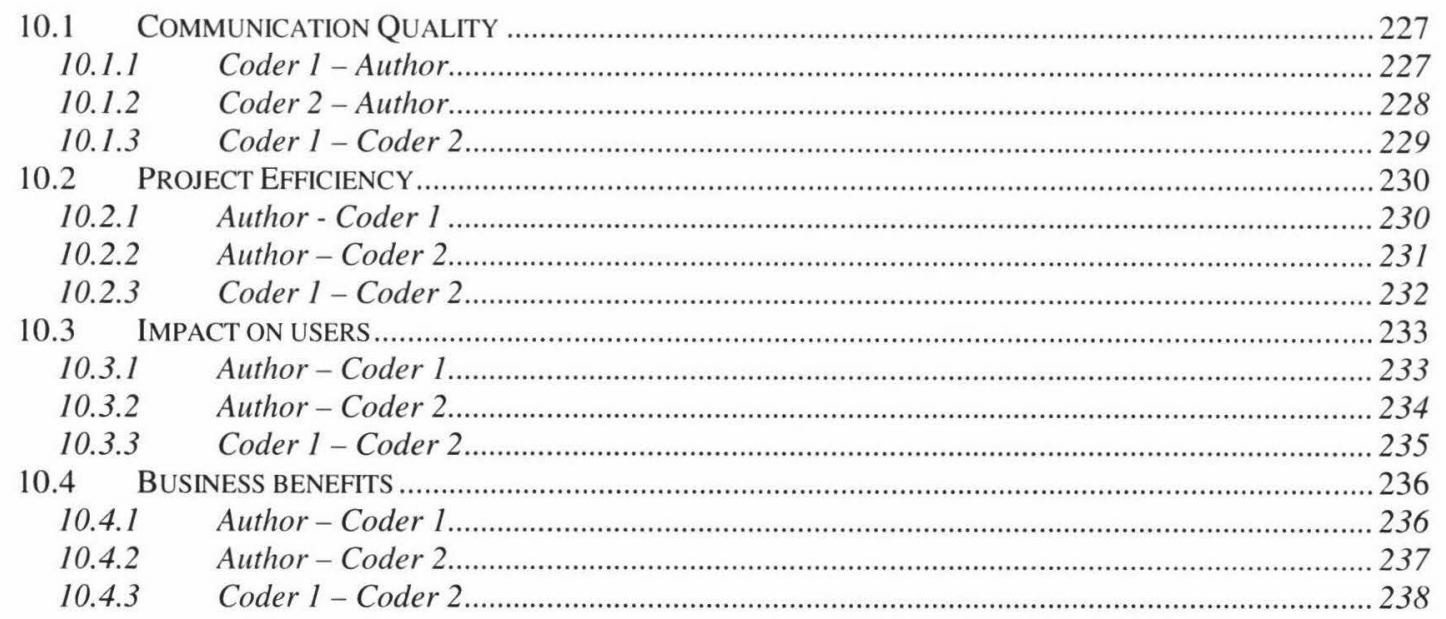




\section{List of Figures}

Figure 1: Time frame of success dimensions (Shenhar et al., 2001, p.716).

Figure 2: Description of success dimensions for various project types (Shenhar et al., 2001, p. 719)

Figure 3: Emerged four success dimensions (Shenhar et al., 2001, p. 712). 34

Figure 4: Research model of the current study..... 44

Figure 5: Coding Schema. 68

Figure 6: Screenshot of the coding process in Maxqda2 70

Figure 7: Communication quality: co-occurrences of attributes. 113

Figure 8: Inter-relationships of communication quality attributes. 114

Figure 9: Occurrences of communication quality attributes in relation to project efficiency 120

Figure 10: Occurrences of communication quality attributes in relation to meeting functional and technical requirements

Figure 11: Occurrences of communication quality attributes in relation to user satisfaction 167

Figure 12: Occurrences of communication quality attributes in relation to system acceptance and use.

Figure 13: Occurrences of communication quality attributes in relation to "Impact on users"

Figure 14: Occurrences of communication quality attributes in relation to business benefits. 184

Figure 15: Attribute occurrences in relationship to ERP project success 186 


\section{List of Tables}

Table 1: Overview of studies examining communication quality in a business context. 15

Table 2: Message content attributes for "communication quality". 17

Table 3: Message process attributes for "communication quality 17

Table 4: Attributes of "communication quality" 18

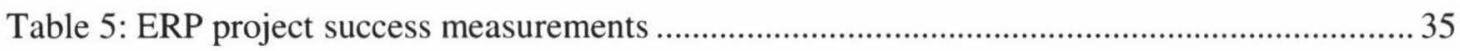

Table 6: ERP ultimate user satisfaction measurement items ............................................................ 41

Table 7: ERP user satisfaction items influenced by communication quality ................................... 46

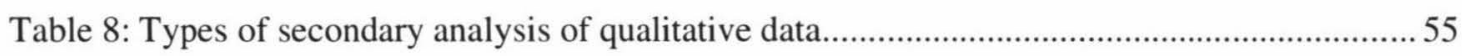

Table 9: Data fit ratios for the individual interviews ................................................................... 58

Table 10: Communication Quality: Kappa-Coefficient results for interrater reliability ................... 68

Table 11: Project Efficiency: Kappa-Coefficient results for interrater reliability.............................68

Table 12: Impact on Users: Kappa-Coefficient results for interrater reliability ................................69

Table 13: Business Benefits: Kappa-Coefficient results for interrater reliability ............................. 69

Table 14: Methodological matters to be described in reports of qualitative secondary studies....... 72

Table 15: Reflexivity issues between primary and secondary study............................................... 73

Table 16: Communication quality attributes with influence on ERP project success measures.... 186

Table 17: Interviewee characteristics. 222

Table 18: Guidelines for assessing the re-usability of qualitative data sets (Heaton, 2004, p. 93) 225 


\section{Acknowledgements}

I would like to express sincere gratitude to my two supervisors Dr Val Hooper and Dr Benoit A. Aubert for the insightful conversations and helpful comments during the development of this thesis.

The thesis is the result of a scholarship offered to me by HEC Montréal and CIRANO as a means to foster the collaboration between those two institutions and the School of Information Management at Victoria University of Wellington. Therefore, I am thankful that this opportunity was offered to me and that I was allowed to be part of the primary research project at CIRANO.

Furthermore, I would like to thank Victoria University of Wellington for awarding the Victoria Master by thesis scholarship to me which enabled me to dedicate myself completely to the thesis. I would also like to thank the School of Information Management for the resources that were provided to me in order to be able to work on my thesis.

It has been a pleasure and an exciting and instructive adventure for me to study abroad at Victoria University of Wellington in New Zealand and in Montréal in Canada. Living in those two countries not only allowed me to advance my academic skills, but also to grow as a person. I think, the experiences have been invaluable to me. I would like to thank my friends I have made and the various people I have met along my way over the last four years. 


\section{Introduction}

Communication between the information systems (IS) specialist and the user has long been recognised in the IS literature as an important aspect for successful information system development projects (for example, De Brabander \& Edstrom, 1977; De Brabander \& Thiers, 1984). Communication is considered as an important aspect to find out user and system requirements, to achieve user buy-in, and to reduce resistance. Although the topic "communication" enjoys a long history within IS research it has not lost any of its importance and relevance yet (for example, Chen, Miller, Jiang, \& Klein, 2005; Gillard, 2005).

Since the 1970s IS researchers have studied the role communication plays in the system development process and its ultimate influence on project/system success. In early studies communication was used as a broad concept (De Brabander \& Thiers, 1984), but more recent studies have looked at communication in more detail, its various aspects and their influence on project outcomes. Johnson (2005) studied the effect of communication frequency and channel richness on the convergence between the Chief Executive Officer (CEO) and the Chief information Officer (CIO) as representatives of the Information Technology (IT) department and the rest of the business. Chen (2005) looked at the level of communication skills and proficiency on IS staff and users. Jiang, Klein, Slyke, and Cheney (2003) and Hornik, Chen, Klein, and Jiang (2003) both looked at the communication skills of IS professionals as well. Evans (2004) and Mann (2002) argued that the education of IS professionals has an impact of the level of their communication skills and consequently influences project success. Patrashkova-Volzdoska, McComb, Green, and Compton (2003) investigated the relationship between communication frequency and team performance. This recent research has shown that communication is a multifaceted concept and that the terms "communication" or "effective communication", as they have been often used in IS literature, might be too broad.

User participation has been studied in IS for a considerable time (for example, Baronas \& Louis, 1988; Doll, 1987; Robey \& Farrow, 1982; Tait \& Vessey, 1988). Hartwick and Barki (2001) considered communication as a dimension of user participation. The two researchers looked at the frequency of information exchange, but argued that this says nothing about the style or form of communication, whether or not the messages are received and the intended meaning. Similarly Gallivan and Keil (2003) argued that specific 
forms of communication might be more valuable than others. The total volume of communication might be a bad indicator to measure if crucial information exchange processes have occurred or not. It is necessary to look beyond the pure information content. They further claim that the nature and quality of the communication between users and developers remains an understudied aspect of user participation.

Communication is not only a dimension of user participation, but spans across virtually all project management activities such as planning, and risk and quality management. Hameri (1997) argued that the role of communication will become an even more important aspect of project management in the future, because technological complexities continue to increase as well as project durations.

In recent years, Enterprise Resource Planning (ERP) systems have been popular information systems development projects. These systems are complex configurable software packages that reach across all functions of an organisation. An increasing number of organisations have tried to pursue ERP implementations in order to gain such benefits as organisational efficiency and effectiveness gains (Al-Mudimigh, Zairi, \& Al-Mashari, 2001; Berchet \& Habchi, 2005; Gupta, 2000). It can take organisations years to implement such systems and reap the benefits.

Although ERP systems emerged in the late 1990s, their implementation and the surrounding issues are still of high interest for organisations and academia. In a survey among CIOs of 628 organisations, ERP systems were ranked third among the top ten IT issues in 2006 after Security and 'Identity Management' ranking first and 'Funding IT' ranking second (Dewey \& DeBlois, 2006).

As ERP projects belong to the most complex IS development and implementation projects, it would be important and beneficial to practitioners and academia to study communication in this context. The nature and quality of the communication between users and developers has remained an understudied area (Gallivan \& Keil, 2003). Conducting research into this area could benefit both academics and practitioners. A better understanding of communication aspects could help to improve the interactions of practitioners with ERP systems and to facilitate successful system developments (Yang \& Wu, 2003). Academics could use the obtained knowledge to develop appropriate frameworks and models to facilitate successful EPR implementation projects. 
Communication has often been mentioned as a critical success factor in ERP implementation projects. On the other hand, communication breakdowns and poor or dishonest communication are considered to possibly lead to several problems that can inhibit project success. These problems can be an increasing number of errors (Jiang et al., 2003), systems that do not fit the users' needs and may consequently remain underutilised or even rejected (Gallivan \& Keil, 2003), as well as intergroup conflicts between the IT department/project team and the rest of the business (Coughlan, Lycett, \& Macredie, 2005). In the worst case a project might turn out to be a failure rather than a success.

There has been a large number of studies attempting to define the dependent variable "IS success" (for example, DeLone \& McLean, 1992, 2003). In the 1980s there were as many measures for success in the IS literature as there were studies. Often surrogates such as 'within budget', 'on schedule', or 'user satisfaction were used. In fact, user satisfaction has been the most widely used surrogate to measure project success (DeLone \& McLean, 1992). Nevertheless, more recent studies argued that project success is a multidimensional concept (DeLone \& McLean, 1992; Linton, 2002) and that a comprehensive definition of IS project success has not emerged yet (Dvir, Raz, \& Shenhar, 2003; Linton, 2002; Shenhar, Dvir, Levy, \& Matlz, 2001; Wateridge, 1998; Zhang, Lee, Huang, Zhang, \& Huang, 2005). Therefore, IS research has argued for more comprehensive project success measures that also take multiple stakeholder viewpoints into account. In the context of ERP success, multiple stakeholder perspectives play a significant role, because ERP systems are integrated systems that reach across virtually all organisational functions. Similarly timeframes become important, because it can take years to implement an ERP system. For that reason, the current research applies a multidimensional instrument in this study to assess ERP project success as recommended by Linton (2002) and DeLone and McLean (2003). The instrument is based on the framework suggested by Shenhar et al. (2001). The instrument takes into consideration multiple stakeholder perspectives and utilises different measurement criteria for different time periods. The framework fits the specific context of an ERP project.

In summary, this study tries to examine the influence of communication quality between IT project team ${ }^{1}$ staff and users on the business $\operatorname{side}^{2}$ on project success within a large ERP

\footnotetext{
${ }^{1}$ The terms "IT project team" and "project team" are used interchangeably in this study. Terms such as 'system designer',' IT staff', 'system specialist', and 'system developer' can be interpreted as being
} 
implementation project. The current research presents multiple stakeholder viewpoints, which has been lacking in the IS literature (Hornik et al., 2003; Willcoxson \& Chatham, 2004). The research question is: "What is the influence of communication quality between business users and IT project team staff on ERP implementation project success?".

The rest of the paper is organised as follows: The first section reviews the existing literature and develops the study's framework to provide the theoretical foundation for this research. The following section explains the research methodology. In the next part the findings are analysed and possible implications are mentioned. Section five presents the discussion and relates the findings back to the IS literature. It also provides implications for academia and practice and offers ideas for future research. The subsequent conclusion rounds the paper off.

representatives of the "IT project team" as well.

${ }^{2}$ The study sometimes refers to users as a specific group within the business. It also sometimes refers to the business as the plant where the implementation took place including all functions and hierarchy levels. The plant was regarded as a "client" or "user" by the project team. 'Organisation' is usually used to refer to the overall company. 


\section{Literature Review}

This section provides a review of topic relevant and pertinent literature to explain the overall topic and context of the research as well as its specifics and constructs. The literature review begins with explanations about Enterprise Resource Planning (ERP) systems. Afterwards the section covers project management, user participation, and communication in implementation projects. Literature on quality and information quality provides the foundation for defining our construct communication quality. The final part defines an ERP project implementation success measure.

\subsection{Enterprise Resource Planning}

Davenport (1998) described Enterprise Resource Planning systems as "the most important development in the corporate use of information technology in the 1990s". Today it is still an area of high interest for both practitioners and academic researchers (for example, Berchet \& Habchi, 2005; Dewey \& DeBlois, 2006; Mabert, Soni, \& Venkataramanan, 2003).

There are numerous definitions of what an ERP system is. A common theme among them is that an ERP system is a configurable software system that provides seamless integration and standardisation of business processes and data across all functions of an organisation to create a single holistic and coherent view to facilitate the effective and efficient management of an organisation's resources (Al-Mashari, Al-Mudimigh, \& Zairi, 2003; Davenport, 1998; Fui-Hoon Nah, Lee-Shang Lau, \& Kuang, 2001; Gupta, 2000; Kumar \& Van Hillegersberg, 2000; Lee \& Lee, 2000; Mabert et al., 2003; Markus, Axline, Petrie, \& Tanis, 2000; Motwani, Subramanian, \& Gopalakrishna, 2005).

Organisations regard ERP systems as a means to maintain and increase their competitiveness in the global marketplace where competition has become more intense (Motwani et al., 2005). ERP systems promise a variety of potential business benefits such as increased interdepartmental connectivity, streamlined data flows (Davenport, 1998), and increased visibility of corporate data (Al-Mashari et al., 2003). This facilitates more accurate analyses (Umble, Haft, \& Umble, 2003) and better decision making (AlMudimigh et al., 2001). Operations can be streamlined using lean manufacturing (Mabert et al., 2003; Tarn, Yen, \& Beaumont, 2002). This reduces production cycle times (Gupta, 
2000; Umble et al., 2003) leading to increased productivity (Al-Mashari et al., 2003; Berchet \& Habchi, 2005; Davenport, 1998; Gupta, 2000). Better production planning and procurement lead to reduced inventory (Al-Mashari et al., 2003; Gupta, 2000) and reduced operating costs (Umble et al., 2003). This improves the organisation's cash flows and increases ultimate profits (Al-Mashari et al., 2003). The overall organisational performance increases through efficiency and effectiveness gains (Al-Mudimigh et al., 2001; Berchet \& Habchi, 2005; Gupta, 2000). This all provides the organisation with more flexibility in the marketplace (Al-Mashari et al., 2003; Davenport, 1998; Tarn et al., 2002). Finally, ERP introduces a higher level of discipline and management control into an organisation (Berchet \& Habchi, 2005; Davenport, 1998).

Investments in ERP systems were some of the largest investments that organisations made in the area of corporate IT during the 1990s (Al-Mashari et al., 2003). Thousands of organisations worldwide implemented ERP systems during that time (Mabert et al., 2003). The market for ERP systems was one of the fastest growing segments of the IT market with average growth rates of $30 \%$ to $40 \%$ per year (Eckhouse, 1999 cited in Berchet \& Habchi, 2005). Even today there is still a strong demand for ERP systems. According to AMR Research the ERP market grew by $14 \%$ to US $\$ 23.6$ billion in 2004 . The prediction for 2006 was positive as well (Woodie, 2005).

These high market growth rates, large investments, and interest in ERP systems can be contrasted with the high failure rates of ERP implementation projects or systems that do not produce the desired results. Thirty-one percent of ERP projects are over budget and $36 \%$ exceed the expected project delivery deadline (Cosgrove \& Ware, 2001, cited in Bernard, Rivard, \& Aubert, 2004). Correspondingly, the Gartner Group reports that $40 \%$ of ERP projects exceed their initial forecasts by more than $50 \%$ (Zrimsek, Phelan, Karamouzis \& Frey, 2001, cited in Bernard et al., 2004). ERP systems and their implementation have acquired the reputation of costing a lot of money and producing meager results (Motwani et al., 2005).

Implementing an ERP system can take several years and can cost tens of millions of dollars for a moderate sized organisation and over US\$100 million for a large international organisation (Mabert et al., 2003). Although the potential benefits of a successfully implemented ERP system are high, the costs of a poor implementation can be significant (Sun, Yazdani, \& Overend, 2005). 
Many managers consider ERP implementation projects to be one of the most difficult system development projects (Wilder and Davis, 1998, cited in Kumar, Maheshwari, \& Kumar, 2003). This is because of their complexity, enterprise-wide scope, and the challenges caused by the accompanying organisational change to a new system and new processes (Kumar et al., 2003). Managing an ERP project and the change it brings is complex and requires knowledge of different areas and issues such as business, technology, and people. Equally important are managerial, political, and project management skills (Kræmmergaard \& Rose, 2002). Consequently, excellent project management is an important aspect of any ERP implementation project.

\subsection{Project Management}

Projects are unique activities that must be completed in a certain amount of time, according to precise objectives, and within specific resource constraints (Lee, 1999, cited in "Management outline: Project Management overview," 2004).

Projects are no recent phenomenon of our time. History has witnessed major undertakings again and again such as the construction of the Egyptian pyramids and the Great Wall of China. These "projects" had to be managed. However, it was not until the 20th century that this kind of management became an object of more serious study (Wideman, 1995).

In 1944 the UK Institute of Civil Engineers recognised the necessity for a systematic approach to planning public works in their Post War Development Report. This systematic approach was supposed to enable people "to carry out work efficiently." During the 1950s and 60s the US Navy and NASA attracted considerable attention through the use of project management in their Polaris and Apollo programs. There is reason to believe that these kinds of projects could not have been completed successfully without systematic project management (Wideman, 1995).

Project management is the disciplined application of certain knowledge, skills (Kenny, 2003), and planning and controlling techniques that aim to minimise disruptive influences to ensure that the project meets the users' needs, is delivered on time, kept within budget ("Management outline: Project Management overview," 2004), and conducted with a gain for the organisation (Wideman, 1995). 
Today, project management is not confined to construction or aeronautics anymore, but has permeated virtually all kinds of areas such as research and development, system development, corporate management, and education. Advances in technology and the changes an increasingly globalised world, such as globally dispersed multinational companies, have increased the complexity of projects. Today projects come in all kinds of sizes and durations, from several hours to several days. Therefore, there has been a need to capture, develop, and conceptualise management approaches for planning and controlling project performance, schedules, and budgets (Wideman, 1995).

A project is usually guided by a steering committee consisting of a project director, the project manager, and department and sometimes supplier representatives. The project director presents project issues at the board level and ensures that the project is in line with the business objectives. The project manger's responsibility is to implement the project plan. The project manager monitors the project, reports the overall progress to the senior management, and ensures effective communication between all members involved in the project. Representatives and system users from different departments ensure that different perspectives are taken into account so that the final deliverable will meet their needs. Suppliers or vendors are involved in the steering committee to provide advice through their perspectives. The overall role of the steering committee is to ensure that project proposals match with the business objectives and to approve or reject proposals accordingly. During a project the committee reviews and monitors the project's progress ("Management outline: Project Management overview," 2004).

\subsection{Project management and user participation}

User participation is widely regarded as an important aspect of information systems development projects and consequently project management (Barki \& Hartwick, 1994; Foster \& Charles, 1999; Ives \& Olson, 1984; Kujala, 2003; Roberts, Leigh, \& Purvis, 2000; Tomes \& Armstrong, 1998).

The terms "user participation" and "user involvement" have often been used interchangeably or with overlapping definitions in IS literature. Barki and Hartwick (1989) suggested distinguishing clearly between the two terms and their inherent concepts. Accordingly, "user participation" refers to "a set of behaviours and activities performed by the users in the system development process" whereas user involvement denotes "the 
subjective psychological state reflecting the importance and personal relevance of the system to the user". Barki and Hartwick (1989) denote user participation as being an important predecessor or cause of user involvement.

Active user participation is believed to offer several benefits such as increasing the probability of system acceptance, reducing possible user resistance, creating a feeling of system ownership among users, creating a more accurate and complete list of actual system requirements, and ultimately higher system quality (Lin \& Shao, 2000; Roberts et al., 2000).

Barki and Hartwick (1994) identified three parts of user participation, namely overall responsibility, the IS-user relationship, and hands-on activities. Overall responsibility means activities and tasks that show the overall accountability and ownership by users of the project, e.g. in being responsible for selecting hardware and software. The IS-user relationship refers to collaboration activities between the two parties, e.g. work agreements and timelines. Hands-on activities means specific design and implementation tasks that the users perform.

Hartwick and Barki (2001) added a fourth construct namely communication activity. They argued that the communication between users and various stakeholders is an important aspect of user participation. Communication activity stands for the performance of information exchange activities as users communicate formally and informally with other participants, for example, the IT staff during the information systems development. It encompasses only the frequency and quantity of information system development related communication activities during the project. It does not include communication style, communication effectiveness, and the intended or perceived meaning of a communication message. Consequently, Hartwick and Barki (2001) recommended that future research should investigate behaviours, types, styles, timing, and how these characteristics impact user participation and its effectiveness.

The current research argues that communication behaviours, types, styles, and their timing are aspects of what the author calls "communication quality". 
Alexander Schnepel

\subsection{Communication}

In general, communication is defined as "a process in which individuals share and create information in order to reach a mutual understanding" (Rogers and Kincaid, 1981, cited in Johnson \& Lederer, 2005). In order for communication to be effective, there has to be mutual agreement after all information has been exchanged (De Brabander \& Thiers, 1984). Effective communication is a meeting of meanings (Gillard, 2005).

Within the social matrix of an organisation human interactions take place and communication is focal to these human interactions (Holden \& O'Toole, 2004). Therefore, communication underlies most aspects of organisational functioning making it crucial for organisational success (Mohr \& Spekman, 1994). However, in many organisations people regard communication as being "poor" (Gillard, 2005).

Communication is a process by which messages are exchanged between individuals or groups of individuals. The communication process encompasses several components: (1) the sender and the receiver, (2) the message, (3) the message's encoding (by the sender) and decoding (by the receiver) process, (4) the transmission medium, (5) the noise during the transmission that can interfere or stop the transmission, and (6) a feedback to ensure that the intended meaning has been understood. In order for two parties to effectively communicate with and understand each other, both need to use a common set of symbols with mutually congruent real world meanings behind them (Holden \& O'Toole, 2004).

In the organisational context, message exchange serves several purposes. There is: (1) task related communication, (2) maintenance communication during regular organisational operations, (3) human communication in the context of interpersonal relationships, and (4) innovative communication enabling the organisation to adapt to its ever changing environment (Holden \& O’Toole, 2004).

A single message can serve multiple purposes at a time (Holden \& O'Toole, 2004). Next to the sole content (topic, subject, or goal) of a message, virtually every message during interpersonal communication also contains a relational aspect including feelings, values, beliefs, and impressions. Research has shown that the relational aspect during a communication process is important, especially because the response is affected by how the message is interpreted by the receiver on a personal level next to its sole content. This includes cognition, perception, emotions, and physical aspects. This aspect of 
communication is affected in large part by the human-relational context that exists or is created during the communication process (Ralph, 1998).

System development and implementation projects are social processes of introducing change into an organisation, involving social interactions (Snead \& Ndede-Amadi, 2002) and consequently communication processes between different parties. These two parties are, users on one side, and IS/IT staff such as designers and analysts on the other side.

Communication is the starting point for an implementation project, but communication between the two sides is not a given (Hornik et al., 2003). The communication between these two parties is often difficult, because they come from different backgrounds with diverse interests, expectations, and priorities (Chen et al., 2005). The two sides communicate from different perspectives and show perception differences (Hornik et al., 2003). Semantics can be different and hampering to a meaningful dialogue (Coughlan, 2003; De Brabander \& Thiers, 1984). Each group uses its specific jargon, metaphors, figures of speech, and terminology (Gillard, 2005).

The communication between users and IT staff is influenced by their understanding and perception of reality. The IT staff often possess a technological world understanding whereas users focus on their personal work relevance, business aspects (Hornik et al., 2003), or a more social-political view focusing on the organisational impact (Wang, Chen, Jiang, \& Klein, 2005). This can lead to incongruence and misunderstandings. IS literature calls this possible misunderstanding or communication difference the "user-designer communication gap" (Laudon \& Laudon, 1996).

Next to possible misunderstanding, this communication gap can lead to frustration, hostility, anger, distrust, and even conflict between the two groups (Wang et al., 2005). Yeh (2001) found intergroup conflict is affected by the quality and frequency of interpersonal interaction. This could result in groups not adhering to the plans and neglecting follow-ups (De Brabander \& Thiers, 1984). The consequences can be a shortage of effective and necessary communication. This suboptimal communication between users and IT staff can lead to wrong assumptions (Hornik et al., 2003). As a consequence decisions might be based on incomplete information and might need to be changed again when confronted with reality. Suboptimal communication can result in trial and error, a 
loss of time, money, and resources (De Brabander \& Thiers, 1984). Ultimately this can result in project failures (Hornik et al., 2003).

\subsection{Interaction quality and communication quality}

Communication is one part of the interaction activities between IS staff and users. However, so far IS research has not looked specifically at the influence of communication quality between these two groups within IT projects and IT project management.

IS researchers have examined areas such as communication frequency (for example, Johnson \& Lederer, 2005; Patrashkova-Volzdoska et al., 2003), channel richness (for example, Johnson \& Lederer, 2005), and quantity (for example, Kuzman, 1989) and their influence on project performance and success. However, quality has been neglected so far.

The overall interaction quality is impacted by the way user training is applied, how user-IS communication is managed, and to what extent users are engaged in the project, thereby creating increased feelings of participation (Wang et al., 2005). Researchers have found that the interaction quality is pivotal to successful system development projects (Hornik et al., 2003; Wang et al., 2005) and that user-developer interaction quality is correlated to effectiveness and team and project performance. Specifically, the quality of communication between IS staff and users can affect user satisfaction (McKeen, Guimaraes, \& Wetherbe, 1994; Wang et al., 2005), which can be seen as an aspect of system success depending on its definition. Moreover, communication quality is central to making accurate decisions, to deliver on time, and to ensure product quality (Holden \& O'Toole, 2004). Therefore, the author argues that it is not only the quantity, frequency, channel richness, or media synchronicity, but also the quality that is a critical aspect (Wang et al., 2005).

\subsection{Quality}

Quality means different things to different people in different situations. It is a complex concept with many definitions depending on the discipline, supporters, and different schools of thought of what encompasses quality (Hardie \& Walsh, 1994; Reeves \& Bednar, 1994). 
Philosophically, quality can be regarded from five perspectives: (1) The transcendent approach, (2) the product-based approach, (3) the user-based approach, (4) the manufacturing-based approach, and (5) the value based approach (Garvin, 1984).

The transcendent approach describes quality as striving for excellence. Quality is in the philosophical sense "logically primitive" and its characteristics can only be understood after being exposed to different objects of different quality allowing judgement of higher vs. lower quality (Garvin, 1984).

In the product-based approach quality is seen as the compliance to precise, defined measures. Each good has a certain number of attributes. Quality is the difference between desired and actual attributes. The approach has its origin in the economics literature. It allows the definition of quality categories and rankings (Garvin, 1984).

The user-based approach regards the term "quality" as relative and basically assumes that "the beauty lies in the eye of the beholder". Every user has different wants and needs. In this sense quality means the congruence with these individual wants and needs (Garvin, 1994).

In the manufacturing approach quality is viewed as the extent to which a good conforms to specification and requirements (Garvin, 1984).

Finally, the value based-approach operates with cost and prices. High quality is considered as high perceived usability value for a certain amount of money (Garvin, 1984).

\subsection{Information quality}

A considerable amount of research about information quality has been conducted within the IS field (English, 2001; Graefe, 2003; Kahn, Strong, \& Wang, 2002; Miller, 2005; Xu, Nord, Nord, \& Lin, 2003). Researchers have attempted to define "information quality", but there is no one encompassing definition. However, a common thread across different studies is a categorisation into four areas of attributes that define information quality:

1. Intrinsic Information Quality: Measures accuracy, believability, objectivity, precision, and reliability and indicates quality inherent in the information itself. 
2. Contextual Information Quality: Measures relevance, timeliness, completeness, and appropriateness and relates to considering information in the context of the task at hand.

3. Representational Information Quality: Includes understandability, interpretability, concise and consistent representation, format and appearance, and addresses how systems store, process and present information.

4. Accessibility Information Quality: Measures accessibility, security, system availability, ease of operation, and privileges, and deals with system aspects of how easy one can "get at" information and how secure is that information (Miller, 2005).

Although IS research has produced a list of attributes, "information quality" is used with multiple meanings. First, it is used to describe the quality of the output of an information system, e.g. in the form of reports or even in the representation in databases (for example, Lillrank, 2003; Miller, 2005). Second, it is used to describe the process of producing quality information or managing and ensuring information quality (for exampleAndersson \& von Hellens, 1997; von Hellens, 1997).

Most organisational processes, such as planning, designing, manufacturing, selling and distributing goods and services, that are conducted within an organisation or with its environment produce information (English, 2001).

Usually information is not generated simply for the sake of producing it. Information needs to be utilised and communicated to be useful. The communication can either happen between individuals or through the representation of an information system. However, the focus in this study is on the communication between individuals and in particular within the context of an ERP implementation project. The purpose is to gain a better understanding of the influence of communication on project success. Representation of information by information systems (in particular ERP systems) and utilisation is not the main focus of this study.

ERP systems are complex, reach across functional boundaries, and their implementation often takes considerable amounts of time. During an ERP implementation, there are numerous processes that produce information. Users and IT staff need to effectively communicate this information to each other and communicate with each other. Within this 
context communication becomes a critical success factor (Nah \& Delgado, 2006; Nah, Lau, \& Kuang, 2001).

During the interactions between users and IT staff, it is not only the information quantity or frequency which are important. The interaction process between the two parties and its quality, including the quality of communication between the two parties, are part of a successful interaction that facilitates a successful project outcome (Wang, 2005).

\subsection{Defining communication quality}

To the author's knowledge, defining and specifically studying the concept of "communication quality" in a business context, and with a similar understanding as in the current research, has only received sporadic attention by academia. The main studies can be found in the areas of general business communication, marketing, and logistics and distribution (see Table 1). However, "communication quality" has not yet been researched adequately in the IS field, let alone in the context of ERP implementation projects and their management. In the IS literature "communication quality" or "quality of communication" is sometimes used as a concept without definition (for example, Feeny, Edwards, \& Simpson, 1992; Lee, Kozar, \& Larsen, 2005) or subsumed under effective communication or as a part of it (for example, Nath \& Lederer, 1996; Tan, 1994).

Therefore, it is deemed necessary to define the meaning of communication quality in the context of this study. The current research draws on previous literature from two areas: First, the research on information quality from the IS field. Second, the sporadic studies on communication quality in studies on other organisational areas, such as general business communication, marketing, logistics, and distribution.

It is deemed appropriate to use "information quality" as a foundation, because the message content in a communicative interaction basically consists of information. Therefore, the current research draws on previous research in this area.

The studies on communication quality from related organisational areas are considered as an appropriate starting point for two reasons. First, these studies have the closest proximity and similarities to IS, because they stem from the context of research on organisations, their processes, internal communication, and operations. Second, IS represents one specific 
field of research on organisations like marketing and logistics as opposed to further related fields such as communication or library studies.

The most common approach across different studies to define quality has been related to "meeting of user or customer requirements", either in studies on information quality in IS or communication quality in other organisational areas. For example, in the IS literature user satisfaction is often based on criteria measuring the satisfaction with the information quality provided by a system (for example, Bailey \& Pearson, 1983). In general, in business customer-oriented approaches have become increasingly common in recent years in supplier-customer interactions and relationships. This can be seen in approaches such as customer-relationship or supply chain management. Therefore, modern organisations adopt a customer and service-oriented approach to manage their external as well as internal processes. Business units and functions have become service units. Consequently, IT departments are often regarded as units delivering services to the rest of the business as if the business represents a customer.

Table 1: Overview of studies examining communication quality in a business context

\begin{tabular}{|c|c|c|c|c|c|}
\hline Author(s) & $\begin{array}{c}\text { Organisational } \\
\text { situation }\end{array}$ & $\begin{array}{c}\text { Description of } \\
\text { study }\end{array}$ & $\begin{array}{c}\text { Dependent } \\
\text { variable }\end{array}$ & $\begin{array}{c}\text { Main } \\
\text { finding(s) }\end{array}$ & $\begin{array}{l}\text { Type of } \\
\text { study }\end{array}$ \\
\hline $\begin{array}{l}\text { Eriksson } \\
(2002)\end{array}$ & $\begin{array}{l}\text { Communication } \\
\text { quality in the } \\
\text { context of } \\
\text { information } \\
\text { systems and } \\
\text { business } \\
\text { processes }\end{array}$ & $\begin{array}{l}\text { Quality of } \\
\text { communication } \\
\text { and material acts } \\
\text { that contribute to } \\
\text { business } \\
\text { relationships. } \\
\text { Business } \\
\text { processes are } \\
\text { considered as a } \\
\text { type of social } \\
\text { interaction and } \\
\text { information } \\
\text { systems as } \\
\text { intermediary } \\
\text { medium for } \\
\text { business } \\
\text { communication } \\
\text { between actors. }\end{array}$ & - & - & $\begin{array}{l}\text { Conceptual } \\
\text { paper }\end{array}$ \\
\hline $\begin{array}{l}\text { Hardie } \\
\text { and } \\
\text { Walsh } \\
\text { (1994) }\end{array}$ & $\begin{array}{l}\text { Communication } \\
\text { quality as one } \\
\text { part of transaction } \\
\text { quality }\end{array}$ & $\begin{array}{l}\text { Quality in the } \\
\text { transactions } \\
\text { between supplier } \\
\text { and customers }\end{array}$ & $\begin{array}{l}\text { Perceived } \\
\text { performance by } \\
\text { the customer }\end{array}$ & - & $\begin{array}{l}\text { Conceptual } \\
\text { paper }\end{array}$ \\
\hline $\begin{array}{l}\text { Holden } \\
\text { and } \\
\text { O'Toole } \\
(2004)\end{array}$ & $\begin{array}{l}\text { Communication } \\
\text { quality in the } \\
\text { context of } \\
\text { manufacturer- } \\
\text { retailer } \\
\text { relationships }\end{array}$ & $\begin{array}{l}\text { Communication } \\
\text { quality as an } \\
\text { aspect of } \\
\text { communication as } \\
\text { a governance tool } \\
\text { for } \\
\text { interorganisational } \\
\text { relationships } \\
\text { between } \\
\text { manufacturers and }\end{array}$ & $\begin{array}{l}\text { Relationship } \\
\text { strength }\end{array}$ & $\begin{array}{l}\text { Only } \\
\text { communication } \\
\text { quality as part } \\
\text { of the } \\
\text { relationship } \\
\text { strength } \\
\text { measurement } \\
\text { framework has } \\
\text { the power to } \\
\text { delineate }\end{array}$ & $\begin{array}{l}\text { Survey of } \\
149 \text { retailers } \\
\text { of } 1 \text { supplier }\end{array}$ \\
\hline
\end{tabular}




\begin{tabular}{|c|c|c|c|c|c|}
\hline & & retailer & & $\begin{array}{l}\text { relationship } \\
\text { structures }\end{array}$ & \\
\hline $\begin{array}{l}\text { Mohr and } \\
\text { Sohi } \\
(1995)\end{array}$ & $\begin{array}{l}\text { Communication } \\
\text { quality in the } \\
\text { context of retailing } \\
\text { distribution } \\
\text { channels between } \\
\text { manufacturers } \\
\text { and dealers }\end{array}$ & $\begin{array}{l}\text { Assessment of } \\
\text { communication } \\
\text { quality and } \\
\text { satisfaction with } \\
\text { communication in } \\
\text { communication } \\
\text { flows in retailing } \\
\text { distribution } \\
\text { channels }\end{array}$ & $\begin{array}{l}\text { Dealer's } \\
\text { perception of } \\
\text { quality of } \\
\text { communication }\end{array}$ & $\begin{array}{l}\text { Dealer's } \\
\text { judgement was } \\
\text { influence by } \\
\text { frequency, } \\
\text { bidirectionality, } \\
\text { and formality } \\
\text { of } \\
\text { communication } \\
\text { flows }\end{array}$ & $\begin{array}{l}\text { Survey of } \\
125 \text { dealers } \\
\text { of } 1 \\
\text { manufacturer }\end{array}$ \\
\hline $\begin{array}{l}\text { Richeson, } \\
\text { Lackey, } \\
\text { and } \\
\text { Starner } \\
(1995)\end{array}$ & $\begin{array}{l}\text { Quality of } \\
\text { communication } \\
\text { between suppliers } \\
\text { and manufactures }\end{array}$ & $\begin{array}{l}\text { Investigation of } \\
\text { qualitative } \\
\text { attributes for } \\
\text { communication } \\
\text { between suppliers } \\
\text { and manufacturers } \\
\text { in a Just in } \\
\text { time/Total Quality } \\
\text { Management } \\
\text { Environment }\end{array}$ & $\begin{array}{l}\text { Just in time } \\
\text { performance } \\
\text { and } \\
\text { effectiveness }\end{array}$ & $\begin{array}{l}\text { Openness and } \\
\text { accessibility } \\
\text { are important } \\
\text { aspects of the } \\
\text { quality of } \\
\text { communication } \\
\text { link between } \\
\text { manufacturer } \\
\text { and supplier. } \\
\text { Effective } \\
\text { communication } \\
\text { can enhance } \\
\text { JIT } \\
\text { effectiveness }\end{array}$ & $\begin{array}{l}\text { Survey of } \\
218 \text { members } \\
\text { of purchasing } \\
\text { departments }\end{array}$ \\
\hline $\begin{array}{l}\text { Shelby } \\
\text { (1998) }\end{array}$ & $\begin{array}{l}\text { Communication } \\
\text { quality in the } \\
\text { context of general } \\
\text { business } \\
\text { communication }\end{array}$ & $\begin{array}{l}\text { Definition of a } \\
\text { communication } \\
\text { quality construct } \\
\text { and its relationship } \\
\text { to message } \\
\text { effectiveness and } \\
\text { efficiency }\end{array}$ & $\begin{array}{l}\text { Message } \\
\text { effectiveness } \\
\text { and efficiency }\end{array}$ & & $\begin{array}{l}\text { Conceptual } \\
\text { paper }\end{array}$ \\
\hline $\begin{array}{l}\text { Harcout, } \\
\text { Richerson } \\
\text {, and } \\
\text { Wattier } \\
\text { (1991) }\end{array}$ & $\begin{array}{l}\text { Communication } \\
\text { quality in the } \\
\text { middle } \\
\text { management of } \\
\text { organisations }\end{array}$ & $\begin{array}{l}\text { Communication } \\
\text { quality as } \\
\text { summary of } \\
\text { perceived level of } \\
\text { feeling informed } \\
\text { about } \\
\text { organisational } \\
\text { topics }\end{array}$ & $\begin{array}{l}\text { Abundance } \\
\text { survey to create } \\
\text { percentage } \\
\text { statistics. No } \\
\text { relationships } \\
\text { tested }\end{array}$ & $\begin{array}{l}\text { Best sources } \\
\text { of information } \\
\text { are network } \\
\text { communication } \\
\text { and formal } \\
\text { communication }\end{array}$ & $\begin{array}{l}\text { Survey of } \\
871 \text { middle } \\
\text { managers in } \\
\text { US } \\
\text { organisations }\end{array}$ \\
\hline $\begin{array}{l}\text { Boyle, } \\
\text { Kumar, } \\
\text { and } \\
\text { Kumar } \\
(2005)\end{array}$ & $\begin{array}{l}\text { Communication } \\
\text { quality as an } \\
\text { organisational } \\
\text { factor in new } \\
\text { product } \\
\text { developments }\end{array}$ & $\begin{array}{l}\text { Influence of } \\
\text { communication } \\
\text { quality between } \\
\text { new product } \\
\text { development } \\
\text { teams on } \\
\text { organisational } \\
\text { support for the } \\
\text { development } \\
\text { teams }\end{array}$ & $\begin{array}{l}\text { Organisational } \\
\text { support for new } \\
\text { product } \\
\text { development } \\
\text { teams }\end{array}$ & $\begin{array}{l}\text { Communicatio } \\
\text { n quality } \\
\text { positively } \\
\text { influences } \\
\text { level of support }\end{array}$ & $\begin{array}{l}\text { Survey of } \\
269 \\
\text { Canadian } \\
\text { and US } \\
\text { manufacturin } \\
\mathrm{g} \\
\text { organisations }\end{array}$ \\
\hline
\end{tabular}

Communication in general involves both process and content (Holden \& O'Toole, 2004; Robertson, 2005). In order to define attributes that constitute "communication quality" the author distinguishes between two categories. The first category contains attributes that constitute the quality of the message content. These attributes are also related to previous IS research on attributes determining information quality. The message content of a communicative interaction basically represents information. Table 2 provides an overview of related studies. 
Table 2: Message content attributes for "communication quality"

\begin{tabular}{|c|c|c|c|c|c|}
\hline & & \multicolumn{4}{|c|}{$\begin{array}{l}\text { Attributes for Communication Quality - Message } \\
\text { content }\end{array}$} \\
\hline & & Completeness & Credibility & Accuracy & $\begin{array}{l}\text { Purpose } \\
\text { Adequacy }\end{array}$ \\
\hline \multirow[t]{9}{*}{ Information Quality } & $\begin{array}{l}\text { Kahn, Strong, and } \\
\text { Wang (2002) }\end{array}$ & $x$ & $x$ & $x$ & $x$ \\
\hline & $\begin{array}{l}\text { Xu, Nord, Nord, and Lin } \\
(2003)\end{array}$ & $x$ & & $x$ & \\
\hline & Miller (2005) & $x$ & $x$ & $x$ & $x$ \\
\hline & English (2001) & $x$ & & $x$ & $x$ \\
\hline & Lillrank (2003) & $x$ & $x$ & $x$ & $x$ \\
\hline & $\begin{array}{l}\text { Bailey and Pearson } \\
(1983)\end{array}$ & $x$ & $x$ & $x$ & $x$ \\
\hline & King and Epstein (1983) & $x$ & $x$ & & $x$ \\
\hline & Miller and Doyle (1987) & $x$ & & $x$ & $x$ \\
\hline & Srinivasan (1985) & & & $x$ & $x$ \\
\hline \multirow{7}{*}{$\begin{array}{l}\text { Communication } \\
\text { Quality }\end{array}$} & Lin and Shao (2000) & $x$ & & & \\
\hline & $\begin{array}{l}\text { De Brabander and } \\
\text { Thiers (1984) }\end{array}$ & $x$ & & & \\
\hline & Robertson (2005) & & $x$ & & $x$ \\
\hline & Gillard (2005) & & $x$ & & \\
\hline & Coughlan (2003) & & $x$ & & \\
\hline & Chen et al. (2005) & & & $x$ & $x$ \\
\hline & $\begin{array}{l}\text { Stewart and Gosain } \\
(2006)\end{array}$ & & & $x$ & \\
\hline
\end{tabular}

The second category entails attributes that constitute the quality of the communication process, as shown in Table 3. The author argues that message content could be of high quality, but the communication process quality not, hence having a negative effect on the interaction between IT staff and users and consequently endangering project success. Vice versa, a high quality communication process does not help much, if the message content is poor.

Table 3: Message process attributes for "communication quality

\begin{tabular}{|l|c|c|c|c|c|}
\cline { 2 - 6 } \multicolumn{1}{c|}{} & \multicolumn{5}{c|}{ Attributes for Communication Quality - Message process } \\
\cline { 2 - 6 } & Timeliness & Openness & $\begin{array}{c}\text { Audience } \\
\text { adequacy }\end{array}$ & Bidirectionality & $\begin{array}{c}\text { Balance of formality } \\
\text { vs. informality }\end{array}$ \\
\hline Cavaye (1995) & & $x$ & & & $x$ \\
\hline Chen et al. (2005) & & & $x$ & & \\
\hline
\end{tabular}




\begin{tabular}{|c|c|c|c|c|c|}
\hline $\begin{array}{l}\text { De Brabander and } \\
\text { Thiers (1984) }\end{array}$ & $x$ & & $x$ & $x$ & \\
\hline $\begin{array}{l}\text { De Brabander and } \\
\text { Edstrom (1977) }\end{array}$ & $\mathrm{x}$ & & & & \\
\hline $\begin{array}{l}\text { Gallivan and Keil } \\
(2003)\end{array}$ & & $x$ & & $x$ & $x$ \\
\hline Gillard (2005) & & & $x$ & $x$ & \\
\hline $\begin{array}{l}\text { Holden and O'Toole } \\
\text { (2004) }\end{array}$ & $\mathrm{x}$ & $x$ & $x$ & & \\
\hline Hornik et al. (2003) & & & $x$ & & \\
\hline Mohr and Nevin (1990) & & & & & $x$ \\
\hline Mohr and Sohi (1995) & $x$ & $x$ & & $x$ & $\mathrm{x}$ \\
\hline $\begin{array}{l}\text { Mohr and Spekman } \\
\text { (1994) }\end{array}$ & $x$ & & & $\mathrm{x}$ & \\
\hline $\begin{array}{l}\text { Patrashkova- } \\
\text { Volzdoska et al. (2003) }\end{array}$ & & & $\mathrm{x}$ & & \\
\hline Robertson (2005) & & $x$ & & & \\
\hline $\begin{array}{l}\text { Taylor-Cummings } \\
\text { (1998) }\end{array}$ & & & & $x$ & \\
\hline Wang et al. (2005) & & $x$ & & & \\
\hline $\begin{array}{l}\text { Stewart and Gosain } \\
(2006)\end{array}$ & $x$ & & & & \\
\hline
\end{tabular}

Table 4 provides an overview of the two proposed categories "Message content attributes" and "Message Process Attributes" with their respective quality determining attributes.

Table 4: Attributes of "communication quality"

\begin{tabular}{|l|r|}
\hline \multicolumn{2}{|c|}{ Communication Quality } \\
\hline Message Content Attributes & \multicolumn{1}{|c|}{ Message Process Attributes } \\
\hline - Completeness & $\bullet$ Timeliness \\
- Credibility/reliability & $\bullet$ Openness \\
- Accuracy & - Audience adequacy \\
- Purpose adequacy & - Bidirectionality \\
& - Balance of formality vs. informality \\
\hline
\end{tabular}

In the current study the term communication is used for all types of communication over various media. This can entail, for example, face to face communication, written communication, promotional communication such as posters, as well as training and education sessions. 
Therefore, the author defines communication quality as a function of the message content and process attributes completeness, credibility, accuracy, purpose adequacy, timeliness, openness, audience adequacy, bidirectionality, and balance between formality and informality that influence the level of perceived satisfaction of the sender and receiver with the communicative interaction during an interaction where information is communicated (Holden \& O’Toole, 2004; Mohr \& Sohi, 1995; Robertson, 2005).

The following sections present a description of the attributes of communication quality as shown in Table 4.

\subsubsection{Completeness}

Completeness means that all information is available which needs to be known (English, 2001; Xu et al., 2003). During ERP system implementation projects the communication between business and the IT department includes such aspects as determining the system's requirements, exchanging information about business processes, plans, actions, timelines, milestones, and planning and coordinating activities. The purpose is to align the organisational processes with the inherent ERP package's processes. This has been proven to be a critical issue for ERP success (Soffer, Golany, \& Dori, 2003) and complete communication is necessary for this.

Often it is necessary to redesign organisational processes in order to achieve this alignment. In order to align the processes, an initial gap analysis is carried out at the outset of the project. The gap analysis is continuously updated and validated during the project through communication between the business and the IT department (Soffer et al., 2003).

Incomplete communication during this updating iterations and alignment process, but also during other project activities, can cause serious mistakes in decision-making processes, because it leaves space for ambiguity and uncertainty (Xu et al., 2003). Decisions and their following actions might need to be changed again when confronted with reality. This would result in a trial and error way of working that wastes efforts and project resources. Moreover, it would result in a loss of time and money (De Brabander \& Thiers, 1984), which might have a negative effect on the ERP project's delivery deadline and budget.

Several studies have indicated that incomplete communication is perceived as a serious quality problem. Unexpected system variations can occur, because requirements might be 
ignored and promises broken (Lillrank, 2003). Therefore, incomplete information contributes to a low level of communication quality.

On the other hand, a more complete way of communication, for example in the form of a complete list of actual ERP system requirements, is supposed to increase system quality and to result in a better user understanding. It increases the likelihood of project success, elevates user satisfaction, and enhances alignment ensuring that the final system supports the real business processes as best as possible (Lin \& Shao, 2000). This would increase communication quality. Hence, completeness of communication represents an attribute within the construct of communication quality.

\subsubsection{Credibility}

In general, communication is one of the most fundamental organisational processes. Therefore, it should be a top priority that communication is conducted with credibility and integrity (Robertson, 2005) in everyday operations as well as in ERP project management.

Credibility describes the degree to which communicated information is considered as true and believable by the message receiver (Kahn et al., 2002; Miller, 2005). This is especially important in a situation of information asymmetry where one communication participant is unable to validate the truthfulness of a piece of communicated information provided by the individual in possession of more information (Graefe, 2003).

A message needs to appear credible in order to be fully considered in an individual's decision-making process. Otherwise the message might be disregarded for making a decision (Graefe, 2003). Therefore, individuals judge the credibility of communicated information on such criteria as expertise and the trustworthiness of the information, personal contact with the sender, design and content of the message, and the level of congruence with the individual's own knowledge (Graefe, 2003). In addition the reputation of the information source is an influencing factor (Kahn et al., 2002).

An IT department's reputation depends on its ability to deliver its promises and to make a contribution to the organisation's strategic objectives. It is important for the IT department during and after ERP projects to build and maintain strong partnerships with the business, to be a knowledgeable strategic partner for the business, and to align IT and business strategies (Willcocks \& Sykes, 2000). 
In order to deliver those benefits to the business the IT department relies on effective leadership and effective project managers. Two important characteristics of effective leadership are credible communication and interpersonal skills (Stewart, 2000) which are used to maintain credibility with salient project stakeholders (Willcocks \& Sykes, 2000). An effective project manager earns the trust and respect of the employees by being forthright during all the communication (Gillard, 2005).

If employees perceive the project manager's credibility as low, they might not trust and believe in the communication they receive. In such a climate it is difficult to achieve reliable and effective communication. Much better results can be expected in a climate of trust where cooperation and negotiation occur (Coughlan, 2003).

In conclusion, credibility contributes to the perceived level of communication quality. If the communication source's credibility is perceived as high, it will have a positive effect on the level of communication quality and vice versa. Hence, credibility of communication represents an attribute of communication quality.

\subsubsection{Accuracy}

Accuracy of communicated information refers to the extent to which it is correct and can be trusted and relied on because it is true and unbiased (English, 2001; Kahn et al., 2002). It represents one of the key dimensions of information quality (Miller, 2005; Xu et al., 2003).

Accuracy is often assumed as a given pre-requisite in business communication. However, organisations consist of humans and humans sometimes make mistakes, either unintentionally or intentionally. Therefore, mistakes and inaccuracies can happen. There is also a tension between accuracy and timeliness of information and people tend to be willing to compromise accuracy for timeliness (Xu et al., 2003).

Although a level of $100 \%$ accuracy is not possible all the time, maybe not even feasible, there are measures that can be taken to increase the likelihood of accurate communication. These could be, for example, standards for the communication content (Chen et al., 2005). In ERP project management these could be standards and guidelines for the memo or email communication. Meetings could follow certain structures and control mechanisms could be put in place to enhance the accuracy of communicated information. 
Inaccurate communication can have severe negative effects on ERP project management. People need accurate information to conduct their tasks properly and in the most efficient way. Good decisions rely on accurate information. Therefore, inaccurate information might lead to bad decisions (Mohr \& Sohi, 1995). Wrong decisions and following actions can result in a waste of time, money, and project resources, and might make it necessary to redo work. This could delay the roll-out of the ERP system and would be detrimental to the motivation of project team members and support of the business for the project.

In conclusion, accurate information is crucial for effective decision-making and to carry out tasks properly. As a key dimension of information quality accuracy it also represents a key attribute in the message content construct of communication quality.

\subsubsection{Purpose adequacy}

Purpose adequacy is the extent to which communicated information is appropriate, applicable, and helpful for the task at hand in order to accomplish set objectives (English, 2001; Kahn et al., 2002; Miller, 2005).

Research has shown that inadequate information is a risk factor in implementations (Sherer \& Alter, 2004) and conversely adequate information is considered as a critical success factor in ERP implementations (Nah, Zuckweiler, \& Lau, 2003).

Communication that is not adequate for the current issues of concern can lead to a decline in the effectiveness of decision making processes by leaving space for interpretation ambiguity (Chen et al., 2005). Inadequate information can also cause role ambiguity, because employees do not have the information at hand that they need in order to carry out their tasks. This can result in dissatisfaction and stress (Joshi \& Rai, 2000).

On the opposite, the more adequate the communication is, the more likely are better decisions and performance. Employees need adequate communication on relevant topics and issues in order to perform well. (Robertson, 2005).

In conclusion, the adequacy of communicated information has been found to be a critical success factor in ERP project implementations. It is important to increase decision-making appropriateness by reducing interpretation ambiguity. It has been found to be linked to user 
satisfactions. Therefore, adequate communication for the corresponding reasons is an attribute of communication quality.

\subsubsection{Timeliness}

Timeliness is a critical dimension of communication quality and refers to the speed of the information transfer (Mohr \& Sohi, 1995). In our conceptual framework it also refers to receiving the necessary information on time as opposed to receiving it too early or too late.

Communication that lacks timeliness is likely to distort the communication process and communication quality is reduced (De Brabander \& Thiers, 1984). Delayed communication might hold other employees back in their work as their progress is dependent on the required information from their peers. If communication is received too late it can lead to feelings of frustration. Information that is received too early might be forgotten by the time it is actually needed or cause confusion. Some information might be time-sensitive and might only be of value at a certain time or for a certain time. Receiving communication either too early or too late might have negative effects (Mohr \& Sohi, 1995).

Frustration also arises if promises on the timeliness of communication are not kept. The receiving group might build up expectations and build their plans on the promised communication. If the communication does not arrive on time, re-planning and additional efforts are necessary. This reduces the efficiency of the project's progress and might endanger reaching set goals (Mohr \& Spekman, 1994). Therefore, timeliness is vital to effective and efficient communication in interactions between business and the IT department (Holden \& O'Toole, 2004) to achieve the goals that are supposed to be reached.

In conclusion, timeliness is an important attribute of communication quality. Because of the complexity of ERP systems, this cross-functional reach, and level of integration, tasks are likely to become more reliant on the work of peers. Therefore, receiving communication on time is vital to the overall functioning of the project's implementation and the everyday operations. 


\subsubsection{Openness}

Communication openness is "the formal and informal sharing of timely information between partners and is concerned with the mutual disclosure of plans, programs, expectations, goals, motives, and evaluation criteria" (Barclay \& Smith, 1997).

Open communication is more likely to occur in an organisational environment that fosters open and supportive communication (Robertson, 2005) and which is based on norms that value information sharing. In such an environment both parties will be willing to communicate openly, but also expect the same from the opposite party. Therefore, the incentives to share are higher (Mohr \& Sohi, 1995).

However, in certain environments can lack openness. Some IT managers believe users are hostile, some business managers feel the IT department is not responsive to their needs. The user might be ignored by the IT staff and be forced to accept their requirements (Cavaye, 1995). Similarly withholding or distorting communication, i.e. the meaning of a message is either intentionally or unintentionally transformed or not submitted by the sender (Mohr \& Sohi, 1995), leads to feelings of secrecy and negative attitudes (Robertson, 2005).

IT managers are sometimes reluctant to submit negative information fearing that it might embarrass them or negative consequences could follow. The IT department might change dates and deadlines without letting the business know in order to bias the development process positively. Over time such behaviour is detrimental to the project's success and the organisation as a whole (Gillard, 2005).

Organisational politics might also be a reason to withhold information in order to maintain power. In both cases, avoiding negative feedback and withholding information for reasons of perceived organisational power, the project manager has to look for such issues and resolve them (Gillard, 2005). This might have negative effects on project performance.

There has been evidence in IS research that trusting and open communication between IT teams and business users has a stronger influence on eventual performance outcomes than only user participation (Wang et al., 2005). The extent of effective user participation depends on the parties' willingness to share information and communicate openly with each other. Open and supportive communication influences people's values, beliefs, and attitudes about each other. It shapes relationships (Robertson, 2005). Communication 
attributes such as honesty and openness are important for the development of a positive

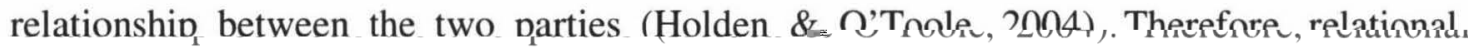
communication should be based on open, honest, and frequent exchange of information (Mohr \& Sohi, 1995). Obstacles to open communication, either horizontal or vertical, need to be removed to facilitate the open exchange of ideas, issues, and opinions (Robertson, 2005).

In the context of ERP implementations open and honest communication has been found to be an influential factor for project success (Gargeya \& Brady, 2005; Molla \& Bhalla, 2006). It facilitates the completion of ERP projects on time, within budget, and according to business requirements. It also reduces uncertainty among employees that is created by new roles and responsibilities as a consequence of the new ERP system (Molla \& Bhalla, 2006).

During an ERP implementation project, issues need to be addressed open and honestly (Davenport, 1998). Otherwise, confusion among the stakeholders might arise and the ERP project objectives and goals remain unclear (Akkermans \& van Helden, 2002).

Open and honest communication in ERP implementations has also been found to reduce perceived differences between IT staff and the business and can foster collaboration between those two groups (Molla \& Bhalla, 2006).

In conclusion, openness is an important attribute of communication quality, because openness reduces uncertainty, increases trust, improves the perception one party holds of the other one and consequently fosters collaboration, which is positively related to ERP project success.

\subsubsection{Audience adequacy}

Audience adequacy entails the adjustment of communication to the audience in order to achieve semantic equivalence in terms of word meanings in order to increase the audience's understanding (Gillard, 2005; Hornik et al., 2003).

IT staff and users come from different departments and functions. They possess different backgrounds, interests, perceptions, values, and expectations (Chen et al., 2005; Hornik et 
al., 2003). Both groups speak figuratively different languages, talk in their own jargon, and use different semantics (Gillard, 2005).

Both groups have a different frame of reference for reality or different schema for reality (Chen et al., 2005). IT staff tend to have a technical frame of reference whereas users tend to apply a work experience frame of reference to their communication (Hornik et al., 2003). Each group possesses knowledge about non-overlapping aspects and stages of the project and each group views this differently from their own perspective (PatrashkovaVolzdoska et al., 2003). These differences hinder communication between the two parties because it results in disparities in the preferred way of communication (Chen et al., 2005).

The level of communication effectiveness between the two groups is related to the amount of shared meanings in terms of congruence between words and their real-world meanings (Holden \& O'Toole, 2004). The bigger the semantic gap, the more costly is the communication and the more difficult is it to understand the other party. In that case more efforts are necessary from both groups to establish semantic equivalence. which is necessary to understand each other in the systems development process (De Brabander \& Thiers, 1984). Seeking semantic equivalence and consonance between business and the IT department increases the likelihood of project success (Hornik et al., 2003).

One approach is to be aware of the differences and understand each other's perceptions (Hornik et al., 2003). It might be helpful to adjust the communication process to the audience, which means using its terminology, and jargon, restating things if necessary, and in general adapting the way of delivery (Gillard, 2005). Trying to close the existing gap from either side can help to achieve common understanding about issues, topics, and problems.

In ERP projects stakeholders from virtually all functions and levels of an organisation are involved. Therefore, semantic gaps within the communication process are likely to occur. This makes it all the more necessary to pay attention to the differences, address them, and adjust the communication process to the audience in order to communicate effectively. If the differences are not addressed, stakeholders are likely to perceive the communication quality as poor. Therefore, an important aspect of communication quality is adjusting the communication to its audience in order to increase their ability to absorb the communicated information and to retain it, and to thereby increase the overall 
effectiveness of the communication process. Hence, audience adequacy represents an important attribute of communication quality.

\subsubsection{Bidirectionality}

Bidirectionality refers to the extent to which two parties mutually provide feedback and input to each other in a two-way flow during the communication. It is a mutual giving and taking where questions can be asked and clarification or verification of assumptions can be obtained (Mohr \& Sohi, 1995).

In many IS studies about user participation in systems development it has been assumed that feedback from users to IT staff and vice versa just happens. However, there are moments when this is not the case and important information might be held back by one party even though there might be a lot of opportunities to express it, e.g. in meetings, memos, or workshops (Gallivan \& Keil, 2003). So one party acts as if there is agreement. The other party might assume that a consensus has been reached although this is actually not the case.

This apparent agreement can create the impression the communication has been successful, but one party becomes upset and emotional about the whole interaction and project later on. As a consequence, it can happen that this party does not adhere to plans that are made. This can result in a loss of time and effort which is one of the reasons for dissatisfaction during the project (De Brabander \& Thiers, 1984).

A more extreme possibility is that the communication process might also be only one-way from the beginning without offering the other party a chance to contribute to the information exchange. The offer to participate would be only a bogus offer in that case. Therefore, one party might be left with unanswered questions lowering the perception of communication quality (Mohr \& Sohi, 1995).

There have been times in systems development when communication between the IT department and the business was like that. In the early 1990s, when business managers and users felt as if they had no choice but to agree to what the IT staff and developers said and proposed. The IT department was relatively independent from the rest of the business (Taylor-Cummings, 1998). However, various studies have shown that misalignment between the two departments and a lack of collaboration could lead to suboptimal results in 
systems development and implementation projects (Grant, 2003; Luftman \& Brier, 1999; Villachica, Stone, \& Endicott, 2004).

Bidirectionality of communication is based on a supportive and trusting climate and environment within the organisation. In such more relational-oriented environments communication tends to be more bidirectional because people are more willing to pass information along and receive information. The same is the case in environments with less power asymmetry. In environments where strong power asymmetries exist, the more powerful party might be perceived as dominant, stimulating the inferior party to withhold information (Mohr \& Nevin, 1990).

In order to ensure bidirectional communication, communication receivers should be asked for their feedback. The receivers also need to be willing to provide feedback. The sender should look for indicators for either understanding or confusion and adjust the communication accordingly. The sender should sincerely ask about the receiver's ideas and development activities (Gillard, 2005).

There needs to be clarity about deliverables and desirables. The project manager plays an important role in this communication process. The project manager needs to seek accurate and sufficient information from the users and at the same time transmit ideas, knowledge, and other information back to the users in an adequate way. Asking the right questions and accurately framing comments and feedback are essential (Gillard, 2005).

Finally, if communication is bidirectional it reduces ambiguity and leads to a closer relationship between the parties. Moreover, commitment and the willingness to cooperate increase (Prahinski \& Benton, 2004).

In ERP projects bidirectionality of communication is vital, because of the interdependencies of tasks and the level of integration between functions and organisational levels.

In summary, communication needs to go both ways between business and the IT department in order to successfully develop and implement an ERP project. Hence, bidirectionality denotes a key attribute of communication quality. 


\subsubsection{Balance of formality vs. informality}

Formality stands for the degree to which communication is structured, planned, regulated, and routinised (Mohr \& Nevin, 1990; Mohr \& Sohi, 1995). Examples of formal communication are official meetings, organised workshops, and required documentation and memos. Informal communication on the other hand, is most often more spontaneous, nonregulated, and personalised. It also might occur outside the office space the organisational premise (Mohr \& Nevin, 1990).

The communication between IT staff and users often consists of formally organised elements, such as meetings, and informal information communication that occurs spontaneously through various channels such as a telephone call or a "watercooler" discussion.

The effectiveness and quality can be influenced by the balance between mandatory formal communication and the amount of informal communication that occurs (Cavaye, 1995), because certain styles (informal vs. formal) may be more effective for certain situations and tasks. It has been shown in IS research that both informal and formal communication influence task efficiency, commitment, and satisfaction (Hartwick \& Barki, 2001).

Informal communication is as important for a successful project outcome as formal communication (Gallivan \& Keil, 2003). Sometimes formal communication might take too long, but formal communication might be required sometimes to ensure completeness, especially when there is no organisational climate with norms enforcing information sharing (Mohr \& Sohi, 1995).

In ERP implementation projects the IT project team delivers the ERP system to the business. During the project constant contact and communication between business and the IT project team is necessary to keep the project on track. This communication can occur either formally or informally, but the level of perceived communication quality depends on the appropriate balance between formal and informal communication. Therefore, the balance of formality vs. informality is an attribute of communication quality.

\subsubsection{Summary}

Communication quality is a construct that consists of attributes that determine the quality of the message content and attributes that influence the quality of the message 
communication process. The message content quality attributes are rooted in the literature of information quality, whereas the process quality attributes are derived from literature on relational aspects of interpersonal and organisational interactions (see Table 4).

Both sets of attributes constitute what the author refers to in this study as "communication quality". This epitomises one part of the often generally used term "effective communication" along with communication frequency, quantity, and channels (task/media fit).

The current research argues that effective communication is a multifaceted concept and needs to be examined in more detail. Communication quality, in the context in which the current research defines it, has not received much attention in the IS literature and only sporadically in the business literature. The author argues that communication quality influences ERP project success by impacting on the relational aspect and effectiveness of the collaboration between business and the ERP project team/IT department.

The next section defines the dependent variable, ERP project success, and highlights the connection to the attributes of communication quality.

\subsection{IS Project and system success}

At the end of a successful IS project stands a successful information system, but what is a successful system or IS project? Research into IS success enjoys a long history (for example, DeLone \& McLean, 1992). Measurements such as time, costs, and accordance to specifications have been used since the 1960s (Wateridge, 1998). In the 1980s there were as many measures for success in the IS literature as there were studies (DeLone \& McLean, 1992). More recent studies have tried to take broader approaches by considering measures beyond time and costs such as user satisfaction or quality improvements. However, even though there have been various attempts to define the dependent variable "IS success" (for example, DeLone \& McLean, 1992, 2003), a comprehensive definition and what makes an IS project successful has not emerged yet (Dvir et al., 2003; Linton, 2002; Shenhar et al., 2001; Wateridge, 1998; Zhang et al., 2005).

Project success is a multifaceted concept and therefore requires a measurement tool that takes this into consideration (DeLone \& McLean, 2003; Linton, 2002; Shenhar et al., 2001). IS projects are usually implemented to enhance organisational performance in the 
long-run. In the short-run, this is difficult to assess. Therefore, different measurements seem to be more appropriate for certain times of an information system's lifecycle depending on the phase of the lifecycle (Markus et al., 2000; Shenhar et al., 2001).

The understanding and perception of IS success also varies from one individual to another one. The senior management might be most interested in the strategical implications and potential business benefits of the system. The users might be most concerned with how their work is impacted. A project manager's main guideline for IS success might be project delivery on time and within budget. Therefore, it appears appropriate to consider multiple stakeholder perspectives when assessing IS success (Markus et al., 2000; Shenhar et al., 2001).

In the context of ERP success the aspects of long-term vs. short-term measures as well as multiple stakeholder perspectives play a significant role. First, ERP projects are usually large implementation projects that can run over years before the whole organisation is on the system. Organisations implement ERP systems for potential business benefits, such as increased process efficiencies and reduced costs. These can often only be realised after a considerable amount of time. Nevertheless, the actual project implementation needs to be managed and its progress measured as well. Second, ERP systems reach across virtually all functions of an organisation. It appears necessary to take account of the perspectives of several stakeholders in order to assess ERP project success.

Therefore, as recommended by Linton (2002) and DeLone and McLean (2003), the current research applies a multidimensional instrument in this study to assess ERP project success. Our instrument is based on the framework suggested by Shenhar et al. (2001). The instrument takes into consideration multiple stakeholder perspectives and utilises different measurement criteria for different time periods. The framework will be adjusted to fit the specific context of an ERP project.

\subsubsection{ERP project success Framework}

The framework assumes that project success cannot be defined by only a few measurements such as time and schedule, because different measurements are more appropriate for different time periods of the project. The ultimate goal of a project is to contribute to organisational objectives and success. A project's impact on that is, however, difficult to assess in the short run. Measuring a project before and during its 
implementation with long-term organisational measures does not make much sense. Therefore, a framework needs to consider different success dimensions for different time periods, like proposed by Shenhar et al. (2001). Figure 1 describes the correlation between project success and the time frame, i.e. the respectively most appropriate success dimension (Shenhar et al., 2001).

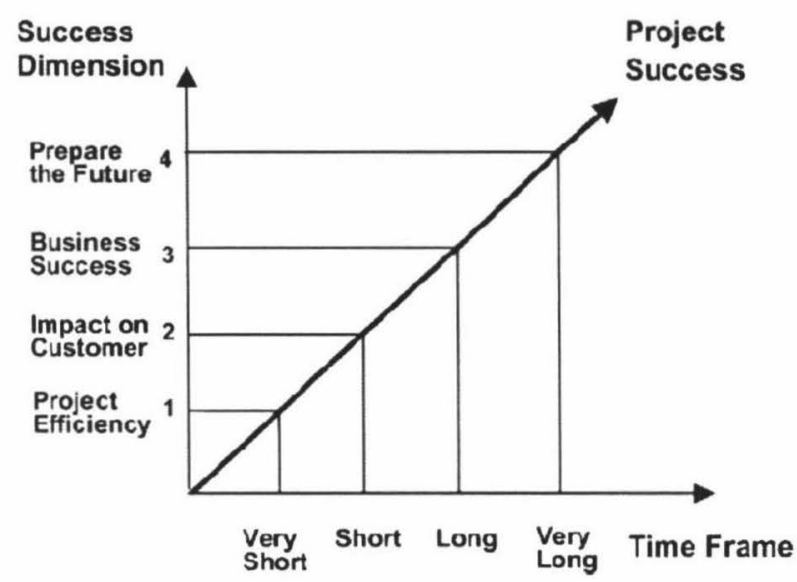

Figure 1: Time frame of success dimensions (Shenhar et al., 2001, p.716)

During the time when the project runs (from project kick-off till delivery deadline) operational measures related to the project's efficiency are most appropriate to monitor the project's efficiency, e.g. how well it is managed within resource constraints. Measures in this first category can be assessed during and immediately after project completion, i.e. the delivery.

After the delivery these operational measures lose significance and the second dimension becomes more important. This dimension assesses the impact the new system has on users. Shenhar et al. (2001) do not specifically distinguish between customers and users in their study. In the current study the author refers specifically to users, i.e. the people who use the new ERP system. Users ultimately work with the new system and are supposed to experience the expected benefits. The impact on users can only be evaluated a few months after the delivery when the users have worked with the new system for a while.

The third dimension represents business success, in other words the achievement of the expected benefits. This takes some time, as people's skills with the new system follow a learning curve. The organisation requires some time to adjust the usual way of working to 
the ERP system. Therefore, assessing the business benefits and success can only be done after a longer period of time, usually one or two years.

Ultimately, the new information system is supposed to prepare the organisation for the future, e.g. creating new markets and products. The new information system is the foundation for this, but the outcomes of this category can only be seen after a considerable time, i.e. after several years.

However, this does not mean that a project's success can only be assessed after a number of years. Project success is a continuum along a certain path over time as described above and depicted in Figure 1. Ultimate project success and the expected benefits will only show after several years, but indications of the success can be seen earlier if the project is on the right path.

Shenhar et al. (2001) developed this framework as a general concept for projects, but they only distinguish projects by technological uncertainty. They acknowledge that projects with different technological uncertainty also differ in the relative importance placed on each success dimension. Figure 2 provides an overview.

\begin{tabular}{|c|c|c|c|c|}
\hline \multirow[t]{2}{*}{ Success dimension } & \multicolumn{4}{|c|}{ Project type: level of technological uncertainty } \\
\hline & Low-tech & Medium-tech & High-tech & Super high-rech \\
\hline Fropect efinciency & Critizal & In:portant & Overruns acceptable & Overrtins most likely \\
\hline Impact on customer & Standard product & $\begin{array}{l}\text { Functional prodect, } \\
\text { adled value }\end{array}$ & $\begin{array}{l}\text { Significantly } \\
\text { inupured cupabilities }\end{array}$ & $\begin{array}{l}\text { Quantum leap in } \\
\text { eflettictuess }\end{array}$ \\
\hline Eus ners suctess & Reasonable poft & $\begin{array}{l}\text { Profit, return on } \\
\text { investment }\end{array}$ & $\begin{array}{l}\text { High profits, market } \\
\text { share }\end{array}$ & $\begin{array}{l}\text { High, sut may come } \\
\text { late: } \\
\text { Marke: leader }\end{array}$ \\
\hline $\begin{array}{l}\text { Freparing fo: the } \\
\text { fiture }\end{array}$ & Almost none & $\begin{array}{l}\text { Gein additional } \\
\text { capatilities }\end{array}$ & $\begin{array}{l}\text { New product line, } \\
\text { new narkets }\end{array}$ & $\begin{array}{l}\text { Leadership-core and } \\
\text { tuture techmologies }\end{array}$ \\
\hline
\end{tabular}

Figure 2: Description of success dimensions for various project types (Shenhar et al., 2001, p. 719)

An ERP project falls into the third category, i.e. "High-tech" projects. Projects of this category deploy technologies that are mostly new, but are existent. The technologies have been developed before the project initiation (Shenhar et al., 2001). ERP systems are software packages such as SAP. These software packages are developed by third party companies, so-called vendors. Organisations usually implement the whole or individual modules of an SAP ERP suite with only minor modification, the so-called vanilla implementation (Gargeya \& Brady, 2005). 
The importance of the individual success dimensions shifts along the technological uncertainty continuum. In low-tech projects project efficiencies are most critical, whereas long-term considerations are virtually neglected. In high-tech projects, and consequently ERP projects, budget overruns are likely to happen, but because of the project's long-term focus this is not as important as for low-tech projects. The impact on users is also significant. High profits are expected as well as new products and markets. Overall, this distribution of importance across the success dimensions of projects in this category, including ERP projects, emphasises again the importance of utilising a multidimensional measurement tool.

Shenhar et al. (2001) also acknowledge that one set of measurements is not suitable for all types of projects. Each project should use specific measurements and each with different degrees of importance. For certain projects and organisations it might be useful to consider additional measurements within each success dimension. Therefore, the author argues that the framework and its success measurements needs to be adjusted to fit into the specific context of an ERP implementation and correspondingly ERP success as Shenhar et al. (2001) recommends. Hence, the author develops a framework based on Shenhar et al. (2001) specifically for the ERP context.

Shenhar et al. (2001) suggested the success dimensions and corresponding measures as shown in Figure 3.

\begin{tabular}{|c|c|}
\hline Success dimension & Mcasures \\
\hline 1. Froect ethciency & $\begin{array}{l}\text { Meeting sibetul? goel } \\
\text { Misting budgot josl }\end{array}$ \\
\hline \multirow[t]{2}{*}{ 2. Impact on the custorrer } & $\begin{array}{l}\text { Mieting furctional performan:e } \\
\text { Meeting tetanical specificitiors }\end{array}$ \\
\hline & $\begin{array}{l}\text { rufilling custorer needs } \\
\text { Solving a ctstomer's protlem } \\
\text { The customer is using the product } \\
\text { Custorer sutisfa:tion } \\
\text { Commoretal surcoss }\end{array}$ \\
\hline \multirow[t]{2}{*}{ 4. Preparing tor the futur? } & $\begin{array}{l}\text { Creating a brge market share } \\
\text { Creating a new market }\end{array}$ \\
\hline & $\begin{array}{l}\text { Crsuting a new prodect line } \\
\text { Developing a new technobgy }\end{array}$ \\
\hline
\end{tabular}

Figure 3: Emerged four success dimensions (Shenhar et al., 2001, p. 712)

In order to customise the framework we apply the following modifications as it can be seen in Table 5. 
Table 5: ERP project success measurements

\begin{tabular}{|c|c|c|}
\hline Success dimension & $\begin{array}{l}\text { Original measures } \\
\text { (Shenhar et al. 2001) }\end{array}$ & Measures in this study \\
\hline \multirow[t]{2}{*}{ 1. Project efficiency } & Meeting schedule goal & Meeting schedule goal \\
\hline & Meeting budget goal & Meeting budget goal \\
\hline \multirow[t]{6}{*}{ 2. Impact on the users } & Meeting functional performance & Meeting functional performance \\
\hline & Meeting technical specifications & Meeting technical specifications \\
\hline & Fulfilling customer needs & \\
\hline & Solving customer's problems & \} ultimate user-satisfaction \\
\hline & Customer satisfaction & \\
\hline & The customer is using the product & $\begin{array}{l}\text { System acceptance and use. } \\
\text { Measured along criteria according to } \\
\text { (Davis, 1989) }\end{array}$ \\
\hline \multirow[t]{2}{*}{ 3. Business success } & Commercial success & Business Benefits \\
\hline & Creating a large market share & $\begin{array}{l}\text { Financial performance gains } \\
\text { (Al-Mashari et al., 2003; } \\
\text { Gupta, 2000) } \\
\text { - Better process performance } \\
\text { (Al-Mudimigh et al., 2001; } \\
\text { Berchet \& Habchi, 2005; } \\
\text { Gupta, 2000) } \\
\text { - Higher quality products } \\
\text { - Less waste and inefficiencies } \\
\text { (Mabert et al., 2003; Tarn et } \\
\text { al., 2002) } \\
\text { - The link between business } \\
\text { benefits and the users' daily } \\
\text { work was communicated } \\
\text { (Kositanurit, Ngwenyama, \& } \\
\text { Osei-Bryson, 2006) } \\
\end{array}$ \\
\hline 4. Preparing for the future & $\begin{array}{l}\text { Creating a new market } \\
\text { Creating a new product line } \\
\text { Developing a new technology }\end{array}$ & $\begin{array}{l}\text { Not assessed because the } \\
\text { research's timeframe is too short }\end{array}$ \\
\hline
\end{tabular}

The main success dimensions remain unchanged. However, some of the measures change in order to adjust the framework to the specific ERP context of this study.

\subsubsection{Project efficiency - Budget and schedule}

Measures such as delivery on time and within budget have often been used in project management as success measures (Carù, Cova, \& Pace, 2004; Cavaye, 1995). These measurements are relatively easy to make and to quantify in monetary terms. This might be a reason why a lot of organisations adhere to financial measures to evaluate success (Shenhar et al., 2001). In fact, organisations often show a great sensitivity about these measurements.

The widespread application of these measures can be explained by an operational mindset that exists in the project management literature and among project managers. Project 
managers and project team members often focus on "getting the job done" in their daily project tasks. This might be beneficial for completing the individual tasks efficiently, but might be detrimental to the overall long-term success and business results (Shenhar et al., 2001). However, project managers often have to focus on time and budget criteria, because these criteria are set by the senior management. A project manager's performance evaluation and future might depend on meeting those criteria (Wateridge, 1998).

Measuring costs or adherence to schedule, or even a combination of both, provides at most a partial picture of project success (Dvir et al., 2003). It can lead to incomplete and misleading project evaluations (Shenhar et al., 2001). Projects that fulfil these two requirements are considered successful although they might not meet the users' requirements at all, which can have an adverse effect on how well users can deal with their potential customers (Dvir et al., 2003; Shenhar et al., 2001). Moreover, projects can still turn out to be a huge success for an organisation in the long-run, although the project itself exceeded budget and schedule in the first place. A large number of studies have shown that the measures "adherence to budget" and "schedule" alone are insufficient to predict organisational success in the long-run (Shenhar et al., 2001).

In ERP projects it is especially difficult to make estimations about timelines and costs, because projects are complex and depend on efficient project management. Nevertheless, organisations put a large amount of effort into defining realistic timelines and budgets for ERP projects (Mabert et al., 2003). However, budget and schedule represent only the first dimension of this study's ERP project success measurement tool, because they are only able to measure one part of project success focus, mainly in the short-run for the actual project duration.

In conclusion it can be seen that a sole focus on budget and schedule represents only a partial view of project success. This view is mainly focused on the short-term and the project itself rather than longer-term, the whole organisation, and the project's contribution to its success.

Budget and schedule as requirements are based on operational focus on "getting the job" done. They apparently disregard another important aspect and stakeholder group in the IS implementation process - the users. Therefore, a measurement focusing on the user is included in this study. 


\subsubsection{Impact on the users}

The "impact on the customer"- dimension is one of the most important criteria in assessing project success, because the users ultimately work with the system (Shenhar et al., 2001). Although ERP packages are most often standard software packages including pre-set business processes developed out of the industry's best practices, it is important to consult the users about the specifications of certain business processes. This influences ERP user satisfaction and ultimately ERP system acceptance, which has been shown to be one of the most commonly cited reasons for ERP failure (Nah, Tan, \& Teh, 2004).

The dimension "impact on users" includes how well technical and functional requirements are met, the level of user satisfaction, and if and how much the users are using the system. Meeting the functional and technical requirements has a direct impact on users, their satisfaction with the system, and its usage. Therefore, it is part of this category and not in the project efficiency category as it is often found in the IS literature (Shenhar et al., 2001).

\subsection{Meeting technical specifications and functional performance}

Technical specifications are developed out of clearly defined requirements. In the IS literature requirements are often referred to as what the users value in a new information system (Coughlan, 2003). Defining system requirements and consequently specifications is one of the most important stages in system development. It clarifies for users and developers what both parties want the system to do. This provides developers a clear starting point for their work as well and users have a clear idea of what they can expect from the future system (Mumford, 1985).

Finding and defining technical specifications is supposed to happen in a collaborative process between users and developers. However, as a consequence of their background, both groups have different perceptions about what is important for the new system. Developers apply a more efficiency-driven frame of mind, whereas users usually focus more the direct impact on their work. These two views are then also confronted with the need to reconcile them with the overall business needs and objectives. This requires an interactive and iterative process of negotiation and collaboration among all stakeholders (Coughlan, 2003).

ERP systems are standard software packages with built-in best practices business processes. The system does not need to be designed and developed from scratch. 
Nevertheless, users and developers need to work together to ensure that the system's and the business' processes are aligned with each other and gaps reconciled. It is also important to make sure that the future system provides the necessary functionality to the users to conduct their daily work.

The process of finding the specifications in collaboration between IT staff and users is associated with risks. This can include misunderstanding between users and developers or the lack of an effective methodology. Wrong functionality, performance shortfalls, and continuous requests for change can be the consequence. In the worst case even project failure can be the result (Sumner, 2000).

Negotiating and defining the technical specification is the prerequisite for having a base line against which to measure one aspect of success after the project is finished and the users start using the system. At this point it will show if there is actually a gap between what the users expected and what the system does, and how large the gap is. This has an influence on user satisfaction, system acceptance and use, and productivity, because the users depend on the system as one tool to perform their jobs.

Next to the static aspect of technical specifications, there is the dynamic part of functional performance, i.e. how well the ERP system actually performs in its daily operations and how this is measured. The organisation's management needs up-to-date information on the effect of the ERP system on business performance (Nah et al., 2001). However, in order to quantify the system's performance, measures need to be constructed carefully and agreed upon by the different parties involved (Umble et al., 2003).

The organisation needs to disseminate clear guidelines for the development of performance measurements including both technical and business operational measures (Mabert et al., 2003). The measures should be related to the business objectives and needs ( $\mathrm{Nah}$ et al., 2001). In addition to measuring the system's performance these measure should next be designed in a way that they encourage behaviours by the employees that the organisation expects. Measuring performance in this way is not a one-time event, but a continuous process (Umble et al., 2003).

It is important to communicate among the stakeholders to arrive at realistic expectations about timeframes and figures for performance increases (Umble et al., 2003). ERP systems are complex and therefore an initial decline in productivity is often the case, but as soon as 
users become more familiar with the system, productivity is likely to increase. However, some managers and employees expect to see a productivity increase as soon as the ERP system becomes operational.

In conclusion, it is important to develop agreed on technical specifications and functional performance measurements among all involved stakeholders to facilitate the users' performance with the new system. Communication quality is a critical aspect in this collaborative, iterative, and continuous process.

\subsection{ERP ultimate user satisfaction}

Although it might appear appealing to use monetary measures due to simplicity and necessity (legislative requirements and at the end of the day most organisations must make a profit or at least watch their costs), such measures of success often only provide a partial indication due to the difficulty of quantifying intangible system impacts. These qualitative benefits might not be able to be expressed or measured in monetary terms. Moreover, some effects, even if monetary quantifiable, might not be directly related to the IS, but the IS might be the root cause. Therefore, it might be difficult to isolate the effects of the IS from other variables in the organisational environment. Therefore, other surrogates such as user satisfaction are often used to assess system success (Wu \& Wang, 2006).

User satisfaction is, in fact, the most widely used measure of IS success (DeLone \& McLean, 1992). User satisfaction is the sum of a person's positive and negative attitudes, feelings, and reactions towards a variety of factors related to the delivery of information products and services based on the interaction with an IS (Baroudi \& Orlikowski, 1988; Bokhari, 2005; Doll \& Torkzadeh, 1988; Wu \& Wang, 2006) and the provided supporting services (Doll \& Torkzadeh, 1988). It represents the extent to which users believe the IS and supporting services meet their needs (Wu \& Wang, 2006).

User satisfaction is regarded as an appropriate surrogate of IS success (Wu \& Wang, 2006). This has several reasons. First, the measure shows high face-validity, because it is difficult to deny that a system is successful if the users like it (DeLone \& McLean, 1992). It is unlikely that an IS would lead to optimal results for the organisation and the user community, if users were unsatisfied with it (Wu \& Wang, 2006; Zviran, Nava, \& Levin, 2005). Second, IS research has developed reliable and sophisticated tools to measure user satisfaction. These are reflected in the work of Bailey and Pearson (1983), Baroudi and 
Orlikowski (1988), and Doll and Torkzadeh (1988). This allows consistency and comparability between different studies.

Although user satisfaction appears to be a good measurement tool for IS success, there are some problems and questions about its general applicability (Bokhari, 2005). First, satisfaction is a perceptual measure and perceptions differ from one individual to another (Baroudi \& Orlikowski, 1988). Second, there has been a discussion in the IS literature about whether user satisfaction causes system use or vice versa, but there is stronger support for the first relationship (Doll \& Torkzadeh, 1988). However, the widespread application of user satisfaction as a measurement of IS success and its level of sophistication as a tool, make it a useful dimension in this study to measure IS and project success.

User satisfaction in the ERP context might be affected by factors other than traditional IS developments and implementations. Therefore, Wu and Wang (2006) constructed a measurement called the "ERP ultimate user-satisfaction construct". The construct is an extended and ERP-specific tool rooted in the work of Bailey and Pearson (1983), Baroudi and Orlikowski (1988), and Doll and Torkzadeh (1988). It is a multidimensional construct along three dimensions: (1) ERP project team and service (PTS), (2) ERP product (P), (3) user knowledge and involvement (UKI). A detailed breakdown can be seen in Table 6.

The three dimensions are interrelated, mutually reinforcing, and represent an integrated measure of the users' perception of what constitutes satisfaction with the whole ERP system and its implementation. It encompasses criteria that assess if the system fulfils the users' needs, if it assists in solving problems, and satisfaction. The communication and relationship with the project team is also part of the measurement criteria. Therefore, the current study applies Wu and Wang's (2006) construct (Table 6) to assess Shenhar et al.s' (2001) measurements "Fulfilling customer needs", "Solving customer's problems", and "Customer satisfaction". This is supposed to yield a more comprehensive view of project success. 
Table 6: ERP ultimate user satisfaction measurement items

\begin{tabular}{|c|c|c|c|c|c|}
\hline & Wu and Wang (2006) & $\begin{array}{c}\text { Bailey and } \\
\text { Pearson } \\
(1983)\end{array}$ & $\begin{array}{c}\text { Baroudi and } \\
\text { Orlikowski } \\
(1988)\end{array}$ & $\begin{array}{c}\text { Doll and } \\
\text { Torkzadeh } \\
\text { (1988) }\end{array}$ & $\begin{array}{l}\text { Zviran } \\
\text { (2005) }\end{array}$ \\
\hline PTS & Relationship with the ERP project team & $x$ & $x$ & & \\
\hline PTS & Communication with the ERP project team & $\mathrm{x}$ & $x$ & & \\
\hline PTS & $\begin{array}{l}\text { The Domain knowledge of the ERP project } \\
\text { team }\end{array}$ & $x$ & & & \\
\hline PTS & Attitude of the ERP project team & $x$ & $x$ & & \\
\hline PTS & Required time for ERP implementation & $x$ & $x$ & & \\
\hline$P$ & Accuracy & $\mathrm{x}$ & $x$ & $x$ & $x$ \\
\hline$P$ & Timeliness & $x$ & & $x$ & $x$ \\
\hline$P$ & Reliability & $x$ & $\mathrm{x}$ & & \\
\hline$P$ & Response time & $x$ & & & \\
\hline$P$ & Completeness & $x$ & $x$ & $x$ & $x$ \\
\hline$P$ & Output requirement & $x$ & & $x$ & $x$ \\
\hline$P$ & Relevancy & $x$ & $x$ & $x$ & $x$ \\
\hline$P$ & System stability & & $x$ & & \\
\hline$P$ & Auditing and control & & & & \\
\hline$P$ & Ease of use & & & $x$ & $x$ \\
\hline$P$ & Usefulness & $x$ & & $x$ & $x$ \\
\hline$P$ & System flexibility & $x$ & & & \\
\hline$P$ & System integrity & $x$ & & & \\
\hline UKI & Training & $x$ & $x$ & & \\
\hline UKI & Documentation & $x$ & & & \\
\hline UKI & Feeling of user involvement & $x$ & & & \\
\hline \multirow[t]{3}{*}{ UKI } & System understanding & $x$ & $x$ & & \\
\hline & Overall satisfaction & & & & $x$ \\
\hline & Perceived success & & & & \\
\hline
\end{tabular}

\subsection{System acceptance and use}

Research into system acceptance and use by users has a long history in the IS discipline (for example, Turner, 1982, cited in Lim, Pan, \& Tan, 2006). Several models have been proposed to explain how users accept new technology and the conditions under which users actively use a new system. One of the most prominent models is Davis' (1989) Technology Acceptance Model (TAM). 
The acceptance and use of a new information system has been found to be an important part of the system's and the organisation's success, because the users are ultimately the people working with the system and supposed to achieve the envisioned benefits.

In the context of ERP, user acceptance and system use also have been found to be crucial determinants of the system's strategic application. How well users accept and to what degree they use the system can influence how much an organisation can capitalise on the functionality an ERP package offers. In many organisations ERP systems are often only used for only basic transactions preventing organisations from benefiting fully from their new ERP system (Lim et al., 2006).

Although various studies have concluded that system use represents a surrogate measure that is not ideal (Ives, Olson, \& Baroudi, 1983; Vandenbosch \& Ginzberg, 1997), there have been studies where it was found to be an appropriate dependent variable (Hiltz \& Johnson, 1989; Ives \& Olson, 1984; Lou \& Scamell, 1996).

Davis (1989) established a measure that has been used in adapted and further developed forms in various studies since then (see for example, Taylor \& Todd, 1995; Venkatesh, Morris, Davis, \& Davis, 2003). Davis (1989) measured system use along a six-position categorical scale with categories labelled "Don't use it at all", "Use less than once a week", "Use about once a week", "Use several times a week", "Use about once each day", and "Use several times each day". The relationships between these use categories and the independent variables were confirmed by regression analysis.

A possible direct relationship between communication and system use has been found in Sarel and Marmorstein's (2002) study, which also applied a system use measure following Davis (1989). They found that the use of new information systems depends on how it is communicated to the users. The authors assessed various communication approaches, which for example varied in the degree of customisation (audience adequacy in the current study's terminology) and found a significant and direct link between the degree of communication customisation and system use. This shows that at least one attribute was found to have an influence on system acceptance and use. Therefore, the author expects that system acceptance and use is influenced by communication quality. The current study examines the influence of all identified attributes of communication quality on system use and acceptance as a success component. 
Although the current study is qualitative in nature it uses a measure based on Davis (1989) assessing the co-occurrences of attributes of communication quality with statements of the participants about system use. This examines in a qualitative way the influence of communication quality on system acceptance and use, and consequently on system success, as system acceptance and use represent components of ERP system success as defined in the current study. This follows the concept of logical induction.

\subsubsection{Business success and business benefits}

The dimension "business success" assesses the immediate and direct impact the ERP project might have on the organisation. This study uses the term business benefits instead of business success. Business benefits can be financial performance gains such as profit increases and improved business results such as better process performance or cycle times and higher quality products (Shenhar et al., 2001). ERP systems are also implemented to reduce costs through trimming down the amount of waste and inefficiencies in the product or service production process. Product or service quality is supposed to lead to higher customer satisfaction and loyalty, and an advantage compared to competitors. ERP systems are implemented to increase quantitative business performance aspects such as financials, but also qualitative aspects such as quality.

Although ERP systems promise a variety of possible economic performance improvements, some difficulties exist. It can be difficult to measure the benefits. It might be complicated to directly relate the performance gains to the ERP investment. Researchers estimate that about half of the benefits of IT investments are derived from the unique characteristics of the organisation and not the IT system as such. These organisational factors can moderate the effect an ERP system has on business performance. In order to overcome the difficulties and gain the economic benefits, organisational factors need to be considered during ERP investments and need to be coupled with organisational changes and strategic alignment (Shin, 2001). 


\subsection{Impact of communication quality on the ERP project success variables}

This section explains the influence of communication quality on the individual ERP project success variables. The current research's model is depicted in Fehler! Verweisquelle

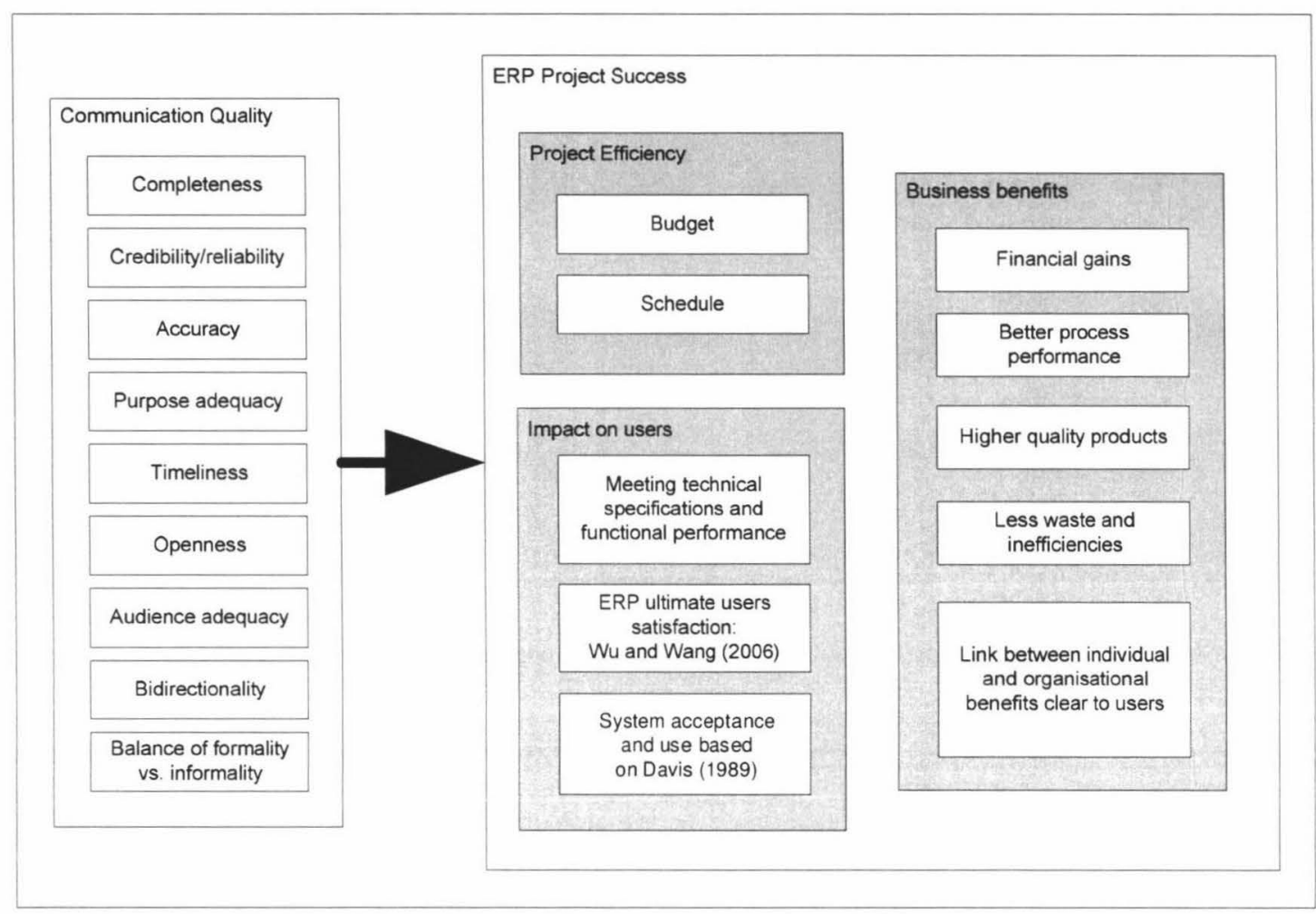

Figure 4: Research model of the current study

konnte nicht gefunden werden.

\subsubsection{Budget and schedule}

Communication, interdepartmental collaboration, and an efficient communication infrastructure was found to be a critical success factor for ERP implementation projects in order to keep the project within budget (Akkermans \& van Helden, 2002; Hameri, 1997; Nah et al., 2001) and on schedule (Hameri, 1997; Nah et al., 2001). In contrast, problems are often related to poor communication (Hameri, 1997).

In the context of ERP implementations open and honest communication has been found to be an influential factor for project success (Akkermans \& van Helden, 2002; Gargeya \& Brady, 2005; Molla \& Bhalla, 2006). It reduces uncertainty among employees that is 
created by new roles and responsibilities as a consequence of the new ERP system. Therefore, it facilitates the completion of ERP projects on time, within budget, and according to business requirements (Molla \& Bhalla, 2006).

Therefore, the author argues that communication quality influences project delivery within budget on schedule through at least one attribute of communication quality - openness.

\subsubsection{Impact on the users}

Communication quality impacts users during the duration of a project. This becomes evident in the areas (1) meeting technical specifications and functional performance, (2) user satisfaction, and (3) system acceptance and use.

\subsubsection{Meeting technical specifications and functional performance}

The communication between users and IT staff has been found to be an important factor in the system development process. It can reduce or avoid conflict and give users a feeling of participation and involvement. This encourages users to strive for better communication with the IT staff in return (Guimaraes, Staples, \& McKeen, 2003).

Several attributes of communication quality influence this collaboration process. The collaboration is more effective if requirements are openly articulated, received, and feedback is provided in a two way communication process. The collaboration process is more meaningful to users, because they see that the IT staff listens to and understands them. This provides clarity in the collaboration process and positively influences the implementation. In the opposite situation, a lower quality of communication in for of incompletely transmitted ideas and expectations can lead to confusion and misunderstandings between the two sides (Guimaraes et al., 2003).

In order the measure the functional performance of the system performance and work indicators are needed. These provide users with feedback about their own and the system's performance. It also allows users to provide their management with more substantiated feedback about working with the system. Communication with the users has been found to be important during the implementation of performance and work indicators. This can include a different training for managers and users, representing audience adequacy. 
Adequate training material and tools teach users and manager how to use the indicators.

This shows purpose adequacy (Walker \& MacDonald, 2001).

\subsubsection{ERP ultimate user satisfaction}

The author argues that ERP ultimate user satisfaction is influenced by communication quality. McKeen et al. (1994) show that users find better communication as satisfying and that communication is an independent predictor of user satisfaction. On the contrary, a lack of communication can lead to disconsonance between users and IS personnel. This can lead to user (and IS personnel) dissatisfaction, as well as to poor system performance (Klein, Jiang, \& Sobol, 2001).

Wu and Wang's (2006) ERP user satisfaction is a multidimensional construct and the author claims that it is partly influenced by communication quality. In general, items directly related to the satisfaction with the system output are thought not to be impacted by communication quality. Items that involve communication with IS staff in any form are expected to be impacted by communication quality. Table 7 shows an overview.

Table 7: ERP user satisfaction items influenced by communication quality

\begin{tabular}{|l|c|l|}
\hline Wu and Wang (2006) & $\begin{array}{c}\text { Influenced by } \\
\text { communication } \\
\text { quality }\end{array}$ & Explanations and justifications \\
\hline Relationship with the ERP project team & $X$ & $\begin{array}{l}\text { The interactions between the user } \\
\text { and the ERP team (Wu \& Wang, } \\
\text { 2006). } \\
\text { Encounters between users and } \\
\text { developers can result in conflict. } \\
\text { Possible reasons can be } \\
\text { withholding information or } \\
\text { distorted communication (Newman } \\
\text { \& Robey, 1992). }\end{array}$ \\
\hline Communication with the ERP project team & $X$ & $\begin{array}{l}\text { The manner and effect of } \\
\text { information exchange between the } \\
\text { user and the ERP team (Wu \& } \\
\text { Wang, 2006). } \\
\text { Poor communication can lead to } \\
\text { increased friction between } \\
\text { systems development staff and } \\
\text { users (Shah, Dingley, \& Golder, } \\
\text { 1994). } \\
\text { Communication quality represents } \\
\text { one aspect of the overall } \\
\text { communicative information } \\
\text { exchange next to quantity, } \\
\text { frequency, and task/media fit }\end{array}$ \\
\hline The domain knowledge of the ERP project team & $X$ & $\begin{array}{l}\text { The domain knowledge exhibited } \\
\text { by the ERP project team (Wu \& } \\
\text { Wang, 2006). } \\
\text { Users and IS personnel show }\end{array}$ \\
\hline
\end{tabular}




\begin{tabular}{|c|c|c|}
\hline & & $\begin{array}{l}\text { different expectations about which } \\
\text { skills are important during the } \\
\text { collaboration. This can lead to an } \\
\text { expectation gap. Communication } \\
\text { can be a way to reconcile the gap } \\
\text { and increase user satisfaction } \\
\text { (Tesch, Jiang, \& Klein, 2003). }\end{array}$ \\
\hline Attitude of the ERP project team & $x$ & $\begin{array}{l}\text { The willingness and commitment } \\
\text { of the ERP project team to support } \\
\text { and assist the user adoption of the } \\
\text { ERP system (Wu \& Wang, 2006). } \\
\text { Support and assistance involve } \\
\text { communication. }\end{array}$ \\
\hline Required time for ERP implementation & $x$ & $\begin{array}{l}\text { The time and duration of the ERP } \\
\text { system (Wu \& Wang, 2006). } \\
\text { The users perception about the } \\
\text { time it takes to implement the } \\
\text { system and the project teams } \\
\text { explanations, feedback about the } \\
\text { implementation time }\end{array}$ \\
\hline Accuracy & & $\begin{array}{l}\text { System output property, not } \\
\text { influenced by communication } \\
\text { between users and IT staff }\end{array}$ \\
\hline Timeliness & & $\begin{array}{l}\text { System output property, not } \\
\text { influenced by communication } \\
\text { between users and IT staff }\end{array}$ \\
\hline Reliability & & $\begin{array}{l}\text { System output property, not } \\
\text { influenced by communication } \\
\text { between users and IT staff }\end{array}$ \\
\hline Response time & & $\begin{array}{l}\text { System output property, not } \\
\text { influenced by communication } \\
\text { between users and IT staff }\end{array}$ \\
\hline Completeness & & $\begin{array}{l}\text { System output property, not } \\
\text { influenced by communication } \\
\text { between users and IT staff }\end{array}$ \\
\hline Output requirement & & $\begin{array}{l}\text { System output property, not } \\
\text { influenced by communication } \\
\text { between users and IT staff }\end{array}$ \\
\hline Relevancy & & $\begin{array}{l}\text { System output property, not } \\
\text { influenced by communication } \\
\text { between users and IT staff }\end{array}$ \\
\hline System stability & & $\begin{array}{l}\text { System property. Not influenced } \\
\text { by communication quality }\end{array}$ \\
\hline Auditing and control & & $\begin{array}{l}\text { System property. Not influenced } \\
\text { by communication quality }\end{array}$ \\
\hline Ease of use & $x$ & $\begin{array}{l}\text { Perception is influenced through } \\
\text { training, similar to Venkatesh et al. } \\
(2003)\end{array}$ \\
\hline Usefulness & $x$ & $\begin{array}{l}\text { Perception is influenced through } \\
\text { training, similar to Venkatesh et al. } \\
\text { (2003) }\end{array}$ \\
\hline System flexibility & & $\begin{array}{l}\text { System property, not influenced by } \\
\text { communication between users and } \\
\text { IT staff }\end{array}$ \\
\hline System integrity & & $\begin{array}{l}\text { System property, not influenced by } \\
\text { communication between users and } \\
\text { IT staff }\end{array}$ \\
\hline
\end{tabular}




\begin{tabular}{|c|c|c|}
\hline Training & $x$ & $\begin{array}{l}\text { Training and communication affect } \\
\text { the perceived ease of use of ERP } \\
\text { systems. Training provides } \\
\text { management with the opportunity } \\
\text { to selectively disseminate } \\
\text { information and influence the } \\
\text { users' beliefs and attitudes } \\
\text { (Amoako-Gyampah \& Salam, } \\
\text { 2004). }\end{array}$ \\
\hline Documentation & $x$ & $\begin{array}{l}\text { Any formal document required for } \\
\text { the ERP system. This can be, for } \\
\text { example, either complete or } \\
\text { incomplete, hazy or clear (Wu \& } \\
\text { Wang, 2006). } \\
\text { The current research looks at all } \\
\text { types of communication } \\
\text { independent from the media. } \\
\text { Therefore, documentation qualifies } \\
\text { as a part of communication. }\end{array}$ \\
\hline Feeling of user involvement & $x$ & $\begin{array}{l}\text { The level of user involvement } \\
\text { largely depends on the willingness } \\
\text { of the management and the } \\
\text { system designer to be open for } \\
\text { discussion (Dewulf \& Meel, 2002). }\end{array}$ \\
\hline System understanding & $x$ & $\begin{array}{l}\text { Training allows users to get to } \\
\text { know the system, obtain first hand } \\
\text { information and experiences, } \\
\text { increase their proficiency in } \\
\text { working with the ERP system. } \\
\text { Training is a form of } \\
\text { communication (Amoako- } \\
\text { Gyampah \& Salam, 2004). }\end{array}$ \\
\hline Overall satisfaction & & $\begin{array}{l}\text { Overall impression. The sum of } \\
\text { the individual criteria }\end{array}$ \\
\hline Perceived success & & $\begin{array}{l}\text { Overall impression. The sum of } \\
\text { the individual criteria }\end{array}$ \\
\hline
\end{tabular}

\subsubsection{System acceptance and use}

The current study applies measures based on Davis (1989) to assess the users' system acceptance and use as well as the role of communication quality in this process. Forms and means of communication that can influence system acceptance and use have been found to be user training, project champions, opinion leaders (Amoako-Gyampah \& Salam, 2004), and user support (Jiang, Klein, \& Chen, 2006). The training should be tailored to the respective audience and appropriate topics and tasks should be covered (Nelson, Whitener, \& Philcox, 1995). In regard to user-support, it has been found that partnering activities such as meetings and workshops including lectures and exercises have a positive correlation to the effectiveness of user-support. Topics such as communication and negotiation are vital parts of the agenda in this kind of partnering (Jiang et al., 2006). 
Therefore, the current study examines how communication in these areas is related in the participants' statements to four adoption criteria along Davis' (1989) framework. The criteria are: "I don't use the system at all", "I hardly use the new system", "I usually use the new system", and "I regularly use the new system".

\subsubsection{Business benefits}

ERP systems are supposed to achieve several organisational benefits such as (1) financial gains, (2) better process performance, (3) higher quality products, and (4) less waste and inefficiencies. It is crucial that employees understand the link between their daily work and the business benefits in order to achieve the benefits (Crosby \& Johnson, 2006). Therefore, communication is one of the organisational factors that can moderate the realisation of benefits from the ERP system. However, organisational benefits are high level measurements, hence not all of them might be directly influenced by the communication quality on the 'project team to one plant'- level.

\subsubsection{Financial gains}

ERP systems are implemented to ultimately contribute to the organisation financially, either through profit gains or cost reductions. Cost reductions might occur through reduced inventory levels, more adequate production planning, and reduced operating costs (AlMashari et al., 2003; Gupta, 2000; Mabert et al., 2003; Tarn et al., 2002). Profit gains might be achieved by being able to work more efficiently and to produce and sell more products (Al-Mashari et al., 2003). However, the author assumes that the aspect of financial gains is not directly influenced by communication quality, because financial gains are the consequences of other organisational improvements such as better process performance or inventory reductions.

\subsubsection{Better process performance}

During the implementation of an ERP software packages the organisational processes are aligned with the processes inherent in the ERP software to achieve better process performance and increases the organisation's efficiency. Existing business processes might need to be changed or redesigned during that alignment process and effective communication has been found to be critical to business process redesign (BPR) (Ackermann, Walls, Meer, \& Borman, 1999). 
It has been found that BPR works better if it is facilitated by a dynamic communication process with feedback loops, a common language between users and developers, and the willingness to raise issues of concern (Ackermann et al., 1999). This highlights the importance of the communication quality attributes of bidirectionality, audience adequacy, and openness. BPR can be successful and deliver benefits to the organisation if it is accompanied by effective communication. The benefits from BPR can even further be reinforced by increased communication flows throughout the organisation (Paper, Tingey, \& Mok, 2003). In general, it is considered as a challenge to ensure effective communication including such an extensive communication process (Terziovski, Fitzpatrick, \& O'Neill, 2003) that emphasises quality. However, neglecting communication is one of the biggest reason for BPR failure (Paper et al., 2003).

\subsubsection{Higher quality products}

Quality management that ensures higher quality products can either be done within an ERP system (Gupta \& Kohli, 2006) or in combining an ERP system with quality management systems. SAP, for example, provides multiple options to perform quality management such as inspection codes for parts as well as the ability to specify test types and testing equipment (Gupta \& Kohli, 2006). ERP systems are also able to track the costs and progress of after-sales services. It can manage mass-customised orders and the related production schedule (Larson, 1998). This forces manufactures to implement standard procedures and to maintain accurate data ("ERP systems improve quality," 2003).

The author argues that higher quality products are mainly a consequence of the system use and are not influenced by communication quality directly.

\subsubsection{Less waste and inefficiencies}

The reduction of inefficiencies and waste needs to be realised by the ERP system users in their daily jobs. Therefore, it is sensible for IT staff to align the ERP system and the human resource roles in collaboration with the users. It is suggested to take into account the users' knowledge and roles. Training can further enhance the functioning of the ERP system and help the users in their new roles (Worleya, Chathac, Westonc, Aguirreb, \& Grabot, 2005).

Communication quality is thought to influence the aspect of less waste and inefficiencies through the training and collaboration efforts between the project team and the business. 
This highlights the attributes of completeness, audience adequacy, purpose adequacy, bidirectionality, and openness.

\subsubsection{Link between daily work and business benefits clear to users}

Financial results are the ultimate measures of strategic effectiveness, but not the original drivers of business success. Consequently, there is a need to link day-to-day activities to financial results. Organisational level measures are important though, but they do not have much impact unless they are communicated to users. This assists users to understand their role in the organisational strategy, because they see how the measures on their level are related to the organisational metrics. Performance measurement models can be used to facilitate the communicate with users in terms that they can relate to (Crosby \& Johnson, 2006). This communication customisation demonstrates the attribute of audience adequacy. The communication between users and developers about the system's overall organisational benefits prevents misunderstandings. In contrast, if communication is not effective and lacks quality, both groups and the organisation lose out (Kettinger \& Lee, 2002).

In sum, communication quality is expected to influence the realisation of benefits through at least one attribute, audience adequacy, in the explanations to users about the link of their daily work and the organisational benefits.

\subsection{Conclusion}

This section proposed a subcategory of communication called "communication quality". Communication quality distinguishes between attributes for the message content and the message process that constitute the level of communication quality. The attributes for the message content are completeness, credibility, accuracy, and purpose adequacy. The attributes for the message process are timeliness, openness, audience adequacy, bidirectionality, and balance of formality vs. informality.

We argue that communication quality influences ERP project success. Project success is a multidimensional concept and a comprehensive and cohesive measure for ERP project success has not emerged yet in the IS literature. Therefore, we developed a comprehensive project success measure specific for the ERP context based on Shenar et al.'s (2001) framework for project success. It assesses ERP project success along the dimensions 
'project efficiency', 'impact on users', and 'business benefits'. The framework was equipped with accepted measures such as Wu and Wang's (2006) 'ERP ultimate user satisfaction' measure and system acceptance and use criteria based on Davis (1989). ERP project success is partly influenced by communication quality through its individual construct items following the principle of logical induction.

The next section explains the applied research methodology and methods in the current study. 


\section{Research Methodology}

The current research aims at exploring the influence of communication quality between the IT project team and the business on ERP project success. The research was conducted in the form of secondary analysis of qualitative data which had been collected by HEC Montréal during a review of an ERP implementation project in a large, multinational, North-American manufacturing company. The author of this study was also a member of the research team during the primary study.

This section briefly explains the rationale behind the choice of methodology and then detail the research method.

\subsection{Research paradigm}

A paradigm is the most fundamental assumption adopted by a community allowing its members to share similar perceptions and to engage in shared practices. Usually a paradigm consists of an epistemological and an ontological part. Epistemology addresses the issue how to gain knowledge, how to use it and what the boundaries are. Ontology defines the relationship between the studied phenomena, the world, and the researcher (Hirschheim \& Klein, 1989; Orlikowski \& Baroudi, 1991).

The epistemology of this research is positivist as a conceptual framework is developed from the literature and the research seeks to support or rebut the model (Marble, 2000). Regarding the ontology the proposed research leans more towards nominalism and social constructivism, as we look at the interaction between humans and technology, a so called socio-technical perspective. It can be assumed that different people interact in different ways with technology, hence creating subjective perceptions about this interaction or the technology itself (Hirschheim \& Klein, 1989).

\subsection{Research method}

The research method applied in this study is secondary analysis of qualitative data (Heaton, 1998, 2004).

Secondary analysis of data is: 
"A research strategy which makes use of pre-existing quantitative data or pre-existing qualitative research data for the purpose of investigating new questions or verifying previous studies." (Heaton, 2004)

The major attribute of secondary analysis is that the data were not specifically collected for the research question at hand (Stewart, 1984), but for the purpose of a prior study that had a distinctly different research interest (Heaton, 1998).

Secondary analysis of quantitative data has been a widely accepted and established research method in many disciplines, for example in Economics, History, and social research (Fielding, 2004; Fielding \& Fielding, 2000; Heaton, 1998). The same is not true for qualitative data (Fielding \& Fielding, 2000; Heaton, 1998), although secondary analysis of data of the researcher's "own choosing" had already been advocated among sociologists in the early 1960s (Glaser, 1963 cited in Heaton, 2004).

To the author's knowledge, methodological guidelines on how to conduct secondary analysis of qualitative data have not been established yet in IS. Therefore, the author referred to social research, health research, and business ethics as reference disciplines and for guidance. In those fields, discussions and applications of secondary analysis of qualitative data have appeared in several studies (for example, Corti, Witzel, \& Bishop, 2005; Cowton, 1998; Fielding, 2004; Fielding \& Fielding, 2000; Heaton, 1998, 2004; Hinds, Vogel, \& Clarke-Steffen, 1997; Mauthner, Parry, \& Backett-Milburn, 1998; Parry \& Mauthner, 2005; Thome, 1998; van den Berg, 2005). However, the topic is a new issue in those fields as well and does not enjoy an established single methodology. Nevertheless, some methodological guidelines have emerged.

Secondary analysis of qualitative data can take multiple forms depending on the focus of the new study and the choice of data sets for that research. Heaton (2004) distinguishes five types of secondary analysis of qualitative data as shown in Table 8 .

The current research qualifies as supplementary analysis, because it examines in depth the issue of communication quality that emerged during the primary study. Communication quality was not specifically the subject of the primary study. However, general communication and various aspects of communication such as channels and effectiveness were part of the primary study. The theme communication quality emerged post hoc as an 
area of interest. Therefore, the focus in the current research has shifted to the particular theme of communication quality and it is explored in more detail (Heaton, 2004).

Table 8: Types of secondary analysis of qualitative data

\begin{tabular}{ll}
\hline Supra analysis & $\begin{array}{l}\text { Transcends the focus of the primary study from which } \\
\text { the data were derived, examining new empirical, } \\
\text { theoretical or methodological questions }\end{array}$ \\
Supplementary analysis & $\begin{array}{l}\text { A more in-depth analysis of an emergent issue or aspect } \\
\text { of the data which as not considered or fully addressed in } \\
\text { the primary study }\end{array}$ \\
Re-analysis & $\begin{array}{l}\text { Data are re-analysed to verify and corroborate primary } \\
\text { analyses of qualitative data sets }\end{array}$ \\
Amplified analysis & $\begin{array}{l}\text { Combines data from two or more primary studies for } \\
\text { purposes of comparison or in order to enlarge a sample }\end{array}$ \\
Assorted analysis & $\begin{array}{l}\text { Combines secondary analysis of research data with } \\
\text { primary research and/or analysis of naturalistic } \\
\text { qualitative data }\end{array}$ \\
\hline
\end{tabular}

\subsection{Research design}

Secondary analysis of qualitative data represents a relatively new method. Therefore, a single and coherent methodology does not exist yet. However, previous studies and researchers in social research have established some guidelines on how to conduct secondary analysis of qualitative data (Heaton, 2004). The following sections explain those guidelines and how they are applied in the current research.

\subsubsection{An outline of the original study}

In order to position the secondary analysis against the primary study it is recommended to include an outline of the original study, including its design, methods, data collection, processes involved in categorising and summarising the data for the secondary analysis, and any other special issues (Fielding, 2004; Heaton, 1998).

The original data were collected during a review of a SAP implementation at one plant of a large North-American manufacturing company. It represented the second implementation phase within the whole process of implementing a complete ERP system across all sites 
and functions of this multinational company. The research was conducted by HEC Montréal, Quebec/Canada from February 2006 to April 2006. The study took the form of a single case study and a total number of 54 semi-structured interviews were conducted during that time. The interviewees ranged hierarchally from the plant manager to shop floor users on the business side, and from the project manager to so called super users and programmers on the IT project team side. Each interview had a length of approximately 45 min. The interviews were always conducted by at least two researchers. The interviews were tape-recorded and, in addition, handwritten notes were taken. The interviews were fully transcribed as soon as possible after the respective interview. The field notes complemented the recordings. In order to ensure completeness the interviews were cross-checked by the second researcher. In addition, the company and interviewees provided company documents such as training materials, the project charter, change management strategies, presentation slides, risk management assessments, and cost estimations.

The transcribed interviews were then loaded into MAXqda2 ${ }^{3}$, a software for the analysis of qualitative data. The interviews were coded along a coding schema based on a framework developed by HEC for an identical previous study with the same company. The framework was based on success and risk factors derived from pertinent IS literature and contained such categories as "Vision", "Communication", "User Management", "Change Management", "Training", and "Management Support".

For the secondary analysis of the current research the complete and un-coded transcripts and recordings were used as well as a selection of company documents. There was neither special preparation nor summarisation of the original raw data before the secondary analysis.

\subsubsection{Epistemological issues of re-using the data}

The secondary analysis of qualitative data raises a couple of epistemological issues that stem from discussions about the compatibility of the methodology with the epistemological foundations of qualitative research. These issues are: (1) the problem of the fit between the data and the secondary study's purpose, (2) not having been there meaning the risk of

\footnotetext{
${ }^{3}$ MAXqda2 is a software package that supports qualitative data analysis and helps users systematically code, evaluate, and interpret texts. Its features include coding, memo-writing, matrix building, and map building. The software can be found and purchased under: http://www.maxqda.com/
} 
de-contextualisation of the data and the relationship between the data, the researcher, and the participants, and (3) the problem of verification (Fielding, 2004; Heaton, 1998, 2004; Parry \& Mauthner, 2005; van den Berg, 2005).

\subsubsection{The problem of data fit}

The data used for the secondary analysis are unlikely to fit as well to the secondary study as it did to the primary study for which it was collected. The degree of fit will depend on: (1) extent of missing data, (2) degree of convergence between the original research question and the current study's one, and (3) the methods used to produce the data, which questions if the secondary analysis uses analysing methods appropriate for the data (Heaton, 2004). In addition, the quality of the data depends on the reputation of the organisation and people that originally collected the data. A reputable organisation with internal quality guidelines is more likely to have collected the primary data accordingly. Also, as the primary data were not collected for the purpose of the current study. Hence, meanings, terms, definitions, classifications, and measurements might be different (Emory \& Cooper, 1991). The extent of missing data can limit the re-use for secondary purposes (Heaton, 2004), because it might not be possible to address parts of the secondary analysis.

\subsection{Data fit and distinctiveness of the secondary research}

An advantage of qualitative data is that it is unstructured, rich and diverse (Heaton, 2004). The nature of semi-structured interviews allowed interviewees to open up and let them express their own thoughts at their own pace (Bernard, 2000). During the flow of the interviews participants answered questions on "communication" sometimes in more detail than expected or with a slightly different focus. The issue of "communication quality" arose as a theme during the process of conducting the interviews in the primary research. The primary researchers found it an interesting aspect that was worth exploring. It did not represent a specific theme or code in the original research. Therefore, the participants' answers contained segments relating to the research question and topic of the current study. The issue "communication quality" could not be explored in the original study though, because it did not exist in the framework used. The idea to conduct a secondary analysis on the same data set thus emerged. However, as "communication quality" was not subject of the original framework used by HEC Montréal, there is an extent of missing data. However, the author argues that this issue is neglectable, because the interview data is rich 
and the complementary documents numerous. Moreover, Table 9 shows a calculation of the interview data sufficiency meaning the ratio of coded text segments in comparison to the complete interview text for the current study. The numbers indicate that the data were sufficient.

Table 9: Data fit ratios for the individual interviews

\begin{tabular}{|c|c|c|}
\hline & Interview (named after job position) & $\begin{array}{l}\text { Interview } \\
\text { sufficiency }\end{array}$ \\
\hline \multirow{21}{*}{$\begin{array}{l}\text { Project } \\
\text { Team }\end{array}$} & Business Analyst Material Master Data & $78 \%$ \\
\hline & Programmer & $57 \%$ \\
\hline & Business Analyst Business Processes and KPIs & $80 \%$ \\
\hline & Business Analyst Supply Management & $76 \%$ \\
\hline & Business Analyst Design & $57 \%$ \\
\hline & Business Analyst Supply Management & $62 \%$ \\
\hline & SAP Application Specialist & $39 \%$ \\
\hline & Department manager data cleansing & $27 \%$ \\
\hline & Business Analyst Supply Management & $38 \%$ \\
\hline & Business Analyst Design & $50 \%$ \\
\hline & Business Analyst Supply Procurement & $70 \%$ \\
\hline & Change Management Director & $54 \%$ \\
\hline & Programmer & $31 \%$ \\
\hline & Business Analyst Master Data & $77 \%$ \\
\hline & Project Team Manager & $69 \%$ \\
\hline & Team Leader Business Analysts and Application Specialists & $54 \%$ \\
\hline & Key Performance Indicator Developer & $35 \%$ \\
\hline & Business Analyst Finance & $41 \%$ \\
\hline & Key Performance Indicator Developer & $67 \%$ \\
\hline & Business Analyst Production Planning & $48 \%$ \\
\hline & Change Management Coordinator & $53 \%$ \\
\hline \multirow[t]{20}{*}{ Business } & Trainer Supply Management & $77 \%$ \\
\hline & User Quality & $67 \%$ \\
\hline & Supervisor Supply Management & $77 \%$ \\
\hline & Business Communication Coordinator & $84 \%$ \\
\hline & Plant Manager & $48 \%$ \\
\hline & Director Supply Management & $80 \%$ \\
\hline & User Supply Management & $58 \%$ \\
\hline & Director Supply Procurement & $39 \%$ \\
\hline & User Supply Management & $72 \%$ \\
\hline & Business Analyst Design & $51 \%$ \\
\hline & Director Production Planning & $64 \%$ \\
\hline & User Supply Management & $80 \%$ \\
\hline & Director Finance & $53 \%$ \\
\hline & User Quality & $67 \%$ \\
\hline & User Quality & $57 \%$ \\
\hline & Supervisor Supply Management & $53 \%$ \\
\hline & User Supply Management & $52 \%$ \\
\hline & Business Analyst Finance & $34 \%$ \\
\hline & Manager Supply Procurement & $47 \%$ \\
\hline & User Production Planning & $58 \%$ \\
\hline
\end{tabular}




\begin{tabular}{|l|l|c|}
\hline & Manager Supply Management & $75 \%$ \\
\cline { 2 - 3 } & Business Analyst Supply Procurement & $27 \%$ \\
\cline { 2 - 3 } & Director Manufacturing & $67 \%$ \\
\cline { 2 - 3 } & User Production Planning & $54 \%$ \\
\cline { 2 - 3 } & Supervisor Production Planning & $59 \%$ \\
\cline { 2 - 3 } & Manager Supply Management & $54 \%$ \\
\cline { 2 - 3 } & Supervisor Design & $55 \%$ \\
\cline { 2 - 3 } & User Production Planning & $69 \%$ \\
\cline { 2 - 3 } & Manager Quality & $69 \%$ \\
\cline { 2 - 3 } & User Design & $69 \%$ \\
\cline { 2 - 3 } & User Supply Management & $56 \%$ \\
\cline { 2 - 3 } & User Supply Management & $59 \%$ \\
\cline { 2 - 3 } & User Finance & $74 \%$ \\
\hline
\end{tabular}

The sufficiency ranged from $27 \%$ to $84 \%$. The average interview sufficiency was $59 \%$ with an average of $55 \%$ on the project side and $61 \%$ on the business side.

The uncoded segments were discarded from the analysis as they contain data that is unrelated to the study's research question.

The author argues that the extent of missing data is less likely to be an issue. The data fits the research question and the coding schema sufficiently. Moreover, the current research is supplementary analysis and the investigated phenomenon is closer related to the original study than in other types of secondary analysis (Heaton, 2004). Hence, the issue of the extent of missing data is minor.

\subsection{Appropriateness of secondary analysis method}

In the primary research the data was produced and analysed following the guidelines for case study research in Information Systems according to Benbasat, Goldstein, and Mead (1987), Lee (1989), and Yin (2002). The secondary data analysis also follows these guidelines.

Therefore, it can be concluded that the secondary analysis used analysing methods appropriate for the data.

\subsection{Quality of data}

The data is of high quality, because they were collected by HEC Montréal, a reputable university which is internationally well respected for its quality of research and publications. 
The meanings, terms, definitions, classifications, and measurements of the current study are very likely to be similar to, even consistent with, the ones of the primary study, because both studies are based on pertinent IS literature, in some cases even the same. Within the IS field and the IS literature there is sufficient congruence in regard to the main terms that are used. Therefore, a high congruence is expected between the terminology of the primary study and the secondary analysis.

\subsection{Conclusion}

In conclusion, we consider the problem of data fit to be neglectable, because the rich data is likely to contain sufficient information on the current research's question, there is a sufficient level of data fit, the terminology between the two studies shows a high congruency, and the data is of high quality as it was collected by a highly reputable research organisation.

\subsubsection{The problem of contextualisation or "not having been there"}

An important aspect of qualitative research is the emphasis of 'seeing through the eyes of the people being studied' and examining the phenomenon in the natural setting of its social context. Therefore, qualitative researchers often spend time in the 'field' or the 'real life situation' to explore the study's area of interest in detail (Heaton, 2004). Fieldwork relationships and the context of the data collection are important (Fielding \& Fielding, 2000). Moreover, researchers try to remain close to the collected data by transcribing it themselves and significantly immersing themselves into the material and the analysis. Knowledge of the context and a high familiarity with the data are considered as important. Consequently, it is questionable if secondary analysis does not violate the fundamental aspects of qualitative research in this regard.

The author of the secondary study was part of the original research team in the primary study. Hence, the author is aware of fieldwork relationships and highly familiar with the context of the study. The researcher also performed the transcribing and analysis during the primary study. Therefore, the author is significantly immersed into the data. Consequently, the problem of "not having been there" is minimised.

Advocates of secondary analysis of qualitative data argue that it should be generally attempted to re-create a study's context as far as possible. However, in general it remains 
debatable if a specific context can be re-constructed sufficiently (Heaton, 2004). Van den Berg (2005) even argues that complete contextualisation is unattainable and will always be limited. Therefore, researchers should apply the principle of parsimony and focus on the contextual features that are assumed to be the most relevant for interpreting the data.

For this reason $V$ an den Berg (2005) suggests six guidelines as minimum requirements for information that should be made available for the purpose of contextualisation in secondary research:

1. Information about the interview discourse, either in the form of audiotapes or at least in form of detailed transcriptions (van den Berg, 2005).

The current research has access to the audiotapes as well as the complete interview transcripts.

2. Possibility to see interviewees' answers seen in discourse, hence complete interviews (van den Berg, 2005).

All interviews are complete. No single one is only partial.

3. Social characteristics about the background or at least the characteristics visible to the participants themselves (interviewer and interviewee) (van den Berg. 2005).

A list and description of the participants and their characteristics can be seen in Table 17 in the appendix.

4. Information about the place, time and setting of the interview relevant to the interaction (van den Berg. 2005).

All interviews were conducted in conference rooms familiar to the interviewees on the premises of the participating organisation during normal business hours.

5. Information about how the interviewee is selected and approached to cooperate, because this might influence the interview discourse (van den Berg, 2005).

The interviewees were selected by the participating organisation according to their level of involvement in the ERP implementation project, their position and function (to ensure a comprehensive view across all stakeholders), and availability at the 
time of the primary study. In addition, HEC requested seven additional interviewees, which either other participants pointed to or to ensure a balanced range of participants across all hierarchical levels. This means additional end-users were requested to receive a more comprehensive view from the user base.

The organisation did neither give detailed information about the purpose of the interviews to the participants beforehand nor what kind of questions would be asked. The primary researchers informed participants about the purpose of the study, objectives, methods, and envisioned final deliverables before the start of each interview. The researchers ensured the interviewees complete confidentiality and anonymity in terms of their answers.

6. Information about relevant others that are known to the interviewee as well as the interviewer such other interviewees (van den Berg, 2005).

The vast majority of interviewees knew each other as they work with each other. However, the participants were not specifically made aware who was interviewed or when others were interviewed.

In conclusion, the context of the original study has been sufficiently explained and restored. Therefore, the author argues that the problem of contextualisation has been addressed sufficiently.

\subsubsection{The problem of verification}

Verification stands for the process through which an independent researcher would arrive at the same conclusions if the data analysis and secondary study were carried out a second time (Heaton, 2004).

The detailed aspects of verification in qualitative secondary analysis are still under discussion (Heaton, 2004). However, the author of this study was supervised by two university senior lecturers with the focus Information Systems. Therefore, interpretations and analysis results could be discussed in depth. This reduces the likelihood of unjustified claims and conclusions. Moreover, the author of the current study took part in the primary research which allowed verification and checking of original meanings in case of ambiguity. This is an advantage of supplementary research in contrast to using third party data in other forms of secondary analysis. Finally, the research method and analysis is 
documented as detailed as possible to ensure the theoretical possibility for an independent researchers being able to carry out the secondary research in a similar way and to arrive at similar results.

\subsubsection{Ethical and legal considerations}

On a surface level secondary research seems to pose fewer challenges in regards to ethical and legal aspects in academic research that primary research, because in most forms of secondary research there is usually no direct interaction between the researcher and the participants. Nevertheless, the re-use of qualitative data raises a number of questions concerning the adherence to the principles underlying ethical research (Heaton, 2004; Thome, 1998) as well as legal issues (Heaton, 2004).

\subsection{Ethical issues}

In terms of ethics, secondary research raises difficulties in the areas of: (1) confidentiality, (2) informed consent, (3) nonmaleficence, and (4) fidelity (Thome, 1998).

\section{Confidentiality}

Confidentiality refers to the regulation of data access and knowledge of the identity of the participants (Heaton, 2004). Although, in some cases secondary data might have been prepared before the second researcher has access to it, the secondary researcher might be at risk of unintentionally violating the confidentiality, because the data had been collected for another purpose. Without knowing the use of quotes and terms could reveal the identity of participants or the case organisation. Primary researchers might have sensitised themselves with the research phenomenon sufficiently to avoid the risk of unintentional de-masking. Hence, individual responses are usually made anonymously (Thome, 1998).

Additionally, access to the data is usually restricted to the researchers involved in the study and the data collection (Heaton, 2004).

In the case of secondary research a few guidelines can be followed to ensure confidentiality: (1) check if the re-use violates the original consent (Heaton, 1998), (2) secondary researchers should familiarise themselves with the actual and potential privacy needs of individuals and institutions represented in the qualitative data (Thome, 1998), (3) all data should be thoroughly anonymised unless interviewees have consented otherwise 
(Heaton, 2004), and (4) all personal information should be kept confidential whether or not a pledge of confidentiality has been given (Heaton, 2004).

In the current study the re-use of the data does not violate the original consent. The contract between the organisation and HEC Montreal allows the signing researcher from HEC Montréal to use the data for additional research project. The signing researcher granted the right to use the data to the author of the secondary study. The author ensured that all data used in material that would become public would be thoroughly anonymised. All personal information would be kept confidential.

\section{Informed consent}

An informed consent for the primary research was obtained by HEC Montréal. Additionally HEC Montréal signed a confidentiality agreement with the case organisation.

\section{Nonmaleficence}

Nonmaleficence refers to the ethical principle of not intentionally inflicting any harm on another person. Instances of nonmaleficence in secondary research might be breaches of privacy or treating a participant simply as a means to conduct the research (Thome, 1998).

The privacy of all participants will be respected in the current study. No names or personal information is released. The participants" integrity is respected. Possible defamatory statements are treated with special attention to avoid any kind of possible identification of the participant.

\section{Fidelity}

Fidelity means the risk of not telling the truth in the interpretation by misinterpreting statements of the participants. In personal interviews in primary qualitative research misunderstandings can be usually corrected immediately through asking for verification or clarification (Thome, 1998).

The risk of fidelity is believed to be comparatively low, because the current research is supplementary research involving a researcher from the primary study who is familiar with the context. 


\section{Conclusion}

The current research is conducted in such a way that ensures the adherence to the principles underlying ethical research. Confidentiality is maintained, an informed consent is present, the principle of nonmaleficence is followed, and the risk of fidelity is low.

\subsection{Legal issues}

The area of legal issues concerning secondary analysis of qualitative data is still a field of large debate. Different countries have different views and legislation concerning the use of qualitative data Nevertheless, there are some preliminary considerations on legal issues in the areas of: (1) copyright, (2) data protection, and (3) defamation (Heaton, 2004; Parry \& Mauthner, 2004).

\section{Copyright}

In any qualitative research utilising interviews there are usually two separate types of copyright involved. The first one is the copyright of the spoken word, which belongs to the interviewee. The second one is the copyright of the tape, which belongs to the organisation conducting the research. Copyright can be transferred, waived, or provided via license so that others might be allowed to use the data. A written agreement is usually better than a verbal one (Parry \& Mauthner, 2004).

In the case of the current research, agreement exists between HEC Montréal and the participating organisation that the data can be used for the current research.

\section{Data protection}

Data protection addresses that interviewees know about the purpose of collecting the information and who would have access to it. No personal data is supposed to be released, which is partly dealt with through confidentiality in the informed consent agreement and anonymisation of the data (Heaton, 2004).

For the current research, each participant was informed at the beginning of each interview about the purpose of the primary research. The participating organisation gave permission to use the data for the current research on behalf of the participants. The data will be handled confidential and only anonymised quotes will be used.

\section{Defamation}


Defamation means that statements of participants could asperse others when published, even in an anonymous format, because the secondary researcher might not be sensitised to the context (Heaton, 2004).

In the current research this is unlikely to happen, as it is supplementary research and the author was involved in the primary study. Therefore, the author is familiar with the primary study's context.

\section{Conclusion}

Legal issues have been taken care of in the current research. A legal agreement exists permitting the use of the data, the access to the data is restricted to the author who is also familiar with the context avoiding the risk of possible defamation.

\subsubsection{Selection of data}

The selection of data for secondary analysis can be divided into two stages. First, a search for relevant data should be conducted. Second, the suitability of the found data set needs to be checked (Heaton, 2004).

The data for this research is considered as relevant, because the research can be categorised as supplementary research investigating an issue that emerged during the primary study. Therefore, there is a pre-existing relationship between the data and the secondary study's purpose and research question.

In order to assess the suitability of the qualitative data Hinds et al. (1997) and Heaton (2004) suggest some guidelines shown in Table 18 (appendix) together with the way it was handled in the current research.

In summary, the data is relevant as well as suitable for the secondary research.

\subsubsection{Analysis}

There is a variety of possible analysis methods (for a discussion, see Heaton, 2004). The current research used re-coding from scratch. Existing codes were completely removed in order to focus entirely on the new research question and its analysis. A new coding schema based on the framework developed in the current research and derived from the literature review was applied to the data. The interview transcripts were coded along the coding 


schema. The schema is shown in

Figure 5.

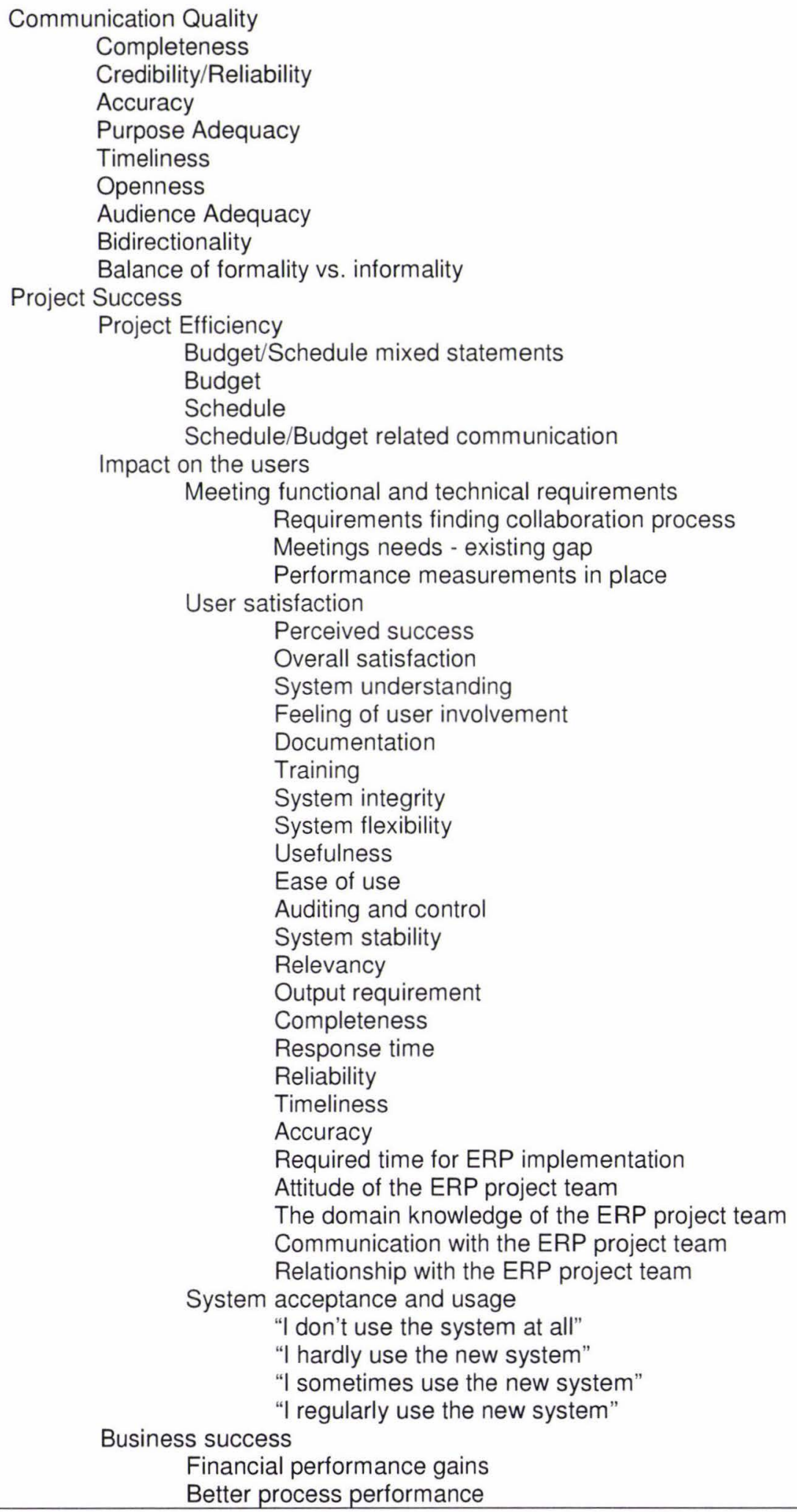

Financial performance gains

Better process performance 


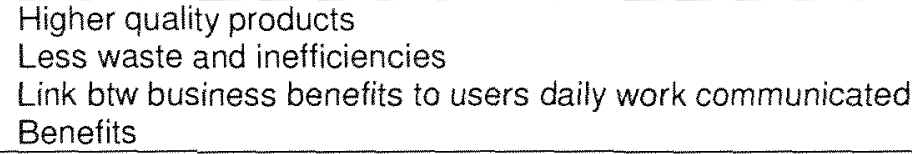

Figure 5: Coding Schema

The sections communication quality, project efficiency, meeting functional and technical requirements, and business success of the coding schema were validated following the suggestions of Paré (2002). These categories were the only new schema elements. The other parts were reliable measures which had been validated in previous research before.

Two independent PhD candidates in Information Systems were asked to act as coders to determine interrater reliability. The author gave the two candidates a $10 \mathrm{~min}$ initial briefing and explanations about the coding scheme to make the coders familiar with the task and the schema. Each coder was asked to assign codes to a series of segments which had been randomly selected from the categories that needed to be validated. The coders' responses and the author's codes were compared on a pairwise basis (Paré, 2002).

Interrater reliability and Kappa-coefficients were calculated with SPSS 14.0. The results are shown in Table 10, Table 11, Table 12, and Table 13. More details can be found in the appendix.

Table 10: Communication Quality: Kappa-Coefficient results for interrater reliability

\begin{tabular}{|c|c|c|c|}
\hline & Author & Coder 1 & Coder 2 \\
\hline Author & $\mathrm{X}$ & $\mathrm{X}$ & $\mathrm{X}$ \\
\hline Coder 1 & 0.717 & $\mathrm{X}$ & $\mathrm{X}$ \\
\hline Coder 2 & 0.789 & 0.786 & $\mathrm{X}$ \\
\hline Average: & \multicolumn{3}{|c}{0.764} \\
\hline
\end{tabular}

Table 11: Project Efficiency: Kappa-Coefficient results for interrater reliability

\begin{tabular}{|c|c|c|c|}
\hline & Author & Coder 1 & Coder 2 \\
\hline Author & $\mathrm{X}$ & $\mathrm{X}$ & $\mathrm{X}$ \\
\hline Coder 1 & 0.706 & $\mathrm{X}$ & $\mathrm{X}$ \\
\hline Coder 2 & 1.000 & 0.706 & $\mathrm{X}$ \\
\hline Average & & 0.804 \\
\hline
\end{tabular}


Table 12: Impact on Users: Kappa-Coefficient results for interrater reliability

\begin{tabular}{|c|c|c|c|}
\hline & Author & Coder 1 & Coder 2 \\
\hline Author & $\mathrm{X}$ & $\mathrm{X}$ & $\mathrm{X}$ \\
\hline Coder 1 & 0.706 & $\mathrm{X}$ & $\mathrm{X}$ \\
\hline Coder 2 & 1.000 & 0.706 & $\mathrm{X}$ \\
\hline Average: & \multicolumn{3}{|c|}{0.804} \\
\hline
\end{tabular}

Table 13: Business Benefits: Kappa-Coefficient results for interrater reliability

\begin{tabular}{|c|c|c|c|}
\hline & Author & Coder 1 & Coder 2 \\
\hline Author & $\mathrm{X}$ & $\mathrm{X}$ & $\mathrm{X}$ \\
\hline Coder $\mathbf{1}$ & 1.000 & $\mathrm{X}$ & $\mathrm{X}$ \\
\hline Coder $\mathbf{2}$ & 0.731 & 0.731 & $\mathrm{X}$ \\
\hline Average: & \multicolumn{3}{|c|}{0.821} \\
\hline
\end{tabular}

The values for Kappa-coefficient range between are all higher than 0.7 and range between 0.7 and 1.0. This indicates that the agreement regarding the coding between the author and the two coders was substantial (Boudreau, Gefen, \& Straub, 2001). For all four constructs and their coding schemes, the average kappa value was 0.76 , which is above the 0.70 interrater minimum reliability recommended by Bowers and Courtright (1984), Landis and Koch (1977), and Miles and Huberman (1994). Therefore, the coding scheme can be considered as robust. It showed to be consisted across different individuals. Hence, the author expects that future researchers will be able arrive at similar results when using this coding schema.

The software Maxqda2 was used as a tool to support the coding process. Figure 6 shows a screenshot. 


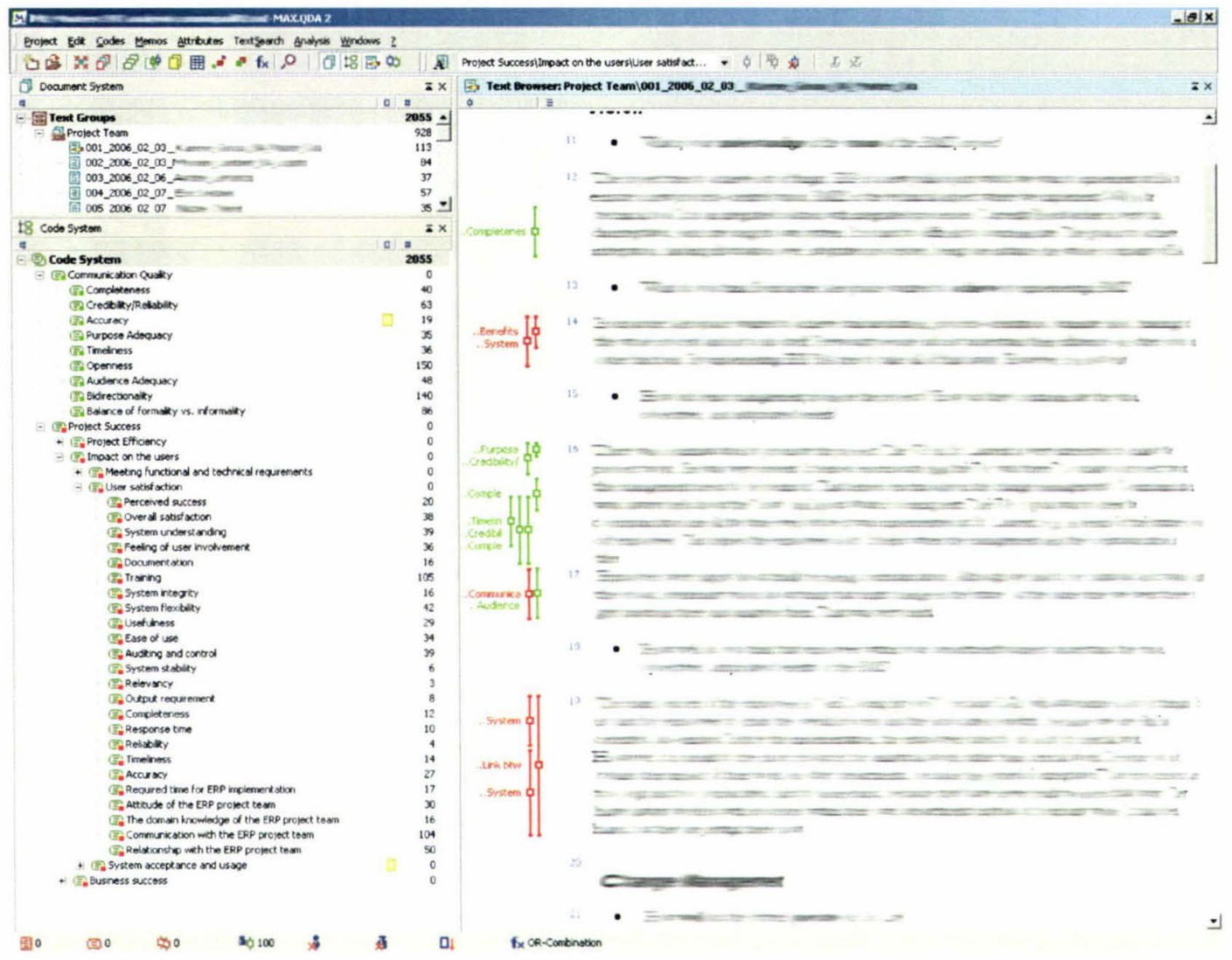

Figure 6: Screenshot of the coding process in Maxqda2

\subsubsection{Quality assurance}

There has been considerable discussion in social research on how the quality of qualitative work can be ensured and shown (Heaton, 2004). A similar discussion has taken place in Information Systems in regard to qualitative research, especially case study research (see, for example, Altheide \& Johnson, 1994; Dubé \& Paré, 2003; Paré, 2002, 2004; Yin, 2002). In the case of secondary analysis of qualitative data, the most common three techniques have been so far: (1) triangulation, (2) member validation, and (3) audit trails. However, methods and guidelines for audit trails in qualitative secondary analysis have not been clearly defined and developed yet in the literature on qualitative secondary research. Therefore, audit trails is not a subject of discussion in the current research. Finally, further methods to ensure quality are: (4) reportage and (5) reflexivity (Heaton, 2004). 


\subsubsection{Triangulation}

Triangulation is defined as the use of multiple measurements of a phenomenon as a means of minimising any bias or partiality from the use of a single method and so establishing the validity of knowledge claims (Murphy et al., 1998, cited in Heaton, 2004).

There are three main methods of triangulation: (1) methodological triangulation, involving the use of different methods to study the same phenomenon, (2) data triangulation, meaning the use of multiple data sources, and (3) investigator triangulation, denoting the involvement of multiple researchers in the same study (Heaton, 2004).

In the current study we apply data triangulation by using interview transcripts as well as company documentation. Investigator triangulation is applied in the sense that there are the author plus two supervisors of which one was also involved in the primary research. The author has the possibility to consult each other regarding the interpretation of results.

\subsubsection{Member validation}

Member validation means an approach to ensure the correct interpretation of results by consulting the participants of the study. It represents the most crucial technique for establishing credibility. The most common method of member validation is the checking of the researcher's analyses by study participants (Heaton, 2004).

Member checking was applied in the current study. The analysis was presented to a coordinator in the organisation, who was part of the project team. She acted as the main contact person between the organisation and HEC Montréal. The coordinator also conducted a presentation of the ERP project at HEC Montréal. The coordinator also reviewed a teaching case about the ERP project written by HEC Montréal. Consequently, the person was well informed about the details of the project. This ensured that it reflected the reality of the organisation.

\subsubsection{Reportage}

Reportage refers to explanations about applied methods in a study. Under-reporting of methods applied in studies using secondary analysis of qualitative data severely limits the extent to which the quality of the work can be assessed. Therefore, Heaton (2004) recommends reporting some basic methodological matters. These are listed in Table 14 with the respective approaches applied in the current study. 
Table 14: Methodological matters to be described in reports of qualitative secondary studies

\section{The data set(s)}

What sort of data was used - personal, informal or formal - and why?

What was the aim of the primary research?

What type(s) of data does the data set(s) contain?

How was the re-usability of the data set(s) assessed?

Personal interviews and formal company documentation regarding the project.

Audit the ERP implementation at the organisation

Transcribed semi-structured interviews, written documentation.

See discussion, "3.3.2.1 The problem of data fit" on page 57

\section{The secondary analysis}

What was the function of the secondary analysis?

(How) did the aim of the secondary study differ from that of the primary research?

(How) was ethical approval obtained for the secondary research?

(How) were the data sorted or pooled for the secondary analysis?

(How) were the data re-coded for the secondary analysis?

What analytical approach was used and why?

(How) was the quality of the secondary analysis assured?

(How) was the primary researcher(s) involved in the secondary study?

(How) did the secondary researcher's previous lack of involvement with the primary research from which the data were derived affect the analysis?

What were the main strengths and limitation of the secondary analysis?

To investigate a new research question of a topic that emerged during the primary study.

The secondary study focus on a topic that was not part of the framework applied in the primary study, but emerged as a side topic during the interviews.

The organisation agreed to the use of the data in the secondary research.

The data was used "as is".

According to the new coding schema developed along the framework of the secondary study in the QDA software MAXqda2.

The guidelines of case study research in Information Systems were followed, because of the congruence of research methods between primary and secondary research

Data and investigator triangulation, member checking.

One as the author, another one as a supervisor.

Not applicable.

Main strengths:

- Access to a large data sample.

- Data fitted the research question quite well. It was possible to analyse most issues thoroughly.

- Involvement in the primary research was valuable for re-contextualisation of the data.

\section{Main limitations:}

- Immaturity of the research method and availability of pertinent literature.

- Extensive methodological documentation 


\subsubsection{Reflexivity}

Reflexivity in primary qualitative research means the self-examination of how research findings were produced, particularly the role of the researcher in their construction (Heaton, 2004). Issues to be addressed are listed in Table 15 along with explanations for primary and secondary research.

Table 15: Reflexivity issues between primary and secondary study

\begin{tabular}{|c|c|c|}
\hline Issue & Primary research & Secondary research \\
\hline $\begin{array}{l}\text { (1) limitations of working with 'given' } \\
\text { data }\end{array}$ & $\mathrm{N} / \mathrm{A}$ & $\begin{array}{l}\text { See discussion " } 3.3 .2 \\
\text { Epistemological issues of } \\
\text { re-using the data" }\end{array}$ \\
\hline (2) the genesis of the project & $\begin{array}{l}\text { The organisation commissioned } \\
\text { HEC Montréal to carry out the } \\
\text { study }\end{array}$ & $\begin{array}{l}\text { The issue of } \\
\text { "communication quality" } \\
\text { arose during the primary } \\
\text { study and was found } \\
\text { interesting enough to } \\
\text { study it in more depth }\end{array}$ \\
\hline $\begin{array}{l}\text { (3) issued involved in re-using the } \\
\text { own data }\end{array}$ & $\mathrm{N} / \mathrm{A}$ & $\begin{array}{l}\text { It offers increased } \\
\text { familiarity with the context } \\
\text { of the primary study. It } \\
\text { bears the risk of not being } \\
\text { able to look at the data } \\
\text { from a "fresh" perspective. }\end{array}$ \\
\hline $\begin{array}{l}\text { (4) how analysing data compares in } \\
\text { the context of primary and } \\
\text { secondary work }\end{array}$ & \multicolumn{2}{|c|}{$\begin{array}{l}\text { The focus and research question are distinctively different. } \\
\text { The analysing techniques (coding of transcripts) and the data } \\
\text { on the other hand are the same. }\end{array}$} \\
\hline $\begin{array}{l}\text { (5) the implications of involving the } \\
\text { original researcher and/or } \\
\text { participants }\end{array}$ & N/A & $\begin{array}{l}\text { It offers increased } \\
\text { familiarity with the context } \\
\text { of the primary study and } \\
\text { makes member } \\
\text { triangulation and } \\
\text { verification possible. That } \\
\text { only a representative of } \\
\text { the organisation can check } \\
\text { the secondary analysis } \\
\text { represents only a second } \\
\text { best solution. Member- } \\
\text { checking would be } \\
\text { preferable, but is not } \\
\text { feasible. Nevertheless, it is } \\
\text { better than no member } \\
\text { verification at all. }\end{array}$ \\
\hline $\begin{array}{l}\text { (6) the different context in which data } \\
\text { were collected and interpreted first } \\
\text { for primary and then for secondary }\end{array}$ & $\begin{array}{l}\text { Collected by HEC Montréal, } \\
\text { ordered by the organisation, } \\
\text { analysed by a team of } 4\end{array}$ & $\begin{array}{l}\text { Analysed at Victoria } \\
\text { university by } 1 \text { Master } \\
\text { student, supervised by two }\end{array}$ \\
\hline
\end{tabular}




\begin{tabular}{|l|l|l|}
\hline purposes. & $\begin{array}{l}\text { researchers at the research } \\
\text { centre. }\end{array}$ & $\begin{array}{l}\text { senior lecturers. One of } \\
\text { them was also involved in } \\
\text { the primary research. The } \\
\text { two different study } \\
\text { backgrounds (HEC } \\
\text { Montreal vs. Victoria } \\
\text { University), in which the } \\
\text { study is analysed, are } \\
\text { fairly similar. }\end{array}$ \\
\hline
\end{tabular}

In summary, all feasible attempts are made to ensure and the quality of the secondary study. This includes data and member triangulation, member validation, reflexivity, and reportage.

This section described the research methodology. The next section presents a brief introduction into the ERP implementation at the case organisation and the findings and analysis of the research along the framework proposed in this research. Moreover, possible implications are highlighted. 


\section{Findings, analysis, and implications}

This section presents the findings of this study. The results are analysed and compared with the framework developed in section three. Possible implications of the findings are also highlighted. The section is structured as follows: First the findings for communication quality are presented and analysed. Second the influence of communication quality on project success is assessed along the success measures project efficiency, impact on users, and business success.

\subsection{Communication quality}

The findings supporting the construct of communication quality including its attributes are presented in the following section. The first attribute is completeness.

\subsubsection{Completeness}

Completeness of communication refers to the degree to which the communicated information between sender and receiver is complete meaning the amount of missing information is as minimal as possible. Several areas were found in which the completeness of communicated information became important in the study. These areas were training and education, the project team's communication about the project status, and the communication activities for users on the business side.

\section{Training and Education}

For the first time the organisation applied a new education and training strategy for the plant that was affected by the implementation module. The education and training strategy was developed by the Change Management department of the project team. The education and training modules within this strategy contained education sessions in which users learned about the rationale behind the ERP implementation, the expected benefits for the organisation, the competitive business environment, the future of the employees' jobs, and the overall mega processes that were defined on an organisational level.

"The roadmap is basically all the activities that should take place before implementation to support the users in their transitions. We designed the roadmap along a methodology that follows phases the users goes through in the transition. [...] This translates into all kind of educational products, which is different from training. [which] is much more focused on transactional training. [...] [T] he education explains why [the organisation] is changing, 
what is the vision. [...] Prior to change we have to explain users all of this."(Change Management Director)

This education complemented the transactional training, which had been the only type of education and training that users received during previous implementation modules.

"The Education Roadmap and BMIS Essentials were created above the transactional training. This helped the employees in their overall understanding and where they fit into the picture." (Business Analyst Material Master Data)

The new approach was received very positively by users.

"The Education roadmap is a key success factor for this project." (Business Analyst Business Processes and KPIs)

"I think the change management guys did a fantastic job on the education roadmap." (Director Supply Management)

In most cases new users reported that their trainers were able to provide them with all the information they needed in order to do their job after GoLive. Only a few found it too much information and a few others would like more.

The roadmap increased the users' motivation and willingness to become involved in the project. Users probably felt that the organisation took them and their needs more seriously.

\section{The project team informs the business about the project's progress and status}

The main mechanism for the project team to inform the business side about the project's progress and status were the biweekly, and closer to GoLive, weekly status meetings with representatives from both sides. Although this implemented a regular communication mechanism, the business perceived communication as incomplete. They found that the project team's management did not provided sufficient details on the project team's progress and problems. The business side felt that they did not receive all the information from the project team that they wanted and needed.

"In the last implementation I did not feel so much prepared, because I did not receive all the information this time." (Trainer Supply Management)

In several cases the business and users had to ask the project for information rather than being provided with it. 
"You had to pull the information out of BMIS. I did not feel well informed the progress of the BMIS implementation throughout the implementation." (Supervisor Supply Management)

The business and users might have felt uninformed which led to uncertainty and frustration. The project team might have been perceived as passive and with an attitude of unwillingness to help. As consequence the business might have reduced its efforts to collaborate accordingly and might have showed a similar attitude towards the project team. This could have been detrimental to the collaboration or the relationship between the business and the project team.

A second communication mechanism was the existing working relationships between departments on the business side and the project side, for example the supply management department on the business side and the supply management project staff within the project team. The level of communication completeness through this mechanism varied across functions. Some functions were better informed than others.

"It was probably best in Supply Management as the change leader is the director of that function." (Change Management Coordinator)

A third communication mechanism was the super and power users. These were especially qualified users from the business that the project team consulted for input such as user requirements. They were also trained by the project team to deliver training and provide support to their peer workers after GoLive in their daily tasks. The communication from the project team to the super and power users was perceived as good and mainly complete by the involved individuals. They were usually more informed than ordinary users on the business side, hence able to provide their peers with information about the project.

"For super users, the communication was good." (User Quality)

Business users were slightly frustrated about the communication they received regarding RFCs (Request for Functionality Changes) from the project team. Users claimed that the feedback on the progress was only partial. The users did not receive enough information about the work progress on the RFCs and why certain RFCs were rejected and not being implemented.

This might have given the business users the impression that the project team did not focus on their needs. It also increased uncertainty, because the users did not what happened with 
the RFCs on the project side. At the same time users were not able to perform their work as well as they thought they could. They could not work in the most productive way, preventing process performance gains. They partly blamed the unanswered RFCs.

The project team also recognised that there were problems in the communication process between project and business side. This was attributed to the improper execution of a part of the planned communication activities.

"We had various communication activities planned. What we probably did not do was properly executing all of those, because it was not properly positioned or properly understood as opposed to there was not the need to do it." (Project Team Manager)

\section{Communication activities to users on the business side}

The senior management on the business side promoted the project very well to the rest of the plant. The plant manager, for example, gave a presentation to his senior management staff and convinced them of the project's importance. After that, the functional directors promoted the project within their functions.

Next to the promotion through senior management there also was mass promotion/advertisement of the project to users in form of an internal TV pogram, posters, cups, and t-shirts.

The mass promotion probably increased the awareness of the project which facilitated user buy-in and contributed towards project success. The mass promotion increased the awareness by repetition and constantly reinforced the users' awareness. If users had not been informed there could have been more negative effects. It might have increased uncertainty about the project. Users could have also started to wonder why they were not informed by their management about something that impacted them. This might have led to suspicion towards the management and the project.

However, not all the intended information reached the users. In some cases the project team communicated information to the business' management. It was then the task of the business management to make sure it was communicated down the hierarchy to the end users. This did not work in some cases.

"Communication was an area identified to be improved. I think the manager level down to users is the one that needs to be improved. [...] To know if a 
certain message was communicated was difficult." (Change Management Coordinator)

\section{Conclusion}

Users reacted positively to the new education strategy which added more background information to the previously solely transactional based training. In general, new users perceived the training and trainers as good providing them all necessary information.

The business perceived the communication from the project as incomplete. Some details were missing and there was the feeling of "having to pull" the information rather than receiving it automatically. The feedback on RFCs was considered as partial.

The level of communication completeness varied across functions and hierarchy levels. The collaboration between the business and the project team worked better in some functions better than in others. Some hierarchy levels were better informed than others.

In conclusion, the attribute "completeness" was found and substantiated. User training and education was close to being complete compared to previous implementations. This was perceived as beneficial by the users and for the project's success in general. In contrast, the incomplete communication on the project's status, details, and RFCs created frustration among the business people.

There might have been doubts among users about whether the project team was truly interested in helping the users and if the project was really for the benefit of the users and not something else. Users might have felt neglected.

\subsubsection{Credibility}

The communication quality attribute credibility/reliability means the degree to which the communicated information is reliable and can be trusted, because it comes from a credible source. Credibility/reliability was found to have been important in regard to the communication of the senior management, the project team's reports to the business in the meetings, and between the power/super users and ordinary users.

\section{Business senior management}

The senior management on the business side regarded communication as one of their priorities, because of experiences made at other plants during previous implementations. 
The senior management was aware that they needed to demonstrate absolute commitment to the ERP implementation or it would have been at risk of encountering problems or even failed. The purpose of the senior management's communication of their commitment was to achieve user buy-in. Therefore, there was continuous communication from the senior management in various forms, such as presentations, meetings with the middle management, and even emails.

"The senior management was very implicated, very involved. They made sure that the communication was going down. They were promoting. [The senior management] knew they had to get behind the project, communicate the hell out of it, make sure the employees knew what was coming." (Key Performance Indicator Developer)

The senior management was present in the status meetings with the project team.

"We had the biweekly reviews where most impacted directors were present." (Director Supply Management)

Functional directors and managers were also present in education and some training sessions for users. They conducted the opening and closing sessions to show users the importance of the project and that the senior management was committed and involved themselves.

"Also in the change management activities and training session. We had directors and managers coming in and making the opening and closing session, showing support, making sure the right resources are freed up." (Director Supply Management)

Some directors and business managers also validated education material beforehand or reviewed mapped processes. Directors of some business units even requested presentations by project team representatives for their users to foster their understanding. In some extreme cases managers also talked individually to users who had concerns regarding the implementation.

The senior management's strong implications and involvement aligned users. Users might have realised that the senior management was interested to go with the users in the same strategic direction. The senior management was able to free necessary resources and to remove roadblocks. This probably made the implementation project easier. If the senior management had not been that involved the overall direction would have been missing as well as the way to complete the project successfully. Without alignment and shared 
commitment between the departments, each department might have worked in their own way or might have even tried to sabotage the project.

\section{The project team jeopardises its credibility with the business}

The project team jeopardised its credibility during the biweekly status meetings. The project team used so-called scorecards with green, yellow, and red light symbols to indicate the status of certain activities. The project team sugar-coated these scorecards showing green lights although the project team had encountered difficulties. The business reacted very negatively to this approach.

"If you only want to be a good boy and show that everything is green all the time, then I think you are not doing a good job." (Director Supply Management)

As a consequence the business probably became very careful and critical in what they could believe and what not. They questioned more areas compared to a situation of collaboration in which credibility existed. This might have wasted time and effort.

\section{Credible super users}

The communication through power and super users to the business was an integral part of the communication strategy. Therefore, credibility among peers was important. In most cases the most skilled and experienced users were selected to become super and power users. So they enjoyed credibility among their peers within the business. The super and power users were trained by the project team and conducted the actual user training. The training and the expertise of most trainers was appreciated by most users. The training evaluation forms were positive for the vast majority.

The opinion leaders probably aligned the users. There was also less hesitation to collaborate with equals. This might have speeded up the learning curve and allowed users to become proficient with the system faster. This could have had positive effects on the productivity and the building of knowledge.

However, a little drawback was that in a few cases super and power users were better informed through their involvement in the project than the users' ordinary superiors. 
Sometimes users received important messages from their peers rather than their management. Some users perceived this as negative, especially regarding problems that the project team had.

\section{Conclusion}

The organisation was aware of the importance of the communication's credibility. Therefore, it was a priority to achieve senior management commitment to the project and let the senior management be actively involved in the communication to the end users. The project team reduced or lost its credibility when they provided false information in the status reports. Also, credibility showed to be important by selecting the most appropriate power and super users, who were respected among their peers. The attribute credibility was found to have been played a role in the communication between the project team and the business. It was substantiated as an attribute of communication quality.

\subsubsection{Accuracy}

The project team intentionally communicated inaccurate information to the business side at several occasions, such as in sugar-coated status reports. These showed that the project was on time and that there were no problems, although there actually were some problems. Similarly some presentations by the project team lacked accuracy communicating wrong information. The business attributed this to the politics involved in an implementation, such as the project team's want to appear successful to the business and the steering committee. The project team wanted to demonstrate that they were able to solve problems internally and were in control of the situation. The project team mentioned as a reason that they did not want to worry the business unnecessarily.

"In those presentations unfortunately there is too much politics involved, so the dashboard needs to look green even when it is not." (Supervisor Supply Management)

"No, I do not feel I was provided accurate information by the project team. There was too much red tape." (Director Supply Management)

However, the business felt it made the business worry and created suspicion. They wished to have been informed accurately even though this might have entailed aspects that were "not nice". The business communication focal provided an example: 
"I do not feel I was provided accurate information by the project team. As an example, in one of the meetings I was questioning something and they said it is going well. So someone said:" So, she is not aware? And I said: "I am not aware of what?" and him: "Oh, no, no, nothing." [...] There was a guy who was supposed to be there, but he was in Rumania because of family issues. This was something that was not brought to us and at the end it turned out that he is the only one [in the project team] that could do a certain task. We had a delay in the project because he was not there. So at the beginning tell the right information even if it is not nice.Then we can understand and deal with problems. I think they do not want to face the reality, because they think we will be scared. but they created the opposite effect." (Business Communication Coordinator)

The level of perceived accuracy varied across functions. Functions that were more involved in the implementation felt more often that they were provided inaccurate information. The communication of inaccurate information was not a one time event and it created frustration within the business functions. The manager of Supply Management explained how the project team provided inaccurate information several times over a longer period of time:

"I am not sure about the accuracy of the information. That was our main concern. [...] One point was a bug in a certain part. [...] That was when I started to doubt more. Before that I already heard warning from people here in May, that things and information you get from the project team are not always clear, but I wanted to make myself a picture. I encountered own evidences in June. Maybe it was not done on purpose. I went to the [project team] and met with their management people to express my and my staff's frustration." (Manager Supply Management)

The project team's inaccurate information might have been perceived as lying by the business. This probably led to a lost of trust in the project team by the business. This made the business more cautios about what to believe the next time or at all. The business would have questioned the project team's integrity more and more and the team reputation was damaged. The re-occurrence of being provided inaccurate information only reinforced the business bad perception of the project team. The business might have started to question if the project team really operates or wants to operate in the best interest of the business side.

\section{Conclusion}

The accuracy of communicated information between the project team and the business played a role during the implementation project. The project team communicated inaccurate information at several occasions leading to frustration with and resentment 
towards the project team. The business side wanted accurate information although it might not have been good news all the time. The quality of communication was affected negatively by the transmission of inaccurate messages. Therefore, accuracy was found to be an attribute of communication quality.

\title{
4.1.4 Purpose Adequacy
}

Purpose adequacy of communicated information means that the information is useful for the task at hand. This became apparent in the areas education and training structure, changes made to the training, and the provided support.

\section{Education and training structure}

The communication in general and during the training and education was designed in such a way to facilitate the employees' understanding of the background and rationale of the ERP project. Compared to previous implementation modules there was a larger focus on the background education. The director of Production Planning described:

\begin{abstract}
"The Education Plan is maybe what made a bit of difference to what happened compared to [a previous implementation]. The preparation we had up front gave us a much better view of [the organisations ERP vision] and SAP. So the employees understood when they went to the computer to do some stuff. So it was not only data crunching." (Director Production Planning)
\end{abstract}

This education and training program was prepared by the change management section of the project team. The sessions also gave users the chance to pronounce their concerns and have discussions, next to the presentations and explanations. The aim was to bring people into action, mobilise them for the change, and make them accept the change. During all those session it was tried not to give users unnecessary information, but to focus on information that the users needed.

This might have made users feel that their needs and concerns were taken serious. It gave the impression that the organisation cared for the employees' needs, which created a positive work environment. It also created motivation for the project and for the users' work in general. Employees might have perceived the organisation as a good employer.

\section{Training changes}

The original training and education strategy was slightly modified, because the business argued it would take too much time. Most users still perceived it as adequate after the cuts. 
"The Education plan was just massive. If you talk about over 100 hours of training per users. That is nearly 3 weeks where the person is trained. Who is doing their regular job? So a challenge was to minimise the amount of training without compromising the content." (Director Supply Management)

"Requests were made to merge modules of to skip a couple of module. The training was modified from the original planning but it was still acceptable." (Business Analyst Business Processes and KPIS)

In some cases users asked super power users to modify the training material to make it more suitable for the actual tasks users perform in their daily work. This was also considered for the next module roll-out.

The user training was a cost issue, because any time that the users do not work represents a loss in productivity. It might have led to a delay in the product delivery because the product delivery schedules were tight anyway. It was necessary to compensate and plan for the time when specific users were in training and not working.

The willingness of the department directors to let their employees participate in the training might have been based on whether the training was seen as a cost factor or as a future investment. Regarding it as a cost factor revealed a short term focus, whereas regarding it as an investment could have been interpreted as long-term orientation. The appropriate training and sufficient training time probably allowed users to work better with the system later on. They were able to use the system faster and to its full potential. This also made them more productive. Therefore, it is a gain in the long run. In addition, training might have also led to higher confidence levels in using the system and a more positive attitude towards the system and work. On the other hand, insufficient training would leave users working with the system below full potential. The learning process, which happens in the daily work, would take longer. There would be more trial and error. Suboptimal and non-standard work routines might slip in. This would have a negative effect on productivity.

\section{Inadequate support}

The on-site support that was provided by the project people after GoLive was perceived as inadequate in some parts. The project mainly assisted with basic support whereas user question were already more elaborated. Some users felt they did not need the kind of provided support, because they were sufficiently familiar with the system. Users wanted to 
know how to improve the system and encountered problems in that area. For those problems users felt the project team was not able to help them and they were not provided with the adequate information they needed for the task at hand.

"The type of problems we encountered could not be solved by the project people support staff that was on site after GoLive." (Supervisor Supply Management)

This might have led to resentment towards the project team and its members. Users might have wondered if the project team really wanted to help them. Therefore, the "we solve it ourselves" attitude probably emerged.

\section{Conclusion}

Users received an education and training program that was different from previous implementations. It had become clear that there was a need for more and different types of information in order to mobilise users and achieve user buy-in. Therefore, a large education strategy was developed. The actual transactional training part of this education strategy was also modified after discussions between the business and change management (part of the project team). Although the amount of training was reduced, it was still perceived as adequate to learn how to use the system. The support after GoLive, on the other hand, was perceived as inadequate, because the support staff was not providing the information the users needed.

Providing users adequate information proved to be an aspect influencing communication quality and was consequently substantiated as an attribute.

\subsubsection{Timeliness}

Timeliness refers to the importance of communication taking place at the right time. It was found to have played a role in several areas, such as the education and training, the communication activities carried out by the business, the communication about problems between project team and business.

\section{Education and training}


Change management tried to consider timing during the development and deployment of their education and training activities. They wanted to conduct them at the right time and the right pace how the Change Management Director explained:

"The aim when developing the material was to deploy the right activities at the right pace, at the time to answer the proper questions people have and also supported with communication and change management and the exposure of the management." (Change Management Director)

However, due to resource constraints close to GoLive some education and training sessions were conducted earlier, in fact a couple of months before the GoLive, than originally planned. The trainers (resources) were needed in their daily functions at this point. Users understood the resource constraints and it resulted in no major negative effects. In one function the training material had not been finished in time and the training was actually conducted two months after GoLive. Users reported it was a bit difficult, but they tried their best to accustom themselves with the system on their own and with the help of their peers.

There was some elasticity about the timeliness of communication as long as the discrepancy was not too large. It did not have a large impact that the training was conducted quite early on. It was important though to let the employees know about the reasons for the early training application. It helped to prepare them and deal with the situation. It also reduced uncertainty. Consequently, they were able to prepare for and adjust to the situation.

\section{The business' share of responsibility}

Specific project kick-off activities were carried out too late by the business, according to the project team. The implementation project had already started when they were conducted. The consequences were not specifically mentioned by either side.

During the biweekly status meetings between business and project team, the business management sometimes sent delegates instead of being present themselves. For most situations the delegates were authorised to make decisions, but in some cases messages had to be submitted back to the management. The project team had wished the business management to be more present in those situations, especially when decisions impacting users had to be made and communicated. A project team business analyst explained: 
"Some aspects of meetings, especially something that will ultimately impact users, but does not need to be communicated to users at this point of time, needed to be communicated directly to the management. However, the communication was often back to the delegates, but not to the management directly." (Business Analyst Material Master Data)

The presence of senior management showed the importance for the business and the appreciation of the project team's work. This perception might have changed towards the negative when the presence of the senior management during the meetings declined. The project team might have wondered if the business' senior management cared for the project enough, and if they did not show up there might have been the impression that the did not care. The project team might have been aware that the communication to delegates instead of the senior management directly took more time to ultimately submit messages. They might have thought the business senior management was willing to accept those delays and consequently the project team's opinion about timely communication changed as well. Timeliness might not have been considered as so important anymore.

Using delegates also introduced an element of uncertainty into the communication process. The project team did not know in which form the messages would be communicated back to the senior management. Also, the project team could not be certain if the delegates would make the same decisions as the actual senior management. The business senior management might not have been satisfied with what the project team reported, but they did not have the chance for immediate feedback (bidirectionality) because by the time when the delegates reported to them, the meetings were over. On the other hand, the senior management appointed the delegates and must have trusted them. Another question is how the personal relationship between the delegates and the project team was compared to the project team and the business' senior management. It might have been different and the intermediaries could have also distorted the communication process. However, there were no data on that.

\section{Change management's attempts to monitor communication}

For the Change Management department it was difficult to see when certain communication activities were carried out within the functions and when they reached which hierarchical level. This lack of transparency caused problems in the communication activities. For example, it led to users not being at the right place at the right time for training or receiving training sessions in the wrong sequence. In order to monitor the 
timely communication of messages Change Management suggested implementing an online tool where managers had to report when messages had been communicated. This was rejected by the functions arguing that there was no time to use this kind of system and do the reporting.

"It was a challenge to find out when things were communicated. There are so
many levels to trickle down a level. So, to know if a certain message was
communicated was difficult. I suggested an online tool where people log in and
tick off that they have done their communication. People told me they are not
going to use it." (Change Management Coordinator)

This might have been confusing for employees and they might have started to wonder about the credibility of their own management. Users also might have wondered if the management honestly cared for them. It required extra effort for users to cope with receiving the training in the wrong sequence. It might have also reduced the perceived level of training quality. It might have negatively influenced the employees' ultimate level of confidence and proficiency with the system.

The report tool would have helped the Change Management department. It might have ultimately benefited users because it had been more likely that they would receive adequate communication for their purpose and in a timely fashion. Maybe the business management saw this tool more a controlling device and they feared being monitored and controlled. It could have been perceived as patronising. It could cause additional work, but the amount depends on the design of the tool and its complexity. The suggestions came from change management, but not from the higher management, so it was easier for the business' middle management to reject the idea, because the Change Management department was not a superior of the business' middle management. Trying to implement change from the bottom of the hierarchy is difficult. Similar difficulties can be expected when the collaboration and relationships are not good. This might have been the case between Change Management (project team) and the business' middle management.

Another issue might have been how the use of such as tool could have been reinforced. Would the middle management have seen enough incentives to make them use it? It could have been made a requirement, but then the senior management would have needed to support of the idea. Another option would have been honesty, but that would have been difficult in a strained relationship. 


\section{The business's opinion about timely communication with the project team}

The communication about the schedule for certain activities was delayed. In some cases the project team delayed the communication because they wanted to solve problems internally and did not want to worry the business unnecessarily. It created the opposite effect on the business side. The business would have liked to be informed earlier about problems by the project team.

In a lot of cases the business had been waiting for feedback on RFCs for a long time, sometimes years. The project team either put the business off when the business asked for the progress on the RFCs. The business hoped for work improvements through the RFCs.

"A lot of RFCs could save us a lot of manual work. We have one RFC that has been there since 2003 and is still unanswered." (User Production Planning)

The business would have liked the project team to give them some kind of feedback faster or at all.

The project team created uncertainty with the missing feedback on the RFCs. This might have given room for speculations on the business side and among users. It also might have made the users feel powerless and having neither influence on nor control of the situation. The slow responses on the RFCs might have made the users feel that the project team neither cared for them nor was interested in their needs or working for them. The uncertainty left room for all types of speculations about the reasons and might have negatively influenced the perception of the project team on the business side.

\section{Different perspectives}

The business argued that the project had a different understanding of deadlines and deliverables. The manager of Supply Management explained:

"The business here at [the plant] is manufacturing and the way we live everyday is we have plans, dates, and commitment. We deliver, and we are really focused on performance and we follow dates and activities. When we look at the project team, we did not feel that they had the same attitude towards dates and deliverables. [...] The [project team] was more like "We will deliver around that date. We are not sure. We do not know." That is like a cultural clash. We said, that we need this at this time and that and we will be impacted if we do not get it. That was a bit difficult. Maybe it is the nature of their job is 
softer, and they cannot provide all the requested information the way we wanted it." (Manager Supply Management)

At the same time the project thought that people on both sides understood when people had to carry out certain tasks. Therefore, the project team did not always see an immediate need for communication back to the business.

The business rather focused on seeing the differences between the project team and the business instead of the similarities. The focus on the differences might have substantiated the "us vs. them" mentality and made understanding each other more difficult. It also hampered teamwork and collaboration, although the willingness for that needs to be evident on both sides. Also, the project team did not provide explanations why they were not able to provide the information to the business. This created uncertainty. Both parties did not communicate about their individual communication wants and needs clearly which reduced the communication's effectiveness.

\section{Conclusion}

In terms of communication in form of training and education little variations in the timeliness did not have a significant negative impact. Users still perceived it as sufficient. In terms of communication between the business and the project team timeliness of communication became an issue. Different expectations about when it is necessary to communicate messages created frustration, mainly on the business side. However, also the business delayed activities that the project wanted them to carry out earlier. This was regarded as negative by the project team. Consequently, timeliness was substantiated as an attribute and found to impact the quality of communication.

\subsubsection{Openness}

Openness stands for the degree to which either side in the communication process communicates open and honestly and do not hold back information. Communication openness aspects were found in the communication between the project team and the business, the exchange between the communication focals, and in differences regarding the goal of the implementation project. 


\section{The project team hid something}

During the implementation the project team hid information from the business about problems that the project team encountered. Officially, the project team had the intention to install transparency. Therefore, they circulated their scorecards on a weekly basis among the business management. They also held biweekly, and later on weekly status meetings, but those meetings did not necessarily reflect the reality showing green lights on the scorecards, although there were problems. The business felt the project team did not tell them everything they needed to know. The communication was perceived as nether honest and nor open enough.

"The communication was not effective. I think that we were not enough open with the business side to let them know the real status of the project" (Business Analyst Business Processes and KPIs)

On the other hand, the business claimed they always communicated the status of their activities to the project.

The business would have liked more transparency from the project. They did not have much insight into how the project was planned and executed by the project team. The business side perceived hiding issues as worse than having to deal with the actual problems. They claimed that problems could have been solved together. On the opposite, the business did not perceive hiding as beneficial for the project.

The project team's closeness created a lack of trust in the project team on the business side. Even users, also not specifically involved in the status meetings, reported a lack of trust in the project team. The business insisted to install a so-called "police" in the status meetings to ensure that the project team told them the truth.

There was a lack of trust between the project team and the business. The existing trust level was low. This became evident in such actions as the "police", which represents the second worst case before not talking to each other anymore. The situation would make it difficult to trust each other again in the future and come back to a "normal" state of collaboration. Trust can be easily lost, but is difficult to build, especially to re-build. 


\section{Improving vs. deploying}

There was a fundamental difference in the understanding of the project team's mandate between the business and the project team. The project team was focused on deploying the in-scope modules to the different sites of the organisation. The business, on the other hand, wanted the current available solution to be improved and to be adapted to their needs. But both sides partly knew about this. The senior and middle business management was mainly aware that the project team's mission is solely to deploy. This was different for the users.

"[The business] has the perception we are there to help and improve, while we are actually there to deploy, which is different. Improving means we make modification to the system, while we deploy we support you with the system and not helping you to modify the system." (Key Performance Indicator Developer)

The project team knew how much the business would have liked to change the current system, because the RFCs had been piling up. However, only a few RFCs were actually answered and completed, because it was not the project team's mandate.

The business users were sometimes so frustrated with this situation that they sometimes just wanted the system delivered and did not see the project team staff in the plant.

"Give me the machine and get it run and get out please. It is sad." (Supervisor Supply Management)

The business users argued that they had specific needs and thought that the project did not understand them. Communication about this was neglected. Meeting in the middle was for both sides a challenge and caused frustration on both sides.

The business felt that the project did not take care of their issues. Feedback or explanations about feasibility were missing from the project team and it was often a "yes or no communication". At the same time the business was sensitive and demanding. They wanted things delivered on time. The business perceived the project as not sensitive enough. On the other side the project team was not sure if business had the ability to see the amount of work the project team did. But neither side did communicate openly about these issues.

"These are really two different worlds." (Business Communication
Coordinator) 
The communication was already down at this stage and people might have wondered where this would lead to. After the complete deployment, the project team was supposed to work on system improvements according to the business needs and strategic objectives. It might be difficult to work together if the foundation for collaboration has been severely damaged or maybe even destroyed. It is unlikely that the two parties would magically work together in a partnership. Instead it will take a lot of effort to rebuild trust between the two parties and restore the communication to collaborate effectively. If this does not happen the system might not fit the business needs as well as it could and should in the end. This would lead to a suboptimal use of the ERP system and defeat the purpose of becoming a more efficient organisation.

\section{The communication focals/coordinators}

For this implementation there were two dedicated communication focals, one on the project team side and the other one on the business side. A few days per week the project team's focal person was at the business plant and both people worked at desks which were next to each other. The collaboration between the two worked well, but there were some interpersonal conflicts between the business communications focal and other parts of the project team.

"There was a coordinator, who works under the change leader. Some people in the team had a challenge with [the communication coordinator]. Interpersonal conflicts took place between the team lead and this coordinator." (Change Management Coordinator)

It was mainly because of differences in understanding.

"The whole follow up of the project was a constant challenge. [The business communication focal] wanted to consider her project partners as a supplier, because she was a procurement agent before. So she was like: 'Ok, I need this at that time. What is your corrective action?' She is very oriented, planned, date, action, and you follow up and owe me answers." (Manager Supply Management)

Also the business communication focal perceived it as impossible to receive information from the project team in some cases.

"[There are] two different worlds, because people here [in the business] are very sensitive and they want things to work. They are very demanding. [In the project team] they are not unconscious, but less sensitive to what will happen if something goes wrong. When I came in last year, I felt both were not good. 


\section{[...] I told them and I was asked to calm down, so I calmed down."(Business} Communication Coordinator)

The project team and the business did not talk about differences in their individual understandings of the necessary communication. The behaviour of the business communication focal was based on her work experience. Maybe the business communication focal should have been more open-minded to working differently. The project side might have felt patronised. The team lead might also have had a totally different perspective when it was necessary to communicate what, if at all. The conflict between the two could have influenced the opinion that other people had about the opposite party. This depended on the position of importance and influence of the two on their respective sides. It could have led to stereotypes, generalisations, and prejudices, which might have been unjustified. It could have created suspicion and apprehension which could have sabotaged the collaboration work and interactions with each other.

\section{"Us versus them" and "client-supplier vs. partnership"}

There were some indications about an "us-versus-them" thinking on both sides.

\section{"We are doing computer projects as they are building [the organisation's products]." (Programmer)}

Both parties did not work in a partnership, but more like in a supplier-customer relationship with the business as the customer and the project team as the supplier.

This is more a negative consequence of unopen communication than a part of it. Again, both parties did not clearly communicate requirements and understandings.

However, it was not quite sure certain who was leading whom in this relationship as both parties claimed the lead role. The project wanted the business to carry out certain activities in the way they prescribed it. The provided the business with a framework and rules the business had to follow. At the same time, the business took the approach of "we lead what is happening in our plant". The plant manager described it as "jumping right onto the dance floor and taking the lead". The business thought this was appreciated by the project, but the project team wanted to lead themselves.

"From the [project team's] perspective to provide the framework, the guidelines, the rules by which they [the business] need to follow and help them in the execution of that." (Project Team Manager) 
"We decided, this is our plant, we take the lead of this. They [the project team] felt comfortable with our decision." (Plant Manager)

The business and the project team did not communicate open enough about their understandings which created misunderstandings.

Both sides wanted to be in control and were not willing to relinquish control or any of their territory. There was not the mind-set for an equal partnership and collaboration. This might have sabotaged the collaboration and led to the strained relationship between the two parties.

\section{Complaining and blaming the other party}

The two sides also blamed each other. One example was when the project team complained about inconsistency of the business in terms of staff, specifically the change leader position. This position had changed after three weeks in the project - in a project that took nine months in total.

"From a change leadership perspective. it is very important to have that consistency, building a relationship starting with the executives in the business units that were helping in support and we then have the same face so we have relationship all the way through. But when after 3 weeks they guy leaves and somebody else comes in." (Project Team Manager)

The business complained that the project team did not carry out certain communication activities properly. The project team claimed that communication execution was more the duty of the business.

On the business side the willingness to listen to the project team decreased over time. The business found the project team was not responsive to their needs. Sometimes both sides wanted information from each other, but were not able connect to each other. The business complained they were often not able to reach the person in the project that they wanted to reach.

\footnotetext{
"We can never reach the person that can help us." (Supervisor Supply Management)
}

During the support phase after GoLive some project some project team staff complained that they did not know the new users and that the business side did not introduce them. At the same time the business side expected the project support staff to be more pro-active 
and walk around and offer help. Together with other aspects, this led to arguments between the project team and the business.

Blaming each other was also more a consequence of bad communication. The willingness to cooperate was low when groups reached a state of blaming each other. They also did not see their own faults and went to destructive blaming instead of constructive criticism.

\section{Openness depends on the business function}

Certain functions worked better together than others. Some functions on the project side communicated more openly with their business counterparts. They tried to involve business in It testing and validation activities. This was appreciated by the business functions. This had a positive influence on the relationship between the two sides.

Where open communication and collaboration happened, it enhanced the relationship. Members showed a higher level of willingness to spend time and energy on the project. It also built a good foundation for future collaboration. It could have a positive influence on user satisfaction and system acceptance.

\section{For the future}

The change management department bemoaned the lack of communication between business and project. Reasons were said to be internal and not the communication channels. Sometimes communication was not organised and administrated properly. At the end of the project lessons learned were compiled as Change Management explained:

"The recommendations for the next project are to improve communications, and to follow up on people, and present ourselves as a team with one goal. That is not easy. We are supposed to work together with the project team at $100 \%$, speak the same language, and have the same mandate. It is not easy because of the different perspectives that the project team and the business have." (Change Management Coordinator)

Change management identified the right areas. The only thing that was missing was how the enhancement was supposed to be achieved. Communication and relationship management could be means to work on improvements. It would require extra effort and would cost something, but it would be a future investment facilitating future collaboration leading to a more efficient system. Another question was who could lead these initiatives and the necessary change? It would need to come from the top. 


\section{Conclusion}

The un-openness in the communication between project team and business led to a number of problems, in particular a weakening of the relationship, reduction in the willingness to work together as a team, and to talk to each other without holding back information. The project was still successful, but the interpersonal relationships between the project team and the business suffered. In contrast, in areas where communication was open, as in some functions, the relationships was better and the collaboration worked better leading to better results.

Openness was found to have a strong influence on communication quality and represents a crucial attribute. Openness was also found to be related to the interaction and relationship quality between the two parties.

\subsubsection{Audience Adequacy}

Audience adequacy means that the audience to which the communication is targeted receives the communicated information in such a format that it best understandable and of most value to them. Support for audience adequacy was found in the areas of training and education and in language differences between the project team and the business.

\section{Tailored training and education}

Change management applied different education and training programs to different hierarchical levels in the business. Education took place on three levels, namely plant manager and directors, managers and supervisor, and employees. Next to differences in the content for each specific level, there was also a timing difference. The upper levels received the education earlier than the lower levels to achieve a top-down preparation and buy-in.

\footnotetext{
"There was not only education developed for the employee level. It goes on three levels, plant manager and directors, functional managers and supervisors, employees. We had education for all three levels. The courses had a bit a different format and the directors and managers received the training one step ahead of the employees." (Change Management Coordinator)
}

Next to these three levels, there was also a special training for the super and power users a while before the user training started in order to work as trainers. 
Change management tried to tailor the training materials and communication activities to the audience, for example for users from the employee level the education consisted out of highly interactive sessions. The aim was make users enjoy it. Moreover, the education was designed in such a way that the users' concerns were collected, discussed, and addressed. Users felt taken seriously in their concerns.

In addition, power and super users tried to identify knowledge gaps among the remaining users. Together with change management, and considering lab and time constraints appropriate training and communication activities were developed for the users.

In general, most users valued this multifaceted training and education approach and said that the education was a valuable complement to the technical transactional training.

This tailored education probably prepared users and any other level better, because it suited their individual and specific needs. It was probably a reason for the easier user buy-in compared to previous projects in the organisation. Users might take the positive mood and experiences from the training into their own daily work. This might have had a positive influence on their attribute towards the system. Also, users might have a positive perception of the Change Management department, which might make future collaboration and changes easier. Change Management would build on those positive experiences. In addition, users might share their positive experiences with co-workers. This word-of-mouth might be helpful for future projects when those employees are affected. It might be a good advertisement. In future deployments users might also show a higher willingness to learn. Their feedback should be taken into account to further optimise the education and training material.

\section{Different languages between project and business}

The project team members felt that representatives from the business side did not speak or understand their language during the biweekly status meetings. It was noticed that the business management was more present in the beginning, but this declined over time and delegates were sent.

"The project manager chaired the meetings, but the business was only there in the beginning, but they did not speak our language." (Business Analyst Material Master Data) 
The communication might not have been tailored to the receiving audience.

On the other hand the business senior management might not have had the time to participate. However, less presence during the status meetings might have given the project team a wrong impression about how much their efforts were valued and appreciated by the senior management. The business' senior management showed constant involvement and commitment to their users. The same might have been necessary to the project team members. This might have increased the willingness to collaborate and provide more feedback, for example, on RFCs. On the contrary, showing less presence might have fostered the separation between the project team and the business.

\section{Reaching different hierarchical levels with different media}

Different types of media were used to communicate the vision of the project to different levels. The change management department gave presentations to the business' senior management. In order to reach a lot of users an internal newsletter was used that was available in the cafeteria. In this newsletter, the latest news of the project's progress were given, efforts of specific people were highlighted, and the project's vision was reinforced.

Additionally at least two other forms of communication reached the users. First, functional managers gave presentations to their users. The presentations were adjusted to the perceived needs of the users. Second, the power and super users were utilised by the project team to communicate to the users in the business, i.e. using peers who speak the language of the users to communicate information about the project.

The appropriate medium plays an important role in suiting the communication to the audience's needs. This correlates to task/media fit theory In this study it also relates to credibility as it was important that managers, or another person with credibility, gave presentation to users to convince them.

\section{Conclusion}

Project related communication, training, and education were mostly tailored to the receiving audience. The audience reacted positively to this customisation. It facilitated their understanding and involvement. In the status meetings audience adequacy was considered less, communication suffered, and the participation of the business' senior 
management decreased. Therefore, audience adequacy was found and substantiated as an attribute of communication quality.

\subsubsection{Bidirectionality}

Bidirectionality addresses the aspect of mutuality in the in the communication process. Both parties send and receive messages. This aspect was found in the areas of collecting the users' input, compiling lessons learned, training and trainer evaluations, communication during the on-site support, and in the information exchange between project team and business.

\section{Taking the users into account}

The opinion of users and their feedback were considered in several ways during the project. Parts of the project team visited the plant and analysed user questions there to find out in which areas users need more information. In some cases debates took place between representatives of the project team and users about the feasibility of certain processes. Also super and power users were quite involved in testing and validating processes, mainly where the project was reliant on their knowledge. However, the extent varied across functions.

The change management team also talked with users who had concerns about the implementation, such as fears to lose their jobs. Their concerns were collected and users were assured that their concerns are valid, but unjustified. The potential benefits of the system were highlighted to show users the positive aspects the system could bring. In some extreme cases managers talked with users and tried to resolve issues together with the project team.

Collecting input and feedback from users might have facilitated user buy-in. Users might have felt they were taken seriously. It might have led to the idea that the system is actually for them and not only for the organisation. This led to strong support for the project and built a good foundation for future projects.

Before the training had started users requested to update some parts of the training material. The suggestions were captured and the changes were made. During the training sessions, users were able to ask the trainers questions and raise doubts and concerns. 
After the training and education had been delivered, change management conducted one to one feedback sessions with users to find out how users felt working with the system.

"There was also 1 to I feedback about people felt working in the system. That feedback was given back to the coordinator." (Change Management Coordinator)

It was a long process, but the organisation conducted similar sessions in past projects. The users were accustomed to it. The results of the feedback sessions were included in the project review.

\section{Lessons learned}

Official lessons learned were produced and included in the project review. Users and project employees were required to compile lessons learned, but there was some frustration, because people did not receive much feedback from their management on the lessons learned. Employees, especially on the project side, as well as the Change Management department, felt that lessons learned were not much addressed later on and followed up.

Then there was the lessons learned that were communicated to the project review team. The lessons learned were done in the format of email and responses to emails. But that was something the project manager did. There is a lot of: "This is my deliverable, I know what to do with it." [...] I said to the project manager we need to tell the people what we will do with the results. I come from the school of thought that when you collect data, you have to follow up on it. He said there would be a workshop with his Business Analysts and Application Specialists, but there was no workshop. [...] It is consistently not followed up. That does not help with future changes." (Change Management Coordinator)

"There are also always lessons learned prepared but nothing is done with them." (Business Analyst Material Master Data)

"They often do lessons learned but 'The more things change, the more they're the same'." (Business Analyst Design)

"In every project we do lessons learned, but no part is taken out of it. Maybe management uses them and it is only a question of perception, but it would be good to receive more feedback on them."(Business Analyst Supply Management)

It might not be beneficial not to follow up lessons learned. This might make future changes more complicated and delay them. It might lead to a longer learning and adoption process, 
because old behaviours might only be stopped slowly, slower than with follow-ups and reinforcements. It might prevent the organisation from becoming a learning organisation. Old mistakes might be repeated, resources used inefficiently, which might not help to improve project efficiency either. The staff's motivation might decrease, because their efforts to compile the lessons are not valued and their ideas for improvements not appreciated by the management. If lessons were followed up staff were given the option to learn systematically, rather than through trial and error. This might make future projects faster. Creating lessons learned and not using them defeats their ultimate purpose and reduces the employees' willingness to thoroughly create lessons learned in the future. Future lessons learned could lack quality. Their creation would be a waste of time and resources and the recommendations might as well.

\section{Trainer evaluations}

Users had the opportunity to evaluate the training content, the facilities, and the trainers through a formal evaluation at the end of the sessions.

"Users filled out questionnaires on a computer before they left the room to measure how aware they are of the changes. We wanted to make sure that certain things were understand." (Change Management Coordinator)

The results were very positive overall showing the training was well received by the users. Change management said that the trainers were allowed to look at their evaluations and that feedback and coaching would be provided.

"We said to all power users that we would provide some coaching." (Change Management Director)

However, not all the trainers were aware that they had to request the results. They thought they would be provided with them automatically.

"Yes, the training was evaluated, but I never saw the score." (Business Analyst Design)

"There was training evaluation, but it was just a final score, but not much has been done with the evaluation results. I had to ask to see my score." (Business Analyst Material Master Data)

The effects of not following up training evaluations might be similar to not following lessons learned. Opportunities to learn and improve might be missed. The evaluations might have identified gaps in the training, if the sheets were filled out honestly. The 
feedback could make the training more efficient and more tailored to the audience representing "audience adequacy".

\section{Support phase}

During the on-site support phase immediately after GoLive, the project team did not receive many questions from users. The project team assumed that there were no problems, but in fact they were some. In reality users avoided to ask the project support for help, because of the bureaucracy of the support process and the attitude of some support staff. Users had to follow a command chain and only address project support staff in case of serious issues. At first, they were required to look into their manual, then ask their peers, then ask super and power users, and only if the issue could not be resolved they were allowed to ask the project support. Users were also reminded of this command chain every time they asked project support for help. Some project staff was not particularly open for the users' questions and. Consequently, users decided not to ask the support staff anymore and to solve issues among themselves with the help of the super and power users.

\footnotetext{
"Yes, there was support staff available on site. There were people, plenty of people to answer, but the process, the bureaucracy and the red tape made it very inefficient. We need what I would call a customer oriented approach. If you are here, your job is to go around, see what users are doing, show them functions. Not sitting at your desk surfing the internet, waiting for someone to come over to you and then look like they are bothering you and answer that this is not a question for you but the super user. Complete bullshit. I was fairly involved in that process. Either you change your behaviour or you get the hell out of here. I think it improved." (Director Supply Management)
}

This might have left a bad impression of the project team among users which spread through word-of-mouth. It might have lowered the willingness for future collaborations. Therefore, some serious problems might not be elevated or the best solutions to certain problems might not be found. This would be neither productive nor efficient. In some areas the business analysts might possess superior knowledge compared to the super and power users. At the same time it was not clear why the project team was so ignorant of what happened around them. Both sides though were too passive and only a few steps were taken to resolve the situation. This might have prevented more efficient and better collaboration. It also had a bad influence on the relationship between the business and the project team. 
After the on-site support phase it was still possible to reach the project team and ask for support in case of questions. This happened mainly by phone. Users called project business analysts to resolve problems, but this took mainly place between employees who knew each other personally.

The attitude during the GoLive support might have also influenced the ongoing support negatively. Questions might not have been asked that needed to be asked. This might have affected the daily operations negatively.

\section{Project success}

The project's success measures also included user feedback in form of training evaluations and user readiness surveys. The results of those surveys were positive, which contributed to the conclusion of having completed the project successfully. The project team manager explained:

"IOn a project level we measure success in] various ways. Firstly in terms of discussion with some of the primary clients, if you like those within the business, gain a view of people's perceptions. This is through the course of a project, were they comfortable, were they happy with the way things were proceeded, were we meeting there expectations. That was one mechanism. Through the training and the education. We got feedback from people's participation, follow people's participation to see if they feel comfortable, if they feel they were being given the right tools that they feel they would be prepared effectively. Those came all back very positively. And finally following the project, we completed a lessons learned survey where we ask a series of questions. We ask people for their feedback about what went well what did not go well, what were the opportunities for improvement and again those results came back as being very positive. So in those terms it was measuring the success through feedback." (Project Team Manager)

It might have yielded an incomplete picture of project success to only use the hard facts such as the evaluation questionnaires as measurements. User satisfaction was only partly assessed through the training evaluations. It also seemed that the project team thought everything went fine, but in fact the relationship between the business and the project team was bad. It might not have been visible to the project team in general, although some project members were aware of it. 


\section{Information exchange between business and project}

There were several mechanisms between the business and the project to communicate with each other and exchange information. First, there were the working relationships between employees on the project and business side. This installed a direct feedback mechanisms between the employees. Second, there were the biweekly meetings. However, the meetings were more of an informative character to inform the business of the project team's progress. Third, there were the official communication focals on both sides, who arranged meetings and were the means to request information from the other side. The focals were authorised to collect information from and communicate it to both sides in both directions. They were also responsible for communicating problematic issues to higher management levels on both sides to make sure actions were taken, if necessary. However, the business side felt they were able to express concerns, but the impact on the project side was little, because complains went into a bureaucratic process on the project side. Only in some cases the business thought their issues were taken into consideration, mainly as long as the issues were in line with the scope of this ERP implementation phase.

Similarly there was a large queue of RFCs which had not been addressed by the project team and the business had received little or no feedback regarding their status and progress.

"There are a lot of open RFCs for the last two years. We are not getting the input or exactly what we want, because they are prioritising RFCs. But if there are 20 RFCs and they prioritise 5 RFCS across 3 plants. We open the RFCs but we do not expect much happening from them." (User Supply Management)

"There are a shit load of RFCs, but not all taken care of. For the previous project] I issued 15 and got 4, for [the] December [deployment I shrunk it to 10 and got 4. So I understand the gymnastics. So now [for the next phase] I am only asking for 1 , only $1 . "$ (Director Supply Management)

However, there seems to exist and explanation why a lot of RFCs were not addressed, but it seems as if it had not been sufficiently communicated to business users, but mainly the business management. The reason seemed that the ERP system was supposed to be standardised across different sites of the whole organisation. Therefore, individual customisation could not be made at this point and had to wait as the project manager explained:

"I think the best thing we can do at this stage is to take the $80 \%$ and the functionality and get that working overall. Then work on getting the $20 \%$ 
improvement for everybody, because if you try investing on getting the $20 \%$ now for a small audience, then you do not get it done by three o'clock. Getting the $80 \%$ and then getting the $20 \%$ would be better." (Project Team Manager)

In some instances the business was successful to influence the project team, e.g. in terms of the overall deployment strategy. It was planned to implement the ERP modules for a specific product program, but the business resisted and made a counter-suggestion, which was ultimately taken into account.

"For the first deployment the first strategy was absolutely stupid. We made a counter suggestion to do make multiple small deployments. However, it was received at some stage. We were very successful in influencing the deployment strategy and the education content. We are still influential in terms of change management and data cleansing." (Director Supply Management)

The project team appeared to be quite unresponsive to users In terms of RFCs. This might have caused users to think that the project team was neither interested nor willing to work for their needs. RFC issues and feedback were not made clear enough to users. This annoyed and frustrated the users. It could be that necessary system changes were not made, reducing the users' productivity. On the other hand, working on individual RFCs before the complete deployment might be a waste of time and resources as they need to be standardised. Otherwise it would have defeated the purpose of one integrated system.

It was beneficial for the collaboration that the project team took their suggestions about the deployment strategy into account. The business might have been more motivated to work on a strategy where they had been involved in the development compared to one that had been imposed on them. It might have also showed the business side that the project team could be responsive. It did not seem to take that much effort to actually collaborate on the strategy development, but the effects were very positive. In general, the used language indicates that the project team did not have a good reputation among the business. Such language in the communication with the project team might also have caused the project team to retreat, especially considering it was the change leader and director of the most affected function. However, not every business member was as vocal as he. The use of language might also indicate that the strategy change was not seen as a collaboration effort to the benefit of both sides, but a victory over the project team. This would indicate a more competitive attitude. 


\section{Conclusion}

The project team took user input and feedback into account to a feasible degree, mainly as long as it was in line with the overall deployment strategy. Additional wishes that the users expressed were often not addressed, which caused frustration. Explanations about the reasons seemed to be missing.

The project team members' feedback was collected and compiled into a project review together with lessons learned. However, among the project team staff there was the feeling that lessons learned were not followed up and things stayed the same instead of being improved. Project team members wished to have received at least some kind of feedback from their management.

Regarding the support, the project site perceived that there were not many questions although there actually were. The business was frustrated with the project team's support process. However, issues were mainly hold back rather than being exchanged and solved.

User feedback was collected for training and education. The ability to evaluate was perceived positively, but trainers were missing the follow up, which was due to a misunderstanding.

Bidirectionality has shown to be an element that influences the perceived quality of the communication process between individuals and groups. If feedback is missing, uncertainty arises leading to resentment and frustration ultimately. In the areas where user feedback was collected and used (for example to improve the training material) it was perceived positively by users. Therefore, bidirectionality was substantiated as an element of communication quality.

\subsubsection{Balance of formality vs. informality}

Various communication media were used for formal communication. There were meetings where the business and the project side were present. During those meetings presentations were delivered. Another formal communication mechanism was the two official communication focals who coordinated the communication flow between the business and the project team. 
Next to formal means, a lot of communication took place through informal ways such as the working relationships, phone calls, and casual conversations. Overall, informal communication was found to be more effective in a lot of cases than formal communication, especially because of time constraints.

"I believe the [functional business] manager sent an email thanking us for the
effort. [...] It is informal. There is an official document that is supposed to be
sent out to the business, requesting them to respond to it, if they are satisfied
with our approach of communication. That is a document I was told to
implement, but honestly I never had time to do it. But it might not get formally
answered anyway, because there is so much to do in the deployment, that
spending hours in that kind of formal communication is neglected. We take our
communication serious, but more on a personal level." (Business Analyst
Production Planning)

During the on-site support phase after GoLive, a formal process was implemented to manage support requests from business users to business analysts from the project team. Users were requested to exactly follow command chain and consult their manuals, peers, and super users first, before they forwarded the question to a business analyst from the project. The director of Supply Management remembered it to be even more complicated in a previous project:

"[The previous project] was terrible. You had to put a little flag on your desk and then someone might see that you have a question. For Christ's sake, just walk around the aisle and answer questions. And manage the hierarchy of super user, power user, and BAs" (Director Supply Management)

In most cases users received support from their peers in the business, but ongoing support from the project team was available. It took mainly place through phone calls. In most cases this happened between employees who know each other personally.

"They still call me, because they now me." (Business Analyst Design)

"If we have problems I call the guy [in the project team]. I know him." (Business Analyst Design)

"The end users have access to ongoing support. They can call us all the time. We never say no to them. I always find the answer for them." (Business Analyst Master Data)

Too much formality can make communication cumbersome. Relying too much on informal communication can be risky as it might not happen at all. In order to improve the 
communication between project team and business it might be necessary to reinforce some formal, communication mechanisms as people might not be willing to collaborate informally anymore. If certain formal communication was not reinforced, the overall communication quality might decrease, because some people would lack information (completeness). Informal communication might also decrease in a bad relationship. Less communication would increase uncertainty worsening the relationship. It is a vicious circle. In order to break it, it would be necessary to work on the relationship, build trust, and reinforce formal communication at first. In a good relationship with good collaboration the use of informal communication might increase again as it offers flexibility and is often faster.

\section{Conclusion}

The communication between the business and the project used both, formal and informal means. Informal communication seemed to appear more often than formal communication and was found more effective. It was found that too formal communication complicated the collaboration, such as the support process. Therefore, the balance between formality and informality was found to be an attribute that influences communication quality.

\subsubsection{Communication quality conclusion}

Overall, evidence was found for all nine proposed attributes of communication quality and it was possible to substantiate them. Openness seemed to have a strong relationship with communication quality. Where the communication was not open as between the project team and the business in meetings and about problems, the communication quality was low resulting in such negative effects as frustration and resentment. In areas with open communication, collaboration worked better and the results were better too. Openness seemed to be related to bidirectionality as well, because the lack of openness also inhibited the mutual message interchange, thus decreasing bidirectionality.

Audience adequacy was considered a lot by the Change Management department of the project team in the area of training and education as well as the general promotion of the project. This seemed to have facilitated user buy-in and the motivation for the project. 
Bidirectionality impacted communication quality in regard to missing feedbacks from the project team to the business. This resulted in higher ambiguity and frustration on the business side. The lack of bidirectionality in the organisation seemed to have been independent of the use of formal or informal means of communication between the project team and the business. The project team was not providing feedback on officially issued RFCs. Similarly the follow-up of trainer evaluations and lessons learned was problematic. Informal communication was the main medium, but took place mainly between employees who knew each other. In other cases the business sometimes found it difficult to reach the person they wanted to within the project team. A lack of openness was correlated to lacking bidirectionality. A lack of both attributes during the On-site support phase prevented effective problem solving and support in general. However, there were instances when both sides collaborated, exchanged information, and the bidirectionality was high, for example during the data cleansing and conversion. This led to better results and was perceived to be beneficial by employees on both sides.

A balance between informal and formal communication means seemed to have been a factor influencing communication quality. Informal communication was often perceived as less complicated and time consuming in an organisation where time was a scarce resource. Formal communication mechanisms such as biweekly meetings or presentations were regarded as important as well by both sides, especially the business side. A lack of accuracy, bidirectionality, and openness seemed to occur independently from formal or informal communication mechanisms. This was an alarming sign that was also mentioned by the Change Management department. The problems did not seem to be the channels or means of communication, but to be internal.

Users perceived it as positive to receive communication that was more complete. This reduced ambiguity whereas incomplete communication caused the opposite and resulted in frustration.

Credibility was substantiated as an attribute of communication quality. It was highly evident in the communication from the senior management to users as well as from the power and super users who were involved in the project team. This was positive and fostered user buy-in and involvement. On the other hand, the project team provided inaccurate information in some status meetings or hid information. The credibility of the project team declined as a consequence, which also impacted the credibility of the project 
team's communication to the business in general negatively. This also showed that credibility was interrelated with openness and accuracy. The project team lost the trust of the business. The quality of the relationship between the two entities decreased accordingly.

Inaccurate information from the project team during the communication led to frustration and resentment on the business side. It reduced the trust in the project team and weakened the relationship. The opposite situation, i.e. being provided with accurate information is usually regarded as a standard. Therefore, accuracy is usually not specifically mentioned or highlighted as something that increases communication quality. It is taken as a prerequisite and only becomes a problem when it is lacking.

Purpose adequacy was found to be an influencing attribute of communication quality. Users received the communication they needed such as the training that built their system understanding and allowed them to carry out their daily tasks. Users also received communication in forms of promotional items which served the purpose facilitating user buy-in. This worked well. Purpose adequacy also showed interrelationships with bidirectionality, audience adequacy, and openness. When the training and education plan needed to be changed, the project team and the business collaborated showing increased bidirectionality. The same was true in the case of updating training material after the users gave their feedback. After the changes had been made the users found the training and education material more adequate for the purpose of learning and understanding. This collaboration showed that higher bidirectionality and was positively related to higher purpose adequacy. The link to audience adequacy became evident in the selective communication of benefits to users by the senior management. The senior management avoided communicating or emphasising certain aspects such as cost reductions in order to avoid fears among the audience end users. In that sense, "hiding" information rendered the communication more adequate for the receiving audience and the purpose of facilitating support for the project.

Timeliness was confirmed as an attribute of communication quality. However, timeliness appeared to have different elasticity in different communication areas. In terms of the general communication between the business and the project team, it was seen as a problem by the business. The business reacted negatively to even slight deviations in the timeliness. This also increased over time. With a lack of openness or a decrease on the side 
of the project team, the business received information later than they wanted. This points to a link of timeliness to openness. On the other hand, the users' reaction to the timeliness of the training showed elasticity. Some training sessions were not conducted at the most optimal time, but most users still perceived it as good. In general, timeliness might have been lightly related to openness.

Overall, all nine attributes were confirmed. However, they did not all influence communication quality equally meaning they might have different weightings of importance. Moreover, interrelationships and co-occurrences were found among different attributes.

Figure 7 shows the co-occurrences of communication quality attributes. The figure only shows how often certain attributes occurred at the same time. It does not show interrelationships. These are depicted in Figure 8.

\begin{tabular}{|c|c|c|c|c|c|c|c|c|c|}
\hline Code System & Formality us, informality & Bidrectionality & Audience Adequacy & Openness & Timeliness & Purpose adequacy & Accuracy & Credibility & Completeness \\
\hline Eormality us, informality & & . & . & . & ' & . & & ' & · \\
\hline E. Bidirectionality & ' & & - & ! & - & 国 & - & घ & ! \\
\hline Gi Audience Adequacy & . & ! & & & 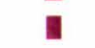 & 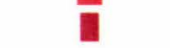 & & घ & ! \\
\hline Eir Openness & - & च & & & - & - & - & - & \\
\hline G Timeliness & - & - & - & - & & 国 & & . & 【 \\
\hline E Purpose adequacy & - & T & ] & - & ] & & & a & 1 \\
\hline E Accuracy & & $\cdot$ & & , & & & & & \\
\hline Ex Credibility & - & ! & - & . & - & - & & & I \\
\hline (E) Completeness & , & - & - & & च & - & & I & \\
\hline
\end{tabular}

Figure 7: Communication quality: co-occurrences of attributes 


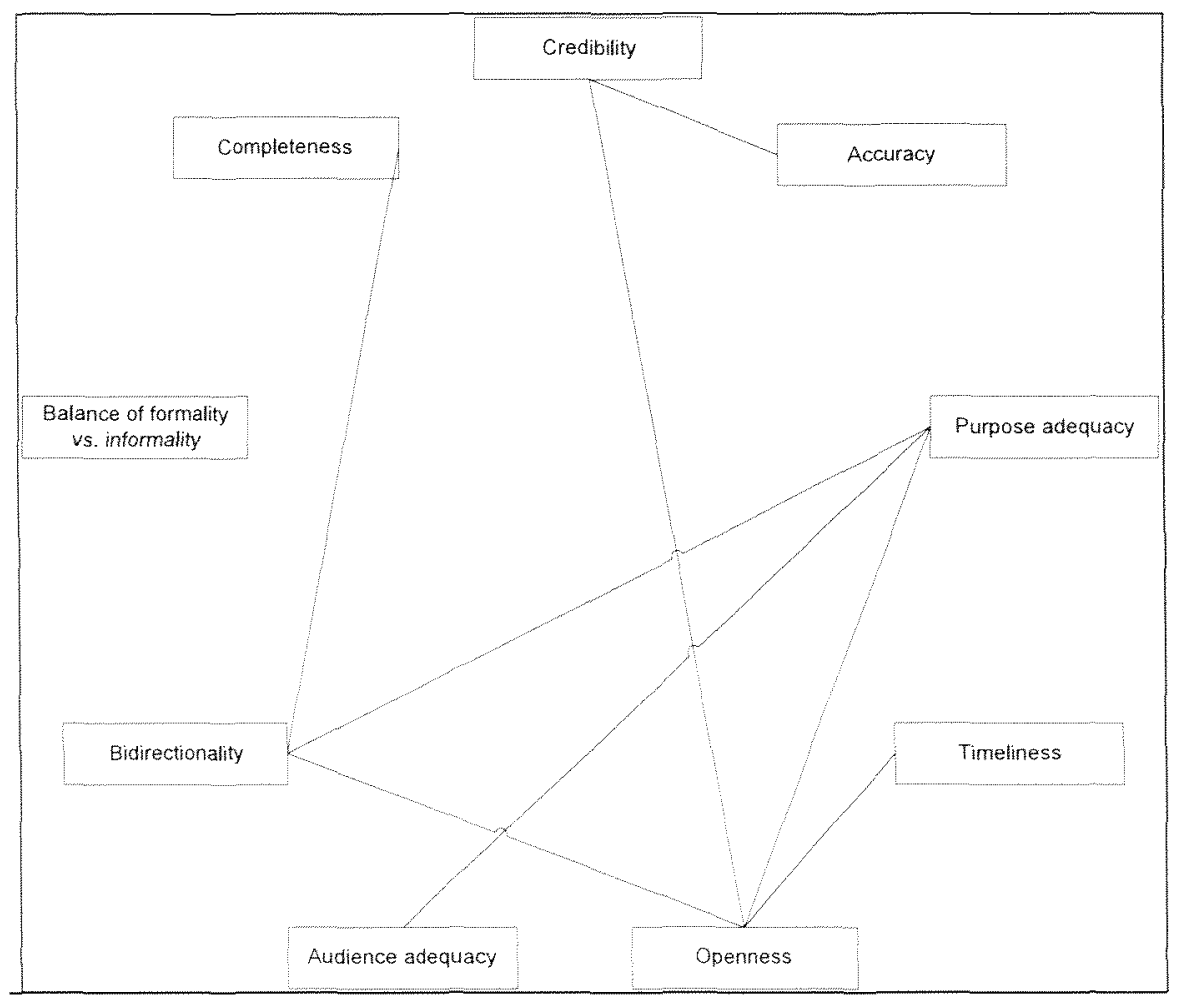

Figure 8: Inter-relationships of communication quality attributes

\subsection{ERP Project success}

The following section contains the findings regarding the construct ERP project success within the three main categories of project efficiency, impact on users, and business benefits.

\subsubsection{Project efficiency}

Project efficiency represents a short-term measurement of project success that is focused on the efficient management of the project itself within its resource constraints. In this study the resource constraints are budget and schedule.

\subsubsection{Budget}

The project's success was evaluated on the measurement "on budget". The project team had one of the largest budgets within the whole organisation at its disposal. The module of this implementation phase was delivered on budget in terms of overall dollars that were spent. 
"In terms of overall dollars we spent we were on budget." (Project Team Manager)

However, employees, mainly on the project side, did a lot of overtime, but they were paid for the overtime. So it was probably considered in the budget calculations.

During the project the overall expenses and expenses for specific activities were measured and monitored. The project team utilised EVA (Economic Value Added).

Employees usually received the equipment they needed to perform their tasks when they asked for it. However, receiving more staff was difficult. First, there was a hiring freeze. Second, new people would have been unskilled and would have needed to be trained in project skills. This would have decreased the project team's performance, because the key resources who could have trained them were needed to work on the project. Third, for some tasks in the project it would have not helped to add more people, because some tasks can only be performed by one person at a time anyway, for example working on a certain data object. Fourth, the best potential staff, which the project team would have liked to have, were also needed on the business side. The project team members were told so and knew about the difficulties to receive more staff. Also budget reasons were often used as justifications for not increasing the number of project team members.

The project team often used budget and resource constraints as justifications why certain RFCs were not done or requests of the business were not granted. However, the business side did not believe this and thought the project team was badly organised and aligned.

"I think they [the project team] have way too many resources. I think they are poorly aligned and they are not efficient internally in the decision making process, in the alignment. It is a very blurry organisation to understand. They do have sufficient resources. I am pretty sure about that." (Director Supply Management)

This area showed a lack of openness in the communication, because the project team did not tell the business side the true justifications, but used the budget as a reason. However, this might have actually contributed to keeping to the budget, because the justifications prevented further spending. On the other hand, it reduced the perceived quality of the communication on the business side. 
Overall, the influence of communication quality on the ERP project success component "budget" might have been small and maybe even slightly negative, because the lack of openness might have helped to keep within the budget.

Possible implications might be that the project team might have reached a decision point. The upcoming projects could have been probably done with the current staffing, but with a high degree of utilisation. This might have caused stress for the project team members. The high degree of utilisation might also have left no time for knowledge transfer from key resources to new or other resources. In that case the statement of the project manager "We need to do the knowledge transfer in a more effective manner." might have been a lip service. An alternative might have been to delay the upcoming rollouts to reduce the pressure on the human resources and create an option for knowledge transfer. Otherwise the project team might run the risk of burning out their key resources for which they had hardly any shadows. A drop out of a key resource might hit the upcoming projects much harder than a slight delay for upcoming rollouts.

Both sides did not seem to be informed enough about the activities on the other side. The project team was overworked, but the business thought the implementation did not progress fast enough and that the project team was not using their resources efficiently. It was unclear if the project team was aware of this perception on the business side, but if so it might have caused the project team to be unresponsive to the business. Therefore, the project team might have reduced the communication and collaboration, because they thought their work was not appreciated.

\subsubsection{Schedule}

Overall the ERP initiative in the organisation had taken longer than originally expected. However, the module that was subject of this study was delivered on schedule. Delivery on time was one of the organisation's internal project success measures and it seemed to be the most important measurement.

The project was planned backwards by starting to set the delivery date and then planning the necessary activities. The project followed an aggressive schedule in which project employees did overtime (up to 30 hours per week) to deliver project on time. The staff were scheduled for seven days a week for four months. 
"There was a lot of pressure regarding the schedule. That was a problem. It was a big mistake to schedule for 7 days a week." (Business Analyst Supply Management)

"I do not find it human to for a person to work every weekend for 4 months. It is not human" (Department Manager Data Cleansing)

There were cases where project members informed their management that it might not be possible to finish certain tasks. In those cases so-called "work-around solutions" were found meaning a laptop to work from home during the night.

"If I tell [the project management] that I won't be able to make a deadline or to a manager that I need a resource, they will usually find a "work around solution". How will you achieved the same result (deadline)? Can we add a night shift, can we provide you a laptop so you will be able to monitor your job from home during night." (Programmer)

Team members were asked to reduce their holidays or being on call during their holidays. The project delivery cost the project team members energy and created tension and stress. The project delivery mentality mirrors the product delivery mentality in the business where delivery on time was also highly important. Originally, most project team members worked in the organisation's plants and seemed to have taken the mentality with them.

Nevertheless, project team members were still very motivated to make the project successful. They found the project interesting and took it as a personal challenge. They wanted to master the challenge and found it helpful that their management stayed with them during the overtime.

It might have been risky to start with the setting of the delivery date a plan backwards. At that time a lot of uncertainty existed. The schedule was tight, maybe too tight. Consequently, after the project was well in progress the scope needed to be reduced to deliver the project on the envisioned date.

The project team members worked with a lot of uncertainty. There was high pressure on key human resources. If one key resource dropped out, the whole project would have been in danger. However, the organisation's competitor did not wait and the organisation was already late in terms of ERP adoption. Therefore, there was pressure on the organisation to implement the ERP system as fast as possible to survive in the market. It was a challenge to do this with minimal resources and led to a high degree of utilisation. A temporary extension of resources might also not have helped, because training those resources had 
taken capacity from the project team. It was fortunate for the organisation that the employees showed such high work ethics and were willing to give as much as possible and necessary. The employees liked their colleagues and appreciated the atmosphere in the project team. There was also a high degree of identification with the organisation. Without that, the organisation might have run into problems.

In order to ensure that the project stays on time activities were broken down and time periods allocated to them. So it was exactly known how much time was needed for a certain task. It was possible to continuously check if the project was on track. Change management activities, for example, were managed with MS Project to monitor progress and completion of activities.

The business side had a slightly different opinion about the schedule. They actually would have liked to see more aspects of SAP delivered faster to carry out their daily tasks. They would have preferred to reduce switching between so many different systems.

"I like to see the SAP modules turned on, rather than having legacy system performing on the side." (User Quality)

Moreover, they wished that system bugs could have been corrected.

The business senior management was mainly informed about schedule-related issues through the biweekly meetings which were also supposed to keep the business informed about the project's status and progress. The main tools to inform the business about the schedule and progress the scorecards presented in the meetings. Those cards were also circulated among the business management. The scorecards were sometimes sugar-coated and did not reflect the reality. This created frustration and mistrust on the business side. The senior business management also had an insight into the project planning of the project team. Middle management and employees had less insight. If the middle management on the business side and the communication focal requested to be informed about progress of activities, the project team's answers were perceived as vague.

The project team's communication in the form of the scorecards showed openness, but lacked accuracy. In terms of planning activities, the project team lacked openness and the answers were vague or did not exist showing a lack of bidirectionality. This reduced the communication quality. 
During the cause of the project it became evident that the project team would not be able to deliver everything on time. Therefore, there was communication between the business and the project team about de-scoping the project, because there were problems in two aspects. The project made recommendations to the business on which parts to de-scope and the business accepted those recommendations.

"We had some issues on the implementation of the [aspect one] and [aspect two]. We had to make the decision if they would be in or out of scope. We present to them [the business] a recommendation and they decided to take away some parts of [aspect one] and some parts of [aspect two]." (Business Analyst Business Processes and KPIs)

In this area the communication showed bidirectionality. The result was a better collaboration and a higher perceived communication quality.

The project planning missed transparency which was not good for the collaboration. In a collaborative partnership efforts are supposed to be achieved together. Better communication and better communication quality, between the business and the project team could have led to more accurate planning, amore efficient use of resources, better deployment strategies, a more accurate schedule and better positioned activities. If both sides had been better informed, it might have fostered collaboration. That would have reduced uncertainty among business employees and project team members and might have improved the relationship.

\section{Conclusion}

The project team delivered on time after the scope was slightly reduced. The business senior management had insight into the project planning to a certain degree and was informed the progress. This showed openness. However, the communication regarding the progress was inaccurate. The score-cards did not always reflect reality. The project team wanted to solve the issues themselves and answered requests by the business middle management and users only vaguely. In this sense the communication lacked bidirectionality. However, when it was necessary to decide about de-scoping, the communication showed bidirectionality and had a positive effect on collaboration and delivering the de-scoped version on schedule. The project was delivered on the envisioned delivery date and was regarded successful in this regard. Overall, communciation was only moderately open and bidirectional, and also inaccurate. Therefore, the influence of the 
communication quality attributes on the ERP project success component "schedule" seemed to have been minimal.

\subsubsection{Project efficiency conclusion}

The project was delivered on budget and on schedule. It was considered a success in this regard by the organisation. Evidence was found for the communication quality attributes of openness, accuracy, and bidirectionality in regard to project efficiency. In terms of its occurrences, openness seemed to have the strongest relationship with project efficiency regarding its occurrences (see Figure 9). However, the actual influence of those communication quality attributes might actually have been minimal.

\begin{tabular}{|l|l|}
\hline Code System & Project Efficiency \\
E Formality vs. informality \\
E Bidirectionality \\
E Audience Adequacy \\
E Openness \\
E Timeliness \\
Eurpose adequacy \\
E Accuracy \\
E Credibility \\
E Completeness
\end{tabular}

Figure 9: Occurrences of communication quality attributes in relation to project efficiency

\subsubsection{Impact on the users}

This section presents the findings in regard to the dimension "impact on users". This includes how well the ERP system meets the technical and functional requirements in the opinion of the users, the level of user satisfaction, and if and how much the users are using the system.

\subsubsection{Meeting functional and technical requirements}

The following passage portrays the findings on how well the ERP system met the functional and technical requirements in the opinion of the users. The passage is subdivided into three areas. The first area shows if the systems rrequirements were found in collaboration between users and developers. The second area explores if the systems was meeting the users' needs and which gaps existed. The thirds are presents if and to which extent performance indicators were in place and used. 


\subsection{Requirements finding in collaboration}

In general, the business side was highly interested in the project and its success. The business was motivated and users wanted to participate in the project. There was the willingness to collaborate with the project team. In most functions the collaboration worked, in some better than in others. The best collaboration was found in Supply Management where most participants had the feeling they worked as one team. This had positive effects on the end result, for example on the accuracy of system data as explained by a business analyst from Supply Procurement:

"We worked together with the project, really all worked together as one team. There was a lot of communication between these two departments [in the project team] and the business. That helped a lot. It made the data more accurate."(Business Analyst Supply Procurement)

The project team/change management conducted a user survey to capture concerns before the implementation project started. These were then addressed in most cases. This shows an indication of bidirectionality. During the project, the project team took feedback from the business only sometimes into account and only to a certain degree. Explanations and feedback were missing.

"Feedback it taken sometimes into consideration [by the project team], but not all the time." (Business Communication Coordinator)

In this area communication lacked bidirectionality. Consequently, frustration came up on the business side. In some areas, for example regarding project problems, the business side wished that there had been more collaboration with the project team. This also shows a wish for more openness.

The interactions from project team members to users were mainly through the business analysts as well as the power and super users and their working relationships, i.e. they worked in the same function, but one party in the business the other one on the project side. Business users participated in this way in the project. In general, communication between the two parties took mainly place via email and phone. The business users also performed the cleansing and delivered them to the project.

Generally, the project team contacted ordinary users only in specific cases and took their input into account as far as it seemed feasible showing bidirectionality. The project team appreciated the work of users and super/power users. 
Super and power users as such were more involved in the project. Super users were, for example, asked about processes and potential impacts in a lot of cases. This represents bidirectionality.

"Yes, I was asked about how new processes would affect the work in our department. First off all they would see how our group, the analyst unit within [Supply] would be impacted, e.g. if our workload would go higher. Then they looked at the store men would have to do, if they would be impacted in any circumstances. That was mostly for the transactions." (User Supply Management)

In addition, there were special collaboration activities between the business and the project team to plan cut-over activities around GoLive. Project team members went to the business and vice versa.

In the collaboration process the influence of communication quality on the ERP project success component "Finding requirements in collaboration" seemed to have become evident. A higher degree of bidirectionality and openness seemed to have led to better collaboration potentially facilitating success, whereas a lack of openness created slight frustration indicating an aggravation of the project team - business relationship.

It might have made users felt taken seriously to work together with the project team and find the requirements in collaboration. Users participated and this might have fostered user involvement and user buy-in. The collaboration might have led to better results and satisfied both sides. The system was more oriented to the users' needs, which might have had a positive influence on the attitudes towards the system and the work attitude. The collaboration also seemed to have led to a smoother cut-over. In contrast, frustration occurred in areas where collaboration was lacking. However, there needed to be limits to the extent of user participation to keep the requirements determination process feasible.

\subsection{Meeting the users' needs and the existing gaps}

In general, the users were happy with the new system, although its performance was sometimes slow. This caused a little bit frustration. However, in general a lot of tasks could be performed faster because previously manual tasks were automated.

The users were still in the learning and discovering process as the director of Supply Management described: 
"How can anyone understand the full capabilities? Keep in mind that is fairly new here. We were not part of the first deployment. For a lot of people started working in SAP in March 2005 with the [previous implementation module]. For them it is not even a year old. I think they start to understand the capabilities, but do not fully understand them yet."(Director Supply Management)

Sometimes users found functionalities in the system that they thought did not exist. The exploration of report functionalities was still in the early stages, because of the level of awareness of what was possible to retrieve and how to retrieve it. Another reason was a slight confusion which data were available and which part of what program was completely covered in SAP.

Most users worked with SAP and the legacy system at the same time, because their tasks were scattered across the different systems. The users were told to work with both systems, e.g. look up information in SAP and enter data in the legacy system.

"People look things up in SAP and enter data in [the legacy system]. That is the process we tell them." (Business Analyst Master Data)

This demontrated the attribute of credibility. It might have increased communication quality, because it reduced ambiguity and uncertainty for the users.

The switching between systems increased the workload slightly, maybe slightly more difficult, because one additional system was added. It was different in some cases, because it also changed workflows, but overall most users perceived their jobs as basically the same compared as before. Users virtually never used the legacy system for tasks that could be done in SAP though. The majority of users also saw the benefits of the new system and imagined the long term benefits.

"The system is a good thing for the future."(Trainer Supply Management)

This positive attitude towards the system might have been rooted in the training and education where users were provided with explanations. The training addressed several communication quality attributes such as completeness, purpose adequacy, timeliness, bidirectionality, and audience adequacy. However, the influence on the users' attitude is indirect.

The users would have liked to have the possibility to perform more of their work tasks in SAP. Therefore, most users wished the implementation would proceed faster. 
"I think we take to much time to implement it." (Trainer Supply Management)

The majority of users also would have liked to customise SAP more to their specific needs. Therefore, they issued RFCs.

"We will use the system with other software. We cannot use it as it is. We changed a lot of things in the vanilla basic setup. For [Supply Management] it is not used at $100 \%$ of the capacity, because the capacity planning is not what we wanted to do with it. We need a bit of development here." (Trainer Supply Management)

Another reason for the RFCs was that users would have liked to see errors and bugs in the system eliminated.

In a few functions there was a little bit resentment about having to use software that was not optimal for the task, but offered compatibility with SAP (for example, a special graphics software) and more benefits for the overall organisational efficiency.

The switching between different systems might have increased the pressure on the employees and their overall degree of utilisation. However, it might have been regarded as a challenge as well. It could have made users re-think all ways of work because they might have started to question themselves and the logic behind certain work steps. In this way it could lead to process improvements. In general, improvements depend on users seeing the benefits of the new system and are willing to change. In this area it might have been a challenge because a lot of employees seemed to be very accustomed to the way the legacy system worked. They requested the same functionality expressed in the high number of RFCs. It would probably be a waste to try to re-create the legacy system in SAP, because it would prevent the organisation from capitalising on SAP's capabilities. It might depend on the employees' willingness to learn and the mindset change would need guidance to be successful.

Communication quality seemed to have influenced the ERP project success component "Meeting the users' needs and the existing gaps" through credibility, when superiors gave their employees clear instructions. In addition there might have been an influence through the training and the evident communication quality attributes there. All of this appeared to have had a positive effect on this component meaning the users' thought that the system largely met their needs and, regarding the gaps, they were aware of what was missing. 


\subsection{Performance indicators in place}

Key Performance Indicators were supposed to be developed from the beginning in 2003 on along with the rest of the ERP implementation project, but the KPI development encountered delays. Originally the organisation tried to create their own business warehouse data cubes instead of using SAP's standard ones, which turned out to be a highly complicated and time-consuming activity.

"There are some pre-existing cubes in there, finance or procurement, but our technical people did not chose to go with those cubes, they created their own ones. That is why it takes a long time." (Key Performance Indicator Developer)

In addition, changes in the organisational strategic direction on KPIs over the last few years had changed priorities in the KPI development process a number of times.

"So the idea was to measure each of the 5 mega processes. We came half way of it, because then priority shifted to another mega process. And then this was stopped in the second phase. In my opinion it was because of the new strategic approach of our CEO called "achieving customer excellence". It is really different. It will lead to a need for KPIs for sure, but there is a bit of confusion. We need to revaluate our KPI approach so far and see if we need to redefine our current way of approaching KPIs." (Key Performance Indicator Developer)

This shows the communication quality attribute of completeness, because the project team's KPI developer was missing information from the business on how to proceed with the KPI development. This caused uncertainty.

KPIs also were a new culture for the organisation.

"KPIs is a new culture for [the organisation]. They do know they need to develop all the measures, but the culture change is taking a while. In some areas they see the links in others they do not. In some areas they do not even realise that they do not see it." (Key Performance Indicator Developer)

Together with budget and schedule pressure KPIs became a minor priority at the time of the study and there was the feeling among users and KPI developers that KPI development was not particularly fostered by the organisation at the time and near future.

"There is nothing on KPIs for [the next project]. It does not seem to be important." (Business Analyst Business Processes and KPIs) 
A reason seemed to be to wait for complete deployment across all sites in order to develop congruent KPIs across all sites.

Nevertheless, there had been some KPI development. There were organisational high level KPIs and for the ERP project a number of mega processes were defined, each of them with a set of KPIs. although the development on those had stopped. But there had been hardly any KPIs developed for the employees' level and the majority of existing KPIs were not linked to each other.

"Indicators from different levels do not fit together. They should but they do not." (Key Performance Indicator Developer)

At the time of the study there had not been much capitalisation on SAP's standard reports either.

"There are heaps of standard reports in SAP we have not even looked at." (Key Performance Indicator Developer)

Users used only a few and simple performance indicators, often in the form of separate reports created outside SAP, for example with the old system or MS Excel. Consequently, it was difficult for the business side to measure the impact and benefits of SAP.

KPIs could guide employees because they provide feedback. This feedback could be used to change behaviours and work processes. This might have been missing and might have made improvements difficult. Changes might happen slower if at all. Missing KPIs and consequently feedback could have also created uncertainty and might have made processes and behaviours develop into the wrong direction. However, the standardisation of KPIs across all sites would be important because business processes were supposed to be the same across sites and so should be the KPIs that measure them. Otherwise there would be neither congruence, efficiency gains, nor the option of interchangability of human resources across different sites. It would have probably also been a waste of resources to develop KPIs earlier, because they could not be used for all sites and might have been discarded after complete deployment. The KPIs could have reinforced behaviours that might need to change again.

It might have saved a lot of time to use SAP's standard cubes and standard reports instead of building them anew. This time and effort could have been spent on other tasks. The 
whole KPI development process needs guidance and a consistent strategic direction in order to bring this part of the project on track.

Overall, the study only found a slight correlation between the ERP project success component "Performance indicators in place" and communication quality, because the topic of KPIs was of minor importance to the organisation. However, the development of KPIs might have been hampered by the lack of completeness in the communication. Therefore, there might have been a minor influence of communication quality on this project success aspect.

\subsection{Conclusion}

The majority of requirements were found in collaboration and the user's input was taken into account to a feasible degree. However, there was some feedback from the project team to users missing on the parts that could not be realised. This created frustration among users.

The communication through the working relationships worked well in general as well as the participation of the super and power users in the project team.

The system so far was not meeting the users' needs completely, because only parts of their daily work had been transferred to SAP. Users wanted to see more parts of their work in SAP meaning a faster deployment. They also wished to improve the current system and remove errors.

In some functions SAP was used together with compatible software which lacked some user-friendliness. The benefit for the whole organisation that was achieved by using that software had not been highlighted sufficiently to users. This caused that users in this functions still bemoaned having to use this software after four years.

There had not been much development on KPIs. There seemed to be confusion among KPI developers about the organisational strategic direction in terms of KPIs development. There were only some simple performance indicators available that users could use.

Overall, the attributes of communication quality seemed to have been an influence on the criteria "Meeting technical and functional requirements" through fostering collaboration 
and meeting user requirements better. Moreover, a lack of completeness might have hampered the KPI development.

Communication quality influenced "Meeting technical and functional requirements", especially through the attributes of bidirectionality and completeness as shown in Figure 10.

\begin{tabular}{|c|c|}
\hline Code System & Meeting technical and functional requirements \\
\hline 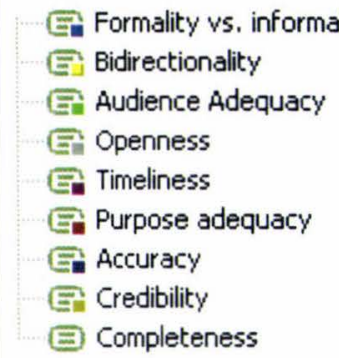 & $\begin{array}{l}\cdot \\
\cdot \\
. \\
.\end{array}$ \\
\hline
\end{tabular}

Figure 10: Occurrences of communication quality attributes in relation to meeting functional and technical requirements

\subsubsection{User satisfaction}

ERP user satisfaction is a multifaceted construct consisting out of satisfaction aspects related solely to the use and interactions with the system and the interactions and communication with the ERP project team. The following sections show findings for all variables related to both areas. The variables stem from Wu and Wang's (2006) ERP ultimate user satisfaction measure. However, communication quality is only suspected to show effects in a few of them.

\subsection{Perceived success}

The business side and project team perceived the project as successful overall and the best deployment so far.

"It was the best deployment we had so far." (Business Analyst Production Planning)

"For the 2005 deployment, I think we did very very well." (Director Supply Management)

The business was only slightly annoyed by the errors in the system. 
The education and training strategy, which included a lot, frequent, and various types of communication with users, was seen as a key success factor for the project by the organisation next to the senior management involvement. In most functions users were able see the first indications of benefits from the new system or at least imagined how it would help them in the future. They expected more benefits after bugs would have been removed and employees would have learned to use the system to its full capabilities. Users were aware that this deployment was only one part of the whole ERP implementation and were waiting for the complete implementation of SAP.

The success might have built the foundation for future deployments. It could have created momentum and could have reinforced a positive attitude about the system. The success was celebrated in a form of a dinner and medals for the project employees. It might have been difficult to celebrate it more because it represented only one part in the overall implementation and the whole ERP implementation was not finished. In addition, the competition does not allow them to rest on their laurels. Competitors already worked with ERP systems and derived benefits from them. The organisation in the study was only catching up to that, but they were on the right track.

Communication was seen as a key to success and communication quality might have been one aspect of it, but the influence was probably indirect. The detailed subsections show the influence of communication quality and how it is linked to project success.

\subsection{Overall satisfaction}

In general users were satisfied with the system.

"I think it is a very good system. I am very happy to use the system." (User Production Planning)

"I agree 100\% with the implementation of the new system." (Manager Quality)

Users would have liked to see more improvements to be made and more KPIs in the system. Users did not particularly like having to work with multiple systems at the same time. They would have liked more parts of their work in SAP. For some tasks users were happy to switch to SAP as it made them easier. Sometimes there was even slight enthusiasm about the possibilities of the new system. Some users also saw SAP as a chance to improve their own skill portfolio as the legacy system was not an industry standard but SAP was. 
"It is a beautiful machine and a beautiful project. It is an exciting time. It has tremendous benefits for the company and for the people." (Director Supply Management)

In general, the overall satisfaction was positive and there was hardly any system resistance. This might have made following deployments easier. It was beneficial that the users accepted and liked the system, because they were the people working with it everyday. They were also supposed to achieve the expected benefits. User satisfaction fosters the achievement of benefits, because employees might have been more motivated to work with a system they liked compared to a system they disliked.

Communication quality might have influenced the overall satisfaction with the system through the education and training program, but the individual sections below provide more details.

\subsection{System understanding}

This time background education was provided to show users the interdependencies between departments and processes. The education also gave an overview of the business environment and reasons for implementing SAP. This complemented the transactional training, which was the only type of training users received during previous deployments. In this sense the communication was more complete. This was received very positively by the users.

The users became increasingly aware which role they play with their work in SAP in the overall picture. However, they were still learning and in the process of overcoming the old mind-set of stand-alone legacy systems. Therefore, sometimes users forgot this in their daily work, but it was becoming better. Users began to see interdependencies in their daily work more and more.

"Yes, my job has a greater impact on other departments in the company since the implementation, because we are integrated and we have to share the data and make sure that the data between different functions is shared. [...] There are more interrelationships with other function with SAP that were not there before." (User Quality)

Users started to understand the negative effects a mistake could have on other departments and the ultimate production of the product. The management said that the "users climbed 
up the learning curve fast" and that "they were still discovering capabilities of SAP nearly every day".

User communicated among each other a lot and helped each other, for example in case they encountered difficulties and did not know how to proceed.

The education and training might have increased the users' knowledge and awareness. This might have fostered system understanding and might have made working with the system more efficient and productive.

Communication quality appeared to have influenced system understanding because a lot of the groundwork for understanding was built in the training and education sessions, the documentation, the project and power user support, and the peer to peer support. In all these activities communication was involved. The training and education was tailored to the audience (audience adequacy) increasing learning efficiency and retention rates. The training was also mainly timely, at least in acceptable boundaries allowing employees to be prepared. Senior management showed their support for the training - representing credibility. The provided training material and documentation was useful and contained the necessary information representing purpose adequacy. The support through power users also represents and element of purpose adequacy as it provided users with the information they needed at the given time. The peer to peer support through co-workers shows an example of a balance between formality and informality. This co-worker coaching was mainly informal, but very helpful. This was in addition to the formal support, which was used as well. This highlights a balance between the two types.

Consequently, there are indications that communication quality migt have influenced the users' attitudes and perception of the system and therefore facilitated the system understanding.

\subsection{Feeling of user involvement}

Overall, users were receptive to the new system. They received a lot of communication about the project and the system. There even was slight enthusiasm. Very few users felt the system was pushed onto them. But it was not seen as a threat. However, in general users had a light feeling of user involvement. The users were convinced of the system, but they regarded it more as a business necessity rather than a user-driven improvement. But they 
accepted and supported the organisation's decision and were willing to go in the same direction.

The whole business side and the users wanted to participate in the project. Some users wished they had been able to participate more.

\section{"I wish I could have been more involved." (User Quality)}

However, the project team involved users to a feasible degree in the form of power and super users. In specific cases normal users were consulted for their knowledge in certain processes.

"I was involved in the implementation. I am the only one who would know about the transactions. I was asked for my input." (User Supply Management)

Most users felt their input was taken into account by the project team. This shows the communication quality attribute of bidirectionality.

Users wished to have received the background education in earlier deployments. It complemented the previous transactional training showing the attribute of completeness. The senior management involvement and promotion was also well received by users and facilitated user buy-in showing the communication quality attribute of credibility.

The user involvement was sufficient, but could have been better. On the other hand, users were not resistant. This facilitated the implementation. Users were allowed to participate in the project to a reasonable degree. More participation could have actually complicated the implementation more than it would have helped. There might have been too many diverging opinions and ideas as well as too much input to process, which would have been complicated considering the human resource constraints in the project team. However, without the applied degree of user participation, the level of user involvement might have been much lower, which could have caused such problems as resistance. There was not really resistance to the system. There was neither the feeling that the system was imposed on the users nor that it was a threat. However, it was not fully embraced, but rather tolerated.

Communication quality might have influenced user involvement through the education and training, the senior management involvement adding credibility to the communication, and the power and super users facilitating bidirectionality. 


\subsection{Documentation}

The documentation for the new system was created in collaboration between the super and power users, the project business analysts, and change management. Some parts of the documentation were updated after feedback from the users that power and super users had collected showing the communication quality attribute of bidirectionality. There was a slight lack of time to make the changes and prepare the documentation. It was a challenge to ensure an excellent quality standard, but most users perceived it as adequate highlighting purpose adequacy Users thought it could be improved further though.

"The documentation was improved. It was good, it is not the best, it could be improved again, but it was better, but that is an ongoing process fixing something in training documentation and you understand something new than you change it." (Supervisor Supply Management)

There is a minor concern though, that users would have not received documentation if there was not another roll-out.

The users still referred to the documentation and also still accessed the training environment from the e-learning courses. This was becoming less though.

"I still refer to the training documentation. Everybody still refers to the training documentation." (Trainer Supply Management)

Some users also created their own documentation to complement or in one extreme case to replace the documentation prepared by the project team and change management.

Communication quality became evident in the documentation. The overall quality of the documentation might have positively influenced the users' perception of the system and the project. The documentation provided the users with accurate information which was adequate for the purpose. It was also tailored in parts to the audience, at least per function, representing audience adequacy. The documentation also showed a high level of completeness even covering tasks that the users perform in their daily jobs. Therefore, they still refer to the documentation.

If the quality were not as high as it was it might have negatively influenced the perception of the system and the project. Users might have run into problems in their daily work. System resistance could have been the consequence. 


\subsection{Training}

The training was an important aspect of the communication between project team and business users. Therefore, this section examines in detail how different aspects of the training actually represent communication quality elements. The explanations, analysis, and implication are given along with the examples from the case.

A new education and training strategy was applied in this deployment. In addition to the transactional training there was an education on the overall processes and the background. This represented the attribute of completeness of communication quality, because users reported that this was missing in previous implementations. It might have facilitated the users' understanding. The education was tailored to specific levels in the business meaning there were different education programs for the senior management, the middle management, and users. The customisation for different levels shows the element of audience adequacy. The customisation might have increased the retention rate and facilitated the learning and understanding. The original education and training plan was perceived as massive by the business in terms of how much time it required. Therefore, it was slightly modified, but users still found it acceptable and good. The business did not find the original education plan adequate for the situation. After the changes the material was perceived as good and helpful for the tasks at hand, representing the element of purpose adequacy. The fact that the business suggestions were taken into account shows bidirectionality.

The senior management conducted the opening and closing session of the education program to show their support for and involvement in the project. This gave the communication credibility. The change management department designed the education sessions quite interactive, with discussions, role plays, and presentations with questions and answers. This customisation of material to the receiving audience symbolises audience adequacy. It might have positively impacted on the perceived quality of the communication. The users reacted very positively to this design and gave positive feedback and high scores on the education evaluation sheets. The fact that the users' feedback was collected shows that the communication took place in both ways. It was received positively by the users that there was the chance to give feedback which seemed to have increased the perceived quality of communication. This shows the element of bidirectionality. 
The transactional training for users was delivered by super and power users, which had been trained by business analysts of the project team and change management.

"Before the training started there was something called "train the trainers". I spent a full day with them. I explained differences between [the legacy system] and SAP." (Business Analyst Production Planning)

"I received SAP and trainers training. We had some training on high level processes before the drop" (Business Analyst Design)

This gave the training communication credibility.

Most of the users were satisfied with the knowledge and skills of the trainers.

"The expertise of the trainers and their ability to do the training were really good. I received both transactional and mega processes training." (User Production Planning)

A little problem was the availability of suitable trainers. Some functions had to rely on trainers from other functions. Consequently function specific knowledge was sometimes missing, but users perceived it as a minor issue.

In the training environment, it was tried to simulate the real working environment as close as possible. Therefore, real part numbers and names were used. In general, users felt the training covered in most parts what they needed to know for GoLive. By simulating the real environment it was possible to prepare users much better and they were more prepared to carry out their tasks in their jobs later on. The training environment was found to be more helpful than abstract parts and numbers in previous implementations. Therefore, this highlights the element of purpose adequacy.

The training material covered the "why" next to the "what" in terms of what users need to do during the transactions. Users were happy about these additional explanations, representing the communication quality attribute of completeness.

"The training material was really good compared to the first drop in 2003. It was delivered in time, the quality is good. The process and background education was high quality. There has been a good progress since the beginning." (User Supply Management)

A few users wished the training material and the amount of training time would have been more individually customised as tasks even vary within a department. However, it was a question of feasibility to not create such customised training material. Customisation is an 
indication for audience adequacy. Although the desired level of customisation did not take place here, the degree of customisation (per department) was perceived as good, actually better than in previous implementations. Again, this shows the attribute of audience adequacy. It did not seem to be necessary to reach a $100 \%$ fit, but a reasonable degree of audience adequacy seems to have a beneficial impact. Some users also made suggestions on how to update the training material and it was taken into consideration in some cases. Taking the users' feedback into account demonstrates the attribute of bidirectionality.

Some parts of the users training were conducted a long time before GOLive, because of resource constraints (trainers needed in their everyday functions at that time) that did not allow for a contemporary application of the training. However, users did not perceive the early timing as a major problem. Also users wished to receive some form of advanced training a while after GoLive to build on their experiences and knowledge of the system that they gained in using it everyday.

"I think employees had the right amount of training. But what they need is an advanced course after a few months working with the new system. We should go back and show them more aspects. That would be very helpful." (Business Analyst Design)

The timing of the training symbolises the attribute of timeliness. However, as discussed earlier, it seemed to have an influence on the perceived quality, but not as much as expected. The attribute of timeliness displayed quite an elasticity.

In general, users were provided enough time to participate in the training session, but they were not always informed about the purpose of the training by their superiors. So they arrived confused at the training session.

"The break in the command chain is hard to identify, but it is probably at the mangers or supervisors level to employees. A concrete example is that employee level is that people arrived at the training and said:" I am not sure if I am supposed to be here. I got a call and I thought it was a mistake." (Change Management Coordinator)

This embodies the attribute of credibility. The information lacked some credibility and completeness in this specific situation. This caused slight confusion which reduced the perceived communication quality. 
The training prepared the users well. It made them proficient and confident in using the system. It increased their trust in the system, because they were mainly aware of what it could do and they knew how to do it. This facilitated the positive attitude towards SAP and the belief that it was the right choice for the organisation. With a lower training quality they might have felt left alone with the task to cope with the system. It might have also given them the feeling that the system was imposed on them. This could have built system resistance. These negative effects were avoided and the positive aspects supporting the implementation were achieved instead. The system's complexity (an integrated system) also made it necessary to educate and train users on the overall processes in order to harvest the full benefits from the system in the future. Users needed to understand that their individual actions had an impact on the collective organisation.

Overall, the high degree of communication quality seemed to have facilitated the training and the users' understanding, thereby influencing user satisfaction.

\subsection{System integrity}

The business units performed the data cleansing and delivered the data to the project team. At GoLive the data accuracy in SAP was good, but most users thought it could have been better. Users began to see the benefits of having the data in a central place and being able to share it. The access to master data was restricted though to decrease the risk of data quality losses.

"We were able to convince the business to cut down the number of people who have access to Master Data in the integrated system order to avoid errors and increase data quality. Previously more people had access and that resulted in problems." (Business Analyst Material Master Data)

At the same time the data in the legacy systems was running out of date as more tasks were transferred into SAP, but this reinforced the need to use SAP instead of the legacy system.

Accurate data is one of the most important aspects in an integrated system, because the data is used in all areas of the business. In addition there are data dependencies and it might result in problems if some data are wrong. An error is not confined to one section as in a stand alone system, but it has impacts virtually everywhere. Therefore, there was an emphasis on data accuracy and system integrity. 
Communication quality is unlikely to have a direct effect on system integrity. Indirect effects could have been that a high quality of communication facilitated better collaboration between the business and the project team during the data cleansing activities.

\subsection{System flexibility}

Users found that SAP provided them with more functionality options than the legacy system, which was received positively. Examples were, more flexibility in the search for parts by using an asterisk (*) character. Some part number changes were easier, i.e. when a parent part was changed, children parts were updated automatically which users had to do manually in the legacy system. Users were also able to create parts centrally which could be used by everyone in the organisation.

The organisation customised SAP and did not stick to a vanilla implementation, which is actually best practice in the industry.

"Considering the vanilla approach, there was a lot of customisation." (Director Supply Management)

The reasons were slightly unclear, but a lack of knowledge about SAP when the initiative started in 2001 was mentioned.

Users perceived the system as flexible, but not in the same way as the legacy system. Users still asked for functionality changes because they wanted a lot of functionality exactly like in the legacy system. However, the organisation tried to move away from customisation, because customised transactions required manual recording every time the system was updated, consequently causing high maintenance costs.

Users used SAP to do their work for the tasks that were in scope. There was only a minimal amount of performing in-scope tasks in the legacy system. Some extra applications (MS Access) were used to complement SAP and allow users to do their job in some cases.

"We have to do some work around solutions to be able to do our work. We are using an Access database to do the work that we are not able to do in SAP." (User Finance) 
In some functions work became a bit more complicated, because the system was perceived as not as flexible as users wished to (e.g. when negotiating contracts with suppliers) or it was perceived as too flexible (a SAP compatible graphic program).

There were positive and negative aspects in terms of system flexibility. The system can make work more efficient and help users. Users saw this which might have increased system acceptance and the willingness to work with the system in order to do their jobs well. The organisation did not stick to a vanilla implementation which might have caused problems. SAP captures the best practices of the industry. The users might have needed to be more willing to challenge their own assumptions and work habits to see if it was really the most efficient way of working.

It was positive that there was virtually no working around SAP through legacy systems. During the transition phase it seemed necessary that users used extra applications to do their job though. Yet, it could have also been a way to search for the easiest way. There was always time pressure which might have made it difficult to explore and learn how to reach the same results in SAP.

The perceived flexibility and nostalgic thoughts might have caused the high number of RFCs. It could have helped to have had better communication on RFCs and on the rationale behind the priority for complete deployment before improvements could be made. This additional effort on the one end might have reduced the project team's workload on RFCs on the other side. The business might have complained less about the missing feedback on RFCs, because it would not have been necessary. This might have enhanced the relationship.

Communication quality might have partly influenced the perceived system flexibility, which is an aspect of the overall system perception. If the training and education had communicated the flexibility better, it might have been possible to reduce the number of additional applications users had to work with. Users might have been more satisfied and happier with the system. Therefore, this represented an aspect of incompleteness. More complete communication could also have reduced RFCs aimed at increasing system flexibility, because the users would have known the circumstances and reasons for the situation better. 


\subsection{Usefulness}

In some areas users perceived SAP more useful than the legacy system. In other areas it was found to be more complex. It depended on the function, the job tasks of the individual user, and the degree of their work that was in SAP. Users found they were able to do more analysis and less clerical work. SAP took care of a lot of previously manual tasks through automatisation. Some users thought their job became easier, faster, and their work output more accurate. In a few cases users mentioned SAP allowed them to increase their performance.

"Yes, I believe the new system has enabled the employees to increase their own performance. Accuracy, speed, less clerical more analytical work. You can do more work per person to a certain limit, but it depends on the person. Some can others cannot. " (Supervisor Supply Management)

All this was appreciated by users, but they also mentioned that they were still in the learning process.

Users applied a few extra applications, because some tasks they needed to do for their daily work was not in SAP at that time. Most users would have liked to see more parts of their work transferred into SAP rather sooner than later.

"For everything that is in scope, we are working with the machine. Everything that is there, we are using it. Could there be more things to put into the machine. Yes, definitely and we would use it more." (Supervisor Supply Management)

The perceived usefulness might have influenced system acceptance and user satisfaction. This might also have created support for the project, which might be beneficial for future projects.

Communication quality might have influenced the perceived usefulness through the training which laid the groundwork for the users' proficiency with the system.

\subsection{Ease of use}

In general, the majority of users find the new system easy to use.

"Yes, the system is easy to use." (Director Supply Procurement)

"Yes, I think the system is easy to use. Everything is there. You can get the information you need. There is no need to call someone else." (User Quality) 
Most users said that it was a question of becoming more familiar with the different screens and interfaces. It was mentioned that users needed to think more when using the new system and know the basics of their job rather than just doing transactions as it was sometimes the case with the legacy system in the past. Certain transactions were also more detailed in the new system and required more attention. Users also found that SAP offered a variety of report possibilities that they were just starting to explore. Additionally, some work processes had changed because of the new system. The users were still in the learning process for all these changes.

"[Q: Is the system easy to use?] I would say, probably half will say yes, half will say no, but the half that says not will change their mind after 3 months after understanding and working with the machine. Then they will realise that it makes it easier and that it is not that difficult." (Supervisor Supply Management)

At the time of the study users said the new system was a give-and-take in terms of making their work easier, because they still worked with multiple systems. In fact, the new system sometimes made their jobs more challenging in terms of discipline, because SAP required the users to work in certain ways and sequences. This was different compared to the legacy system where steps could be skipped. Sometimes users felt the system was missing certain functionalities which held them back. Overall, the users expected a similar learning experience with SAP as with the legacy system when it was implemented in the early $1990 \mathrm{~s}$.

A higher perceived ease of use might have increased the users' confidence with the system and fostered acceptance. Users seemed to understand that it was a learning process and were willing to learn. This might have been a positive attitude for a positive perception of ease of use as well. If the perception had been negative and users had thought it was virtually impossible to learn the system, the perceived ease of use might have been lower. Users would have become frustrated and their willingness to learn had decreased, maybe even to a degree of closed-mindedness. However, the opposite was the case.

Communication quality might have influenced the perceived ease of use through training.

\subsection{Auditing and Control}

Users had a higher degree of visibility of their and others' work in SAP. 
"We are seeing things better in the system." (Business Analyst Material Master Data)

There also existed a few performance indicators, but they were often found to be insufficient and there were not enough. Therefore, users requested more suitable KPIs.

"I think the Material Master KPI is good. I think there should be more KPIs." (User Production Planning)

At the time of the study users used their own indicators with the data and options they had available, but often those were no complete KPIs. Standard reports and indicators in SAP were not used to their full potential either.

The senior management and managers had slightly more visibility about the work performance and progress of their employees, because of the new system. However, the senior management was slightly reluctant to emphasise KPIs or use KPIs much, because they feared it might have sent out a negative message to employees and created fears. In most cases though, the performance measures for employees had not changed, because the KPIs had not been developed at that time.

SAP's rigour and strict working routines fostered work discipline among users which was different to the legacy system where it was possible to find work arounds.

"The system is now more structured and you cannot bypass the system." (SAP Application Specialist)

All legacy systems were still in place. Only in some instances the access was blocked, but working in SAP was mainly encouraged by the senior management by highlighting the benefits. They underlined that SAP was the way to go and showed zero tolerance for using the legacy system. Consequently there was hardly any working around the new system through the legacy systems. This showed the communication quality attribute credibility.

The missing feedback because of the unavailability of suitable KPIs might have made it difficult to apply corrective actions. Therefore, it might have not been possible to optimise business processes and to improve working styles. However, the effectiveness of using KPIs as corrective instruments might depend on their perception among users. If they perceived it as a tool to assist them it would have been possible to improve processes. If users perceived it as a tool to control and monitor them, they might have shown resistance to using them. The corrective actions and improvements would be unlikely to be realised. 
It might have been that the management's fears were reasonable that the employees were not ready at the time. Therefore, it might have been sensible to withhold some information in order to avoid fears and confusion among employees.

It might have been helpful to take actions to make employees more comfortable with KPIs and start a culture shift. On the other hand, the apparently non-facilitating of KPI development might actually have helped with their acceptance. Instead of imposing KPIs on employees before they were ready consequently creating rejection, it might be the intention to let employees work with the system for a while first. After a while they would discovered themselves that they need KPIs and then their wanting to implement KPIs would be user-driven. This would ensure user buy-in.

It was positive that users used SAP in most cases most of the time. It showed how successful the promotion and the senior management commitment were. All those introduced light control mechanisms such as highlighting benefits and sanctions for nonuse. The users were consequently drawn to the good aspects and repelled by the negative aspects.

Communication quality might have influenced auditing and control through the senior management and the project's promotion. In this case, the communication quality was actually increased by withholding information. Although this might seem contrary to the aspect of openness, it actually fits into the concept of purpose adequacy. The users did not seem ready for the truth. Therefore, it was sensible to only provide them with the information that was necessary to fulfil the tasks at hand such as working with the system. The information was also incomplete in that sense. Moreover, credibility was seen to be important. Because the senior management did not communicate this information, it made the situation more bearable for users, because they were likely to believe the senior management's statements. It might not seem reasonable or logical to withhold information to achieve something, but it would have been much more difficult to achieve user buy-in when all the information had been communicated.

\subsection{System stability}

The system was usually stable and reliable during the daily work, although it ran a bit slow at certain times. At GoLive, the system operated well, but it was sometimes slow. Over time the performance issues were improved, but not completely resolved. At the time of 
the study there was an issue when finance ran their monthly reports. This made another system at another site crash, but the organisation was working on it. Apart from that, if the system was running well, users were able to perform tasks fast and were satisfied with the system.

A stable system was the foundation to work reliably and achieving the work objectives. In this sense it impacted user satisfaction positively. However, the system's stability is unlikely to be linked to communication quality.

\subsection{Relevancy}

The new system allowed the users to perform more analysis rather than only clerical tasks.

"I think it uses their brain more. It elevates a lot of clerical work. The whole task from the daily routine that was mind paralysing. Now you ask them to take the data and make analysis and make decision you are using their brain power more." (Director Supply Management)

In general, the system provided relevant information and outputs. In some functions there were minor data accuracy issues, but they were in the process of being resolved. In a few functions, the users' tasks were scattered across SAP and various legacy systems which made certain data from SAP incomplete. Users had to complement the data manually with the help of the legacy systems.

The system needed to be a relevant tool for the users. The system mainly fulfilled this. Users regarded it as positive which was good for user satisfaction. Relevancy was not directly influenced by communication quality, but there were activities during the implementation, such as data cleansing, that might have ultimately influence the relevancy of the system output. These activities required collaboration and good communication between the project team and the business.

\subsection{Output requirements}

The SAP report capabilities had not been fully explored at the time, although SAP provided a lot of options to customise the reports. Users were still learning how to create the reports, but at the same time users had to fulfil their work duties, which restricted the time they were able to spend on learning. A user from Supply Management explained: 
"I am using graphics that I print out and use, but they are not connected to SAP. For example, the errors and the inventory over lthe warehouse management system]. That's about it at the moment. The only ones I have. In [the legacy system] we had a report that is called "on time" told us when something is closed, but SAP does not offer the time range. We are not using the maximum, because it is not providing us what we need and it is not obvious how to get the information. What we can use we use it. We try to define something that SAP could give us, but it is always long and we do not really have the time to figure that out." (User Supply Management)

Managers sometimes wanted their reports in the format they were accustomed to from the legacy system. Therefore, some users put in additional work and applications to create those reports.

"The plant manager is used to certain formatting. He seems to be not that confident in using the system or doesn't want to change. We are reformatting information and reports to make them look alike the plant manager is used to see it. (Business Analyst Finance)"

The standard reports would have probably saved time and effort in the long-run. It would have probably been easier to create the reports with only one application automatically rather than with multiple applications manually. It might have been seen as easier in the short run to create the reports manually, because users did not need to explore and learn the reporting capabilities of SAP. In the long run it might turn out to be inefficient though. The plant manager's requirements to receive reports in the same format as he used to might not have provided an incentive for the employees to use SAP for reports and keep using the legacy system and external applications. If the plant manager changed his requirements, it might have facilitated the use and acceptance of SAP's report functionalities. It might have been easier to introduce a change from the top, as seen in the general project approach. It would also have been a waste not to use SAP and its capabilities. Moreover, it would defeat the purpose of having one integrated system. On the other hand, not using SAP for reporting could also be due to the lack of data availability in the system.

The request by the plant manager could be regarded as the attribute of credibility. Apart from that, output requirements did not seem to be influenced by further attributes of communication quality.

\subsection{Completeness}


Information from the new system was sometimes incomplete, because not all tasks of a user's job were in SAP. It was not possible to see all the necessary data, for example, inventory data, because not all sites were deployed.

"In terms of inventory it is difficult because not all of the inventory data and everything is in SAP yet and we do not see inventory of other sites. But as soon as the other sites are in the system, we can shift parts between different sites when necessary." (Business Analyst Supply Management)

Historical data was left in the legacy system, so users sometimes need to look that up manually. Users complemented SAP's information with information from the legacy system manually.

The incomplete system output caused additional work for employees. Users knew it was because of the chosen deployment strategy and only temporary. This might have caused a bit of frustration, but users seemed to see light at the end of the tunnel. Communication quality is not related to the completeness of system output. Only the aspect that users knew the incompleteness was temporary might be related to communication, but not the outputs as such.

\subsection{Response time}

Sometimes the system's performance was slow and it responded slowly to standard tasks/requests, especially at GoLive. It became better after GoLive, but was not completely resolved. Some functions adjusted their system usage accordingly. They run batches at different times instead of at one time.

"The system was really slow. So, we decided to run different batches at different times." (Business Analyst Design)

Users were annoyed by the sometimes slow response times.

"It caused a lot of frustration if you used to perform the task in 10 seconds and now it takes you 2 minutes. (Supervisor Supply Management)"

Apart from that they were happy with the system. The users did not know why the system was slow and had not received an explanation for that. Among project team members though, there were speculations that either the customisations or the large volume of parts in combination with an old hardware infrastructure caused the system to be slow. 
The frustration could have negatively influenced the attitude towards the system, but this did not seem to have happened. The slow response time could have had negative effects on the work and could have caused production delays, but this did not happen either. The project team was working on resolving the system performance issue. However, response time was not influenced by communication quality.

\subsection{Reliability}

The system ran usually reliable apart from the sometimes slow performance. Users, however, were aware that the system was sometimes a bit fragile and had sometimes doubts about the reliability of the system. One supervisor of Supply Management described:

"[The system's performance] has been improved, but the issue has not been resolved. I can say right now the system is steady, but my level of confidence that tomorrow something new such a transaction is uploaded. We sense that it is shaky. Some days it is slow and transactions take longer than regularly. If it is fixed I do not want commit to that." (Supervisor Supply Management)

The information that the system provided (the one that was available), on the other hand, was generally considered reliable. This might have increased the trust in the system and made it seem useful.

Unreliability could have introduced uncertainty in the work, but this did not happen or only to a minor extent that did not have a significant influence. However, system reliability was not related to communication quality.

\subsection{Timeliness}

Apart from the slow performance at times, users were able to retrieve the information they needed from the system usually on time. The shop floor was highly reliant on receiving the information they needed on time. Therefore, the other departments adjusted their work accordingly to deliver to them on time. If there was a request from the shop floor that could not be answered immediately, the stress increased for users in other departments.

"Their job is to [manufacture the product]. They don't have the time to wait. When there is a request on the floor you need to answer quickly. If they are not ready to use the hew system, they will live under stress for a couple days and that is normal." (SAP Application Specialist) 
In general, SAP made it possible to receive information much faster, but it was still incomplete. For certain tasks it took users time to receive the information they needed, because the task were scattered across various systems. Most users believed that the complete deployment and the RFCs could change something towards the positive. However, only if they were answered and implemented by the project team.

The timely retrieval of information was crucial as highlighted by the shop floor example. If the production were delayed, it might have meant concession fines for the organisation for late product delivery to their customers. There was no connection found between timeliness of system information output and communication quality.

\subsection{Accuracy}

During the data conversion an accuracy of $97 \%$ was achieved, which was considered as a big success by the project team and the business side. Collaboration efforts between the business and the project helped to make the data more accurate. A business analyst from Supply Procurement provided an example:

"During the data cleansing, there was a problem. So we sent back the Excel file and they did not ask any questions, but collaborate and did it. [...] The business did the data cleansing. [...] That is why I sad it was good working together, because we had real and accurate data." (Business Analyst Supply Procurement)

The data that users received from SAP is mostly accurate. In very few cases incorrect data were uploaded as it would have been taken too long to correct the data before the GoLive. It was easier to correct them afterwards. The inaccurate data caused some minor complications, for example in spare parts the information was not very accurate and created a bit frustration among the people who had to work with the data.

"In some aspects easier in others it gives me a real headache. The problem areas are where we have problems with data accuracy, because there is some crap in the system." (Business Analyst Design)

The legacy systems were still in place, but compared to SAP the data was not updated anymore. The users worked in virtually all cases (for tasks that were in scope) with SAP, so the outdated data in the legacy systems were not such a problem. A few users found it challenging to maintain the data in the new system. 
Accurate data was the crucial foundation for the organisation's work. It was important in an integrated system as the data was available to all functions. In most functions the work went well probably, although there have been some accuracy problems. It was more difficult for functions which were directly impacted by the inaccurate data. However, they tried to do their job as well as possible and took corrective actions. However, the users were sometimes still silo-minded and still acquiring knowledge about data maintenance.

System accuracy is unlikely to be related to communication quality.

\subsubsection{Required time for implementation}

The organisation-wide ERP implementation had experienced delays. It was expected to have the ERP system deployed across all sites earlier. In some areas modules were not deployed that users expected to be implemented, which caused frustration. However, the deployment in this study was on time, although some de-scoping was necessary to achieve that. This was a compromise made by the business and the project team. Overall, the study's implementation project took about nine months.

It was the first priority to deliver this project on time. The delivery deadline had been set by steering committee and the general plant manager meeting. The project team accepted the deadline, although they knew it was tight.

\section{"I think coming down from the steering committee which is having the overall guidelines, the objectives giving us the scope of work and the timelines to work within." (Project Team Manager)}

"Projects are planned in that way that someone on the top makes a decision based on the budget. I do not think people in their leadership position have enough character to say that it is not feasible. So they just go along and play the game." (Director Supply Management)

The project team members worked a lot of over time. They were scheduled for long hours and weekends for months, which created frustration within the project team.

"We did a lot of overtime, up to 30 hours in the worst case. The only important think is the shedul and hudge the sshedule was yery thigh" "Rusiness

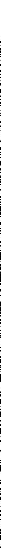


The business side on the other hand was impatient and wanted more modules delivered faster so that users did not have to work with multiple systems. In addition, the business and users wanted to improve the system, but the project team was mainly focused on implementing. The business users were waiting for RFCs to be answered.

"I thought the development would be faster and get us more results than where we are now." (Trainer Supply Management)

The business and the project team did not seem to communicate their different understandings and perspectives. The project team did not inform the business about what was feasible and what not. The business was not aware of the workload of the project team and communicated impatience. The two aspects showed a lack of openness and bidirectionality. In this sense communication quality might have influenced this aspect of user satisfaction. The misunderstanding might have caused a decline in the relationship quality.

\subsection{Attitude of the ERP project team}

The project team members were highly motivated to work on the project and to make it a success. Some of them saw it as a personal challenge they wanted to master. Virtually all team members liked their jobs and found working on the ERP project interesting.

"I like the people, I like the team and I want to see this project happen. This one will be rock ' $n$ ' roll. I don't want to be a spectator. I want to be on the ice." (Programmer)

"It is really interesting to work on the project." (Business Analyst Master Data)

"It is a good enterprise and I still like my job." (Business Analyst Supply Management)

The project team's management admitted that the project team sometimes became very short-term focused on a specific deliverable and did not pay much attention to system improvements. The available human resources worked on the implementation and there was hardly any slack to let some of them work on RFCs. It was difficult to devote more time and resources into the knowledge transfer from key resources to others, which could have helped to reduce the human resources' degree of utilisation and freed some people up to work on RFCs. A number of people on the business side thought that the project did not 
take enough care of the RFCs. The main complains were that feedback was missing or their requests were just brushed off by the project team.

"On the project side some issues were floating, we mentioned it and it seemed
like no one took care of it. We had issues with RFCs. We gave a list with the
most important issues to the [project team], the minimal requirements. A
month later the list came back and [the project team] said that they do not care
about it. We had to start from scratch. Since 2003 we have been saying we
need a mass change option, but it has not been provided yet. This is a major
issue." (Business Analyst Design)

This represented a case of lacking bidirectionality. It caused misunderstandings and facilitated the formation of negative perceptions towards the project team.

Regarding the project's progress, status, and problems, the business was aware that project hid information in some cases. This highlighted the attribute openness which was lacking. It caused ambiguity on the business side and opened up room for speculations.

During the on-site support phase there were some misunderstandings between the business and the project support staff. Some project business analysts waited for the business people to introduce the new users to them so that they were able to provide support. At the same time the business complained that the project support staff was too passive. The support was generally perceived as not proactive enough, except for some business analysts. The business would have liked to see a more customer-oriented approach such as the support staff walking around and offering help to users. In addition, some users were brushed off when they requested help from the project support staff, which was asking them if they had checked their manuals first and that such a question was supposed to be directed to a super user. This shows the communication quality attribute formality vs. informality. The support process was more formal than necessary or the users needed it. Therefore, users perceived the support as less helpful and the communication quality as lower.

A few business users perceived some project business analysts showing an attitude of "We have delivered. Now it is the business' problem. Other users mentioned that some project business analysts seemed lost at times when answering questions, because they had been out of the business for years and were missing the latest information. This created frustration and on the business side and among the users emerged an attitude of "we solve our problems ourselves here'. This presents the aspect of purpose adequacy. The lack of 
adequate communication for the purpose decreased the perceived quality of the communication.

Within the project it was perceived as if users did not have that many questions, but actually there were some. Users had questions but avoided to ask the project staff showing a lack of openness. Users asked their management to send the project support staff back to their own facilities. Some business managers complained to the project management about the problems and had the impression it changed a little bit. In this case bidirectionality became evident. The situation became better when bidirectionality increased.

The following sections present the different views about the support phase:

\section{The business' view:}

"They came over here after GoLive and [...] users said to me they do not want to see the project business analysts here. I was asked to ship them back to [their facilities]. It was more frustrating for the users. I tried to reconcile. When the business analysts came here, it was like, we have delivered and now it is you problem. That was the attitude they have. When someone had a question they first have to check their manual, asked their power user, ask someone in the group. So usually it is like: 'Do not come to see us'. It was the worst situation I have ever experienced. I do not think we will ask the BAs next time to come here at all. It was not because there were no questions. There were questions." (Business Communication Coordinator)

"Users avoided to ask them for help again after getting such a brush off. And also the feeling of being stucked with the system and having the feeling not getting help." (Director Supply Management)

\section{The support staff's view:}

"I was there for support for two weeks, but we had one question a day. That was the maximum. Apparently the super users had questions, but nothing they could not answer and had to come up to us. There was a kind of chain of command. The users went to the super users, the super users went to the power users, and only if they could not answer that the question would be directed to us the business analyst." (Business Analyst Supply Management)

"In the past I spent three week, in the last implementation I was there for 1,5 weeks and then I left because there was nothing to do for me. They did not have any work for me to do anymore. So they sent me back and said they gave me a call when they need it. Again that is showing that there is improvement, in training as well. A lot less problems this time." (Business Analyst Production Planning) 
Some project team members were involved in providing ongoing support to business users. This mainly took place through phone calls. However, it seemed to be more frequent in cases where employees knew each other personally.

The attitude might have been poisonous to future collaboration. It did not become clear why the project staff showed this attitude. It might just have been because of a different understanding of how to provide support. In this case coordination might have been lacking between the project team and the business before the support started. The support phase caused frustration on both sides and divided both sides. It also weakened their relationship. Future collaboration might be more difficult because of the negative experiences people made.

Communication quality might have been related to the attitude of the ERP project team and its perception on the business side. The attributes of completeness, purpose adequacy, openness, bidirectionality, and balance of formality vs. informality seemed to have influenced attitude of the project team. The project team's attitude probably had a negative influence on user satisfaction.

\subsection{The domain knowledge of the project team}

The domain knowledge and the implementation skills of the project team were good. Most of the team members had been in the team since the beginning in 2001. During this time the team members had acquired valuable project skills and knowledge. The project team's management also mostly stayed the same.

"I have been here for over 4 years. I came in just a few months after the beginning. [...] I am pleased that the management team has basically stayed the same over the last 4 years and that there have not been major changes. That has been very beneficial to keep everything going into the same direction." (Business Analyst Production Planning)

The skill level of the project team probably facilitated the implementation project.

Most project business analysts were especially knowledgeable and skilful employees in their specific function. However, knowledge of other functions was slightly lacking, which caused some challenges during the user training, when some business analysts and power 
users gave training for other functions. This showed a lack of purpose adequacy in the communication.

This might have caused some minor frustration, but the vast majority of users reported it did not have a significant impact.

In a few cases project team members asked users with specific knowledge for certain areas to go through the affected business processes, because the knowledge was lacking in the project team. This represented an indication of bidirectionality of the communication and was received positively by the users.

It was most likely beneficial for the project that the project team were willing to retrieve specific knowledge in some areas from users. Instead of trying to fill in the gap or approximating, the project team did visit the users and ask for the information. This was probably more effective, faster, and easier than trying to fill in the knowledge gaps themselves. The business and users also felt involved which left a positive impression of the project team in this regard. This example showed that it was valued by both sides when collaboration worked. It was possible to collaborate, if the willingness, and the perceived need and benefit were evident.

The project team relied on a few key people with their specific skills. Their utilisation was quite high and there were hardly any shadows for those key human resources. The knowledge transfer from the key human resources to other resources to relieve them was not effective.

"I think putting it in terms of an amount of slack is well expressed. I think we have the resources. I think we have the people with the right knowledge, right capabilities, but I think we have very little slack. We are using them to a very high degree, utilisation if you like. We have got some key resources we have a lot invested in them in their competencies and their expertise is very narrow and very valuable to us in terms they are the only people who know how to do that. [...] So, I think we have the right people, I just do not think we have the right mix between the people that are very focused on and with key competencies and skills versus other people who we need to develop, do the knowledge transfer in a much more effective manner. [...] We do not have enough shadows for key people. Maybe 30\%. [...] I think we are not doing neither enough to ensure the knowledge transfer within nor the career development that goes with it. We get very focused on short terms such as specific project deliveries, but we are not giving enough thought to what will going to happen with the next project or where does the person want to be in one years time, three years time." (Project Team Manager) 
It was an advantage for the project team to possess some highly skilled personnel, but it was also somewhat risky to rely on them without shadows and use them to a degree of utilisation close to burn out. If they had fallen out there would have been no replacements. This could have led to delays or even project failure.

The business side also had the perception that it was always the same people doing most of the work.

\section{"It was always the same people, They were tired." (Manager Supply Management)}

However, the business also believed that the project had enough resources and skills but was badly organised causing the delays in terms of answering RFCs and implementing faster in general.

"At the internal project management level, I believe the have enough people and resources to deliver. In fact, I would say the project team has too many resources." (Plant Manager)

"For the project side, I feel they have enough resources, but they lack control, This was only a small implementation. But they have had the people from [ the previous] implementations. "(Director Supply Procurement)

"I am sure the project team has enough resources, they are a big team." (Director Production Planning)

This showed a lack of openness in the communication. The project team might have created an unbeneficial image of themselves in the sense that the business thought a few people only do most of the work. In a way it was true though. The project team relied on some key human resources, but the other staff worked as well. However, this impression of key resources doing most the work might have caused the perception in the business that the project team possesses too many resources. The business might not have been aware how much the project team relies on some key resources and how the project structures it work internally. This perception of having excess resources also facilitated the frustration regarding the RFCs. The business users might have wondered why it took so long to answer RFCs, although in their perception the project team possesses so many resources. The communication about the project team's mandate and project and work structure were missing. This might have prevented of weakened the perception of an unorganised project team with too many resources that seemed to be unresponsive or unwilling to help. At the 
same time the project team missed to inform the business more. These misunderstanding might need to be clarified in order to collaborate effectively in the future.

The domain knowledge of the project team is unlikely to be influenced by communication quality, but its perception on the business side might have been.

\subsubsection{Communication with the ERP project team}

This section looks specifically at the communication between the business/users and the project team and its impact on user satisfaction. Communication quality represents only one aspect of communication. Therefore, this section briefly recaps parts of communication quality and their impact on user satisfaction. A more detailed breakdown of communication quality can be found in section 4.1 Communication quality. In addition communication quantity, frequency, task/media fit, and each side's view on the responsibility to carry out communication are briefly explored with their impact on user satisfaction. These aspects are presented to highlight that they have been considered as having a potential impact on user satisfaction. Addressing these other aspect also allows showing that it is indeed communication quality and its attributes in this study that have an impact on user satisfaction.

\subsection{Communication quality}

\section{Completeness}

Most users reacted very positively to the new education and training approach. They appreciated to receive more explanations about the rationale behind the implementation and found that this complemented the transactional training well. Most users were satisfied with the education and training and evaluated it positively.

In terms of regular communication between the project team and the business, there were some areas in which the business was not satisfied with the project team's communication. The business side found that the project team provided incomplete information during the biweekly meetings about status and progress. This resulted in frustration, mistrust, and resentment towards the project team on the business side. At the end of the project, the project team concluded that the communication could have been better than it actually was. 
Another major point of dissatisfaction was the feedback on RFCs that the project team provided or did not provide. The business users perceived it as too short or not evident at all causing disappointment and dissatisfaction concerning the level of provided service.

\section{Credibility}

The project team jeopardised its credibility by providing sugar-coated scorecards during the biweekly status meetings. As a consequence, the project team lost trust on the business side regarding the truthfulness of other provided information. The business side kept wondering why they were not informed about the real project status and potential problems. The business would have liked to solve problems together with the project team instead of being shut out. The business and users were dissatisfied with this communication approach.

\section{Accuracy}

The sugar-coated score cards also communicated inaccurate information to the business. The project team actually encountered problems on the project side, but the team communicated that everything was going well. Providing inaccurate information and the project team's attempt to solve problems internally, looking good to the business side, and avoiding to worry, actually created frustration and suspicion on the business side. The business and users were not satisfied with being provided inaccurate information.

\section{Purpose adequacy}

Most users perceived the training and education prepared by the project team and the change management department as adequate in order to be able to use the system after GoLive and to perform their daily work tasks. The users were mainly satisfied, although the training and education amount and coverage were reduced due to resource and time constraints.

An area of dissatisfaction was the on-site support provided by project team staff after GoLive. This was perceived as inadequate. The business users had the impression that the support staff did not focus on their needs as much as they needed it or wished for. Some project staff referred users to their manuals and super users instead of trying to help. Additionally some users had the feeling that the support staff did not want to or was not able to solve their problems. This created frustration and dissatisfaction with the provided 
support and the involved communication. Finally it resulted in a "we solve our problems ourselves" attitude among business users.

\section{Timeliness}

Most users were mainly satisfied with the training's timing, although it was mentioned it could have been better. However, most users understood the resource constraints that made it necessary to deploy the training a long time before the actual GoLive. Some users wished for more advanced training after GoLive, but most users were comfortable working with SAP anyway. So, this was more a "nice-to-have" rather than a "must-have".

The business had the perception that they received some messages from the project team too late, for example being informed about certain problems during the implementation, changing plans, and considerations to reduce the project's scope. The business was dissatisfied with not being informed immediately. However, there seemed to be a difference in understanding about intermediate deadlines and deliverables. The business side appeared to be very focused on any type of deadlines including milestones, whereas the project was more focused on the final delivery.

\section{Openness}

The business side felt that the project team was hiding information, for example about project problems and difficulties such as the absence of key project team members. The business was not satisfied with the degree of openness that the project team provided. The business wanted more transparency and insight into what the project team did. This lack of openness attributed to a lost of trust and created frustration on the business side.

Another area of dissatisfaction was, that users and super users found it difficult to reach people they wanted to reach within the project team. The project team was perceived as a "blurry organisation". Most of the time it was the same project people who did the work that the business requested, although they might not have been the first person who had been addressed.

\section{Audience adequacy}

The business as a whole and users were satisfied with customisation of communication efforts for different types of audiences. This included the different training and education modules tailored to each hierarchy level, but also the use of meetings of presentations in 
the middle management and the internal newsletter and TV in the cafeteria for shop floor users.

\section{Bidirectionality}

The project team took the users' input, such as knowledge about specific business processes or to change parts of the training material, into account to a feasible degree. Most users were satisfied with how their input was received by the project team. The majority thought providing the information influenced the final project deliverable and overall outcome.

The business was not satisfied with the degree of feedback provided by the project team regarding the status of RFCs and problems that the business had communicated to the project team. The missing feedback created frustration.

The Change Management department collected feedback about the training and the education. Lessons learned were also created. Everything was compiled in the project review. However, there was the impression that the project team's management did not follow up this feedback and the included recommendations.

\section{Formality vs. informality}

Most users felt that informal communication with the project team (for example when encountering problems) worked better than formal communication apart from the training and project's promotion. Users preferably communicated to people they knew within the project team. In general the majority of users were satisfied with the informal communication, but less with the formal communication in the area of problem-solving between business and project.

\subsection{Communication frequency}

There was frequent communication between the project team and the business. The biweekly status meetings was one of the media that were regularly used. The majority of people on the business side agreed that they received regular communication about the progress of the implementation from the project team.

"Yes, we received regular communication. We have the biweekly meetings." (Director Production Planning) 
The director of Supply Management also made sure that there was a possibility for frequent communication with the project team through the business communication focal:

"The communication focal reports to me. From a business perspective, that person is about two desks away from my office. [...] Every time there was an issue, we could have a chat about it." (Director Supply Management)

Apart from those formal communication mechanisms, the most frequently used method of communication between project team and business was informal through phone and email between employees who know each other.

The internal newspaper, posters, and the internal TV, which were placed in the cafeteria, were other ways to frequently inform a lot of users.

In general, there was frequent communication in various formats. The business side and users were satisfied with the frequency of communication that they received. Frequent communication was there and not the cause for problems between the business and the project team.

\subsection{Communication quantity}

Users received a lot of communication through their peers, meeting with superiors, the education and training program, and the general promotion efforts in form of posters, newsletters, t-shirts, and coffee mugs. Users agreed that:

\section{"There was a lot of publicity before the go-live" (Manager Supply Management) and \\ "A lot of meetings" (Business Analyst Supply Procurement [business side])}

Considering the training it was mentioned tha:

"The biggest course was seven days. We really take the time to do the training." (User Production Planning)

There was a lot of informal communication in most function. Where communication took place, the business side and users were satisfied, as an example from Supply Management showed:

"There was a business analyst, who gave us a lot of information about how is it going, business wise and within the project. [...]. For this drop, we were very well informed." (User Supply Management) 
In general, there was a large quantity of communication in most areas of the business and the users were satisfied with the quantity of the received communication.

\subsection{Communication channels and task/media fit}

Different media were used for different purposes. Face to face meetings were the main mechanism in the daily work on either the project side or the business side and found to be the most effective ones, because

"I found face to face meetings most effective, because we can ask questions and we can get real time feedback. It reduces disruptions." (Supervisor Design)

Between the project team and the business face to face meetings were not found to be most effective for several reasons such as sugar-coated scorecards and hiding information. It was more the aspects of communication quality rather than a task/media misfit that made the communication ineffective.

Presentations, a variation of face to face meetings, were another channel that was appreciated by users:

"Oral presentations are the most effective channel because all questions can be asked and answered. There is immediate feedback." (User Quality)

For the majority of tasks between the project team and the business:

"We communicate by email and phone. These are the biggest channels." (Business Analyst Master Data)

This was found to be a fast and efficient way to contact each other and to collaborate. In addition memos and documentation were exchanged.

In order to inform a large number of users internal newsletters were used. In addition a lot of promotional items were used to increase the general project awareness.

However, although such a variety of channels were used for different tasks, the change management department concluded that:

"The communication between the business and the project lacked a lot. [...] The reasons are internal and not the channels." 
In conclusion, a large variety of channels were used and in most cases the respective channel helped to carry out the task at hand. Both, business and project side, had a number of possible channels at their disposal to communicate. The facilities of both sides (the project team resided in a separate facility than the business) were also only $10 \mathrm{~min}$ apart by car. The possibilities to communicate via different channels were certainly there and were utilised. In general, users were satisfied with the channels used for the tasks that were done.

\subsection{Responsibility for communication}

The business and the project team had different expectations and point of views on how to communicate with the other party. In general, the business expected better communication from the project team and the project team did not quite see it as one of their key responsibilities to actually perform communication activities.

"We were responsible for providing what are the key messages, what are the key communication activities and ensuring that those communication activities were planned. The responsibility to do the communications was far more on the business side in terms of the execution." (Project Team Manager)

The attitude of both parties was more re-active rather than pro-active. Each side waited for the other side to communicate and resolve issues. In such a situation each party might have looked for evidence as to why the other party was not doing anything. This evidence might have been used as justification for the bad behaviour of the other party and the good behaviour of oneself. It might have made collaboration more difficult.

\subsection{Conclusion}

Overall, neither the frequency, quantity, nor the used channels were found to be a problem causing user dissatisfaction. There was a lot of communication between the business and project in general. In some areas the business was provided with information, but it was inaccurate and some information was being withheld. Channels were available and in most cases frequently used, but the communication was lacking in the area of communication quality, which might have led to frustration and dissatisfaction on the business side, including the users. 


\subsection{Relationship with the ERP project team}

The relationship between and the project was not good during and after the project. It had already suffered from previous implementation phases, but old mistakes were repeated again in this study's roll-out, such as neglecting communication, especially quality aspects, between project and business and vice versa.

On a project to business level the relationship was more considered as a working relationship in the form of a supplier-customer relationship rather than a collaborative partnership. The business was the customer and the project the supplier.

In this customer-supplier relationship each side wanted to be the driver of the project. Both sides wanted to take the lead and requested the other party to perform certain tasks.

"From the [project team's] perspective to provide the framework, the guidelines, the rules by which they [the business] need to follow and help them in the execution of that." (Project Team Manager)

"We decided, this is our plant, we [the business] take the lead of this. They [the project team] felt comfortable with our decision." (Plant Manager)

The change management department concluded that there was not the awareness or mindset for a collaborative partnership:

"In my opinion we cannot work in a client-supplier relationship, we have to work in a partnership relationship. If you work in a partnership, it is not about declining or implementing a change, it is about building it together. [...] That requires a total different mindset. That requires a shift in the mindset." (Change Management Coordinator)

These two aspects, who was leading whom and a supplier-customer relationship, made the collaboration difficult and led to misunderstandings as in the case of the business communication focal:

"[The business communication focal] wanted to consider her project partner as a supplier, because she was a procurement agent before. So she was like: "Ok, I need this at that time. What is your corrective action?" She is very oriented, planned, date, action, and in the way "You follow up and owe me answers." (Manager Supply Management)"

"Some people in the project team had a challenge with [the business communication focal]. Interpersonal conflicts took place between the team lead [project side] and this coordinator." (Change Management Coordinator) 
Both the business and the project had good intentions for collaboration such as, for example, the senior business management:

"[The plant manager] put a lot of emphasis on all of us working together as a one team" (Supervisor Design)

and on the project side:

"We tried to involve the business more this time." (Business Analyst Material Master Data)

but in the end it did not work as well as intended.

Both sides blamed the other party for responsibility of this strained relationship and did not take any responsibilities themselves.

"Of course we [the business] owe answers too, but we were always there when we had to provide answers to the project team." (Manager Supply Management)

"We would make sure as much as possible that there was transparency. So that there was never any blocks or never any 'No, you cannot see this.' or 'No, you cannot participate in this meeting. 'If they [the business] wanted to we would first of all invite them." (Project Team Manager)

However, this intended transparency by the project team was in contrast to the sugarcoated scorecards, the inaccurate information that was provided, and the hiding of problems. These were examples of the communication quality attributes openness and accuracy. As a consequence of the lack of both attributes the level of trust in the relationship dropped on the business side. In fact so far that the business required a socalled "police" to be present in the meetings in order to be provided with accurate information and achieve the level of transparency and openness that the business wanted. In general, the business would have liked the project team to show a higher degree of transparency in terms of their activities. The project team thought they were transparent though.

"I do not think it was a bigger black box than it was in the past. We would make sure as much as possible that there was transparency." (Project Team Manager)

A large part of the business also thought that the project team was not focused enough on their needs and did not listen to them as much as necessary. This was especially evident in 
the high number of unanswered RFCs, which represented a lack in bidirectionality. It led to frustration on the business side.

However, at the same time the business management seemed to have been aware of the project team's mandate, which is to deploy first across all sites and then fix the minor details.

"The mandate that we understand and hear is: 'Deploy, deploy, deploy.", (Manager Supply Management)

On the other hand, the users did not seem to have been equally aware of that.

"The changes we asked for, the RFCs, should be done faster." (User Production Planning)

"[The project team should] work more on the RFCs ro reduce our time we pass on the job." (User Production Planning)

As a consequence of these misunderstandings and the lack of trust and transparency, the project team was perceived to be apart from the business and not being focused on the users" needs.

"The project team and business are really apart from each other." (User Supply Management).

In addition, on both sides an "us" versus "them"- attitude has emerged.

"We [the project team] are doing computer projects as they are building [the organisation's products]." (Programmer)

"They [the project team] were a bit disconnected to what we [the business] are living." (Trainer Supply Management)

"We [the business] do not understand why they [the project team] need the data so early, they do not understand why we are so firm about it." (Director Supply Management)

"We [the business] did not feel that they [the project team] had the same attitude towards dates and deliverables." (Manager Supply Management)

However, some functions worked together better than others. In some cases this was due to individual efforts.

"Any question we had on the business, she [a project team member] would bring it back to [the project team]. And if there was something within [the project team] or they got back with a solution [the specific project team 
member] was the contact person and she explained when a solution was not quite what we expected. $80 \%$ of the quality of the relationship we had in our function is due to her. (User Supply Management)"

Generally, the business perceived the relationship as worse than the project team did. There were more complains on the business side about the bad quality of the relationship than on the project team's side. In fact, only very few project team members mentioned problems in the relationship. The strained relationship created frustration, mainly on the business sides, but also on the project side.

"The relationship between project and business create frustration in both ways. [...] We are not best friends." (User Supply Management)

"It was not an easy relationship." (Manager Supply Management)

The implementation was "successful" and working relationship satisfactory. A distinction was made that the relationship was good on a "working level".

"On a working level we have a good interrelationship." (Project Team Manager)

The interpersonal relationships suffered though.

"The relationship between the business and the project was strained." (Change Management Coordinator)

"On a scale from 0 to 10,1 would say the relationship between the business and the project was al 3, where o means hell." (Supervisor Supply Management)

The strained relationship lacked trust. This might have made the collaboration more difficult and inefficient than with trust. The situation might make future collaborations more complicated. It might take activities such as trust-building between the two parties to return to a "normal" relationship. A shift in the parties' mind-sets might also be necessary, such as providing information voluntarily and relinquishing control in some parts. These activities might take time and effort, which might be difficult if the organisation is under time pressure regarding the ERP implementation. Also the efforts of each party might be focused on other areas. The project team is focused on system deployment. The business is focused on manufacturing. It is a difficult situation. It might be difficult to work on RFCs and KPIs in the future with such a relationship, because it might require a lot of coordination, communication, and collaboration. 
A lack of communication quality seemed to have influenced the relationship negatively.

\subsection{User satisfaction conclusion}

The majority of users were satisfied with the system as such, apart from some bugs and the sometimes slow performance. Users were satisfied with the training and the documentation. However, they were not satisfied with several aspects of the communication between the project team and the business such as missing bidirectionality, accuracy, and openness. This had a negative effect on the relationship between the business and the project team. Nevertheless, the project as such was perceived as a success overall by both parties. A lack of communiation quality seemed to have a negative influence on the relationship with the project team. A higher level of communication quality seemed to have increased the users's satisfaction with the system as such and improved the training. Therefore, user satisfaction seemed to have been influenced by communication quality. Figure 11 shows the occurrences of the attributes of communication quality in relationship to user satisfaction in terms of cooccurences.

\begin{tabular}{|c|c|}
\hline Code System & User satisfaction \\
\hline E. Formality vs, informality & - \\
\hline Eidirectionality & \\
\hline E Audience Adequacy & - \\
\hline E Openness & [ \\
\hline E Timeliness & - \\
\hline E Purpose adequacy & 圆 \\
\hline E Accuracy & - \\
\hline E Credibility & : \\
\hline (E) Completeness & - \\
\hline
\end{tabular}

Figure 11: Occurrences of communication quality attributes in relation to user satisfaction

\subsubsection{System acceptance and usage}

This section provides the findings for the system acceptance and use construct along the framework of Davis (1989) and highlights the influence of communication quality attributes on the system acceptance and use measures. First, the section examines the overall system acceptance and use and the link to communication quality. Second, the attributes of communication quality that were found are explained in more detail. 


\subsection{Overall system acceptance and use and communication quality}

In general, the system was accepted and used by most employees, although its use was mandatory.

"There was not much resistance. Resistance was mainly verbal." (User Supply Management)

"No, there were no users resisting. Complaining, but not resisting." (User Supply Management)

However, most employees still had to use the legacy system for some of their tasks, because part of their work was supposed to be transferred to SAP in future roll-outs.

"I would say $100 \%$ of the employees in my department still use the legacy systems, because not everything has been put into SAP yet. For everybody a part of their job is in SAP. Out of 10 tasks SAP captures maybe six, the other four are still in the legacy system. So they need to go back for those tasks." (Supervisor Supply Management)

Yet the legacy systems were not used for tasks that were supposed to be done in SAP.

"The legacy system is not use as a work around solution." (User Quality)

The majority of employees welcomed the system.

"I like the new system" (User Supply Management)

"I think it is a very good system. I am very happy to use the system." (User Production Planning)

These positive aspects were attributed, among other things, to the quality of the provided communication.

"There is a link with the quality of the communication to end users. If the communication provided is good, chances are that the resistance will lower. At [plant I and 2], it was good" (Business Analyst Supply Management)

Acceptance or resistance was not equally distributed across all departments and users. Therefore, the next sections examine the various degrees of resistance and how attributes of communication quality impacted the situation. 


\section{Strong resistance-I don't use the system at all}

\section{Credibility}

If there was strong resistance, this was escalated to the Change Management department and the senior management, showing credibility.

"Change management dealt with users resisting the system. Change Management addresses the users' concerns through communicating with them. [...] So we made sure that the director came in to highlight the aspects of SAP and that it is not here to take away jobs" (Business Analyst Material Master Data)

As a consequence, the resistance of those users decreased or diminished completely.

\section{Bidirectionality}

In the same subject (resistance because employees feared to lose their jobs), bidirectionality also became evident in the communication process, enhancing communication quality and lowering resistance. Users concerns were captured and addressed showing a two way communication.

"People resisting the system were mainly those employees fearing to lose their jobs. Their concerns were captured and addressed and it was communicated that SAP is not here to take away any jobs." (Business Analyst Material Master Data)

\section{Moderate to low resistance - I usually use the system}

\section{Completeness}

A particular user group had the impression that the training did not cover all relevant topics. However, the trainers thought all relevant topics were covered. From the users perspective the communication was not complete in this regard. That the issue was not resolved might even be an indication for a lack of openness.

"[For a certain group] we repeated the training. It was like they forgot what we taught them or said they never got the necessary information. I am not sure that they used what we showed them. [...] There is some resistance." (Business Analyst Master Data) 


\section{Credibility}

In some cases a small number of employees still used the legacy system. In this instance, the non-acceptance of the new system was caused by a lack of credibility in the communicated information as explained by a programmer:

"Employees still use the legacy system without any hesitation, because there are some things users do not want to do in SAP because it takes longer, are more difficult. Maybe users were not convinced enough by the information we provided to use SAP." (Programmer)

Yet in other cases positive outcomes became visible when equipping the communication with credibility, in this example a trainer. Completeness and openness also seemed to be important, as the trainer communicated positive and negative aspects equally.

I sit down with users who were resisting the system and show them the possibilities. I show them things they can do now, which were painful before. But, I also show the negative sites and the aspects connected to integration where their action impact others." (Business Analyst Design)

We sit longer with them and explained the system to them. It worked very well. (User Production Planning)

"Those fears were taken care of." (User Supply Management)

Also the involvement of the senior management reduced resistance.

\section{"What has been done to encourage employees to use the system (SAP instead of the legacy system)?}

In [the plant here] it was the way their own management thinks, the [General Manager of the plant] and his way of thinking about going to the new system and using it. The message is coming down." (Business Analyst Supply Procurement)

\section{Purpose Adequacy}

The training by the Change Management department and the surrounding communication fitted the purpose of motivating users to accept the system.

Were there users resisting the system? 
"People were coached well by change management." (Business Analyst Business Processes and KPIs)

"Usually there is some resistance, but this time people were actually waiting for the system to come in. I think change management did an incredible job. Everyone was properly trained, properly communicated, everything they needed to know before we came in to support them, they actually did not need us much, because they had the information needed." (Team Leader Business Analysts and Application Specialists)

\section{Audience adequacy}

Different hierarchy levels were addresses in different ways highlighting audience adequacy. This reduced resistance and facilitated system acceptance as the project manager explains:

"But I think, in general the communication flows happened, I think as we did a lot of stuff from a trickle down perspective overtly, I think in reality we were going in at all levels at the same time. [...] We would present it to all levels that were the key participants in the project at that time, so that the messages got out in many different ways. That helped to gap if there was any missing formal communication, because it was happening at different levels at the same time." (Project Team Manager)

Timeliness and a balance between formal and informal became evident as well facilitating system acceptance and use.

\section{Bidirectionality}

In the training and communication with users bidirectionality became evident. The users' concerns and questions were taken seriously, addressed and answered by the trainers and super users.

"There were not that many questions from users. There were some questions to tell users more how the screen would look like and to compare old versus new, because user wanted to have back references." (Business Analyst Material Master Data)

"User who resisted the system were told that their concerns are understood. On the other side benefits were highlighted to them such as better reports or less errors. However, they were told their concerns are valid." (Programmer) 
"The managers listened to the employees to understand their problems and try to resolve them with the project team. (Business Analyst Business Processes and KPIS)

As a consequence resistance diminished and users accepted and used the system.

"The users were very happy with the feedback and level of support. The results were really good during the cut-over activities. Users always knew were to go, as far as I know." (Business Analyst Supply Procurement)

\section{Balance in formality vs. informality}

The attribute "balance of formality vs. informality" showed to be related to system acceptance and use as well. The communication used both formal and informal means, sometimes even combined with time aspects and audience adequacy.

"We did not go as formly and presented just to the management team and then expect them to be a down brief afterwards. We would present it to all levels that were the key participants in the project at that time, so that the messages got out in many different ways. That helped to gap if there was any missing formal communication, because it was happening at different levels at the same time." (Project Team Manager)

The informal communication between employees was considered important as well to foster system acceptance and use.

\section{"What is your department doing to encourage employees to use the system?" \\ "We re-used some of the people from previous implementation so they helped with talking to other employees and did the coaching. "(User Supply Management)}

\section{Very low resistance}

\section{Credibility}

In some departments the role model of the management supporting SAP encouraged employees to use the new system. This shows how credibility facilitates system use and acceptance. 


\title{
What has been done to encourage employees to use the system (SAP instead of the legacy systems)?
}

"Communication, management embracing SAP saying we go with it. But one has to keep telling it again and again. But to be honest, I have not seen anyone in [the plant] going into the legacy system." (Key Performance Indicator Developer)

\section{Puspose Adequacy}

Although the support was not completely adequate, it did not hinder system acceptance and use significantly, because there were enough users working in the system who were able to assist their colleagues.

\begin{abstract}
"People know what the machine can do, what is in it and what not. People in the last drop were there to support, but they did not get too many questions asked, because people have been working in that system already. The users knew the limits of the machine. It is not necessarily that type of support we needed." (Supervisor Supply Management)
\end{abstract}

\section{Balance of formality vs. informality}

During the cutover activities it became evident that users also referred more to their colleagues using informal means of communication. This might be a consequence of inadequacy, but also highlighted the importance of a balance of formality vs. informality to increase system acceptance and use. But when the subject became more complex users referred to the business analysts for support.

"The users' attitude towards the system was good and positive. The first week went without any questions. So we were wondering if the new system was really working so well or if users still use the old system. But they were in the new system. The coworkers helped them and when there were problems, they came to see us, In the second and third week questions started such as how to do the analysis." (Business Analyst Supply Management) 


\subsection{System use and acceptance conclusion}

Overall a higher level of communication quality seemed to have influenced system acceptance and use positively. Although the system use was mandatory in general, the opinion of users about the system varied. There were cases of strong resistance, but credibility and bidirectionality (management support and capturing user concerns) seemed to have a positive effect easing the situation. In the context of moderate to low resistance, the communication attributes completeness, credibility, purpose adequacy, audience adequacy, timeliness, and balance of formality vs. informality were found to have an impact on system acceptance and use. Moderate resistance occurrences were caused by perceived incompleteness of communication and lacking credibility. However, system acceptance and used increased with increasing credibility in the communication. It became clear that communication that is adequate for the receiving audience and the purpose transmitted at the right time also increased system acceptance and use. The use of informal communication to complement formal means of communication generated the right balance and fostered system use and acceptance accordingly. Figure 12 shows the quantified relationship co-occurrences between individual communication quality components and system use and acceptance measured.

\begin{tabular}{|c|c|}
\hline Corte Syctem & cystem arrephtarre, and I1<e \\
\hline 프 Completeness & - \\
\hline$\equiv$ Credibiity & \\
\hline (E) Accura:y & \\
\hline E Purpose acequacy & : \\
\hline$\Xi$ Birecticnality & $\mathbf{0}$ \\
\hline (iㅡㄹ Tirrolinoss & $\cdot$ \\
\hline 프 Openness & - \\
\hline E Audienze adequacy & - \\
\hline E Balance of formality and inf... & $\mathbf{0}$ \\
\hline
\end{tabular}

Figure 12: Occurrences of communication quality attributes in relation to system acceptance and use

The figure summarises the concluding findings of this sections and shows that credibility was found to have the largest influence on system use and acceptance. Purpose adequacy, bidirectionality, and a balance between formal and informal communication were found to have a moderate effect. Completeness has a low effect. Timeliness, openness, and audience adequacy show a very low influence. No evidences were found to support a relationship between accuracy and system use and acceptance. 


\subsubsection{Impact on users conclusion}

The system was not quite meeting the users' functional and technical requirements at the time. This was mainly due to the incremental deployment strategy rather than an absence of collaboration during the requirements determination process. However, the project team was mainly unresponsive to additional requirement requests that went beyond the deployment and scope strategy. Similarly, KPIs, which could have assisted users, were minimal. But the senior management was concerned nevertheless that the users were not ready for KPIs at that time. Another reason for the lack of KPIs was the need to standardise KPIs across all sites.

The majority of users were satisfied with the system. The training had laid a good foundation and the users' understanding was increasing. Users were generally satisfied with the system's information output and the system as such, although there were some system stability concerns. Missing information was complemented manually. However, there was only a slight extent of user involvement.

Users were dissatisfied with the time that the implementation had been taking. The majority of users desired a faster deployment overall and further system improvements. In this regard users were dissatisfied with the project team's attitude and willingness to help. It seemed as if the priority to deploy across all sites first had not been communicated sufficiently to the users. This might have been a contributing factor to this misunderstanding and the frustration among users. However, the project team's behaviour also added to the negative perception within the business. The project team did not do much to change this perception - their main mandate was the system deployment anyway.

In terms of communication there was neither a lack of frequency nor quantity. The media that were used also fitted the tasks. Therefore, it seemed to be the quality that impacted user satisfaction. The lack of communication quality between the project team and the business seemed to have dissatisfied the majority of users and the business in general. As a consequence the relationship quality declined. This also impacted user satisfaction negatively. The applied ERP ultimate user satisfaction measure contained many criteria. The categories did not all have the same importance and weighting. Therefore, it would be difficult to summarise user satisfaction as either positive or negative. Maybe it would be fair to conclude that most users were generally satisfied with the system, but not with the 
interactions with the project team involving aspects of communication quality. Figure 13 shows the occurrences of communication quality in relationship with "Impact on users".

\begin{tabular}{|c|c|}
\hline Code System & Impact on users \\
\hline $\begin{array}{l}\text { E Formality vs, informality } \\
\text { E. Bidirectionality } \\
\text { E Audience Adequacy } \\
\text { E Openness } \\
\text { E Timeliness } \\
\text { E Purpose adequacy } \\
\text { E Accuracy } \\
\text { E Credibility } \\
\text { E Completeness }\end{array}$ & 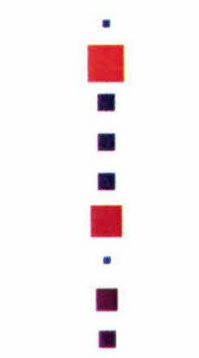 \\
\hline
\end{tabular}

Figure 13: Occurrences of communication quality attributes in relation to "Impact on users"

On the whole, the impact on users was multifaceted. There were a few aspects of "the impact on user" success components that were not completely positive, but they did not hinder the overall system success. The impact on users might depend on the weighting of the individual criteria such as user satisfaction and system acceptance and use. However, overall the impact on users was mainly positive and contributed positively towards ERP system success.

\subsubsection{Business benefits}

The category "business benefits" assesses the impact the ERP system has on the organisational performance. This section present the business benefits in the areas "financial performance gains", "better process performance", "higher quality products", "less waste and inefficiencies", and "the awareness of users of the link between their daily work and the organisational benefits".

\subsubsection{Financial performance gains}

\section{Legacy system still in operation}

At the time of this study none of the legacy systems had been decommissioned. The implementation was done by product program and the required functionalities were scattered across all kinds of systems. During each phase a certain amount of functionalities was transferred into SAP, but the users still needed the legacy systems and additional 
application to perform their daily tasks. Consequently a variety of systems needed to be maintained to a certain degree which cost money. The business side expected that the financial benefits would be realised after everything was in SAP and legacy systems were decommissioned.

\section{Financial benefits not as originally expected}

People on the project and business side had come to the awareness that projection about potential cost reductions, as stated in the original business case, were too optimistic.

"I think that in 2000 we set the bar to high. They thought it would save them millions of dollars in inventory [...] We are not anywhere near what the original business case said. [...] The overhead reduction is there, but it is very minimal in terms of dollars." (Key Performance Indicator Developer)

"I think, there is high expectation in terms of having benefits in terms of inventory reduction, reduction in non value activities. [...] Everybody accepts that it will bring improvements. Everyone is equally unsure on how to put a financial figure or dollar sign against that. [...] We know it is the right thing to do, we know where we are going to get our benefits from, but we are not able to get solid commitment on the realisation of those afterwards. I think, [the ERP project] is now in a bit of a trap, where we set out in 2000 very high level of financial benefits, provided the rationale, the justification to make the investment that we did from a people and systems perspectives." (Project Team Manager)

The organisation expected to see a larger reduction after the complete deployment of SAP across all sites and in all functions. Also a lot of unexpected cost overruns were not considered in the cost estimation either. Only small inventory reductions had not taken place at the time of the study, because not all sites and programs were in the system. Inventory transparency and cost savings through central purchasing had not been realised. Therefore, the financial benefits were expected to be lower than originally anticipated. In some areas users were able to see first signs of financial performance gains in their work, but there was also a lack of KPIs to help users to quantify those benefits. The project manager explained:

"Now that we have implemented it, we are struggling to actually really say what we have got, have the right KPIs in place that give us the measures of that, so tells us here is the benefit or whether we actually see the reductions. We get a lot of push backs like we got more work as a result [in some functions]. The benefits are clearly stated in the business case what we expect them to be. What we still struggle to do is to rationalise the realisation of those." (Project Team Manager) 
The original business case might have underestimated the efforts necessary to implement an ERP system. Similar organisation had struggled with ERP implementations too. At the beginning there was a lot of enthusiasm about the possibilities and potential benefits, but the necessary efforts were underestimated. The organisation also stared to become impatient, because the implementation was thought to be easier than it turned out to be. However, over time the organisation had realised that an ERP system does not only provide benefits, but that it also takes a lot of effort to implement the system and achieve the benefits.

It might be difficult to monitor the achievement of benefit without the proper KPIs and the respective benefit ownership, because it is unknown how much benefits might be realised and which corrective action would have which kind of effect.

\section{Communication about financial benefits to users}

There is a difference regarding the communication of financial benefits between the business' senior management and the user on the employee level. The senior management was more involved and better informed about the financial benefits. The senior management tried to avoid focusing too much on cost reductions and financial benefits in their communication to users on the employee level. The purpose was to avoid creating the impression financial gains were the main reasons for the implementation and not facilitating the users' work. Also communication about cost reductions was suspected to create fears of losing jobs. Therefore, the potential growth of the organisation was highlighted in the communication to users and on the employee level, as the plant manager described:

"I am involved [in the definition and monitoring of benefits], but I try to stay far from it. If you talk too much to our employees about the financial results, financial benefits, costs reductions that SAP gave us, then the employees will probably believe that you did not do it for the right reason. You did not do it for the growth of the company, but for cost reduction aspect. It is not something I put in my speech all the time. The right reason must be to say not just to reduce our cost. Reducing our costs is a consequence of the system, but must not be the main reason why." (Plant Manager)

Sometimes it might be better not to divulge everything at one time. The financial aspects could have scared users and reduced their willingness to commit to the project. If users had 
known that they worked on a project that might reduce jobs, the willingness to work on it might have reduced significantly.

Communication quality was difficult to see in areas related to financial gains. The financial gains were just starting to be realised. Audience adequacy and purpose adequacy were evident though. The senior management adapted its communication to users to emphasise the benefits for them rather than for the organisation. They thought that financial details might have caused confusion and fears. This represents the element of audience adequacy. Therefore, they only supplied the users with the information necessary to carry out the implementation successfully, which demonstrated the attribute of purpose adequacy.

\subsubsection{Better process performance}

Users were still in the process of learning how to use the system. Therefore, not many improvements had been realised. Besides, users also needed to operate SAP in addition to the legacy systems. It was a balance between gains from SAP and losses from operating in multiple systems. Super and power users provided support in addition to their usual work so they had more work to do and the productivity gain from SAP was probably absorbed by that.

Users saw that some tasks had become easier. Repetitive and previously manual tasks were reduced and automated. The data accuracy had increased and there was more analytical rather than clerical work to do. On the other hand, certain tasks took users longer, because they did not achieve the same results or results in the same way with SAP as they were used to from the legacy systems. Opinions varied among users:

"My job seems more difficult because of the new system. In a year I might say no, but for now we are still adapting to the new system. So a little bit more difficult, because we have to question more on what we are doing and doing things we are not used such as entering serial numbers which we did not do before. It is rigorous working. If you do something wrong somebody it going to know it. It is a good system. I like it." (User Supply Management)

"[Q: Is your job easier or more difficult because of the system?] It's about the same thing for the users. For standard transactions, information is easier to get." (User Quality)

[The system has made my job] much easier. There is more automation in SAP than in the legacy system. We don't need to do the planning everyday. (User Supply Management) 
Certain tasks in some departments had become larger and longer, because those departments took over responsibilities from other departments. It was expected to be an overall gain, but the organisation was not where they wanted to be in terms of process improvements.

The work procedures might not have been final, because the legacy systems were still used. It might have been difficult to work on work improvements in this environment. In addition, users were still learning and KPIs were missing.

Most users were convinced the performance gains would come and some users said they were already seeing first indications. In general, users were able to see that SAP was more rigorous than the legacy system in terms of how to perform transactions and to handle data. This was expected to result in higher data quality. However, how much processes had improved was not quantifiable because of a lack of KPIs.

Sometimes the system showed a lack in performance. It was slow. The reasons were not quite clear and it was speculated to be either the enormous volume of parts and high utilisation of hardware or the customised transactions in SAP.

"Instead we built our own transactions that take forever to run." (Key Performance Indicator Developer)

"There were some performance problems mainly because of the enormous volume of parts." (Business Analyst Material Master Data)

In the manufacturing department a new clocking system was introduced as part of the SAP initiative to increase process performance. The implementation took place in close collaboration between the manufacturing department and the project team. The director of Manufacturing described:

"The main thing that [the ERP initiative] brought to assembly workers [...] is a clocking system and to find are where workers are in the job and what the performance is. We had 3 persons [from the project team] here which were really extraordinary, it was clear, it was simple to understand. The three persons came into my staff meeting to update us of whatever problem we had. They went with most people through the new system in 8 hours. That went very very smooth." (Director Manufacturing)

The system led to process improvements in the manufacturing department as the director of Manufacturing further explained: 
"If we talk about [the clocking system] and its benefits, the gain has been shown. If I look at the production hours, we reduced our production hours in the last three years by $17 \%, 24 \%$, and $28 \%$. But you cannot say that was only [the clocking system], it was part of it. It was also processes and we put more information on the shop floor. These things happened at the same time. So the ERP system was part of it." (Director Manufacturing)

In this area communication quality became evident in the form of openness and bidirectionality. The project team and the manufacturing department communicated open and in a bidirectional way. This led to better results. In other departments the influence of communication quality was less visible, but might have been evident in the form of audience adequacy in the training.

It might defeat the purpose of implementing SAP if it is customised too much. SAP incorporates the industry's best practices. The organisation might not benefit from those if the system is customised too much. Best practices processes might be more efficient than the organisation's own ones.

The customisation could also pose a risk to the infrastructure, if the customised transactions were the reason for the slow performance and a shaky system. In that case, the organisation should possibly move away from customisations. If the performance was only slow because of an outdated hardware infrastructure, it could have been resolved through an upgrade.

\subsubsection{Higher quality products}

The ERP system was also intended to allow different sites to share customer data to fit products better to the customer's needs and to increase the perceived product and service quality. However, sharing customer data had not been completely achieved at the time of the study.

The organisation introduced a new business initiative about achieving customer excellence a few months before the study's implementation phase. The initiative was still in its early stages. Feedback and information on how to work towards customer excellence were supposed to be given to the employees through KPIs. This was supposed to allow users to extrapolate data and results and adjust their work accordingly. However, the KPIs still needed to be developed. 
"We started a program called achieving excellence which is a feedback to the employees through KPIs in their sectors." (Director Manufacturing)

It was too early to see the implications and effects of the system on higher quality products.

\subsubsection{Less waste and inefficiencies}

Reducing waste and inefficiencies was one of the organisation's three organisational priorities. Employees tried to apply this in their daily work and in the interactions between the project team and the business. The three priorities were also part of the education and training program developed by change management.

"I mean it is part of our overall strategy within our business units and within the project team. What we are looking to do is that we ensure that we have the most effective way to work so that we are able to organise things properly, make sure we are eliminating the waste within the organisation." (Project Team Manager)

Most employees are dedicated to reduce waste in their daily work and do their best for the organisation.

"All the people I work with, we all try to do our best for the company, try to reduce the waste." (Business Analyst Master Data)

Most people on the business side expected the organisation to be more efficient overall after the deployment would have been completed. First improvements could already be seen. The business side attributed those benefits to more efficient work methods and processes.

It was possible to reduce inefficiencies in certain areas, e.g. in the area of pending parts. SAP's rigorous way of working was found to reduce the amount of incorrect data handed over to other departments and less duplicated data.

It might be beneficial that employees internalised the organisations' priority to reduce waste and inefficiencies. This might help to realise the benefits expected from this priority. It might be a starting point to see how individual efforts benefit the whole organisation.

Communication quality impacted this area through the attribute of credibility, because the priorities were communicated to employees from the very top of the organisation. 


\subsubsection{Link between daily work and business benefits}

Users were able to see indications of benefits in their daily work. However, the link to the overall business benefits was still vague, although education had tried to address this. But the education plan was new in this implementation. It was still too complicated for users to understand the whole overall picture and processes. The users were still in the learning process and users were concentrating more on performing their individual tasks properly rather than the organisational perspective.

"It's too high level for me to say if the expected organisational benefits have been achieved, but I can say that it improved my job." (User Supply Management)

Yet, the users' awareness of the link between their daily work and the organisational perspective was increasing.

"It is important and relevant to the business. It is really important to have a system like that." (Business Analyst Design)

Also there was a lack of KPIs, which made it difficult for users to "see" the benefits. Consequently, there was also a lack in terms of benefit ownership meaning a certain department would be aware that they were responsible for achieving certain benefits and how this was linked to the organisational benefits perspective. The project manager described the situation:

"The organisation is responsible for achieving the benefits, but that everybody and nobody. That is one of the big things we struggle with as an organisation. We like to refer to this term in the abstract as opposed to the specifics and then it comes down to the hard reality that I mentioned. Yes, we set out there would be these kind of financial benefits. If it is raw material, the people in [Supply] are responsible to report the status against that. If it is to reduce workload at closing periods in the finance group, then they are responsible for that. If it is a reduction in overhead and management from a production line perspective that relates to my ratio to production for [production planning], then [production planningl people. What we do not have is this buy-in, this sort of individual departmental, people saying this is me. We have it at the business level, at lan organisational] level, but we have not been able to transfer that down to the reality. "(Project Team Manager)

It might be difficult for the organisation to realise the benefits without having the employees' awareness of the links. The employees were still in the learning process and their understanding seemed to improve. 
Communication quality might have influenced this area through the training and purpose adequacy, but it seemed to be too early to see the effect among users.

\subsubsection{Business benefits conclusion}

The financial benefits were small and less than originally expected at the time of the study. Inventory sharing and reductions as well as central purchasing had not been realised. The legacy systems were still in operation causing costs. Users had to work in multiple systems and were still in the learning process which kept the process performance gains to a minimum. The organisation implemented an initiative to achieve higher product quality and to reduce waste and inefficiencies within the organisation. This was still in the early stages, but employees became more aware and they tried to apply this in their everyday work.

Users were able to see indications of the benefits that would potentially be realised. However, there were hardly any KPIs available to allow users to measure them. In addition, users were just starting to see the link between their individual work and the achieved benefits and the overall organisational perspective.

The influence of communication quality on business benefits was difficult to see, because the realisation of benefits was in its early stages. However, from the coding occurrences in Figure 14 it could be assumed that credibility, purpose adequacy, and audience adequacy were the attributes that were related the strongest to business benefits.

\begin{tabular}{|l|l|}
\hline Code System & Business Benefits \\
\hline & Eit Formality vs, informality \\
E. Bidirectionality & \\
E Audience Adequacy & \\
E Openness \\
E Timeliness \\
E Purpose adequacy \\
E Accuracy \\
E Credibility \\
(E) Completeness
\end{tabular}

Figure 14: Occurrences of communication quality attributes in relation to business benefits 
Communication quality might have influenced this area through the training and purpose adequacy, but it seemed to be too early to see the effect among users.

\subsubsection{Business benefits conclusion}

The financial benefits were small and less than originally expected at the time of the study. Inventory sharing and reductions as well as central purchasing had not been realised. The legacy systems were still in operation causing costs. Users had to work in multiple systems and were still in the learning process which kept the process performance gains to a minimum. The organisation implemented an initiative to achieve higher product quality and to reduce waste and inefficiencies within the organisation. This was still in the early stages, but employees became more aware and they tried to apply this in their everyday work.

Users were able to see indications of the benefits that would potentially be realised. However, there were hardly any KPIs available to allow users to measure them. In addition, users were just starting to see the link between their individual work and the achieved benefits and the overall organisational perspective.

The influence of communication quality on business benefits was difficult to see, because the realisation of benefits was in its early stages. However, from the coding occurrences in Figure 14 it could be assumed that credibility, purpose adequacy, and audience adequacy were the attributes that were related the strongest to business benefits.

\begin{tabular}{|c|c|}
\hline Code System & Business Benefits \\
\hline \multicolumn{2}{|c|}{ Ex Formality vs, informality } \\
\hline Eidirectionality & $*$ \\
\hline Audience Adequacy & 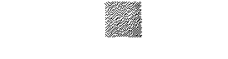 \\
\hline openness & \\
\hline . Timeliness & $\cdots$ \\
\hline E Purpose adequacy & 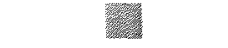 \\
\hline Accuracy & \\
\hline credibility & 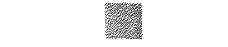 \\
\hline Completeness & 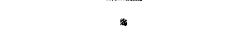 \\
\hline
\end{tabular}

Figure 14: Occurrences of communication quality attributes in relation to business benefits 


\subsubsection{ERP project success conclusion}

ERP project success was measured in the dimensions project efficiency, impact on users, and business benefits. In most categories the positive indications outweigh the negative ones. In terms of project efficiency the ERP project was successful. In regard to the impact on users it could be seen that the majority of users were mainly satisfied with the system, but were dissatisfied with the interactions and relationship with the project team and the involved communication. Evaluating user satisfaction depends on the weighting and prioritisation of criteria. The system was accepted and used. In the dimension business benefits it was only possible to see first indications of the realisation of organisational benefits. Nevertheless, overall the ERP project as such can be considered as a success, but with negative consequences for the business-project team relationship and collaboration.

Communication quality impacted ERP project success through the individual criteria in the subcategories of ERP project success. All attributes were found to have an impact at some point. Some attributes had a stronger influence than others. Especially bidirectionality, purpose adequacy, and credibility seemed to have the strongest relationships with ERP project success - as can also be seen in Figure 15. However, Figure 15 does not distinguish between positive and negative influence on ERP project success. In the case of bidirectionality, for example, the business and users mainly felt a lack of mutual information exchange with, and feedback from, the project team, which had a negative impact on user satisfaction. Credibility was mainly evident in communication from the senior management to the users which facilitated system acceptance and use. Purpose adequacy became evident in the training, documentation, and promotional communication. Users received the communication they needed which seemed to have facilitated user satisfaction and system acceptance and use, thereby positively influencing ERP project success. 


\begin{tabular}{|c|c|}
\hline Code System & ERP project success \\
\hline 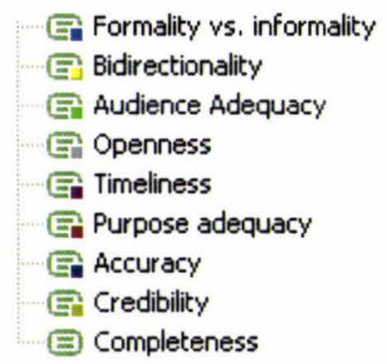 & 国 \\
\hline
\end{tabular}

Figure 15: Attribute occurrences in relationship to ERP project success

Table 16 shows a more detailed breakdown of the influence of communication quality attributes on ERP project success variables.

Table 16: Communication quality attributes with influence on ERP project success measures

\begin{tabular}{|l|l|}
\hline \multicolumn{1}{|c|}{ Variable } & \multicolumn{1}{|c|}{$\begin{array}{c}\text { Support for influence by the } \\
\text { communication quality attribute... found }\end{array}$} \\
\hline Budget & $\begin{array}{l}\text { Openness } \\
\text { (although in a different direction than } \\
\text { expected. A lack of openness might have } \\
\text { prevented further expenses) }\end{array}$ \\
\hline Schedule & $\begin{array}{l}\text { Openness } \\
\text { (lack in terms of activity transparency, } \\
\text { open in terms of scorecard circulation) } \\
\text { Accuracy } \\
\text { (scorecards lacked accuracy) } \\
\text { Bidirectionality } \\
\text { (Status request lacked bidirectionality, de- } \\
\text { scoping activities showed bidirectionality) }\end{array}$ \\
\hline Meeting functional and technical requirements & $\begin{array}{l}\text { Bidirectionality } \\
\text { (Existing in form of users surveys, received } \\
\text { positive. Was missing in terms of feedback } \\
\text { during the project from the project team. } \\
\text { Existed in requirements collaboration and was } \\
\text { appreciated by users) } \\
\text { Openness } \\
\text { (was missing in terms of collaboration on } \\
\text { problems) }\end{array}$ \\
\hline Meeting the users' needs and the existing \\
gaps & $\begin{array}{l}\text { Credibility } \\
\text { (Users were told by the project team how to } \\
\text { deal with the situation of having to use multiple } \\
\text { systems) } \\
\text { Completeness, purpose adequacy, }\end{array}$ \\
\hline
\end{tabular}




\begin{tabular}{|c|c|}
\hline & $\begin{array}{l}\text { timeliness, bidirectionality, and audience } \\
\text { adequacy } \\
\text { (Influenced through training the users' attitude } \\
\text { towards and perception of the system) }\end{array}$ \\
\hline Performance indicators in place & $\begin{array}{l}\text { Completeness } \\
\text { (The project team's KPI developer did not } \\
\text { have all the information from the business } \\
\text { regarding how to proceed with the KPI } \\
\text { development. This caused uncertainty and } \\
\text { potentially delayed the KPI initiative.) }\end{array}$ \\
\hline System understanding & $\begin{array}{l}\text { Completeness, purpose adequacy, } \\
\text { timeliness, bidirectionality, and audience } \\
\text { adequacy } \\
\text { (Influenced through training the users' } \\
\text { understanding of the system) }\end{array}$ \\
\hline Feeling of user involvement & $\begin{array}{l}\text { Completeness, purpose adequacy, } \\
\text { timeliness, bidirectionality, and audience } \\
\text { adequacy } \\
\text { (Influenced through training the feeling of user } \\
\text { involvement) } \\
\text { Bidirectionality } \\
\text { (The super and power user were involved by } \\
\text { the project team) } \\
\text { Credibility } \\
\text { (The senior management showed involvement } \\
\text { and commitment in their communication to } \\
\text { users) }\end{array}$ \\
\hline Documentation & $\begin{array}{l}\text { Bidirectionality } \\
\text { (Users were allowed to give feedback on how } \\
\text { to improve training material. Feedback was } \\
\text { taken into account.) } \\
\text { Purpose adequacy } \\
\text { (Users perceived documentation as adequate) }\end{array}$ \\
\hline Training & $\begin{array}{l}\text { Completeness } \\
\text { (Training and education perceived as more } \\
\text { complete compared to previous deployments) } \\
\text { Audience adequacy } \\
\text { (Training material and sessions were tailored } \\
\text { to the audience) } \\
\text { Purpose adequacy } \\
\text { (The education plan was changed and still } \\
\text { perceived as adequate) } \\
\text { Credibility } \\
\text { (Positive: Senior management conducted } \\
\text { opening and closing of education sessions. } \\
\text { Negative: Users were not always informed } \\
\text { properly by their superiors about the training) } \\
\text { Bidirectionality } \\
\text { (Feedback and suggestions of the business } \\
\text { taken into account by the project team) }\end{array}$ \\
\hline
\end{tabular}




\begin{tabular}{|c|c|}
\hline & $\begin{array}{l}\text { Timeliness } \\
\text { (Training was deployed way before the } \\
\text { GoLive. One department had training after } \\
\text { GoLive. Users perceived it still as adeqaute } \\
\text { showing an elasticity of the attribute } \\
\text { timeliness) }\end{array}$ \\
\hline System flexibility & $\begin{array}{l}\text { Completeness } \\
\text { (Training might have communicated the } \\
\text { system's flexibility better. In this sense the } \\
\text { communication was incomplete) }\end{array}$ \\
\hline Usefulness & $\begin{array}{l}\text { (Influenced through training. See section } \\
\text { "training") }\end{array}$ \\
\hline Ease of use & $\begin{array}{l}\text { (Influenced through training. See section } \\
\text { "training") }\end{array}$ \\
\hline Auditing and Control & $\begin{array}{l}\text { Credibility } \\
\text { (The senior management's communication } \\
\text { and commitment convinced users to use the } \\
\text { system and not work around it) } \\
\text { Openness } \\
\text { (The senior management hold back some } \\
\text { information in order to avoid unnecessary } \\
\text { confusion and fear among users) } \\
\text { Purpose adequacy } \\
\text { (Through withholding of information users } \\
\text { were better able to concentrate on and carry } \\
\text { out their tasks.) }\end{array}$ \\
\hline Output requirements & $\begin{array}{l}\text { Credibility } \\
\text { (The plant manager requested the financial } \\
\text { reports to be in the same format as in the } \\
\text { past.) }\end{array}$ \\
\hline Required time for the implementation & $\begin{array}{l}\text { Openness } \\
\text { Bidirectionality } \\
\text { (Business and project missed to communicate } \\
\text { openly about different understandings and } \\
\text { perspectives. They did not exchange their } \\
\text { views and opinions.) }\end{array}$ \\
\hline Attitude of the ERP project team & $\begin{array}{l}\text { Bidirectionality } \\
\text { (Feedback from the project team to the } \\
\text { business about the RFCs lacked.) } \\
\text { Openness } \\
\text { (The project hid information from the business } \\
\text { in certain cases. The business decided not to } \\
\text { ask the project team for further support, but } \\
\text { did not tell them either.) } \\
\text { Formality vs. informality } \\
\text { (The project team's support staff required the } \\
\text { users to follow a highly formal process to } \\
\text { receive support. It was perceived as more } \\
\text { complicated than necessary and caused } \\
\text { frustration.) }\end{array}$ \\
\hline
\end{tabular}




\begin{tabular}{|c|c|}
\hline & $\begin{array}{l}\text { Purpose adequacy } \\
\text { (In some areas the support staff was not able } \\
\text { to assist the users.) }\end{array}$ \\
\hline Domain knowledge of the project team & $\begin{array}{l}\text { Purpose adequacy } \\
\text { (Some project team members conducted } \\
\text { training for foreign functions and consequently } \\
\text { lacked some specific knowledge. It was seen } \\
\text { as a minor problem though.) } \\
\text { Bidirectionality } \\
\text { (The project team consulted certain users to } \\
\text { retrieve their knowledge about specific } \\
\text { processes. This was beneficial for the project.) } \\
\text { Openness } \\
\text { (The project team lacked openness in their } \\
\text { communication and organisation. This built the } \\
\text { foundation for speculations and negative } \\
\text { perceptions on the business side.) }\end{array}$ \\
\hline Relationship with the ERP project team & $\begin{array}{l}\text { Openness } \\
\text { (Both sides insisted to have been open, but } \\
\text { both did not communicate open with the other } \\
\text { side. This facilitated an attitude of blaming the } \\
\text { other party and inhibited possible } \\
\text { collaboration.) } \\
\text { Accuracy } \\
\text { (The project team provided sugar-coated } \\
\text { scorecards. This reduced the trust in the } \\
\text { project team.) } \\
\text { Bidirectionality } \\
\text { (Lacking feedback on RFCs. It created } \\
\text { frustration on the business side) }\end{array}$ \\
\hline $\begin{array}{l}\text { "I don't use the system at all" - Strong } \\
\text { resistance }\end{array}$ & $\begin{array}{l}\text { Credibility } \\
\text { Bidirectionality } \\
\text { (Change Management and Senior } \\
\text { Management addressed user concerns) }\end{array}$ \\
\hline $\begin{array}{l}\text { "I usually use the system." - Moderate to low } \\
\text { resistance }\end{array}$ & $\begin{array}{l}\text { Completeness } \\
\text { (Some training materials incomplete) } \\
\text { Credibility } \\
\text { (Some users doubted the given instruction of } \\
\text { the project team, but other users appreciated } \\
\text { that super users, trainers, and senior } \\
\text { managers addressed their concerns) } \\
\text { Purpose Adequacy } \\
\text { (Training material was found to suit the } \\
\text { purpose) } \\
\text { Audience Adequacy } \\
\text { (Communication was adjusted to different } \\
\text { hierarchy levels) } \\
\text { Timeliness } \\
\text { (Communication was done at appropriate }\end{array}$ \\
\hline
\end{tabular}




\begin{tabular}{|c|c|}
\hline & $\begin{array}{l}\text { times) } \\
\text { Balance of formality vs. informality } \\
\text { (Informal communication in form of peers and } \\
\text { super users complemented formal } \\
\text { communication) } \\
\text { Bidirectionality } \\
\text { (Trainers and manages listened to user } \\
\text { concerns) }\end{array}$ \\
\hline $\begin{array}{l}\text { "I regularly use the system" - Very low } \\
\text { resistance }\end{array}$ & $\begin{array}{l}\text { Credibility } \\
\text { Balance of formality vs. informality }\end{array}$ \\
\hline $\begin{array}{l}\text { Communication about financial benefits to } \\
\text { users }\end{array}$ & $\begin{array}{l}\text { Audience adequacy } \\
\text { (The senior management adapted its } \\
\text { communication to users.) } \\
\text { Purpose adequacy } \\
\text { (Management supplied the users only with the } \\
\text { information necessary to carry out the } \\
\text { implementation successfully.) }\end{array}$ \\
\hline Better process performance & Might have been influenced through training \\
\hline Less waste and inefficiencies & $\begin{array}{l}\text { Credibility } \\
\text { (Senior management stressed importance to } \\
\text { reduce waste and inefficiencies) }\end{array}$ \\
\hline
\end{tabular}




\section{Discussion}

Communication is a core process in organisations. Communication in organisations, and particularly during system development and implementation projects, enjoys a long research tradition in the IS field. It is still a highly relevant topic, because more integrated systems such as ERP systems connect all departments of an organisation and communication can be one of the keys to success. IS research has explored various aspects of communication such as communication quantity, frequency, the task media fit and their impact on project and team performance. IS research has again and again emphasised the importance of effective communication in IT projects. However, effective communication seems to entail more than quantity, frequency, and task/media fit. The IS literature started to recognise that such things as communication style, behaviour, and other aspects might play a role as well. Yet, studies exploring communication from this angle have been missing in the IS literature so far.

A similar story can be told about IS research and IS project success. IS success had been researched for a considerable time. Various studies applied different success measures such as budget and schedule or user satisfaction. However it has become evident that IS success is a multifaceted concept. A few dimensions might not be able to encompass the complexity of success. A project that is over budget, but satisfies the users and delivers business benefits could be regarded as either a success or failure depending on the choice of the success measure. Therefore, IS research recommended the development and application of multidimensional IS success measures. However, so far IS research has neither established such a measure for IT projects in general nor let alone for ERP projects which possess distinct features compared to other IT projects. Their magnitude, complexity, duration, and the idea of one integrated system demand specific success measures.

Therefore, the current study presents the concept of communication quality in the interaction between an IT project team and the rest of the business and the communication quality's influence on an ERP project success assessed via a multidimensional specific ERP success measure. The aim is to enhance the understanding of attributes of communication quality during ERP projects, their impact, interrelationships, and influence on ERP project success. The increased understanding can act as a foundation for future research and can assist practitioners during ERP system implementations. 
Nine attributes of communication quality were identified in the literature. However, as the topic is relatively new in the IS field and does not possess a well established theoretical base, it was necessary to refer back to reference disciplines in related fields such as marketing. The IS literature on information quality was used as a foundation. The nine attributes were divided into two categories, message content attributes and message process attributes. The message content attributes were completeness, credibility, accuracy, and purpose adequacy (Bailey \& Pearson, 1983; Chen et al., 2005; Coughlan, 2003; De Brabander \& Thiers, 1984; English, 2001; Gillard, 2005; Kahn et al., 2002; King \& Epstein, 1983; Lillrank, 2003; Lin \& Shao, 2000; Miller, 2005; Miller \& Doyle, 1987; Robertson, 2005; Srinivasan, 1985; Xu et al., 2003). The message process attributes were timeliness, openness, audience adequacy, bidirectionality, and a balance of formality vs. informality (Cavaye, 1995; Chen et al., 2005; De Brabander \& Edstrom, 1977; De Brabander \& Thiers, 1984; Gallivan \& Keil, 2003; Gillard, 2005; Holden \& O'Toole, 2004; Hornik et al., 2003; Mohr \& Nevin, 1990; Mohr \& Sohi, 1995; Mohr \& Spekman, 1994; Patrashkova-Volzdoska et al., 2003; Robertson, 2005; Taylor-Cummings, 1998; Wang et al., 2005). Based on these attributes communication quality was defined as a function of the message content and process attributes completeness, credibility, accuracy, purpose adequacy, timeliness, openness, audience adequacy, bidirectionality, and balance between formality and informality that influence the level of perceived satisfaction of the sender and receiver with the communicative interaction during an interaction where information is communicated (Holden \& O'Toole, 2004; Mohr \& Sohi, 1995; Robertson, 2005).

An ERP project success measure was developed based on the IS project success framework by Shenhar et al. (2001) along the three dimensions project efficiency, impact on users, and business benefits. The framework took into consideration that IS project success was a multifaceted concept and that different measures were appropriate to assess project success at different times. The framework was adjusted to the specific context of ERP implementation projects. The first success dimension contained the criteria budget and schedule as recommended by Shenhar et al. (2001). The second success dimension 'impact on users' was equipped with Wu and Wang's (2006) ERP ultimate user satisfaction construct measuring user satisfaction, and a model based on Davis (1989) assessing system acceptance and use. The third success dimension was business benefits such as financial performance gains, better process performance, higher quality products, 
less waste and inefficiencies, and that users understood the link of their individual tasks to the organisational benefits.

Based on the communication quality and ERP project success constructs, a structural model was developed examining the influence of communication quality on ERP project success. The results confirmed the attributes of communication quality.

The lack of openness in the communication between project team and business led to negative attitudes on the business side (Robertson, 2005). It also led to confusion among the stakeholders on the business side (Akkermans \& van Helden, 2002). The project team hid information to avoid worries on the business side, but it might have been in order to avoid embarrassment or negative consequences (Gillard, 2005). In areas where communication was open, it actually fostered collaboration and had a positive influence on project activities and consequently project success (Gargeya \& Brady, 2005; Molla \& Bhalla, 2006).

A correlation between bidirectionality and openness was found. The lack of openness also inhibited bidirectional communication in the sense that the business reduced its communication efforts, which decreased openness further. This is congruent with the findings of Maeda and Miyahara (2003) that openness is not only reached by information disclosure, but also by bidirectional communication. Bidirectionality and openness are also believed to be means to establish trust between individuals and groups. In the current study the business lost trust in the project team and the lack of openness and bidirectionality might have been important contributing factors for that.

The change management department or the project team considered audience adequacy when they tailored the education and training plan to the receiving audience. The change management department seemed to have been able to understand how users might have perceived the training. Differences between the training material that the project team's business analysts prepared and the users' needs were also reconciled (Hornik et al., 2003). It seemed to be helpful that the communication process was adjusted to the audience. The highly interactive education sessions represented a means of adapting the way of delivery to the audience (Gillard, 2005). The customisation helped to achieve a better understanding of the ERP project among the users. 
The communication process between the project team and the business lacked bidirectionality, especially in terms of missing feedback on RFCs. In a way the communication process was mainly one-way and the business was not really involved to contribute to the information exchange and the project in the form or providing input through RFCs. The business side was left with unanswered questions which lowered the perceived communication quality (Mohr \& Sohi, 1995). The project team as a sender mostly did not look for indications of either understanding or confusion on the business side and did not change its way of communication. This was in contrast to the idea of bidirectional communication (Gillard, 2005). If communication was bidirectional it might have reduced ambiguity and led to a closer relationship between the parties. Moreover, the commitment and the willingness to cooperate might have increased (Prahinski \& Benton, 2004). However, overall the opposite happened such as increased ambiguity, a weakening of the relationship, and less willingness to cooperate more than necessary especially on the business side. Only in a few areas was there high bidirectionality which resulted in better collaboration and better results, such as higher data quality during the data cleansing. The lack of bidirectionality in the organisation occurred independently from either formal or informal means of communication in the case organisation. This could be seen as an indicator of the bad quality of the relationship and unwillingness to collaborate between the project team and the business.

Informal communication was often seen as less complicated and time-consuming. Nevertheless, formal communication, such as presentations and meetings, also played an important role. Either way was perceived as more effective to solve certain situations and tasks (Hartwick \& Barki, 2001).. It seemed that the effectiveness and quality of the communication was influenced by the balance between mandatory formal communication and the amount of informal communication that occurs (Cavaye, 1995). Overall, informal communication was as important for a successful project outcome as formal communication (Gallivan \& Keil, 2003).

A lack of accuracy, bidirectionality, and openness seemed to occur independently from either formal or informal means of communication. This might have been an indication of internal problems rather than the communication means themselves. This was supported by statements of the Change Management department. 
The more complete way of communication, for example in the form of the more sophisticated education and training program, resulted in a better user understanding. It increased user satisfaction and contributed positively to project success, elevates (Lin \& Shao, 2000). Ambiguity and uncertainty was reduced as a consequence of more complete communication (Xu et al., 2003).

Credibility was evident in the communication from the senior management and super and power users to ordinary users. Users found that the messages came from reputable sources (Kahn et al., 2002) which was judged on such criteria as expertise, trustworthiness, and personal contact (Graefe, 2003). Therefore, users took the received communication probably more into consideration for their decision-making (Graefe, 2003).

The project team's reputation and credibility suffered when promises were not delivered and the team's general unresponsiveness to the business (Willcocks \& Sykes, 2000). The low credibility probably led to a decline in trust for the project team's communication. This made it difficult to achieve effective and high quality communication (Coughlan, 2003).

Accuracy was found to have been lacking in the communication from the project team to the business. Consequently, the business reported they were not able to carry out their project tasks as well as possible (Mohr \& Sohi, 1995), because it caused uncertainty and ambiguity. The communication of inaccurate information also reduced the business' trust in the project team and weakened the relationship.

Purpose adequacy was substantiated as an attribute of communication quality. Users received the communication they needed, such as training, in order to carry out their jobs. They received adequate communication on relevant topics and issues allowing them to perform well (Robertson, 2005). The adequate information avoided role ambiguity that could have been caused by inadequate communication. This avoided dissatisfaction and stress (Joshi \& Rai, 2000). The project promotion also achieved its purpose of accomplishing user buy-in. Purpose adequacy showed strong interrelationships with completeness, credibility, bidirectionality, audience adequacy, and timeliness, especially through the training and education communication. There was also a relationship to openness, but in the opposite direction to what was expected. The senior management hid certain information to avoid fears and achieve user-buy-in. 
Timeliness was found to be an element of communication quality. The communication from the project team to the business lacked timeliness which distorted the communication process and communication quality (De Brabander \& Thiers, 1984). Employees in the business thought that the lack of timeliness had a negative impact on their part of the work on the project. This caused frustration (Mohr \& Sohi, 1995).

In terms of training, timeliness showed some elasticity. Most users received the training long before GoLive, and one department even one month after GoLive. It was regarded as not optimal, but it did not have any significant negative impact on work performance or project success.

Timeliness was slightly related to openness. As the openness in the interaction between project team and the business declined, the timeliness of communication decreased accordingly. This might have been caused by frustration and an attitude of "they did not give us the information when we needed it".

Overall, all proposed attributes of communication quality were substantiated.

The ERP project was successful overall. The success was influenced by the attributes of communication quality. However, looking at the individual success criteria yields a more comprehensive picture.

\subsection{Project efficiency}

\section{Budget and Schedule}

Although the literature suggests that open and honest communication is an influential factor for project success in terms of budget and schedule (Akkermans \& van Helden, 2002; Gargeya \& Brady, 2005; Molla \& Bhalla, 2006), this could not be completely confirmed by the current study. In the current study the communication between project team and business showed openness in only certain areas. The middle management and users did not have much insight into the project team's planning, but the senior management did. Consequently, the communication lacked also bidirectionality on the user and middle management level. The project team circulated the scorecards openly, but they communicated inaccurate information. The communication lacked openness and honesty in some parts, but the project was still delivered within budget and on schedule. It might be that openness is not a dichotomic 'yes or no' attribute, but more like a continuum. It might 
be that the degree of openness in the case organisation was sufficient to keep the project within budget and on schedule. However, the lack of openness and the two related attributes, bidirectionality and accuracy, seemed to have a negative effect on user satisfaction and the business IT relationship.

\subsection{Impact on users}

\subsubsection{Meeting function requirements and technical performance}

Openness, bidirectionality, and completeness were expected to influence the collaboration process (Guimaraes et al., 2003) and in most parts of the collaboration between users and the project team communication was sufficiently open. Bidirectionality was missing and led to a slight lack of clarity and frustration among users. Completeness could not be found in this situation and could not be substantiated.

The organisation still needed to develop KPIs as there were hardly any in place. Some users would have liked more suitable KPIs, but it could only be speculated how users would react to their introduction. However, the positive experiences from the training and education for the ERP project in general might be an indication that adequate and tailored training for different audiences might facilitate the KPI adoption and usage process (Walker \& MacDonald, 200I).

\subsubsection{ERP ultimate user satisfaction}

The relationship between the project team and the business suffered and could be described as bad. A lack of transparency, openness, and accuracy in terms of the scorecards reduced the business' trust in the project team. The business found it necessary to install a so-called 'police' during the status meetings to ensure open and accurate communication. In terms of RFCs, bidirectionality was lacking as the feedback of the project team was sometimes vague. Encounters of this kind led to conflict between the two parties (Newman \& Robey, 1992). The two sides did not communicate more than necessary with each other and an "us vs. them-attitude' emerged on both sides, but more strongly on the business side. The reasons for the bad relationship were a lack in the communication quality attributes of openness, accuracy, and bidirectionality or in other words withholding information and distorted communication (Newman \& Robey, 1992). 
The communication between the project team and the business did lacked neither frequency nor quantity, nor were the channels inappropriate for the tasks. Rather a low level of communication quality had negative effects on user satisfaction. The communication quality was low in parts across all attributes except credibility and audience adequacy at times. The poor communication led to increased frictions between the business and the project team (Shah et al., 1994) and decreased user satisfaction (Wu \& Wang, 2006).

The project team possessed the necessary domain knowledge and skills to implement the ERP system. However, users wanted the project team to also improve the system. The project team might have possessed those skills, but their main objectives were to implement the system first, rather than to work on RFCs and system improvements. In such a situation communication can be a way to reconcile the two differing expectation sets and increase user satisfaction (Tesch et al., 2003), but the communication lacked openness and bidirectionality. Therefore, the expectation gap was not closed and user satisfaction decreased accordingly.

The missing feedback (bidirectionality) and openness regarding the RFCs also fostered the perception in the business that the project team did not assist the users with the system adoption (Wu \& Wang, 2006). This perception was also reinforced through the attitude of the project team during support, where the project team required the business users to follow an unnecessarily formal and complicated support process structure (unbalance of formality vs. informality). Business users also avoided asking questions to avoid rejection by the project team members. These issues were only discussed openly in parts, therefore again lacking openness.

The users and the business side as a whole found that the ERP implementation's progress was too slow. On the other hand, the project team was working with a high staff utilisation. The business was not aware of this, in fact it thought they had too many resources and used them inefficiently. This showed a lack of openness. The business expected more RFCs to be answered and implemented, but the project team's main objective was to deliver the ERP across all sites first and then work on improvements. Explanations about that to the business were lacking. The users found the project team's explanations and the required time as unreasonable and unacceptable rather than reasonable and acceptable, which decreased user satisfaction (Wu \& Wang, 2006). 
As expected most of the ERP system information output attributes were not influenced by communication quality. These attributes were accuracy, timeliness, reliability, response time, completeness, relevancy, and system stability. The users' perception for some attributes might have been indirectly influenced by communication quality though. Output requirements might have been influenced by credibility, because parts of the senior management requested users to create reports in ways they were accustomed to. Similarly, the senior management avoided promoting the use of KPIs to prevent unreasonable fears among the users. However, these two aspects were not part of the communication between business and the project team, but internal business, and therefore not a main focus of the current study.

The users' perception about system flexibility and system integrity might have been indirectly affected by communication quality. Training might have affected the perception of system flexibility. It might not have been complete enough to teach users all aspects. However, the perceived missing information might have resulted from the partial deployment or that users were still in the process of learning the system. In terms of system integrity, the collaboration between the data cleansing could have been beneficial. However, in both cases arguing for an influence of communication quality would be too much speculation.

The training and education programs provided the management and the project team with the opportunity to disseminate information and influence the users' beliefs and attitudes (Amoako-Gyampah \& Salam, 2004). The training and education exhibited multiple attributes of communication quality during this dissemination of information. Both, training and education sessions, were more complete compared to previous deployments by explaining the rationale and ERP project background in conjunction with the transactional training. The education program was tailored to be adequate for different audiences across different hierarchical levels. The training and education plan was modified in collaboration between the project team and the business. Users also gave feedback about the training material. The feedback was incorporated showing bidirectionality. The senior management conducted the opening and closing sessions of the education secessions enhancing credibility. However, the credibility was reduced somewhat by the middle management not informing some users properly about training 
sessions. The training material covered topics relevant to the users' everyday work showing purpose adequacy.

The documentation and training material was influenced by communication quality. It was found to be adequate for the purpose of learning and operating the system by most users. User feedback was incorporated highlighting bidirectionality. The training and documentation material was also mainly complete which facilitated user satisfaction (Wu \& Wang, 2006).

The degree of user involvement was facilitated by the willingness of the management and the project team to be open for discussion (Dewulf \& Meel, 2002). Although the project team's communication lacked openness in some parts, users were involved by the project team into the project to a considerable degree. In most parts users participated through the super and power users, but in specific cases the project team also involved ordinary users to ask for their input, which showed openness and bidirectionality. The management and project team members reviewed processes together with some users adding credibility to the communication. However, overall there was only a slight feeling of user involvement, but it was nevertheless fostered by communication quality.

The users' system understanding was advanced through the training where users got to know the system and received first hand experience from working with the system (Amoako-Gyampah \& Salam, 2004). The training facilitated the users' understanding of the ERP system and their role in the overall picture. This understanding was considered as important, because it had been lacking in previous ERP module implementations Educating users about the interdependencies and rationale of integrated systems, such as ERP systems, was found to increase training effectiveness and to be necessary with these types of systems compared to old stand alone systems (Sein, Bostrom, \& Olfman, 1999). This fostered the users' system understanding.

\subsubsection{System acceptance and use}

The use of the new ERP system was related to how it was communicated to the users. It was possible to confirm a link between communication and system acceptance and use (Sarel \& Marmorstein, 2002). It was possible to confirm the importance of audience adequacy, but credibility, bidirectionality, purpose adequacy, and a balance of formality vs. informality were found to be even more important. In sum, it was most important for the 
users to receive communication, which was believable and backed up by the management, which suited the purpose, that the users' feedback was taken into account, that the information was communicated in an understandable way, and that there were more than the one formal way to receive the information. This facilitated system use and acceptance and consequently ERP project success.

Means that were used to influence system acceptance and use were found to be user training, project champions, opinion leaders (Amoako-Gyampah \& Salam, 2004), and to a minor degree user support (Jiang, Klein, \& Chen, 2006). The project champion and the opinion leaders, meaning the super and power users, encouraged the users to use system, which was facilitated by their reputation and knowledge. Users, for example, consulted super and power users in case of problems dealing with the uncertainty caused by the new system ( $\mathrm{Lu}, \mathrm{Yao}, \& \mathrm{Yu}, 2005)$. The training was tailored to the respective audience and appropriate topics and tasks should were covered (Nelson et al., 1995), which fostered system acceptance and use.

Although system use was actually mandatory a positive atmosphere was evident among the users towards the system. Participants and the organisation itself attributed this to quality of the communication. Despite the communication was not perfect, it was in general found to be a vast improvement to previous roll outs and to have successfully prevented system avoidance as in a previous roll out. Consequently, system acceptance and use was found to be positive related to communication quality.

\subsection{Business benefits}

The ERP benefits in the form of financial gains inventory and costs reduction (Al-Mashari et al., 2003; Gupta, 2000; Mabert et al., 2003; Tarn et al., 2002) were minimal at the time of the study. They were much less than originally expected, but this might have been because the benefits were expected earlier than it was possible to achieve them. The aspect of achieving financial benefits was not influenced by communication quality

The process performance improvements were in their early stages. Users were able to see the first indication. In the manufacturing department the process improvements were a mix of the new system and changed and redesigned processes. The redesigning and changing of processes took place in a dynamic communication process with feedback loops, a common language between the project team people and the manufacturing department, and a willingness to raise issues (Ackermann et al., 1999). Therefore, it was influenced by communication quality, especially the attributes of openness, bidirectionality, and audience 
adequacy. Effective communication can support business process redesign success (Paper et al., 2003), and communication quality seemed to have supported the success as well.

The organisation started an initiative to achieve higher quality products and higher customer satisfaction, but it was in its early stages. Similarly, there was not enough evidence to see if this area was influenced by communication quality.

Reducing waste and eliminating inefficiencies was expected to be realised through collaborative job role design between the IT staff and users (Worleya et al., 2005), but this could not be supported by evidence. On the other hand there was evidence that this area might be influenced through credible communication. User behaviour was reinforced by the commitment and communication of the senior management, which was found to influence the users' beliefs and attitudes (Amoako-Gyampah \& Salam, 2004). This might have influenced the users" behaviour.

The organisation had realised that there was a need to communicate the link of day-to-day activities to organisational benefits such as financial results (Crosby \& Johnson, 2006). However, the organisation preferred to emphasise more qualitative benefits such as growth and work improvements rather than financial aspects such as cost reduction. There was the fear this might have caused concerns among the users that cost reduction could mean job cuts. The link between the organisational and individual benefits was highlighted in the training and education sessions which covered the overall organisational processes, the individual work tasks, and how they fitted together. This highlighted the communication attributes of completeness and audience adequacy.

Additionally, performance measurement models could have been used to explain the link to users (Crosby \& Johnson, 2006), but hardly any KPIs were in operation at the time of the study. The KPI development initiative had stopped, because of several organisational strategic changes. Business and KPI developers were slightly confused and waited for the other side to take some initiative. The communication was not effective in that area and both groups lost out (Kettinger \& Lee, 2002).

\subsection{Implications for academia}

The current study has several implications for academia. The study proposed the concept of communication quality with nine attributes. Although communication between the IS 
specialist and the users has been a subject of research in the IS field since the 1970s (De Brabander \& Edstrom, 1977; De Brabander \& Thiers, 1984), it was not until recently that researchers noted that there might be more facets to communication than frequency, quantity, and task/media fit (Gallivan \& Keil, 2003). However, so far and to the author's knowledge communication quality has not received much attention in IS research. Therefore, this study contributes to the academic body of knowledge by proposing and studying the concept of communication quality in a large ERP project in an organisation. This advances the understanding of communication in organisations, but especially communication between the IT project team or department and the rest of the business including the users during ERP implementations projects. The study showed that communication quality is an important aspect of the often generally used term "effective communication" next to quantity, frequency, and task/media fit.

The study confirmed the construct of communication quality and its nine attributes, through high interrater reliability and the research's results. Therefore, the construct of communication quality can be used to study aspects and areas more specifically in which communication quantity, frequency, or task/media fit do not yield conclusive results. This might help to explain situations and results more adequately, considering that communication is indeed a multifaceted construct.

In addition, the current study developed and applied a multidimensional ERP project success measure incorporating multiple stakeholder viewpoints which has been lacking in IS research (Willcoxson \& Chatham, 2004). The author followed Shenhar et al.'s (2001) argument that project success is a multidimensional concept with different success measurements appropriate for different times of a project. The framework was modified to fit the specific context of an ERP implementation project. The tool demonstrated its usefulness mainly in analysing ERP project success with multiple stakeholder perspectives. In the past IS research often used surrogates to analyse project success such as budget and schedule or user satisfaction. However, this provided only a partial picture of IS project success and might have overlooked crucial aspects. Moreover, it might have led to incorrect conclusions. A project might have been judged as successful according to delivery on schedule and within budget, although the users were completely dissatisfied with the system and rejected it (Shenhar et al., 2001). Therefore, the ERP project success 
framework in the current research provides IS research with a tool to analyse ERP project success and achieve a more comprehensive view of it.

The ERP project success measure utilised well respected and validated measurements such as Wu and Wang's (2006) ERP ultimate user satisfaction and a framework based on Davis' (1989) model of system acceptance and use. This confirmed their applicability and usefulness. The additional parts of the ERP project success framework in this study were validated by two independent coders showing a consistently high interrater reliability between each other and with the author. Therefore, the framework showed that it is indeed a useful tool to analyse ERP project success granting it applicability and validation.

Both constructs, communication quality and ERP project success, were applied in a single case in-depth case study with 54 interviews and copious company documentation in a large North-American manufacturing company. This yielded an in-depth insight into the organisation and the communication between an IT project team and the business including the users. Access to and effective collaboration with a case organisation has sometimes been troublesome in IS research. Therefore, the current study distinguished itself from a lot of IS studies in this regard.

The current study also introduced a new type of research methodology into IS research. To the author's best knowledge, there have been hardly any studies in IS applying the research method of secondary analysis of qualitative data. Therefore, the current study enriches the methodological area of IS research by introducing this research method from sociology and psychology. In future this method can be utilised in IS to analyse particular topics in more detail, conduct supplementary research on interesting topics that emerge during primary research, and to reanalyse existing data from different theoretical angles. This might contribute to a deeper understanding of various subjects and confirm or disconfirm previous studies. This might advance the IS body of knowledge further.

Finally, the current study used software to support the analysis process of the large amount of qualitative data. This was extremely useful. It would been significantly more time consuming to analyse the same amount of data manually, for example by working with paper, different coloured pens, and literally cutting interviews into pieces (see, Hramiak, 2005; Krueger, 2002). Some critics of using software have argued that the researcher might lose contact with the data by using software (Seidel, 1991). However, the author argues 
that it depends on the type of software. The software used mainly supported the text retrieval process, but did not code or analyse the data automatically. There might be software available which can do this, but it was not used in the current research. The coding and analysis were still the author's tasks. Therefore, the author still immersed himself into the data sufficiently. In addition, the software provided the author with some interesting further analysis options such as code co-occurrences and code relationship illustrations. Therefore, it was found that the use of software greatly supported the data analysis process.

\subsection{Implications for practice}

The study suggested that communication quality influences ERP project success. The study's results indicate that it might be beneficial to consider communication quality in ERP system implementations. Further it might make sense to analyse project success from multiple perspectives and not only according to monetary terms and schedule.

The study highlighted how important a sophisticated training, education, and communication strategy is to facilitate ERP project success. Although there is often a perception among practitioners that these things are only time and money consuming with unclear results, it has shown again and again that they pay off in the intermediate and long run. The vast majority of users in the current study regarded the training and education strategy as one of the key success factors for the ERP project.

It was also shown that it is not enough to focus on communication quantity, frequency, or channels. Overall, there was frequent and a lot of communication over various channels within the organisation. Nevertheless, in some areas communication was not effective. It became evident that communication quality was lacking. Therefore, practitioners might pay more attention to the quality of communication as well to facilitating project success according to a more comprehensive and holistic view. It might be possible to deliver ERP projects successfully in the traditional sense, i.e. within budget and on time, but intraorganisational relationships and users satisfaction might suffer. This could have detrimental effects on the future success of projects and the organisational working environment. Especially for ERP system projects as integrated systems, it has been shown to be important to have the buy-in and understanding of the users to make them a success (Crosby \& Johnson, 2006; Worleya et al., 2005). 
The study also shows how two parties, which actually belong to the same organisation, can have such different objectives, perspectives, and understandings about the same ERP project. The user-project team divide also seemed to have diverged further over time. The relationship between the two sides became bad, although both sides should actually act in concert. Consequently an "us vs. them" attitude emerged and the two sides were more like two separate entities. One could argue though that this might only be temporary and for the duration of the ERP project. However, the project implementation has been taking five years and was expected to continue for about 2-3 years. After that it might be necessary for some time to work on system improvements to achieve the benefits that the organisation originally expected. This might be really challenging with a bad relationship and lacking communication. Therefore, this might highlight how important it is to manage differences in expectations and understandings. Moreover, relationship management and the businessIT alignment gain importance. At the basis of all of this is communication and one needs to pay attention to communication quality.

The last few projects were planned backwards meaning the delivery date was set first. This might have led to several problems, because estimations about project delivery without assessing resources and the necessary tasks might have been inaccurate. As a consequence there was a high pressure on the schedule and the human resources. Ultimately the project had to be de-scoped to deliver on time. It might have been better to analyse the necessary tasks and resources first. The organisation also tended to hang on to their way of product delivery when planning and executing projects. A different approach might be more appropriate for projects.

One aspect that resulted out of this way of project planning was the high degree of human resources within the project team. Again it might be argued that it is a temporary project, but it has been taking years. Of course, the organisation was under pressure as the main competitors already had implemented ERP systems and the competitive business environment did not give any time to breathe. However, the organisation was walking a tightrope without a safety net underneath, because the key human resources had hardly any shadows who could replace them if they had dropped out. Of course, the human resources aspect was a double edged sword and there were time and money constraints, but it simply did not fit with appreciating the human resources as a valuable asset and with the 
organisation's aspiration of "building a save and rewarding work environment for the employees".

The ERP project also showed that it might take longer than anticipated to implement an ERP system organisation wide for various reasons. This could be the extraction and transfer of data from the legacy system and the alignment process between existing processes and SAP's inherent processes. Developing KPIs that are standardised and accepted across all sites of an organisation might also be more difficult than one might expect. All these aspects might also delay the realisation of benefits. The organisation realised that it was not only a technical issue to implement the ERP system, but a whole organisational and cultural change. This was even more challenging and took longer than the technical aspects. Therefore, the organisation decided to put more emphasis on the education and training strategy, which might assist the organisation in its business transformation process.

One aspect that did not facilitate the business transformation was the lack of follow up of lessons learned. The management asked the employees (especially in the project team) to compile lists of lessons learned, but most employees and the Change Management department had the impression they were hardly ever followed up. Employees concluded they were always coming back to the same old methodology on how to perform tasks and solve problems. In this area a lack of communication quality became evident as well, because there was a lack of feedback.

A further area where communication was lacking, was the KPI development. The business and the KPI developers were waiting for the other side to act first. The organisation was also still in the cultural change process to accept and use KPIs to develop as an organisation. In this area communication and education might become important in the near future.

Finally, the organisation customised SAP instead of sticking to a vanilla implementation which is regarded as best practice (Gargeya \& Brady, 2005). This might have led to several problems such as slow system performance. Moreover, the organisation might have not been able to capitalise on SAP's full potential. 


\subsection{Study limitations and future research}

Although the current research had 54 interviews and company documentation at its disposal, it was still an exploratory single-case study. The constructs 'communication quality' and 'ERP project success' were confirmed, but so far it remains questionable how generalisable and generally applicable they are. Further studies should be conducted to confirm or disconfirm parts of or the complete two constructs. Multiple case studies or quantitative studies with survey instruments seem especially appropriate.

Case studies might have the problem that interviewee answers are biased in order to let themselves and the organisation appear in the best light. However, in the current study this is not believed to be the case, although it cannot be completely rejected. The case organisation ordered HEC Montréal to conduct an audit of their ERP implementation in the primary study. Therefore, it can be assumed that the bias is minimal if evident at all. However, only further studies can show that the results are not biased, but generalisable.

The study was also only exploratory in nature. It might be that both the communication quality and ERP success constructs miss items or that there are more appropriate ones, although a thorough literature review was conducted and the study findings did not indicate so. However, different research methods might unearth further or more appropriate variables.

The study applied a new research methodology in terms of use within the IS field. Even in sociology secondary analysis of qualitative data is not a solidly established research methodology. However, the author tried to ensure a thorough documentation of the research method. Yet it represents one the first in the IS field and might benefit from fine honing in future studies. These could establish general rules and guidelines on how to conduct secondary analysis of qualitative data in the IS discipline.

Another point of debate could be if sociology was suitable to serve as a reference discipline to support the research methodology. However, IS and sociology are believed to have reasonably sufficient characteristics in common. Sociology has used several times as a reference discipline for IS research. Therefore, the research methodology is believed to be applicable for IS research. However, further studies could explore the specific details and which aspects are in fact specific to only IS research. 
The research methodology is somewhat cumbersome in its current form. It requires restoring more contextual cues than in an ordinary case study in primary research. Examples are the social characteristic for each interviewee such as age, gender, and nationality. Usually position and role are used in primary case studies. Future research could explore which contextual cues are salient and which parts of the methodology are most important. Future research could streamline the research method for the IS field.

A further point is the reconciliation of the method with different research paradigms. Secondary research is mainly based on interpretivism. However, in IS research other paradigms are also common such as positivism. However, IS and other researcher have argued for mixed approaches (Creswell), but future studies could explore specifically the paradigm aspect in relation to secondary analysis of qualitative data for the IS field.

The current research applied frameworks, especially the ERP success construct, that contain a number of variables. It was difficult to thoroughly explore all interrelationships. In certain cases it was not possible because of missing data, but that was a minor factor. The main challenge was simply the vast amount of possible interrelationships and the level of detail in the current model. Future studies might want to focus on individual aspects such as the influence of communication quality on user satisfaction or system acceptance. This might also yield more detail in those areas and make the research more manageable. The current study results might have suffered as a consequence of the framework size and number of variables. However, the author tried to ensure thoroughness and rigour in the study. Arguably, in its current form the research lacks readability and reader-friendliness.

The current research also found a few interrelationships between the attributes of communication quality. Future research could assess if the attribute categories lack distinctiveness and/or what the interrelationships are.

Similarly, the relationship of the individual success variables deserves attention. It has not become clear so far which variable is associated with which level of importance. Can user satisfaction overall be denoted as negative if only the communication was negative, but everything else such as the system interactions were positive? Therefore, future research should investigate this on the level of user satisfaction, but also on the level of project success. If user satisfaction was used as the only project success surrogate it was easy to conclude that a project was either successful or unsuccessful. However, how does it look if 
it is used in a framework such as the ERP success framework in the current research? Could user satisfaction be negative, but all the other variables positive, and the project still be called successful? Or should it be denoted as unsuccessful? Is it possible to refer to a project as either successful or not at all, if the success measure is multidimensional as in the current study? Various options for future research open up.

Shenhar (2001) developed his framework with the consideration of time and the possibility of change for the most appropriate success variables. In the current study the author did not assess the fourth dimension "Preparing for the future" at all. It was not expected to be visible in the study's timeframe. However, even in the third dimension "Business benefits" it was difficult to receive decisive results. The main problem was that it was simply too early for the organisation to see the full extent of the benefits. On the one hand this might question the general feasibility of this ERP success framework in general. On the other hand, future research could explore ERP project success over longer time frames to receive a truly comprehensive view of ERP success. However, in the case of such a long timeframe other variables might impact the ultimate success. Therefore, it would be necessary to clearly isolate the effect of the variables on ERP success in the framework from external ones.

The current ERP success framework is also specific to ERP systems and their degree of technological uncertainty (Shenhar et al., 2001). As Shenhar et al. (2001) argued project efficiency, impact on users, commercial success, and preparing for the future can vary in their importance across projects with other degrees of technological uncertainty. Therefore, the current framework is probably very specific to the context of ERP systems, but future research might explore its applicability to similar IS system such as Enterprise Application Intergation (EAI).

Finally, the IT project team-user relationship (quality) and IT-business alignment seemed to be two areas that might be strongly impacted by communication quality. Future research should explore those topics. 


\section{Conclusion}

As the review of the literature and empirical results have shown, communication quality is a neglected yet important aspect of effective communication between an IT project team and the business and influences ERP implementation project success. Our results suggest that communication quality constitutes of at least nine attributes, divided into two categories - 'message content' and 'message process'. The attributes for the message content are completeness, credibility, accuracy, and purpose adequacy. The attributes for the message process are timeliness, openness, audience adequacy, bidirectionality, and a balance of formality vs. informality. Our findings further indicate that ERP implementation project success is a multidimensional concept in which the most appropriate success measures are dependent on the project phase and the examined timeframe, the stakeholder perspective, and the technological uncertainty and complexity respectively. The study shows that communication can lack effectiveness, even though there is frequent and a large quantity of communication over media that are most appropriate for the respective task. The lack of communication effectiveness is caused by a lack of communication quality, which influences ERP project success negatively. Therefore, communication quality represents an additional aspect of effective communication. However, the degree of the influence of communication quality on ERP implementation project success varied across the different measurement criteria of ERP project success. A lack of communication quality especially seems to deteriorate the relationship between the IT project team and the business resulting in slightly dissatisfied users. Project efficiency measures such as 'staying within budget' and 'on schedule' are impacted negatively by poor communication quality, although only to a minor extent. Even in an environment of mandatory use, system acceptance and use seems to be facilitated by better communication quality. The realisation of business benefits seems to be related indirectly to communication quality via the users' daily work and the communication they receive in various forms for work preparation, such as training. Consequently, there seems to be an influence of communication quality on ERP project success in a positive correlation. IS researchers and practitioners need to pay more attention to communication quality, its attributes, and their influence on ERP implementation project success and its individual criteria in the future. 


\section{References}

Ackermann, F., Walls, L., Meer, R. v. d., \& Borman, M. (1999). Taking a strategic view of BPR to develop a multidisciplinary framework. The Journal of the Operational Research Society, 50(3), 195-204.

Akkermans, H., \& van Helden, K. (2002). Vicious and virtuous cycles in ERP implementation: a case study of interrelations between critical success factors. European Journal of Information Systems, 11(1), 35-46.

Al-Mashari, M., Al-Mudimigh, A., \& Zairi, M. (2003). Enterprise resource planning: A taxonomy of critical factors. European Journal of Operational Research, 146(2), 352-364.

Al-Mudimigh, A., Zairi, M., \& Al-Mashari, M. (2001). ERP software implementation: an integrative framework. European Journal of Information Systems, 10(4), 216-226.

Altheide, D. L., \& Johnson, J. M. (1994). Criteria for assessing interpretive validity in qualitative research. In Denzin, N. K. \& Lincoln, Y. S. (Eds.), Handbook of qualitative research (pp. 485-499). Thousand Oaks, CA: Sage Publications.

Amoako-Gyampah, K., \& Salam, A. F. (2004). An extension of the technology acceptance model in an ERP implementation environment. Information \& Management, 41(6), $731-745$.

Andersson, T., \& von Hellens, L. A. (1997). Information systems work quality. Information and Software Technology, 39(12), 837-844.

Bailey, J. E., \& Pearson, S. W. (1983). Devlopment of a tool for measuring and analysing computer satisfaction. Management Science, 29(5), 530-545.

Barclay, D. W., \& Smith, J. B. (1997). The effects of organizational differences and trust on the effectiveness of selling partner relationships. Journal of Marketing, 61(1), 321.

Barki, H., \& Hartwick, J. (1989). Rethinking the concept of user involvement. MIS Quarterly, 13(1), 53-63.

Barki, H., \& Hartwick, J. (1994). User participation, conflict, and conflict resolution: The mediating roles of influence. Information Systems Research, 5(4), 422-438.

Barki, H., \& Hartwick, J. (2001). Interpersonal conflict and its management in information system development. MIS Quarterly, 25(2), 195-228.

Baronas, A.-M. K., \& Louis, M. R. (1988). Restoring a sense of control during implementation: How user involvement leads to systems acceptance. MIS Quarterly, 12(1), 111-124.

Baroudi, J. J., \& Orlikowski, W. J. (1988). A short-form measure of user information satisfaction: A psychometric evaluation and notes on use. Journal of Management Information Systems, 4(4), 44-59.

Benbasat, I., Goldstein, D. K., \& Mead, M. (1987). The case research strategy in studies of Information Systems. MIS Quarterly, 11(3), 369-386.

Berchet, C., \& Habchi, G. (2005). The implementation and deployment of an ERP system: An industrial case study. Computers in Industry, 56(6), 588-605.

Bernard, H. R. (2000). Social research methods - qualitative and quantitative approaches. Thousands Oaks, CA: Sage Publications.

Bernard, J.-G., Rivard, S., \& Aubert, B. A. (2004). L'exposition au risque d'implantation de ERP : éléments de mesure et d'atténuation. Systèmes d'information et management, 2(9), 25-50.

Bokhari, R. H. (2005). The relationship between system usage and user satisfaction: a meta-analysis. Journal of Enterprise Information Management, 18(1/2), 211-234. 
Boudreau, M.-C., Gefen, D., \& Straub, D. W. (2001). Validation in information systems research: A state-of-the-art assessment. MIS Quarterly, 25(1), 1-16.

Bowers, J. W., \& Courtright, J. A. (1984). Communication Research Methods. Glenview, IL: Scott, Foresman.

Boyle, T. A., Kumar, U., \& Kumar, V. (2005). Organizational contextual determinants of cross-functional NPD team support. Team Performance Management, $l /((1 / 2))$, 27-39.

Carù, A., Cova, B., \& Pace, S. (2004). Project success: Lessons from the Andria case. European Management Journal, 22(5), 532-545.

Cavaye, A. L. M. (1995). User participation in system development revisited. Information \& Management, 28(5), 311-323.

Chen, H. H. G., Miller, R., Jiang, J. J., \& Klein, G. (2005). Communication skills importance and proficiency: Perception differences between IS staff and IS users. International Journal of Information Management, 25(3), 215-227.

Corti, L., Witzel, A., \& Bishop, L. (2005). On the potentials and problems of secondary analysis. An introduction to the FQS Special Issue on secondary analysis of qualitative data, Forum Qualitative Sozialforschung/Forum: Qualitative Social Research (Vol. 6).

Coughlan, J. (2003). Communication issues in requirements elicitation: A content analysis of stakeholder experiences. Information and Software Technology, 45(8), 525-537.

Coughlan, J., Lycett, M., \& Macredie, R. D. (2005). Understanding the business-IT relationship. International Journal of Information Management, 25(4), 303-319.

Cowton, C. J. (1998). The use of secondary data in Business Ethics research. Journal of Business Ethics, $17(4), 423-434$.

Crosby, L. A., \& Johnson, S. L. (2006). Cause and effect. Marketing Management, 15(3), $12-13$.

Davenport, T. H. (1998). Putting the enterprise into the enterprise system. Harvard Business Review, 76(4), 121-131.

Davis, F. D. (1989). Perceived usefulness, perceived ease of use, and user acceptance of information technology. MIS Quarterly, 13(3), 319-340.

De Brabander, B., \& Edstrom, A. (1977). Successful information system development projects. Management Science, 24(2), 191-199.

De Brabander, B., \& Thiers, G. (1984). Successful information system development in relation to situational factors which affect effective communication between MISusers and EDP-specialists. Management Science, 30(2), 137-155.

DeLone, W. H., \& McLean, E. R. (1992). Information System Success: The quest for the dependent variable. Information Systems Research, 3(1), 60-95.

DeLone, W. H., \& McLean, E. R. (2003). The DeLone and McLean model of information systems success: A ten-year update. Journal of Management Information Systems, $19(4), 9-30$.

Dewey, B. I., \& DeBlois, P. B. (2006). Top-ten IT Issues 2006. Educause Review, 41(3), $58-79$.

Dewulf, G., \& Meel, J. v. (2002). User participation and the role of information and communication technology. Journal of Corporate Real Estate, 4(3), 237-247.

Doll, W. J. (1987). Encouraging user management participation in systems-design. Information \& Management, 13(1), 25-32.

Doll, W. J., \& Torkzadeh, G. (1988). The measurement of end-user computing satisfaction. MIS Quarterly, 12(2), 259-274.

Dubé, L., \& Paré, G. (2003). Rigor in Information Systems positivist case research: Current practices, trends, and recommendations. MIS Quarterly, 27(4), 597-636. 
Dvir, D., Raz, T., \& Shenhar, A. J. (2003). An empirical analysis of the relationship between project planning and project success. International Journal of Project Management, 21(2), 89-95.

Emory, C. W., \& Cooper, D. R. (1991). Business research methods (4th ed.). Boston, MA: Richard D. Irwin.

English, L. P. (2001). Information quality management: the next frontier. In Annual Quality Congress Proceedings (pp. 529-533). Milwaukee, WI: American Society for Quality.

Eriksson, O. (2002). Communication quality in the context of information systems and business processes. In Liu, K., Clarke, R. J., Andersen, P. B. \& Stamper, R. K. (Eds.), Coordination and communication using signs: Studies in organisational semiotics (pp. 115-128). Boston: Kluwer Academic Publishers.

ERP systems improve quality. (2003). Quality, 42(5), 16.

Evans, A. (2004). Retrieved May 11, 2006, from University of Pretoria, South Africa

Feeny, D. F., Edwards, B. R., \& Simpson, K. M. (1992). Understanding the CEO/CIO relationship. MIS Quarterly, 16(4), 435-448.

Fielding, N. (2004). Getting the most from archived qualitative data: epistemological, practical and professional obstacles. International Journal of Social Research Methodology, 7(1), 97-104

Fielding, N., \& Fielding, J. (2000). Resistance and adaptation to criminal identity: using secondary analysis to evaluate classic studies of crime and deviance. Sociology, 34(4), 671-689.

Foster, T., Jr., \& Charles, R. F. (1999). User involvement during information systems development: A comparison of analyst and user perceptions of system acceptance. Journal of Engineering and Technology Management, 16(3/4), 329-348.

Fui-Hoon Nah, F., Lee-Shang Lau, J., \& Kuang, J. (2001). Critical factors for successful implementation of enterprise systems. Business Process Management Journal, 7(3), 285-296.

Gallivan, M. J., \& Keil, M. (2003). The user-developer communication process: a critical case study. Information Systems Journal, 13(1), 37-68.

Gargeya, V. B., \& Brady, C. (2005). Success and failure factors of adopting SAP in ERP system implementation. Business Process Management Journal, 11(5), 501-516.

Garvin, D. A. (1984). What does "product quality" really mean?. Sloan Management Review, 26(1), 25-43.

Gillard, S. (2005). Managing IT projects: communication pitfalls and bridges. Journal of Information Science, 3I(1), 37-43.

Graefe, G. (2003). Incredible information on the Internet: Biased information provision and a lack of credibility as a cause of insufficient information quality. In Eppler, $M$. \& Helfert, M. (Eds.), Proceedings of the Eighth International Conference on Information Quality (pp. 133-145). Cambridge, Massachusetts, USA.

Grant, G. G. (2003). Strategic alignment and enterprise systems implementation: The case of Metalco. Joumal of Information Technology, 18(3), 159-175.

Guimaraes, T., Staples, D. S., \& McKeen, J. D. (2003). Empirically testing some main user-related factors for systems development quality. The Quality Management Journal, 10(4), 39-54.

Gupta, A. (2000). Enterprise resource planning: The emerging organizational value systems. Industrial Management \& Data Systems, 100(3-4), 114-118.

Gupta, M., \& Kohli, A. (2006). Enterprise resource planning systems and its implications for operations function. Technovation, 26(5-6), 687-696. 
Hameri, A.-P. (1997). Project management in a long-term and global one-of-a-kind project. International Journal of Project Management, 15(3), 151-157.

Harcout, J., Richerson, V., \& Wattier, M. J. (1991). A national study of middle managers' assessment of organisation communication quality. The Journal of Business Communication, 28(4), 348-365.

Hardie, N., \& Walsh, P. (1994). Towards a better understanding of quality. The International Journal of Quality \& Reliability Management, 1/(4), 53-63.

Hartwick, J., \& Barki, H. (2001). Communication as a dimension of user participation. IEEE Transactions on Professional Communication, 44(1), 21-36.

Heaton, J. (1998). Secondary analysis of qualitative data, Social Research Update (Vol. Issue 22).

Heaton, J. (2004). Reworking qualitative data. London: Sage Publications Ltd.

Hiltz, S. R., \& Johnson, K. (1989). Measuring acceptance of computer-mediated communication systems. Journal of the American Society for Information Science, 40(6), 386-397.

Hinds, P. S., Vogel, R. J., \& Clarke-Steffen, L. (1997). The possibilities and pitfalls of doing a secondary analysis of a qualitative data set. Qualitative Health Research. 7(3), 408-424.

Hirschheim, R., \& Klein, H. K. (1989). Four paradigms of information systems development. Communications of the ACM, 32(10), 1199-1216.

Holden, M. T., \& O'Toole, T. (2004). A quantitative exploration of communication's role in determining the governance of manufacturer-retailer relationships. Industrial Marketing Management, 33(6), 539-548.

Hornik, S., Chen, H.-G., Klein, G., \& Jiang, J. J. (2003). Communication skills of IS providers: An expectation gap analysis from three stakeholder perspectives. IEEE Transactions on Professional Communication, 46(1), 17-34.

Hramiak, A. (2005). A method for the analysis of data from online educational research. Journal of Interactive Online Learning, 4(2), 82-93.

Ives, B., Olson, M., \& Baroudi, J. J. (1983). The measurement of user information satisfaction. Communications of the ACM, 26(10), 785-793.

Ives, B., \& Olson, M. H. (1984). User involvement and MIS success: A review of research. Management Science, 30(5), 586-603.

Jiang, J. J., Klein, G., \& Chen, H.-G. (2006). The effects of user partnering and user nonsupport on project performance. Journal of the Association for Information Systems, 2(1), 68-90.

Jiang, J. J., Klein, G., Slyke, C. V., \& Cheney, P. (2003). A note on interpersonal and communication skills for IS professionals: Evidence of positive influence. Decision Sciences, 34(4), 799-812.

Johnson, A. M., \& Lederer, A. L. (2005). The effect of communication frequency and channel richness on the convergence between chief executive and chief information officers. Joumal of Management Information Systems, 22(2), 227-252.

Joshi, K., \& Rai, A. (2000). Impact of the quality of information products on information system users' job satisfaction: an empirical investigation. Information Systems Journal, 10(4), 323-345.

Kahn, B. K., Strong, D. M., \& Wang, R. Y. (2002). Information quality benchmarks: Product and service performance. Communication of the ACM, 45(4), 184-192.

Kenny, J. (2003). Effective project management for strategic innovation and change in an organizational context. Project Management Journal, 34(1), 43-53.

Kettinger, W. J., \& Lee, C. C. (2002). Understanding the IS-user divide in IT innovation. Communications of the ACM, 45(2), 79-84. 
King, W. R., \& Epstein, B. J. (1983). Assessing information system value. Decision Sciences, 14(1), 34-45.

Klein, G., Jiang, J. J., \& Sobol, M. G. (2001). A new view of IS personnel performance evaluation. Communications of the ACM, 44(6), 95-101.

Kositanurit, B., Ngwenyama, O., \& Osei-Bryson, K.-M. (2006). An exploration of factors that impact individual performance in an ERP environment: an analysis using multiple analytical techniques. European Journal of Information Systems, 15(6), 556-568.

Kræmmergaard, P., \& Rose, J. (2002). Managerial competences for ERP journeys. Information Systems Frontiers, 4(2), 199-211.

Krueger, R. A. (2002). Designing and conducting focus group interviews. St. Paul, MN: University of Minnesota.

Kujala, S. (2003). User involvement: A review of the benefits and challenges. Behaviour \& Information Technology, 22(1), 1-16.

Kumar, K., \& Van Hillegersberg, J. (2000). ERP experiences and evolution. Communication of the ACM, 43(4), 23- 26.

Kumar, V., Maheshwari, B., \& Kumar, U. (2003). An investigation of critical management issues in ERP implementation: empirical evidence from Canadian organizations. Technovation, 23(10), 793-807.

Kuzman, R. J. (1989). Managing very large system development efforts. Journal of Systems Management, 40(1), 10-14.

Landis, J. R., \& Koch, G. G. (1977). The measurement of observer agreement for categorical data. Biometrics, 33(1), 159-174.

Larson, M. (1998). Meet customer demands with new ERP systems. Quality, 37(2), 80-81.

Laudon, K., \& Laudon, J. P. (1996). Management Information Systems, Organization and Technology (4 ed.). Upper Saddle River: Prentice-Hall.

Lee, A. S. (1989). A scientific methodology for MIS case studies. MIS Quarterly, 13(1), 33-52.

Lee, Y., Kozar, K. A., \& Larsen, K. R. (2005). Does avatar email improve communication? Communications of the ACM, 48(12), 91-95.

Lee, Z., \& Lee, J. Y. (2000). An ERP implementation case study from a knowledge transfer perspective. Journal of Information Technology, 15(4), 281-288.

Lillrank, P. (2003). The quality of information. The International Journal of Quality \& Reliability Management, 20(6/7), 691-703.

Lim, E. T. K., Pan, S.-L., \& Tan, C. W. (2006). Managing user acceptance towards Enterprise Resource Planning (ERP) systems - Understanding the dissonance between user expectations and managerial policies. European Journal of Information Systems, 14(2), 135-149.

Lin, W. T., \& Shao, B. B. M. (2000). The relationship between user participation and system success: A simultaneous contingency approach. Information \& Management, 37(6), 283-295.

Linton, J. D. (2002). Implementation research: State of the art and future directions. Technovation 22(2), 65-79.

Lou, H., \& Scamell, R. W. (1996). Acceptance of groupware: The relationships among use, satisfaction, and outcomes. Journal of Organizational Computing and Electronic Commerce, 6(2), 173-190.

Lu, J., Yao, J. E., \& Yu, C. S. (2005). Personal innovativeness, social influences and adoption of wireless Internet services via mobile technology. Journal of Strategic Information Systems, 14(3), 245-268. 
Luftman, J., \& Brier, T. (1999). Achieving and sustaining business-IT alignment. California Management Review, 42(1), 109-122.

Mabert, V. A., Soni, A., \& Venkataramanan, M. (2003). Enterprise resource planning: Managing the implementation process. European Journal of Operational Research, 146(2), 302-314.

Maeda, Y., \& Miyahara, M. (2003). Determinants of trust in industry, government, and citizen's groups in Japan. Risk Analysis, 23(2), 303-310.

Management outline: Project Management overview. (2004). The British Journal of Administrative Management (Oct/Nov), 26.

Mann, J. (2002). IT education's failure to deliver successful information systems: Now is the time to address the IT-user gap. Journal of Information Technology Education, l(4), 253-267.

Marble, R. P. (2000). Operationalising the implementation puzzle: An argument for eclecticism in research and in practice. European Journal of Information Systems, 9(3), 132-147.

Markus, M. L., Axline, S., Petrie, D., \& Tanis, C. (2000). Learning from adopters' experiences with ERP: problems encountered and success achieved. Journal of Information Technology, 15(4), 245-265.

Mauthner, N. S., Parry, O., \& Backett-Milburn, K. (1998). The data are out there, or are they? Implications for archiving and revisiting qualitative data. Sociology, 32(4), 733-745.

McKeen, J. D., Guimaraes, T., \& Wetherbe, J. C. (1994). The relationship between user participation and user satisfaction: An investigation of four contingency factors. MIS Quarterly, 18(4), 427-451.

Miles, M. B., \& Huberman, A. M. (1994). Qualitative data analysis: An expanded sourcebook. Thousand Oaks, CA: Sage Publications, Inc.

Miller, H. (2005). Information quality and market share in electronic commerce. Journal of Services Marketing, 19(2), 93-102.

Miller, J., \& Doyle, B. A. (1987). Measuring effectiveness of computer based information systems in the financial services sector. MIS Quarterly, II(1), 107-124.

Mohr, J., \& Nevin, J. R. (1990). Communication strategies in marketing channels: A theoretical perspective. Journal of Marketing, 54(4), 36-51.

Mohr, J., \& Sohi, R. S. (1995). Communication flows in distribution channels: Impact on assessments of communication quality and satisfaction. Journal of Retailing, 71(4), 393-415.

Mohr, J., \& Spekman, R. (1994). Characteristics of partnership success: Partnership attributes, communication behavior, and conflict resolution techniques. Strategic Management Journal, 15(2), 135-152.

Molla, A., \& Bhalla, A. (2006). Business transformation through ERP: A case study of an Asian company. Journal of Information Technology Case and Application Research, 8(1), 34-54.

Motwani, J., Subramanian, R., \& Gopalakrishna, P. (2005). Critical factors for successful ERP implementation: Exploratory findings from four case studies. Computers in Industry, 56(6), 529-544.

Mumford, E. (1985). Defining system requirements to meet business needs: a case study example. The Computer Journal, 28(2), 97-104.

Nah, F. F.-H., \& Delgado, S. (2006). Critical success factors for Enterprise Resource Planning implementation and upgrade. The Journal of Computer Information Systems, 46(5), 99-113. 
Nah, F. F.-H., Lau, J., \& Kuang, J. (2001). Critical factors for successful implementation of Enterprise Systems. Business Process Management Journal, 7(3), 285-296.

Nah, F. F.-H., Tan, X., \& Teh, S. H. (2004). An empirical investigation on end-users' acceptance of Enterprise Systems. Information Resources Management Journal, $17(3), 32-53$.

Nah, F. F.-H., Zuckweiler, K. M., \& Lau, J. L. (2003). ERP implementation: Chief Information Officers' perceptions of critical success factors. International Journal of Human Computer Interaction, 16(1), 5-22.

Nath, R., \& Lederer, A. L. (1996). Team building for IS success. Information Systems Management, 13(2), 32-37.

Nelson, R. R., Whitener, E. M., \& Philcox, H. H. (1995). The assessment of end-user training needs. Communications of the ACM, 38(7), 27-39.

Newman, M., \& Robey, D. (1992). A social-process model of user-analyst relationships. MIS Quarterly, 16(2), 249-266.

Orlikowski, W. J., \& Baroudi, J. J. (1991). Studying information technology in organizations: Research approaches and assumptions. Information Systems Research, 2(1), 1-28.

Paper, D., Tingey, K. B., \& Mok, W. (2003). The relation between BPR and ERP systems: A failed project. Annals of Cases on Information Technology, 5, 45-62.

Paré, G. (2002). Enhancing the rigor of qualitative research: Application of a case methodology to build theories of IT implementation. The Qualitative Report, 7(4), Retrieved June 5, 2006, from http://www.nova.edu/ssss/QR/QR20072004/pare.html.

Paré, G. (2004). Investigating Information Systems with positivist case study research. Communications of the AIS, 13(18), 233-264.

Parry, O., \& Mauthner, N. (2004). Whose data are they anyway? Practical, legal and ethical issues in archiving qualitative research data. Sociology, 38(1), 139-152.

Parry, O., \& Mauthner, N. (2005). Back to basics: who re-uses qualitative data and why? Sociology, 39(2), 337-342.

Patrashkova-Volzdoska, R. R., McComb, S. A., Green, S. G., \& Compton, W. D. (2003). Examining a curvilinear relationship between communication frequency and team performance in cross-functional project teams. IEEE Transactions on Engineering Management, 50(3), 262-269.

Prahinski, C., \& Benton, W. C. (2004). Supplier evaluations: Communication strategies to improve supplier performance. Journal of Operations Management, 22(1), 39-62.

Ralph, E. G. (1998). Insights on effective communication: Some "sabbatical" observations. Academic Research Library, 119(1), 20-27.

Reeves, C. A., \& Bednar, D. A. (1994). Defining quality: Alternatives and implications. Academy of Management Review, 19(3), 419-445.

Richeson, L., Lackey, C., \& Starner, J. W., Jr. (1995). The effect of communication on the linkage between manufacturers and suppliers in a just-in-time environment. International Journal of Purchasing and Materials Management, 3l(1), 21-28.

Roberts, T. L., Jr., Leigh, W., \& Purvis, R. L. (2000). Perceptions on stakeholder involvement in the implementation of system development methodologies. The Journal of Computer Information Systems, 40(3), 78-83.

Robertson, E. (2005). Placing leaders at the heart of organizational communication. Strategic Communication Management, 9(5), 4-7.

Robey, D., \& Farrow, D. (1982). User involvement in information system development: A conflict model and empirical test. Management Science, 28(1), 73-85. 
Sarel, D., \& Marmorstein, H. (2002). Migrating customers to new distribution channels: The role of communication. Journal of Financial Services Marketing, 6(3), 254266.

Seidel, J. (1991). Method and madness in the application of computer technology to qualitative data analysis. In Fielding, N. G. \& Lee, R. M. (Eds.), Using computers in qualitative research (pp. 107-116). London: Sage.

Sein, M. K., Bostrom, R. P., \& Olfman, L. (1999). Rethinking end-user training strategy: applying a hierarchical knowledge-level model. Journal of End User Computing, $11(1), 32-39$.

Shah, H. U., Dingley, S., \& Golder, P. A. (1994). Bridging the culture gap between users and developers. Journal of Systems Management, 45(7), 18-21.

Shelby, A. N. (1998). Communication quality revisited: Exploring the link with persuasive effects. The Journal of Business Communication, 35(3), 387-404.

Shenhar, A. J., Dvir, D., Levy, O., \& Matlz, A. C. (2001). Project success: A multidimensional strategic concept. Long Range Planning, 34(6), 699-725.

Sherer, S. A., \& Alter, S. (2004). Information Systems risks and sisks factors, are they mostly about Information Systems? Communications of AIS, 14(1), 29-64.

Shin, N. (2001). The impact of information technology on financial performance: the importance of strategic choice. European Journal of Information Systems, 10(4), 227-236.

Snead, K. C., Jr., \& Ndede-Amadi, A. A. (2002). Attributional bias as a source of conflict between users and analysts in an information systems development context hypotheses development. Systemic Practice and Action Research, 15(5), 353-365.

Soffer, P., Golany, B., \& Dori, D. (2003). ERP modeling: a comprehensive approach. Information Systems, 28(6), 673-690.

Srinivasan, A. (1985). Alternative measures of system effectiveness: Association and implications. MIS Quarterly, 9(3), 243-253.

Stewart, D. W. (1984). Secondary research. Information sources and methods. Newbury Park, California: Sage Publications.

Stewart, G. (2000). Organisational readiness for ERP implementation. In Proceedings of the 2000 Americas Conference on Information Systems (pp. 966-971). Long Beach, California, USA: AIS.

Stewart, K. J., \& Gosain, S. (2006). The impact of ideology on effectiveness in Open Source Software development teams. MIS Quarterly, 30(2), 291-314.

Sumner, M. (2000). Risk factors in enterprise-wide/ERP projects. Journal of Information Technology, 15(4), 317-327.

Sun, A. Y. T., Yazdani, A., \& Overend, J. D. (2005). Achievement assessment for enterprise resource planning (ERP) system implementations based on critical success factors (CSFs). International Journal of Production Economics, 98(2), 189203.

Tait, P., \& Vessey, I. (1988). The effect of user involvement on system success: A contingency approach. MIS Quarterly, 12(1), 91-108.

Tan, M. (1994). Establishing mutual understanding in systems design: An empirical study. Journal of Management Information Systems, 10(4), 159-182.

Tarn, J. M., Yen, D. C., \& Beaumont, M. (2002). Exploring the rationales for ERP and SCM integration. Industrial Management \& Data Systems, 102(1-2), 26-34.

Taylor-Cummings, A. (1998). Bridging the user-IS gap: A study of major information systems projects. Journal of Information Technology, 13(1), 29-54.

Taylor, S., \& Todd, P. A. (1995). Assessing IT usage: The role of prior experience. MIS Quarterly, 19(2), 561-570. 
Terziovski, M., Fitzpatrick, P., \& O’Neill, P. (2003). Successful predictors of business process reengineering (BPR) in financial services. International Journal of Production Economics 84(11), 35-50.

Tesch, D., Jiang, J. J., \& Klein, G. (2003). The impact of information system personnel skill discrepancies on stakeholder satisfaction. Decision Sciences, 34(1), 107-129.

Thome, S. (1998). Ethical and representational issues in qualitative secondary analysis. Qualitative Health Research, 8(5), 547-555.

Tomes, A., \& Armstrong, P. (1998). Managing tensions in user groups. Technovation, 18(2), 79-89.

Umble, E. J., Haft, R. R., \& Umble, M. M. (2003). Enterprise resource planning: Implementation procedures and critical success factors. European Journal of Operational Research, 146(2), 214-257.

van den Berg, H. (2005). Reanalyzing qualitative interviews from different angles: The risk of decontextualization and other problems of sharing qualitative data, Forum Qualitative Sozialforschung/Forum: Qualitative Social Research (Vol. 6).

Vandenbosch, B., \& Ginzberg, M. J. (1997). Lotus Notes and collaboration: Plus ca change. Journal of Management Information Systems, 13(3), 65-81.

Venkatesh, V., Morris, M. G., Davis, G. B., \& Davis, F. D. (2003). User acceptance of Information Technology: Toward a unified view. MIS Quarterly, 27(3), 425-478.

Villachica, S. W., Stone, D. L., \& Endicott, J. (2004). Project alignment: Ensuring successful development and implementation from day one. Performance Improvement, 43(10), 9-15.

von Hellens, L. (1997). Information systems quality versus software quality. A discussion from a managerial an organizational and an engineering viewpoint. Information and Software Technology, 39(12), 801-808.

Walker, G., \& MacDonald, J. R. (2001). Designing and implementing an HR scorecard. Human Resource Management International Digest, 40(4), 365-377.

Wang, E. T. G., Chen, H. H. G., Jiang, J. J., \& Klein, G. (2005). Interaction quality between IS professionals and users: Impacting conflict and project performance. Journal of Information Science, 31(4), 273-282.

Wateridge, J. (1998). How can IT projects be measured for success. International Journal of Project Management, 16(1), 59-63.

Wideman, R. M. (1995). Criteria for a project-management body of knowledge. International Journal of Project Management, 13(2), 71-75.

Willcocks, L. P., \& Sykes, R. (2000). The role of The CIO and IT function in ERP. Communications of the ACM, 43(4), 28-32.

Willcoxson, L., \& Chatham, R. (2004). Progress in the IT/business relationship: A longitudinal assessment. Journal of Information Technology, 19(1), 71-80.

Woodie, A. (2005). ERP market grew solidly in 2004, AMR Research says. Retrieved June, 15, 2006, from http://www.itjungle.com/tfh/tfh062005-story03.html

Worleya, J. H., Chathac, K. A., Westonc, R. H., Aguirreb, O., \& Grabot, B. (2005). Implementation and optimisation of ERP systems: A better integration of processes, roles, knowledge and user competencies. Computers in Industry, 56(6), 620-638.

Wu, J.-H., \& Wang, Y.-M. (2006). Measuring ERP success: the ultimate users' view. International Journal of Operations \& Production Management, 26(8), 882-903.

Xu, H. J., Nord, J. H., Nord, G. D., \& Lin, B. (2003). Key issues of accounting information quality management: Australian case studies Industrial Management \& Data Systems, 103(7), 461-470. 
Yang, C., \& Wu, C.-Y. (2003). Perception difference between users and information professionals: A case study of TaiPower. In Proceedings of American Society for Information Science and Technology (pp. 119 - 127). Silver Spring, Maryland, USA: American Society for Information Science and Technology.

Yeh, Q. J. (2001). Two conflict potentials during IS development. Information \& Management, 39(2), 135-149.

Yin, R. K. (2002). Case study research, design and methods (3rd ed.). Beverly Hills, CA: Sage Publications.

Zhang, Z., Lee, M. K. O., Huang, P., Zhang, L., \& Huang, X. (2005). A framework of ERP systems implementation success in China: An empirical study. International Joumal of Production Economics, 98(1), 56-80.

Zviran, M., Nava, P., \& Levin, R. (2005). Measuring user satisfaction and perceived usefulness in the ERP context. The Journal of Computer Information Systems, $45(3), 43-52$. 


\section{Appendix - List of interviewees}

Table 17: Interviewee characteristics

\begin{tabular}{|c|c|c|c|c|}
\hline Position & Gender & $\begin{array}{l}\text { Approximate } \\
\text { Age }\end{array}$ & $\begin{array}{l}\text { Interview } \\
\text { Language }\end{array}$ & Role during the implementation \\
\hline \multicolumn{5}{|l|}{ Project Team } \\
\hline $\begin{array}{l}\text { Business Analyst } \\
\text { Material Master Data }\end{array}$ & Female & 35 & English & $\begin{array}{l}\text { Cut-over and data conversion of } \\
\text { Master data, Communication } \\
\text { coordinator between project and } \\
\text { business }\end{array}$ \\
\hline Programmer & Male & 40 & English & Data integration \\
\hline $\begin{array}{l}\text { Business Analyst } \\
\text { Business Processes } \\
\text { and KPls }\end{array}$ & Male & 40 & English & $\begin{array}{l}\text { Business processes review and KPI } \\
\text { development }\end{array}$ \\
\hline $\begin{array}{l}\text { Business Analyst } \\
\text { Supply Management }\end{array}$ & Female & 35 & English & $\begin{array}{l}\text { Processing request for change for } \\
\text { Supply Management }\end{array}$ \\
\hline $\begin{array}{l}\text { Business Analyst } \\
\text { Design }\end{array}$ & Female & 40 & French * & Process Mapping for Design \\
\hline $\begin{array}{l}\text { Business Analyst } \\
\text { Supply Management }\end{array}$ & Female & 30 & English & $\begin{array}{l}\text { Process mapping, development of } \\
\text { training material }\end{array}$ \\
\hline $\begin{array}{l}\text { SAP Application } \\
\text { Specialist }\end{array}$ & Male & 40 & English & Data conversion \\
\hline $\begin{array}{l}\text { Department manager } \\
\text { data cleansing }\end{array}$ & Male & 45 & English & Data migration from legacy systems \\
\hline $\begin{array}{l}\text { Business Analyst } \\
\text { Supply Management }\end{array}$ & Male & 40 & English & Process gap analysis, user assistance \\
\hline $\begin{array}{l}\text { Business Analyst } \\
\text { Design }\end{array}$ & Male & 55 & English & Data conversion for Design \\
\hline $\begin{array}{l}\text { Business Analyst } \\
\text { Supply Procurement }\end{array}$ & Female & 30 & English & $\begin{array}{l}\text { Processing request for change for } \\
\text { Supply Procurement }\end{array}$ \\
\hline $\begin{array}{l}\text { Change Management } \\
\text { Director }\end{array}$ & Male & 60 & English & $\begin{array}{l}\text { Defining the change education } \\
\text { strategy }\end{array}$ \\
\hline Programmer & Male & 40 & English & $\begin{array}{l}\text { Data conversion for Supply } \\
\text { Management }\end{array}$ \\
\hline $\begin{array}{l}\text { Business Analyst } \\
\text { Master Data }\end{array}$ & Female & 30 & English & Material master data validation \\
\hline $\begin{array}{l}\text { Project Team } \\
\text { Manager }\end{array}$ & Male & 40 & English & Project Coordination \\
\hline $\begin{array}{l}\text { Team Leader } \\
\text { Business Analysts } \\
\text { and Application } \\
\text { Specialists }\end{array}$ & Male & 45 & English & $\begin{array}{l}\text { Ensuring collaboration between } \\
\text { Business Analysts and Application } \\
\text { Specialists }\end{array}$ \\
\hline $\begin{array}{l}\text { Key Performance } \\
\text { Indicator Developer }\end{array}$ & Male & 55 & English & KPI development \\
\hline $\begin{array}{l}\text { Business Analyst } \\
\text { Finance }\end{array}$ & Female & 35 & English & $\begin{array}{l}\text { Facilitator between Application } \\
\text { Specialists and Business Analysts in } \\
\text { Financials }\end{array}$ \\
\hline $\begin{array}{l}\text { Key Performance } \\
\text { Indicator Developer }\end{array}$ & Male & 40 & English & $\begin{array}{l}\text { Leading the business analysts and } \\
\text { KPI development }\end{array}$ \\
\hline
\end{tabular}




\begin{tabular}{|l|l|l|l|l|}
\hline $\begin{array}{l}\text { Business Analyst } \\
\text { Production Planning }\end{array}$ & Male & 50 & English & Conversion of data for Standards \\
\hline $\begin{array}{l}\text { Change Management } \\
\text { Coordinator }\end{array}$ & Female & 35 & English & Helping with leadership alignment \\
\hline
\end{tabular}

\section{Business}

\begin{tabular}{|c|c|c|c|c|}
\hline $\begin{array}{l}\text { Trainer Supply } \\
\text { Management }\end{array}$ & Female & 40 & English & $\begin{array}{l}\text { Training material development and } \\
\text { training }\end{array}$ \\
\hline User Quality & Male & 35 & French * & $\begin{array}{l}\text { Data cleansing and conversion for } \\
\text { Standards, Training }\end{array}$ \\
\hline $\begin{array}{l}\text { Supervisor Supply } \\
\text { Management }\end{array}$ & Male & 40 & English & $\begin{array}{l}\text { Supervising supply management data } \\
\text { population }\end{array}$ \\
\hline $\begin{array}{l}\text { Business } \\
\text { Communication } \\
\text { Coordinator }\end{array}$ & Female & 40 & English & $\begin{array}{l}\text { Coordination of communication and } \\
\text { activities between business and } \\
\text { project team }\end{array}$ \\
\hline Plant Manager & Male & 45 & English & Project sponsor \\
\hline $\begin{array}{l}\text { Director Supply } \\
\text { Management }\end{array}$ & Male & 55 & English & Change leader \\
\hline $\begin{array}{l}\text { User Supply } \\
\text { Management }\end{array}$ & Male & 35 & French * & Super-User, Master data construction \\
\hline $\begin{array}{l}\text { Director Supply } \\
\text { Procurement }\end{array}$ & Female & 55 & English & $\begin{array}{l}\text { Directing of sourcing contracts and } \\
\text { input into SAP }\end{array}$ \\
\hline $\begin{array}{l}\text { User Supply } \\
\text { Management }\end{array}$ & Female & 35 & English & $\begin{array}{l}\text { Super-User, assisting users in case of } \\
\text { production problems }\end{array}$ \\
\hline $\begin{array}{l}\text { Business Analyst } \\
\text { Design }\end{array}$ & Male & 55 & English & Data transfer, validation, configuration \\
\hline $\begin{array}{l}\text { Director Production } \\
\text { Planning }\end{array}$ & Male & 60 & English & Coordinate production planning \\
\hline $\begin{array}{l}\text { User Supply } \\
\text { Management }\end{array}$ & Female & 30 & English & $\begin{array}{l}\text { Creating supply management } \\
\text { transactions }\end{array}$ \\
\hline Director Finance & Female & 55 & English & Monitoring the financials \\
\hline User Quality & Male & 40 & English & Indexing of parts \\
\hline User Quality & Male & 45 & English & Technical support as a super-user \\
\hline $\begin{array}{l}\text { Supervisor Supply } \\
\text { Management }\end{array}$ & Male & 35 & French * & Production planning \\
\hline $\begin{array}{l}\text { User Supply } \\
\text { Management }\end{array}$ & Male & 30 & French * & Super-user and trainer \\
\hline $\begin{array}{l}\text { Business Analyst } \\
\text { Finance }\end{array}$ & Male & 45 & French * & $\begin{array}{l}\text { Super-user providing user assistance } \\
\text { in Financials }\end{array}$ \\
\hline $\begin{array}{l}\text { Manager Supply } \\
\text { Procurement }\end{array}$ & Male & 50 & English & Data management in Procurement \\
\hline $\begin{array}{l}\text { User Production } \\
\text { Planning }\end{array}$ & Male & 45 & English & $\begin{array}{l}\text { Data cleansing and transfer, as a } \\
\text { super user training to users }\end{array}$ \\
\hline $\begin{array}{l}\text { Manager Supply } \\
\text { Management }\end{array}$ & Male & 45 & English & Managing Supply \\
\hline $\begin{array}{l}\text { Business Analyst } \\
\text { Supply Procurement }\end{array}$ & Male & 30 & English & Inputting supplier contracts into SAP \\
\hline $\begin{array}{l}\text { Director } \\
\text { Manufacturing }\end{array}$ & Male & 55 & English & Directing the manufacturing of goods \\
\hline
\end{tabular}




\begin{tabular}{|l|l|l|l|l|}
\hline $\begin{array}{l}\text { User Production } \\
\text { Planning }\end{array}$ & Male & 30 & English & $\begin{array}{l}\text { Data cleansing, documentation, } \\
\text { super-user }\end{array}$ \\
\hline $\begin{array}{l}\text { Supervisor Production } \\
\text { Planning }\end{array}$ & Female & 35 & French * & Supervising data cleansing \\
\hline $\begin{array}{l}\text { Manager Supply } \\
\text { Management }\end{array}$ & Male & 45 & French * & $\begin{array}{l}\text { Business focal for supply } \\
\text { management }\end{array}$ \\
\hline Supervisor Design & Male & 35 & English & $\begin{array}{l}\text { Training material development, } \\
\text { validation, and training, KPIs }\end{array}$ \\
\hline $\begin{array}{l}\text { User Production } \\
\text { Planning }\end{array}$ & Male & 35 & French * & Manufacturing goods \\
\hline Manager Quality & Male & 40 & French * & Leading a team of quality checkers \\
\hline User Design & Male & 35 & French * & Leading a team of designers \\
\hline $\begin{array}{l}\text { User Supply } \\
\text { Management }\end{array}$ & Female & 35 & French * & User \\
\hline $\begin{array}{l}\text { User Supply } \\
\text { Management }\end{array}$ & Female & 30 & French * & User \\
\hline User Finance & Male & 30 & French * & User \\
\hline
\end{tabular}

* Interviews conducted in French were translated into English during the transcribing process 


\section{Appendix - Guidelines for assessing the re-usability of qualitative data sets}

Table 18: Guidelines for assessing the re-usability of qualitative data sets (Heaton, 2004, p. 93)

\begin{tabular}{|c|c|}
\hline Category & Current research \\
\hline \multicolumn{2}{|l|}{ Accessibility } \\
\hline $\begin{array}{l}\text { Where, when and how can the data set } \\
\text { be accessed? }\end{array}$ & $\begin{array}{l}\text { The secondary researchers have full } \\
\text { access to the data set for the time of their } \\
\text { study }\end{array}$ \\
\hline $\begin{array}{l}\text { Are all the data accessible, or only part } \\
\text { of the data (e.g. transcripts but not } \\
\text { tapes) }\end{array}$ & $\begin{array}{l}\text { Primarily the transcripts and tapes are } \\
\text { available plus some company documents } \\
\text { from the primary study }\end{array}$ \\
\hline $\begin{array}{l}\text { Have informants given informed consent } \\
\text { for the data to be used for the purposes } \\
\text { of the proposed study? }\end{array}$ & $\begin{array}{l}\text { The organisation has given consent on } \\
\text { behalf of the participants. }\end{array}$ \\
\hline $\begin{array}{l}\text { Are there conditions, or terms of usage, } \\
\text { associated with the use of the data set? }\end{array}$ & $\begin{array}{l}\text { Ethical and legal issues as outlined above } \\
\text { have to be respected at all times. }\end{array}$ \\
\hline $\begin{array}{l}\text { Can the primary investigator(s) be } \\
\text { consulted, if desired? }\end{array}$ & $\begin{array}{l}\text { The primary researchers are part of the } \\
\text { current research's team. }\end{array}$ \\
\hline \multicolumn{2}{|l|}{ Quality } \\
\hline $\begin{array}{l}\text { Is the data set complete for the purpose } \\
\text { of the secondary study (i.e. no or } \\
\text { minimal missing data)? }\end{array}$ & The data set is complete. \\
\hline $\begin{array}{l}\text { Has the data been recorded fully and } \\
\text { accurately (e.g. accuracy of } \\
\text { transcriptions)? }\end{array}$ & Yes. \\
\hline $\begin{array}{l}\text { Have any data been modified (e.g. to } \\
\text { preserve anonymity) and if so, how? }\end{array}$ & No, not the raw data that will be used. \\
\hline $\begin{array}{l}\text { Has the data been adequately prepared } \\
\text { for possible secondary analysis? }\end{array}$ & $\begin{array}{l}\text { The data is in the same format as for the } \\
\text { primary analysis. The analysis methods of } \\
\text { primary and secondary study are the } \\
\text { same, only a different coding schema will } \\
\text { be used. }\end{array}$ \\
\hline $\begin{array}{l}\text { Is the meta-documentation of the data } \\
\text { set sufficient for the purposes of the } \\
\text { secondary analysis? }\end{array}$ & $\begin{array}{l}\text { There is sufficient documentation plus the } \\
\text { context knowledge of the involved primary } \\
\text { researchers. }\end{array}$ \\
\hline $\begin{array}{l}\text { Was the primary study well designed and } \\
\text { executed? }\end{array}$ & Yes. \\
\hline Suitability & \\
\hline
\end{tabular}




\begin{tabular}{|l|l|}
\hline $\begin{array}{l}\text { Is the data set 'fit' for the purposes of the } \\
\text { proposed research? }\end{array}$ & $\begin{array}{l}\text { Yes, it does. See discussion, "3.3.2.1 The } \\
\text { problem of data fit" on pp. 57 }\end{array}$ \\
\hline $\begin{array}{l}\text { Are there sufficient data to address the } \\
\text { proposed question? }\end{array}$ & $\begin{array}{l}\text { Yes. See discussion, "3.3.2.1 The problem } \\
\text { of data fit" on pp. 57 }\end{array}$ \\
\hline $\begin{array}{l}\text { Is the type, and format, of the qualitative } \\
\text { data compatible with the proposed } \\
\text { research? }\end{array}$ & $\begin{array}{l}\text { Yes, both studies use code-retrieval } \\
\text { analysis from transcripts along a pre- } \\
\text { defined coding schema. This is consistent } \\
\text { with the guidelines of conducting case } \\
\text { studies in Information Systems. }\end{array}$ \\
\hline $\begin{array}{l}\text { Can the data be combined or compared } \\
\text { with other data sets, if required? }\end{array}$ & $\begin{array}{l}\text { Yes, there is the possibility to complement } \\
\text { the data with remaining company } \\
\text { documentation from the primary study plus } \\
\text { raw data from a similar study of the same } \\
\text { organisation 3 years ago. }\end{array}$ \\
\hline Is the age of the data set appropriate? & $\begin{array}{l}\text { The used data is 6 months old, therefore } \\
\text { current and considered as appropriate. }\end{array}$ \\
\hline
\end{tabular}




\section{Appendix - Crosstables and Kappa-coefficient Calculations}

\subsection{Communication Quality}

\subsubsection{Coder 1 - Author}

Case Processing Summary

\begin{tabular}{|c|c|c|c|c|c|c|}
\hline & \multicolumn{6}{|c|}{ Cases } \\
\hline & \multicolumn{2}{|c|}{ Valid } & \multicolumn{2}{|c|}{ Missing } & \multicolumn{2}{|c|}{ Total } \\
\hline & $N$ & Percent & $N$ & Percent & $N$ & Percent \\
\hline Author ${ }^{*}$ Coder 1 & 16 & $100.0 \%$ & 0 & $.0 \%$ & 16 & $100.0 \%$ \\
\hline
\end{tabular}

\begin{tabular}{|c|c|c|c|c|c|c|c|c|c|c|c|}
\hline & & \multicolumn{9}{|c|}{ Coder 1} & \multirow[t]{2}{*}{ Total } \\
\hline & & $\begin{array}{c}\text { Compl } \\
\text { etenes } \\
s\end{array}$ & $\begin{array}{l}\text { Credi } \\
\text { bility }\end{array}$ & $\begin{array}{c}\text { Accura } \\
\text { cy }\end{array}$ & $\begin{array}{c}\text { Purpose } \\
\text { Adequa } \\
\text { cy }\end{array}$ & $\begin{array}{c}\text { Timelines } \\
s\end{array}$ & $\begin{array}{c}\text { Openne } \\
\text { ss }\end{array}$ & $\begin{array}{l}\text { Audience } \\
\text { Adequacy }\end{array}$ & $\begin{array}{c}\text { Bidirec } \\
\text { tionalit } \\
y\end{array}$ & $\begin{array}{c}\text { Balance } \\
\text { of } \\
\text { formality } \\
\text { us. } \\
\text { informalit } \\
y\end{array}$ & \\
\hline \multirow[t]{9}{*}{$\begin{array}{l}\text { Auth } \\
\text { or }\end{array}$} & Completeness & 2 & 0 & 0 & 0 & 0 & 0 & 0 & 0 & 0 & 2 \\
\hline & Credibility & 0 & 2 & 0 & 0 & 0 & 0 & 0 & 0 & 0 & 2 \\
\hline & Accuracy & 0 & 0 & 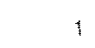 & 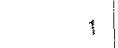 & 0 & 0 & 0 & 0 & 0 & 2 \\
\hline & $\begin{array}{l}\text { Purpose } \\
\text { Adequacy }\end{array}$ & 0 & 0 & 0 & 2 & 0 & 0 & 0 & 0 & 0 & 2 \\
\hline & Timeliness & 0 & 1 & 0 & 0 & 1 & 0 & 0 & 0 & 0 & 2 \\
\hline & Openness & 0 & 0 & 0 & 0 & 0 & 2 & 0 & 0 & 0 & 2 \\
\hline & $\begin{array}{l}\text { Audience } \\
\text { Adequacy }\end{array}$ & 0 & 0 & 0 & 0 & 0 & 0 & 1 & 1 & 0 & 2 \\
\hline & Bidirectionality & 0 & 0 & 0 & 0 & 0 & 1 & 0 & 0 & 0 & 1 \\
\hline & $\begin{array}{l}\text { Balance of } \\
\text { formality vs. } \\
\text { informality }\end{array}$ & 0 & 0 & 0 & 0 & 0 & 0 & 0 & 0 & 1 & 1 \\
\hline Total & & 2 & 3 & 1 & 3 & 1 & 3 & 1 & 1 & 1 & 16 \\
\hline
\end{tabular}

\section{Symmetric Measures}

\begin{tabular}{|c|c|c|c|c|}
\hline & Value & $\begin{array}{l}\text { Asymp. } \\
\text { Std. } \\
\text { Error(a) }\end{array}$ & $\begin{array}{c}\text { Approx. } \\
T(b)\end{array}$ & Approx. Sig. \\
\hline $\begin{array}{l}\text { Measure of Agreement Kappa } \\
N \text { of Valid Cases }\end{array}$ & $\begin{array}{r}.717 \\
16\end{array}$ & .120 & 8.018 & .000 \\
\hline
\end{tabular}

a Not assuming the null hypothesis.

b Using the asymptotic standard error assuming the null hypothesis. 


\subsubsection{Coder 2 - Author}

Case Processing Summary

\begin{tabular}{|c|c|c|c|c|c|c|}
\hline & \multicolumn{6}{|c|}{ Cases } \\
\hline & \multicolumn{2}{|c|}{ Valid } & \multicolumn{2}{|c|}{ Missing } & \multicolumn{2}{|c|}{ Total } \\
\hline & $N$ & Percent & $N$ & Percent & $N$ & Percent \\
\hline Author * Coder 2 & 16 & $100.0 \%$ & 0 & $.0 \%$ & 16 & $100.0 \%$ \\
\hline
\end{tabular}

Author ${ }^{*}$ Coder 2 Crosstabulation

\begin{tabular}{|c|c|c|c|c|c|c|c|c|c|c|c|}
\hline & & \multicolumn{9}{|c|}{ Coder 2} & \multirow[t]{2}{*}{ Total } \\
\hline & & $\begin{array}{c}\text { Complet } \\
\text { eness }\end{array}$ & $\begin{array}{c}\text { Credibilt } \\
y\end{array}$ & $\begin{array}{c}\text { Accurac } \\
y\end{array}$ & $\begin{array}{c}\text { Purpose } \\
\text { Adequac } \\
y\end{array}$ & $\begin{array}{l}\text { Time- } \\
\text { liness }\end{array}$ & $\begin{array}{l}\text { Open- } \\
\text { ness }\end{array}$ & $\begin{array}{c}\text { Audienc } \\
e \\
\text { Adequac } \\
y \\
\end{array}$ & $\begin{array}{c}\text { Bidirec } \\
- \\
\text { tionalit } \\
y \\
\end{array}$ & $\begin{array}{c}\text { Balance } \\
\text { of } \\
\text { formaity } \\
v S . \\
\text { informalit } \\
y\end{array}$ & \\
\hline \multirow{9}{*}{$\begin{array}{l}\text { Auth } \\
\text { or }\end{array}$} & Completeness & 2 & 0 & 0 & 0 & 0 & 0 & 0 & 0 & 0 & 2 \\
\hline & Credibility & 0 & 2 & 0 & 0 & 0 & 0 & 0 & 0 & 0 & 2 \\
\hline & Accuracy & 0 & 0 & 2 & 0 & 0 & 0 & 0 & 0 & 0 & 2 \\
\hline & $\begin{array}{l}\text { Purpose } \\
\text { Adequacy }\end{array}$ & 0 & 0 & 0 & 1 & 0 & 1 & 0 & 0 & 0 & 2 \\
\hline & Timeliness & 0 & 1 & 0 & 0 & 1 & 0 & 0 & 0 & 0 & 2 \\
\hline & Openness & 0 & 0 & 0 & 0 & 0 & 2 & 0 & 0 & 0 & 2 \\
\hline & $\begin{array}{l}\text { Audience } \\
\text { Adequacy }\end{array}$ & 0 & 0 & 0 & 0 & 0 & 0 & $\uparrow$ & 1 & 0 & 2 \\
\hline & Bidirectionality & 0 & 0 & 0 & 0 & 0 & 0 & 0 & 1 & 0 & 1 \\
\hline & $\begin{array}{l}\text { Balance of } \\
\text { formality us. } \\
\text { informality }\end{array}$ & 0 & 0 & 0 & 0 & 0 & 0 & 0 & 0 & 1 & 1 \\
\hline Total & & 2 & 3 & 2 & 1 & 1 & 3 & 1 & 2 & 1 & 16 \\
\hline
\end{tabular}

Symmetric Measures

\begin{tabular}{|l|r|r|r|r|}
\hline & & $\begin{array}{c}\text { Asymp. } \\
\text { Std. } \\
\text { Error(a) }\end{array}$ & $\begin{array}{c}\text { Approx. } \\
\text { T(b) }\end{array}$ & Approx. Sig. \\
\hline $\begin{array}{l}\text { Measure of Agreement } \\
\text { N } \text { Kappa } \text { Valid Cases }\end{array}$ & $\begin{array}{rlr}.789 \\
16\end{array}$ & .108 & 8.966 & .000 \\
\hline
\end{tabular}

a Not assuming the null hypothesis.

b Using the asymptotic standard error assuming the null hypothesis. 


\subsubsection{Coder $1-$ Coder 2}

Case Processing Summary

\begin{tabular}{|c|c|c|c|c|c|c|}
\hline & \multicolumn{6}{|c|}{ Cases } \\
\hline & \multicolumn{2}{|c|}{ Valid } & \multicolumn{2}{|c|}{ Missing } & \multicolumn{2}{|c|}{ Total } \\
\hline & $N$ & Percent & $N$ & Percent & $\mathrm{N}$ & Percent \\
\hline Coder $1{ }^{*}$ Coder 2 & 16 & $100.0 \%$ & 0 & $.0 \%$ & 16 & $100.0 \%$ \\
\hline
\end{tabular}

\section{Coder 1 * Coder 2 Crosstabulation}

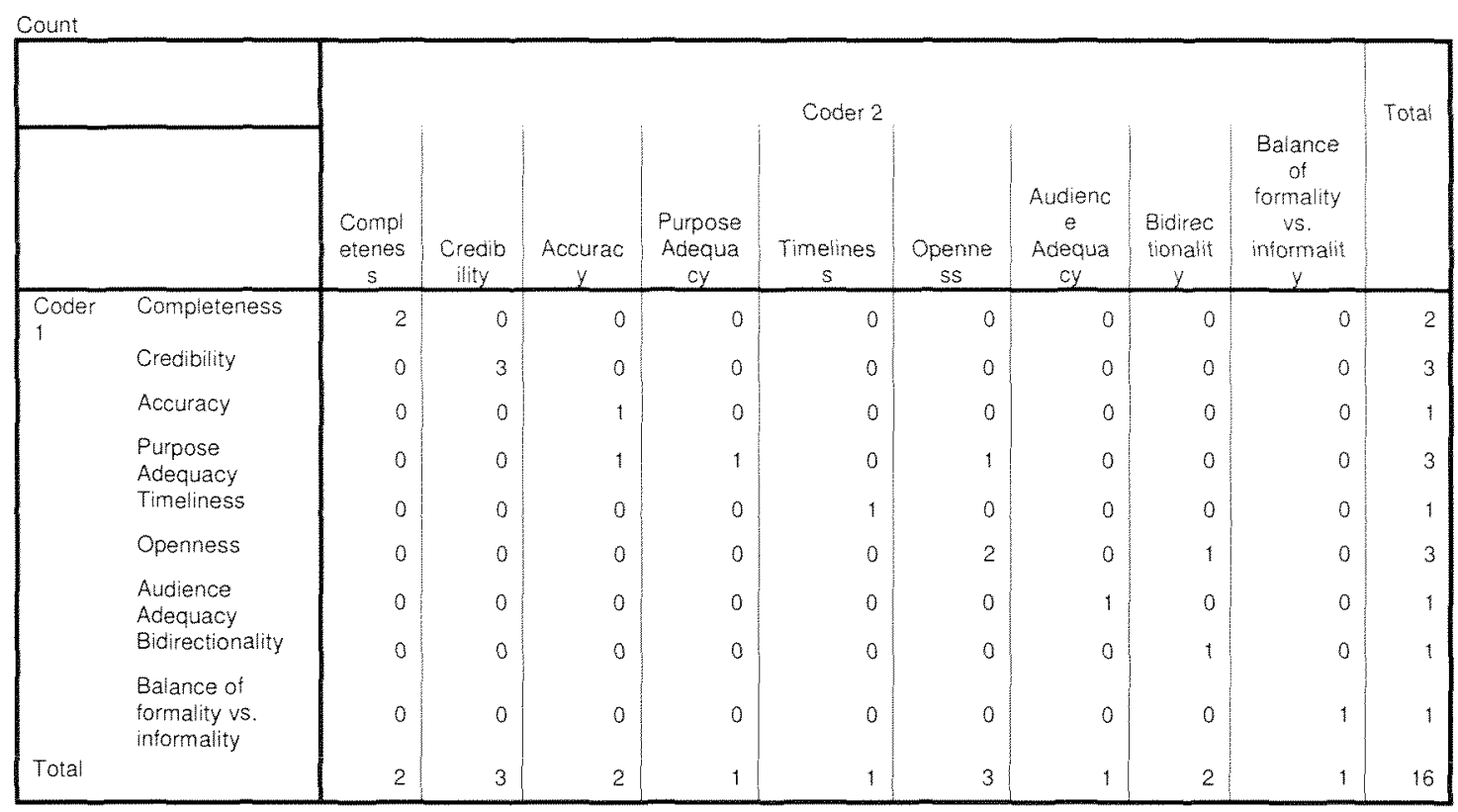

Symmetric Measures

\begin{tabular}{|c|c|c|c|c|}
\hline & Value & $\begin{array}{l}\text { Asymp. } \\
\text { Std. } \\
\text { Erroria) } \\
\end{array}$ & $\begin{array}{l}\text { Approx. } \\
\text { T(b) }\end{array}$ & Approx Sig. \\
\hline $\begin{array}{l}\text { Measure of Agreement Kappa } \\
N \text { of Valid Cases }\end{array}$ & $\begin{array}{r}.786 \\
16\end{array}$ & .110 & 8.568 & .000 \\
\hline
\end{tabular}

a Not assuming the null hypothesis.

b Using the asymptotic standard error assuming the null hypothesis. 


\subsection{Project Efficiency}

\subsubsection{Author - Coder 1}

Case Processing Summary

\begin{tabular}{|c|c|c|c|c|c|c|}
\hline & \multicolumn{6}{|c|}{ Cases } \\
\hline & \multicolumn{2}{|c|}{ Valid } & \multicolumn{2}{|c|}{ Missing } & \multicolumn{2}{|c|}{ Total } \\
\hline & $N$ & Percent & $N$ & Percent & $\mathrm{N}$ & Percent \\
\hline Author ${ }^{*}$ Coder 1 & 5 & $100.0 \%$ & 0 & $.0 \%$ & 5 & $100.0 \%$ \\
\hline
\end{tabular}

Author * Coder 1 Crosstabulation

\begin{tabular}{|c|c|c|c|c|c|}
\hline & & \multicolumn{3}{|c|}{ Coder 1} & \multirow[b]{2}{*}{ Total } \\
\hline & & $\begin{array}{c}\text { Schedule/Budg } \\
\text { et }\end{array}$ & Budget & Schedule & \\
\hline \multirow[t]{3}{*}{ Author } & Schedule/Budget & 1 & 1 & 0 & 2 \\
\hline & Budget & 0 & 1 & 0 & 1 \\
\hline & Schedule & 0 & 0 & 2 & 2 \\
\hline Total & & 1 & 2 & 2 & 5 \\
\hline
\end{tabular}

\section{Symmetric Measures}

\begin{tabular}{|c|c|c|c|c|}
\hline & Value & $\begin{array}{l}\text { Asymp. } \\
\text { Std. } \\
\text { Error(a) }\end{array}$ & $\begin{array}{l}\text { Approx } \\
\text { T(b) }\end{array}$ & Approx. Sig. \\
\hline $\begin{array}{l}\text { Measure of Agreement Kappa } \\
N \text { of Valid Cases }\end{array}$ & $\begin{array}{r}.706 \\
5\end{array}$ & .240 & 2.410 & .016 \\
\hline
\end{tabular}

a Not assuming the null hypothesis.

b Using the asymptotic standard error assuming the null hypothesis. 


\subsubsection{Author - Coder 2}

Case Processing Summary

\begin{tabular}{|c|c|c|c|c|c|c|}
\hline & \multicolumn{6}{|c|}{ Cases } \\
\hline & \multicolumn{2}{|c|}{ Valid } & \multicolumn{2}{|c|}{ Missing } & \multicolumn{2}{|c|}{ Total } \\
\hline & $\mathrm{N}$ & Percent & $\mathrm{N}$ & Percent & $N$ & Percent \\
\hline Author * Coder 2 & 5 & $100.0 \%$ & 0 & $.0 \%$ & 5 & $100.0 \%$ \\
\hline
\end{tabular}

\section{Author * Coder 2 Crosstabulation}

\begin{tabular}{|c|c|c|c|c|c|}
\hline & & \multicolumn{3}{|c|}{ Coder 2} & \multirow[b]{2}{*}{ Total } \\
\hline & & $\begin{array}{c}\text { Schedule/Budg } \\
\text { et }\end{array}$ & Budget & Schedule & \\
\hline \multirow[t]{3}{*}{ Author } & Schedule/Budget & 2 & 0 & 0 & 2 \\
\hline & Budget & 0 & 1 & 0 & 1 \\
\hline & Schedule & 0 & 0 & 2 & 2 \\
\hline Total & & 2 & 1 & 2 & 5 \\
\hline
\end{tabular}

\section{Symmetric Measures}

\begin{tabular}{|c|c|c|c|c|}
\hline & Value & $\begin{array}{l}\text { Asymp. } \\
\text { Std. } \\
\text { Error(a) }\end{array}$ & $\begin{array}{l}\text { Approx. } \\
T(b)\end{array}$ & Approx. Sig. \\
\hline $\begin{array}{l}\text { Measure of Agreement Kappa } \\
N \text { of Valid Cases }\end{array}$ & $\begin{array}{r}1.000 \\
5\end{array}$ & .000 & 3.068 & .002 \\
\hline
\end{tabular}

a Not assuming the null hypothesis.

b Using the asymptotic standard error assuming the null hypothesis. 


\subsubsection{Coder $1-$ Coder 2}

Case Processing Summary

\begin{tabular}{|c|c|c|c|c|c|c|}
\hline & \multicolumn{6}{|c|}{ Cases } \\
\hline & \multicolumn{2}{|c|}{ Valid } & \multicolumn{2}{|c|}{ Missing } & \multicolumn{2}{|c|}{ Total } \\
\hline & $N$ & Percent & $N$ & Percent & $N$ & Percent \\
\hline Coder $1{ }^{*}$ Coder 2 & 5 & $100.0 \%$ & 0 & $.0 \%$ & 5 & $100.0 \%$ \\
\hline
\end{tabular}

\section{Coder $1^{*}$ Coder 2 Crosstabulation}

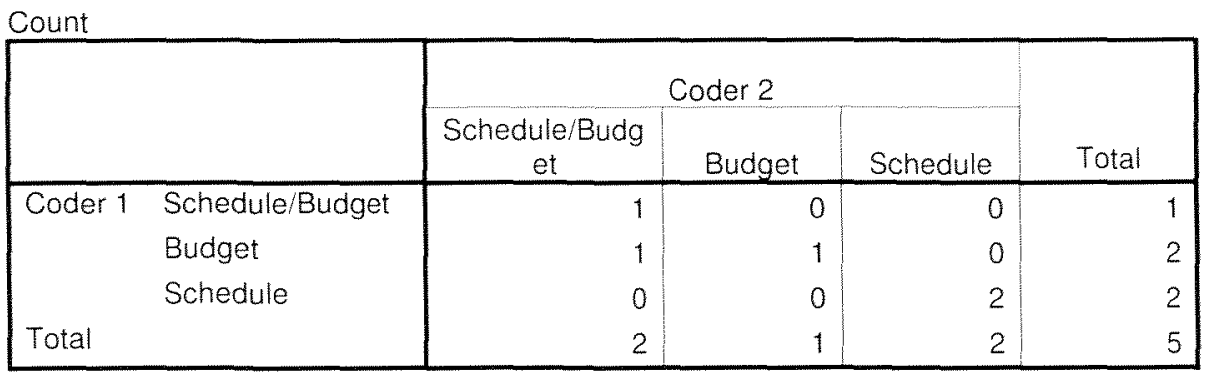

\section{Symmetric Measures}

\begin{tabular}{|c|c|c|c|c|}
\hline & Value & $\begin{array}{l}\text { Asymp. } \\
\text { Std. } \\
\text { Erroria) }\end{array}$ & $\begin{array}{l}\text { Approx } \\
\text { T(b) }\end{array}$ & Approx. Sig. \\
\hline $\begin{array}{l}\text { Measure of Agreement Kappa } \\
N \text { of Valid Cases }\end{array}$ & $\begin{array}{r}.706 \\
5\end{array}$ & .240 & 2.410 & .016 \\
\hline
\end{tabular}

a Not assuming the null hypothesis.

b Using the asymptotic standard error assuming the null hypothesis. 


\subsection{Impact on users}

\subsubsection{Author - Coder 1}

Case Processing Summary

\begin{tabular}{|l|r|r|r|r|r|r|}
\hline \multirow{2}{*}{} & \multicolumn{4}{|c|}{ Vases } \\
\cline { 2 - 7 } & \multicolumn{2}{|c|}{ Valid } & \multicolumn{2}{c|}{ Missing } & \multicolumn{2}{c|}{ Total } \\
\hline Author * Coder 1 & $\mathrm{~N}$ & Percent & $\mathrm{N}$ & Percent & $\mathrm{N}$ & Percent \\
\hline
\end{tabular}

\section{Author * Coder 1 Crosstabulation}

\begin{tabular}{|c|c|c|c|c|c|}
\hline \multicolumn{6}{|c|}{ Coder 1} \\
\hline & & $\begin{array}{c}\text { Schedule/Budg } \\
\text { et }\end{array}$ & & Schedule & Total \\
\hline \multirow[t]{3}{*}{ Author } & Schedule/Budget & 1 & 1 & 0 & 2 \\
\hline & Budget & 0 & 1 & 0 & 1 \\
\hline & Schedule & 0 & 0 & 2 & 2 \\
\hline Total & & 1 & 2 & 2 & 5 \\
\hline
\end{tabular}

\section{Symmetric Measures}

\begin{tabular}{|c|c|c|c|c|}
\hline & Value & $\begin{array}{l}\text { Asymp. } \\
\text { Std. } \\
\text { Error(a) }\end{array}$ & $\begin{array}{l}\text { Approx } \\
T(b)\end{array}$ & Approx. Sig. \\
\hline $\begin{array}{l}\text { Measure of Agreement Kappa } \\
N \text { of Valid Cases }\end{array}$ & $\begin{array}{r}.706 \\
5\end{array}$ & .240 & 2.410 & .016 \\
\hline
\end{tabular}

a Not assuming the null hypothesis.

b Using the asymptotic standard error assuming the null hypothesis. 


\subsubsection{Author-Coder 2}

Case Processing Summary

\begin{tabular}{|c|c|c|c|c|c|c|}
\hline & \multicolumn{6}{|c|}{ Cases } \\
\hline & \multicolumn{2}{|c|}{ Valid } & \multicolumn{2}{|c|}{ Missing } & \multicolumn{2}{|c|}{ Total } \\
\hline & $N$ & Percent & $N$ & Percent & $N$ & Percent \\
\hline Author" Coder 2 & 5 & $100.0 \%$ & 0 & $.0 \%$ & 5 & $100.0 \%$ \\
\hline
\end{tabular}

\section{Author * Coder 2 Crosstabulation}

\begin{tabular}{|c|c|c|c|c|c|}
\hline & & \multicolumn{3}{|c|}{ Coder 2} & \multirow[b]{2}{*}{ Total } \\
\hline & & $\begin{array}{c}\text { Schedule/Budg } \\
\text { et }\end{array}$ & Budget & Schedule & \\
\hline \multirow[t]{3}{*}{ Author } & Schedule/Budget & 2 & 0 & 0 & 2 \\
\hline & Budget & 0 & 1 & 0 & 1 \\
\hline & Schedule & 0 & 0 & 2 & 2 \\
\hline Total & & 2 & 1 & 2 & 5 \\
\hline
\end{tabular}

\section{Symmetric Measures}

\begin{tabular}{|c|c|c|c|c|}
\hline & Value & $\begin{array}{l}\text { Asymp. } \\
\text { Std. } \\
\text { Error(a) }\end{array}$ & $\begin{array}{c}\text { Approx. } \\
T(b)\end{array}$ & Approx. Sig. \\
\hline $\begin{array}{l}\text { Measure of Agreement Kappa } \\
N \text { of Valid Cases }\end{array}$ & $\begin{array}{r}1.000 \\
5\end{array}$ & .000 & 3.068 & .002 \\
\hline
\end{tabular}

a Not assuming the null hypothesis.

$b$ Using the asymptotic standard error assuming the null hypothesis. 


\subsubsection{Coder $1-$ Coder 2}

Case Processing Summary

\begin{tabular}{|c|c|c|c|c|c|c|}
\hline & \multicolumn{6}{|c|}{ Cases } \\
\hline & \multicolumn{2}{|c|}{ Valid } & \multicolumn{2}{|c|}{ Missing } & \multicolumn{2}{|c|}{ Total } \\
\hline & $\mathrm{N}$ & Percent & $N$ & Percent & $N$ & Percent \\
\hline Coder $1^{*}$ Coder 2 & 5 & $100.0 \%$ & 0 & $.0 \%$ & 5 & $100.0 \%$ \\
\hline
\end{tabular}

Coder $1^{*}$ Coder 2 Crosstabulation

\begin{tabular}{|c|c|c|c|c|c|}
\hline & & \multicolumn{3}{|c|}{ Coder 2} & \multirow[b]{2}{*}{ Total } \\
\hline & & $\begin{array}{c}\text { Schedule/Budg } \\
\text { et }\end{array}$ & Budgel & Schedule & \\
\hline \multirow{3}{*}{ Coder 1} & Schedule/Budget & 1 & 0 & 0 & 1 \\
\hline & Budget & 1 & 1 & 0 & 2 \\
\hline & Schedule & 0 & 0 & 2 & 2 \\
\hline Total & & 2 & 1 & 2 & 5 \\
\hline
\end{tabular}

\section{Symmetric Measures}

\begin{tabular}{|c|c|c|c|c|}
\hline & Value & $\begin{array}{l}\text { Asymp. } \\
\text { Std. } \\
\text { Error(a) }\end{array}$ & $\begin{array}{l}\text { Approx } \\
T(b)\end{array}$ & Approx. Sig. \\
\hline $\begin{array}{l}\text { Measure of Agreement Kappa } \\
N \text { of Valid Cases }\end{array}$ & $\begin{array}{r}.706 \\
5\end{array}$ & .240 & 2.410 & .016 \\
\hline
\end{tabular}

a Not assuming the null hypothesis.

b Using the asymptotic standard error assuming the null hypothesis. 


\subsection{Business benefits}

\subsubsection{Author - Coder 1}

Case Processing Summary

\begin{tabular}{|l|rr|r|r|r|r|r|}
\hline \multirow{2}{*}{} & \multicolumn{4}{|c|}{ Cases } \\
\cline { 2 - 8 } & \multicolumn{2}{|c|}{ Valid } & \multicolumn{2}{c|}{ Missing } & \multicolumn{2}{c|}{ Total } \\
\cline { 2 - 8 } & $\mathrm{N}$ & Percent & $\mathrm{N}$ & Percent & $\mathrm{N}$ & Percent \\
\hline Author * Coder 1 & & 9 & $100.0 \%$ & & 0 & $.0 \%$ & 9 \\
\hline
\end{tabular}

\section{Author * Coder 1 Crosstabulation}

\begin{tabular}{|c|c|c|c|c|c|c|c|c|}
\hline & & \multicolumn{6}{|c|}{ Coder 1} & \multirow[t]{2}{*}{ Total } \\
\hline & & $\begin{array}{c}\text { Financial } \\
\text { Performance } \\
\text { Gains }\end{array}$ & $\begin{array}{c}\text { Process } \\
\text { Performance } \\
\text { gains } \\
\end{array}$ & $\begin{array}{l}\text { High quality } \\
\text { products }\end{array}$ & $\begin{array}{l}\text { Less waste } \\
\text { and } \\
\text { inefficiencies }\end{array}$ & $\begin{array}{l}\text { Link between } \\
\text { business } \\
\text { benefits and } \\
\text { daily work }\end{array}$ & Benefits & \\
\hline \multirow[t]{6}{*}{ Author } & $\begin{array}{l}\text { Financial } \\
\text { Performance Gains }\end{array}$ & 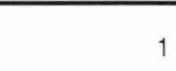 & 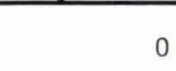 & 0 & 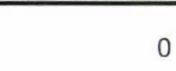 & (1) & 0 & 1 \\
\hline & $\begin{array}{l}\text { Process Performance } \\
\text { gain }\end{array}$ & 0 & 2 & 0 & 0 & 0 & 0 & 2 \\
\hline & High qualty products & 0 & 0 & 1 & 0 & 0 & 0 & 1 \\
\hline & $\begin{array}{l}\text { Less waste and } \\
\text { inefficiencies }\end{array}$ & 0 & 0 & 0 & 1 & 0 & 0 & 1 \\
\hline & $\begin{array}{l}\text { Link between } \\
\text { business benefits } \\
\text { and daily work }\end{array}$ & 0 & 0 & 0 & 0 & 2 & 0 & 2 \\
\hline & Benefits & 0 & 0 & 0 & 0 & 0 & 2 & 2 \\
\hline Total & & 1 & 2 & 1 & 1 & 2 & 2 & 9 \\
\hline
\end{tabular}

\section{Symmetric Measures}

\begin{tabular}{|l|r|r|r|r|}
\hline & \multicolumn{1}{|c|}{$\begin{array}{c}\text { Asymp. } \\
\text { Std. } \\
\text { Error(a) }\end{array}$} & $\begin{array}{c}\text { Approx. } \\
\text { T(b) }\end{array}$ & Approx. Sig. \\
\hline $\begin{array}{l}\text { Measure of Agreement } \\
\text { N of Valid Cases }\end{array}$ & $\begin{array}{r}\text { Value } \\
\text { Kappa }\end{array}$ & .000 & 6.410 & .000 \\
\hline
\end{tabular}

a Not assuming the null hypothesis.

b Using the asymptotic standard error assuming the null hypothesis. 


\subsubsection{Author - Coder 2}

Case Processing Summary

\begin{tabular}{|c|c|c|c|c|c|c|}
\hline & \multicolumn{6}{|c|}{ Cases } \\
\hline & \multicolumn{2}{|c|}{ Valid } & \multicolumn{2}{|c|}{ Missing } & \multicolumn{2}{|c|}{ Total } \\
\hline & $N$ & Percent & $\mathrm{N}$ & Percent & $N$ & Percent \\
\hline Author * Coder 2 & 9 & $100.0 \%$ & 0 & $.0 \%$ & 9 & $100.0 \%$ \\
\hline
\end{tabular}

Author ${ }^{*}$ Coder 2 Crosstabulation

\begin{tabular}{|c|c|c|c|c|c|c|c|c|}
\hline & & \multicolumn{6}{|c|}{ Coder 2} & \multirow[t]{2}{*}{ Total } \\
\hline & & $\begin{array}{c}\text { Financial } \\
\text { Performanc } \\
\text { e Gains } \\
\end{array}$ & $\begin{array}{c}\text { Process } \\
\text { Performan } \\
\text { ce gain } \\
\end{array}$ & $\begin{array}{l}\text { High } \\
\text { quality } \\
\text { product } \\
5\end{array}$ & $\begin{array}{l}\text { Less waste } \\
\text { and } \\
\text { inefficiencie } \\
s \\
\end{array}$ & $\begin{array}{l}\text { Link } \\
\text { between } \\
\text { business } \\
\text { benefits and } \\
\text { daily work }\end{array}$ & Benefits & \\
\hline \multirow[t]{3}{*}{ Author } & $\begin{array}{l}\text { Financial } \\
\text { Performance } \\
\text { Gains } \\
\text { Process } \\
\text { Performance gain }\end{array}$ & 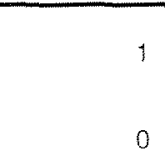 & 0 & 0 & 0 & 0 & 0 & 2 \\
\hline & $\begin{array}{l}\text { High quality } \\
\text { products } \\
\text { Less waste and } \\
\text { inefficiencies }\end{array}$ & 0 & $\begin{array}{l}0 \\
0\end{array}$ & 1 & 0 & 0 & 0 & 1 \\
\hline & $\begin{array}{l}\text { Link between } \\
\text { business benefits } \\
\text { and daily work } \\
\text { Benefits }\end{array}$ & 0 & $\begin{array}{l}0 \\
0\end{array}$ & $\begin{array}{l}0 \\
0\end{array}$ & 1 & 1 & 0 & 2 \\
\hline Total & & 1 & 2 & 1 & 2 & 2 & 1 & 9 \\
\hline
\end{tabular}

Symmetric Measures

\begin{tabular}{|c|c|c|c|c|}
\hline & Value & $\begin{array}{l}\text { Asymp. } \\
\text { Std. } \\
\text { Error(a) }\end{array}$ & $\begin{array}{l}\text { Approx } \\
\text { T(b) }\end{array}$ & Approx. Sig. \\
\hline $\begin{array}{l}\text { Measure of Agreement Kappa } \\
N \text { of Valid Cases }\end{array}$ & $\begin{array}{r}.731 \\
9\end{array}$ & .167 & 4.905 & .000 \\
\hline
\end{tabular}

a Not assuming the null hypothesis.

b Using the asymptotic standard error assuming the null hypothesis. 


\subsubsection{Coder $1-$ Coder 2}

Case Processing Summary

\begin{tabular}{|c|c|c|c|c|c|c|}
\hline & \multicolumn{6}{|c|}{ Cases } \\
\hline & \multicolumn{2}{|c|}{ Valid } & \multicolumn{2}{|c|}{ Missing } & \multicolumn{2}{|c|}{ Total } \\
\hline & $\mathrm{N}$ & Percent & $\mathrm{N}$ & Percent & $\mathrm{N}$ & Percent \\
\hline Coder $1{ }^{*}$ Coder 2 & 9 & $100.0 \%$ & 0 & $.0 \%$ & 9 & $100.0 \%$ \\
\hline
\end{tabular}

Coder $1^{\star}$ Coder 2 Crosstabulation

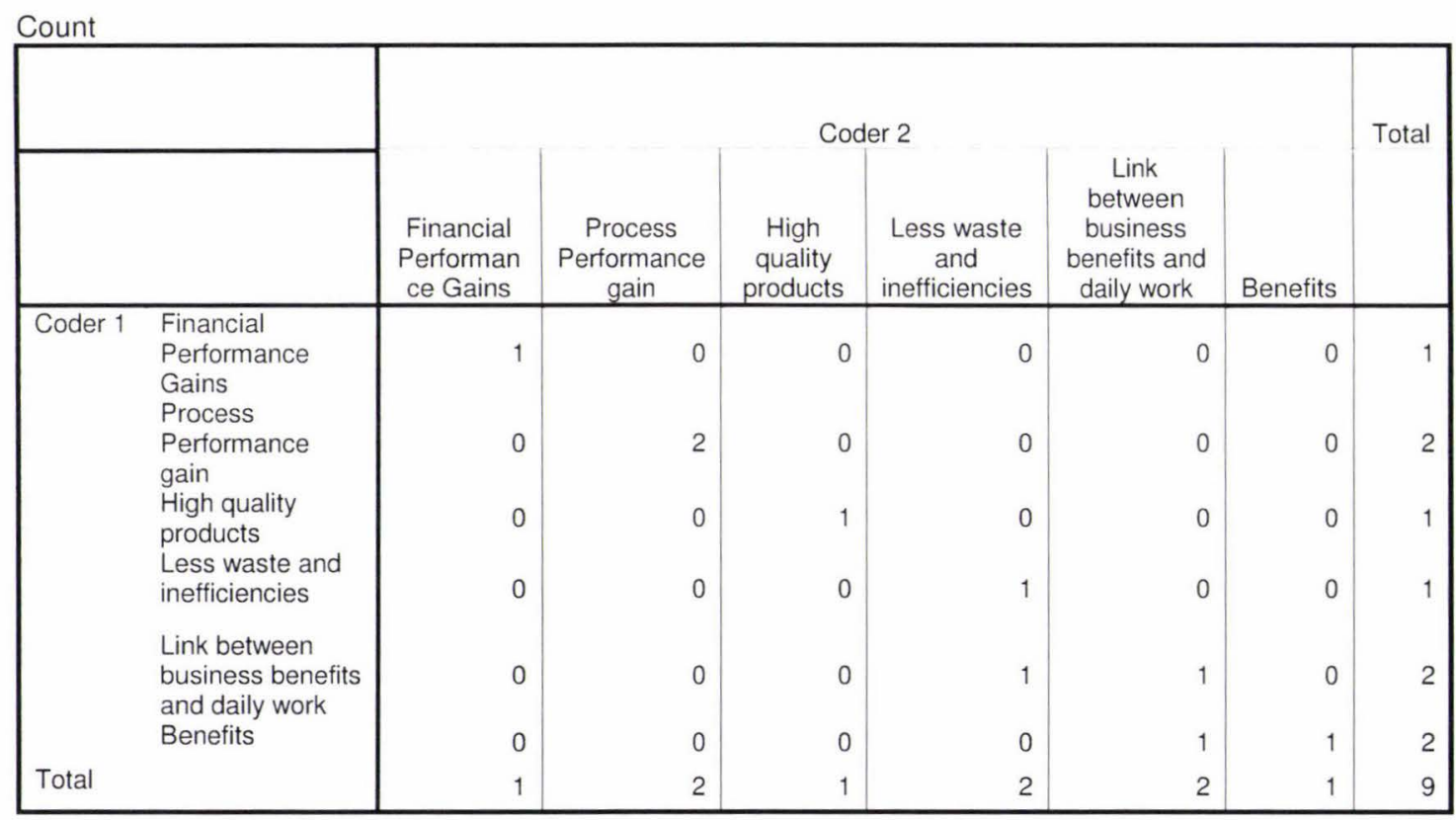

\section{Symmetric Measures}

\begin{tabular}{|c|c|c|c|c|}
\hline & Value & $\begin{array}{l}\text { Asymp. } \\
\text { Std. } \\
\text { Error(a) }\end{array}$ & $\begin{array}{l}\text { Approx. } \\
\text { T(b) }\end{array}$ & Approx. Sig. \\
\hline $\begin{array}{l}\text { Measure of Agreement Kappa } \\
\mathrm{N} \text { of Valid Cases }\end{array}$ & $\begin{array}{r}.731 \\
9\end{array}$ & .167 & 4.905 & .000 \\
\hline
\end{tabular}

a Not assuming the null hypothesis.

b Using the asymptotic standard error assuming the null hypothesis. 